\title{
THE LITTORAL CRUSTACEAN FAUNA OF THE GALAPAGOS ISLANDS.*
}

\author{
By LEE Boone
}

\author{
Part I: Brachyura
}

(Figs. 34-102C incl.)

The Crustacean collections secured by the Arcturus Oceanographic Expedition, of the Department of Tropical Research, New York Zoological Society, under the directorship of Dr. William Beebe have proven so comprehensive a representation of the fauna of the regions explored that it has been deemed advisable to report upon the major faunal regions separately.

One of the most interesting collections secured by the expedition is that of the littoral Brachyuran crustacean fauna of the Galapagos Islands, which forms the subject of this paper. The Arciurus Expedition secured forty-six of the sixty-nine species of Brachyuran crabs that inhabit the littoral zone of the Galapagos archipelago, making the collection the largest of its kind ever brought from the islands by a single expedition. Of these forty-six species, five are new species, nine establish the first Galapagan record of species hitherto known only from the west Mexican-Panamic faunal regions, contributing a further bit of significant evidence of the probable past relationship of these islands to the mainland; five species are representatives of rare Galapagan forms, three of which have been hitherto known only from the types, which are no longer extant.

The value of the collection has been inexpressibly augmented by the extensive field-notes on the little known habits of these animals, made personally by the director of the expedition, Dr. William Beebe. His indefatigable industry in securing a large series of specimens has brought to light many interesting facts upon the unknown life cycles of these crabs. Identifiable zoea or megalops of eight Galapagan crabs were obtained, in addition to large masses of eggs and developing embryos of twenty-one species. The significance of this item is more fully appreciated when it is recalled that the life histories of less than a dozen species of American Brachyurans are known. 249 .

* Contribution, New York Zoological Society Department of Tropical Research, No. 
The series of exquisite, photographically accurate color plates of many of the species, made under the direction of Dr. Beebe, by Miss Isabel Cooper, scientific artist of the expedition, has contributed much valuable data to a phase of carcinology usually ignored. Since it is impractical to publish all of these color plates, I have endeavoured to transcribe the data, using Ridgway's "Color Standards and Color Nomenclature" to interpret the color terms.

The preparation of this report has so emphasized the scattered literature of the Galapagan Crustacea obtained by the many previous expeditions, that, in an effort to render it of greater service, the scope of the present paper has been extended to include a description and illustration of every species of Brachyuran crab known from the littoral fauna of the Galapagos. The littoral, as distinguished from the deep-sea fauna, is here taken to include those species found from the shore down to a depth of 100 fathoms. It is fully realized that there is no such arbitrary line dividing the littoral from the deep-sea fauna; however, the few Galapagan Brachyurans taken below the hundred fathom line have their affinities with typical deep-sea forms, and while one or two such species have been occasionally taken above the one hundred fathom zone, they are omitted from the present report, for the above reason. In several instances, the absence of material for examination has made it necessary to quote the type description and copy the original illustration; full acknowledgment of this is made under each species so treated.

The photographs of the Arcturus and Noma crustaceans were made by Mr. John Tee-Van, assistant to the director, and Mr. Floyd Crosby.

The line drawings were made by Miss Isabel Cooper, with the exception of figures $39,40,41,46$, and 47 , which were made by Mrs. Helen Damrosch Tee-Van, and figures 21, 26, 54, 74 and 102A, B, and C, by Mrs. John Gregory.

Mr. Serge Chetyrkin, preparateur of the Tropical Research Station, has made a careful preliminary separation of the many groups of thousands of crustaceans that comprise the Arcturus collection. I am especially indebted to him in connection with the present paper for the painstaking counting of thousands of crab eggs and larvae necessary to determine the potential offspring of a species.

In connection with the preparation of this paper, I have enjoyed 
full privileges of study in the biological laboratory and library of the American Museum of Natural History. I am also indebted to Dr. Alex Wetmore, in charge of the United States National Museum, for the loan of three Brachyuran crabs obtained by the Harrison Williams Galapagos Expedition.

I wish to thank Dr. Beebe, the Director of the Department of Tropical Research, for the splendid facilities he has given me to prosecute this work. His suggestions and criticisms have been invaluable. I hope this account will serve as a reliable monograph of the crustacean fauna of Galapagos, and increase the interest in that amazing archipelago. 


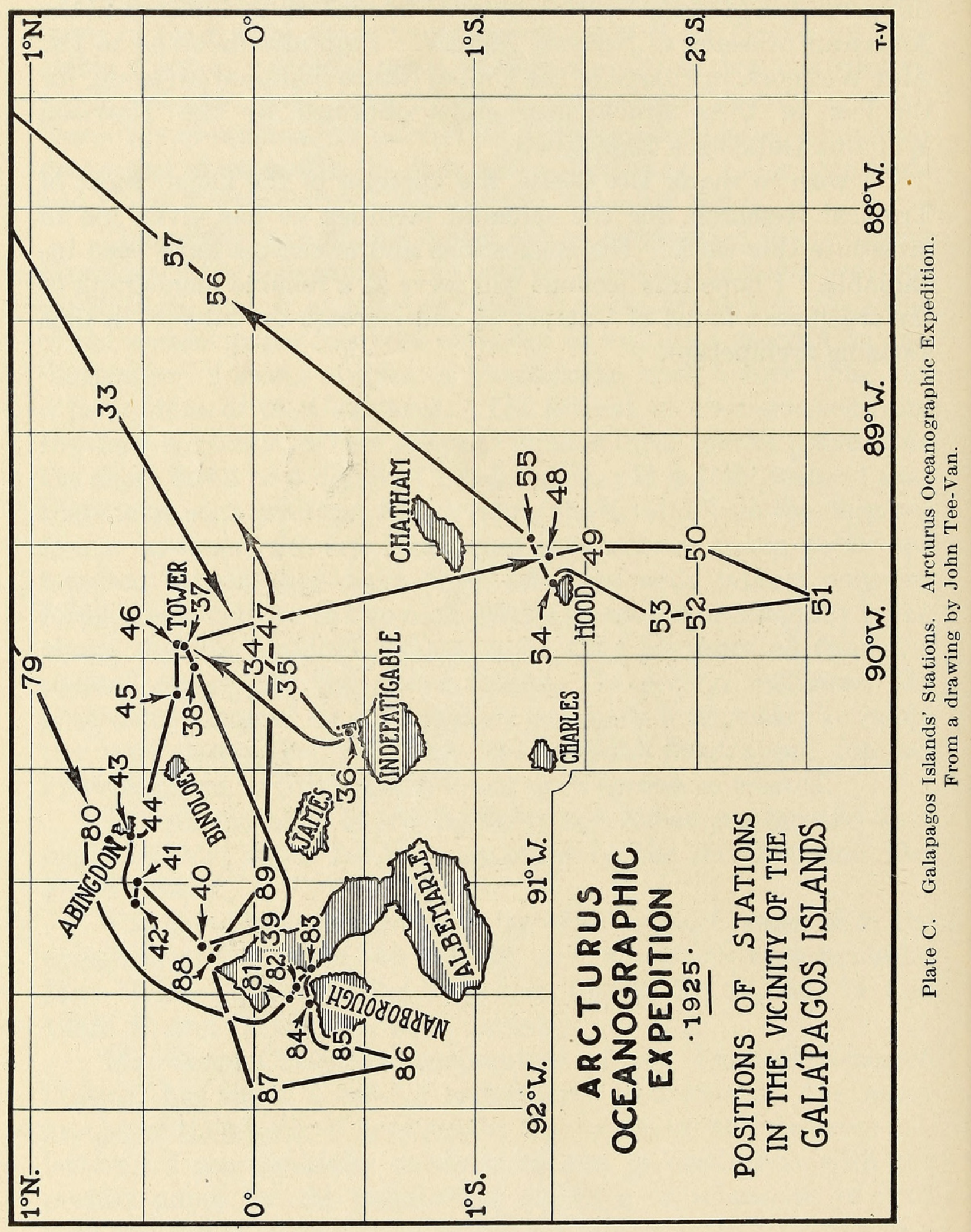


Order: DECAPODA

Suborder: REPTANTIA

Tribe: BRACHYURA

Subtribe: BRACHYGNATHA

Superfamily: OXYRHYNCHA

Family: MAJIDAE

Subfamily: INACHINAE

Genus Stenorynchus Lamarck, 1818

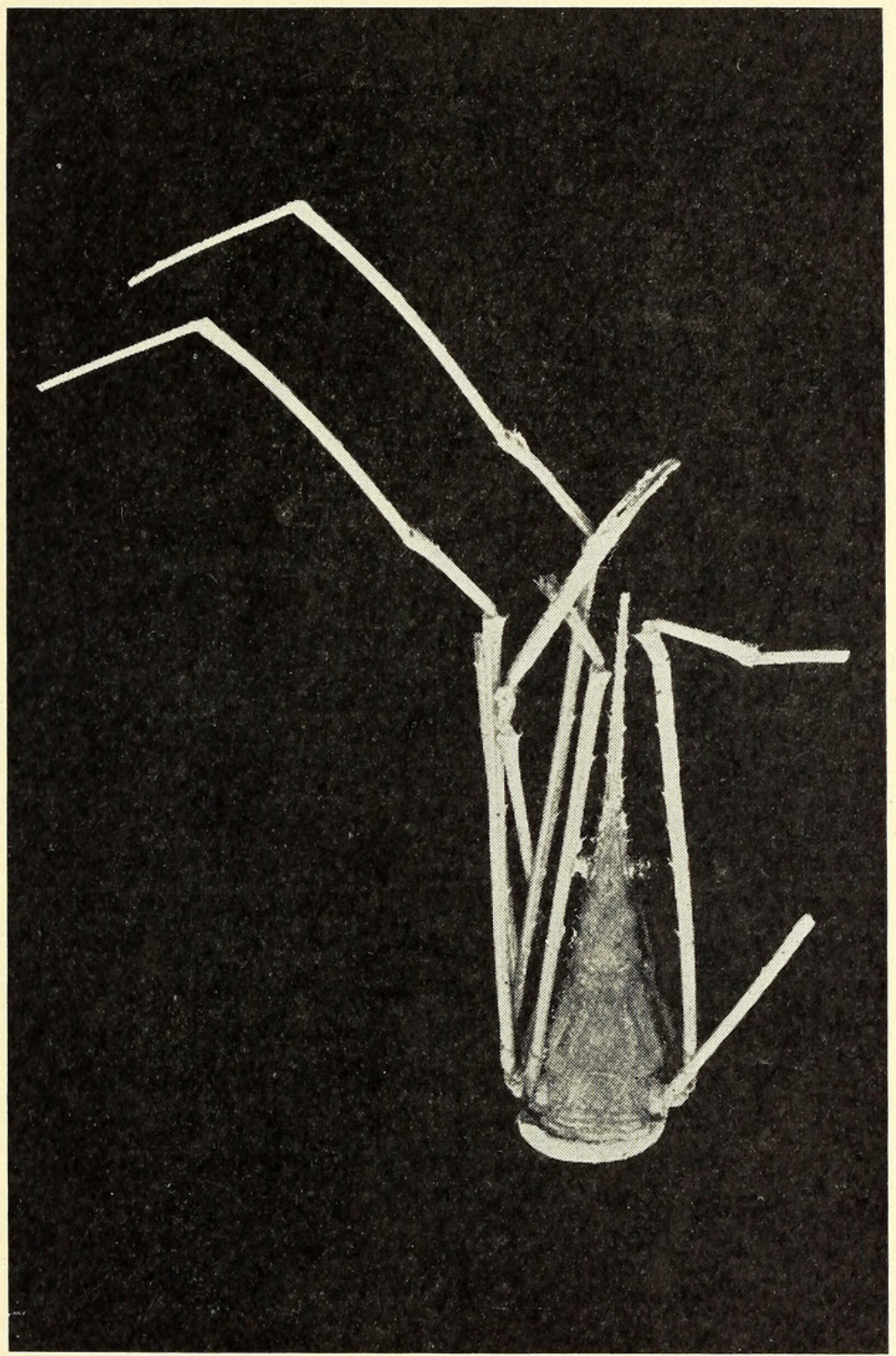

Fig. 34. Stenorynchus debilis $\times 11 / 3$.

Stenorynchus debilis Smith. (Arrow Crab).

Leptopodia sagittaria Milne Edwards and Lucas, d'Orbigny's Voy. l'Amer. Merid., vol. 6, pt. 1, p. 3, 1843; atlas vol. 9, Crust., pl. 4, figs. 3-3c, 1847; Valparaiso; not $L$. sagittaria Leach:-A. Milne Edwards, Crust. Rég. Mex. p. 172 (part) 1878; Miers, Challenger Rept., vol. 17, p. 4 (part) 1886 
Leptopodia debilis Smith, Rept. Peabody Acad. Sci. 1871, p. 87, for 1869 and 1870, appendix 1871; Rathbun, Proc. U. S. Nat. Mus., vol. 17, p. 44 $1894 ;$; $a x o n$, Mem. Mus. Comp. Zool., vol. 18, p. 5, 1895.

Leptopodia modesta A. Milne Edwards, Crust. Rég. Mex. p. 173, 1878

Stenorynchus debilis Rathbun, Proc. U. S. Nat. Mus., vol. 21, p. 568, 1898 vol. 38, p. 570, 1910; Proc. Washington Acad. Sci. vol. 4, p. 283, 1902 Bull. 129, U. S. Nat. Mus. p. 18, pls. 4 and 5, 1925.

Diagnostic Characters.-Chelipeds much shorter, with proportionately longer fingers, than Stenorynchus seticornis. Rostrum about as long as the carapace. There is a small spine at the extremity of the basal antennal article.

Type.-Professor Smith's type came from the Bay of Realejo, Nicaragua, and is deposited in the Museum of Comparative Zoology, Cambridge, Mass.

Galapagos Distribution.-Four males and one female were taken at Tagus Cove, Albemarle Island, by the Hopkins-Stanford Expedition; one specimen from Tower Island, Arcturus station 37.

General distribution.-Gulf of California, Mexico, Nicaragua, Panama and the Galapagos Islands.

Material examined.-One specimen (broken) from Tower Island, Station 37, taken by the Arcturus.

Technical description.-Carapace convex, smooth, finely setiferous; branchial regions tumid. The rostrum is nearly twice as long as the carapace, and is cylindrical, tapering, slender, setiferous distally; there is a row of short spines arming each side of the rostrum. There is a strong acuminate spine on the basal antennal segment. Just behind the orbit there is a pair of similar spines, one on each side.

The chelipeds, one of which is broken in my specimen, are said by Prof. Smith to be equal. They are slender extending almost to the distal end of the carpal joint of the first ambulatory legs. The ischium is armed with a few spines on the inner side; the merus is much longer than the ischium, but not quite so long as the palm of the propodus, and is slender, cylindrical, armed with a series of spines along both lateral margins and with three more prominent spines on the inner distal margin; the carpus is short with a few spines on the outer lateral margin, and two spines at the inner distal angle; the palm is cylindrical, smooth, rather finely tomentose; the fingers are nearly as long as the hand, moderately channelled longitudinally, nearly straight except at the tips, which are curved inward; sparsely setiferous. The cutting edges of the fingers meet and are dentate proximally, finely serrate distally.

The ambulatory legs are long, slender, cylindrical and armed with spinules. The first pair of ambulatories are about six and one-half times as long as the carapace.

The female abdomen is very similar to that of $S$. seticornis. The male abdomen is said by Prof. Smith to have the third segment the broadest of the series, while the terminal article is composed of the completely anchylosed sixth and seventh segments.

Genus Podochela Stimpon, 1860

Podochela margaritaria Rathbun.

Podochela margaritaria Rathbun, Proc. Washington Acad. Sci. vol. 4, p. 283, pl. 12, fig. 12, 1902; Bull. 129, U. S. Nat. Mus. p. 43, pl. 15, pl. 209, fig. 1, 1925. 


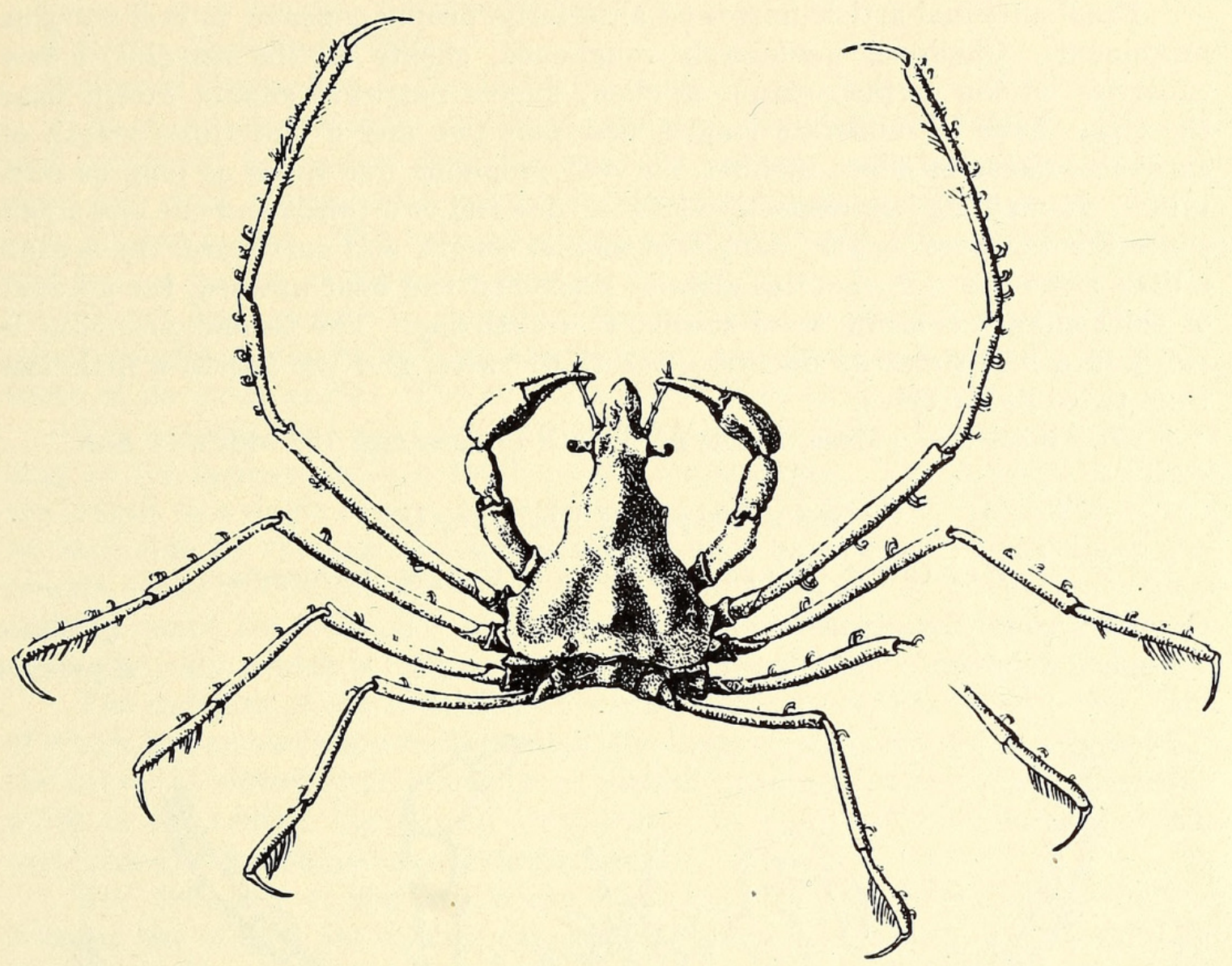

Fig. 35. Podochela margaritaria, male $\times 2$ (After Rathbun).

Diagnostic Characters.- "Rostrum hood-shaped, carinate. No postorbital lobe. Sternum coarsely granulate. Fingers of adult male narrowly gaping." (Rathbun).

Type.-One male specimen was taken at Tagus Cove, Albemarle Island, Galapagos Islands, in 12 fathoms, by the Hopkins-Stanford Galapagos Expedition and is deposited in the United States National Museum.

Galapagos Distribution.-Known only from four specimens taken at Tagus Cove, Albemarle Island.

General Distribution.-Known only from the type-locality.

Technical Description. - The following is a copy of Miss Rathbun's description of this species:

"Ventral surface covered with coarse, pearly granules; dorsal surface inconspicuously granulate, especially on the depressed portions and the branchial regions. A high conical tubercle on the cardiac and on the gastric region. Rostrum long, hood-shaped, the hood thin, sharply cristate on median line. No postorbital lobe. Hepatic region small, swollen, converging to a small, downward-pointing tubercle. A similar pterygostomian tubercle. Sternal segments high closely covered with white granules, and separated by deep smooth depressions; two tubercles in front of the abdomen terminate ridges leading upward between which is a deep trough. 
Basal antennal article narrowed anteriorly, deeply concave, lateral margins prominent. Chelipeds moderately roughened, chiefly on the margins, a few tubercles on the carpus, manus swollen, fingers narrowly gaping except near the tips. Legs of moderate length, first pair two and a half times length of carapace, dactylus short, slender, curved, propodus five times as long as dactylus. Remaining legs respectively twice, one and two-thirds and one and a half times the carapace length; dactyli of similar length and curvature, the second a little slenderer. Propodites distally thickened and bent upward, the amount of thickening increasing from second to fourth leg. The second propodus is two and a half times its dactylus, the third twice, and the fourth a little less than twice its dactylus.

Measurements.-Male, holotype, length of carapace 15, width $11 \mathrm{~mm} . "$

\section{Genus Dasygyius Rathbun, 1897}

Key to the Galapagos species of the genus Dasygius.

Carapace convex, rostrum bifid.

gibbosus

Carapace depressed; rostrum simple, entire. depressus

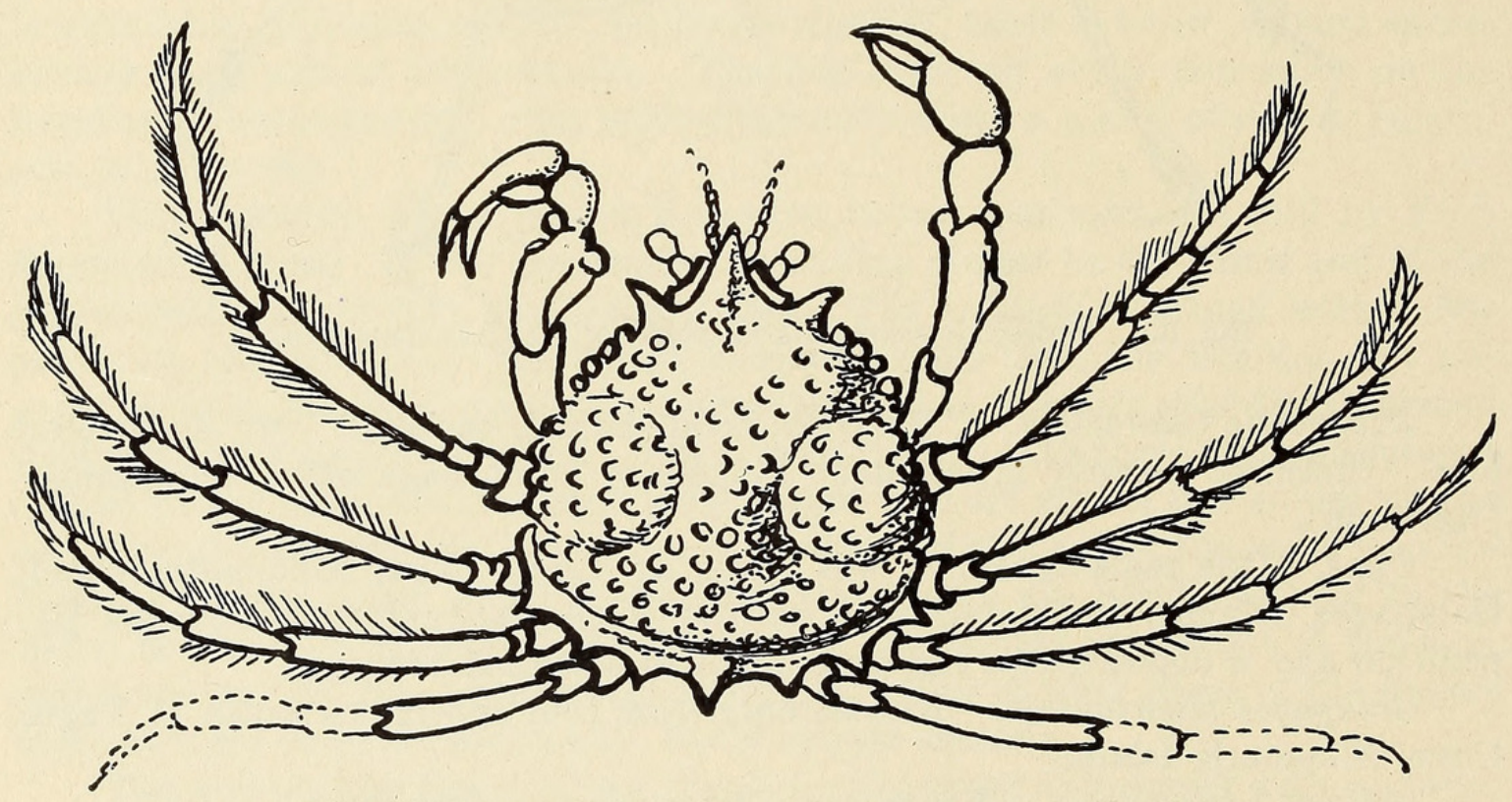

Fig. 36. Dasygyius gibbosus, male $\times$ about 2 (After Bell).

Dasygyius gibbosus Bell.

Microrhynchus gibbosus Bell, Proc. Zool. Soc. London, vol. 3, p. 88, 1835; Trans. Zool. Soc. London, vol. 2, p. 41, pl. 8, figs. 1-1c, 1836.

Neorhynchus gibbosus A. Milne Edwards, Crust. Rég. Mex. p. 187, 1880.

Dasygyius gibbosus Rathbun, Proc. U. S. Nat. Mus., vol. 38, p. 571, 1910; Bull. 129, U. S. Nat. Mus. p. 138, pl. 274, figs. 1-4, 1925.

Diagnostic Characters.-Carapace rather flat; rostrum simple, triangular; ambulatory legs decreasing in length in the following order: 3, 2, 4, 1 pairs.

Type.-The type of this species was taken by D. Cuming at the Galapagos Islands. Known only from type specimen.

Galapagos Distribution.-Galapagos Islands. 
General Distribution.-Galapagos Islands.

Material Examined.-None.

Technical Description.-The following is Bell's description of the type:

"The carapax is broadly pyriform, gibbous, rounded; the regions elevated, and separated by rather deep furrows; the surface covered, particularly on each branchial region, with numerous distinct rounded tubercles resembling very minute pearls. The rostrum is very small and bifid. The orbits are wide, and have a hollow at the outer side for the lodgment of the eyes when at rest, though not deep enough to conceal them entirely. A small fissure divides the upper margin of the orbit from the rostrum, and another externally from the tooth of its outer angle. The eyes are larger than their peduncles.

The external antennae are half as long as the body, the basilar joint as long as the rostrum, with a tooth at the outer angle. The internal antennae are lodged in a single cavity, open in front, bounded above by the rostrum, and on each side by the basilar joint of the external antennae. The pedipalps resemble those of Camposcia, excepting that the second joint of the inner footstalk is more heart-shaped, and deeply notched for the attachment of the moveable palp, which is long and greatly developed.

The abdomen of the male (the only sex yet observed) has seven joints, each of which has an elevation in the center: the first, which is wholly apparent when the animal is viewed from above, is somewhat quadrate, with a small tubercular tooth in the centre; the second very short; the third much broader than the rest, and the remainder abruptly narrower.

The first pair of legs are thicker than, but not much more than half as long as the others; the surface granulated; the hand rounded, and terminated by arched fingers which meet only at the apex, where they are denticulated. The four posterior pairs of legs are on the average nearly twice the length of the body, diminishing in the order $3,4,2,5$. They are cylindrical and hairy; and the nails are long, slender, and but slightly arched.

The general colour of the specimen is yellowish white.

Length of the carapax 6 lines; breadth 5 lines.

"One specimen only, a male, was obtained by Mr. Cuming at the Gallapagos Islands in sandy mud at six fathoms depth."

Dasygyius depressus Bell.

Microrhynchus depressus Bell, Proc. Zool. Soc. London, vol. 3, p. 88, 1835; Trans. Zool. Soc. London, vol. 2, p. 42, pl. 8, figs. 2, 2d-f, 1836.

Neorhynchus depressus A. Milne Edwards, Crust. Rég. Mex., p. 187, 1880.

Dasygyius depressus Rathbun, Proc. U. S. Nat. Mus., vol. 21, p. 570, 1898; vol. 38, p. 571, 1910; Bull. 129, U. S. Nat. Mus. p. 138, pl. 1; pl. 274, figs. 5-8, 1925.

Diagnostic Characters.- "Carapace depressed, granulate; rostrum small, triangulate, entire." (Bell.)

Type.-The type of this species was taken at the Galapagos Islands by

H. D. Cuming. It is believed to be no longer extant.

Galapagos Distribution.-Galapagos Islands (type-locality).

General Distribution.-Galapagos Islands and Gulf of Lower California.

Material Examined.-None.

Technical Description. - The following is Mr. Bell's description of the type: 


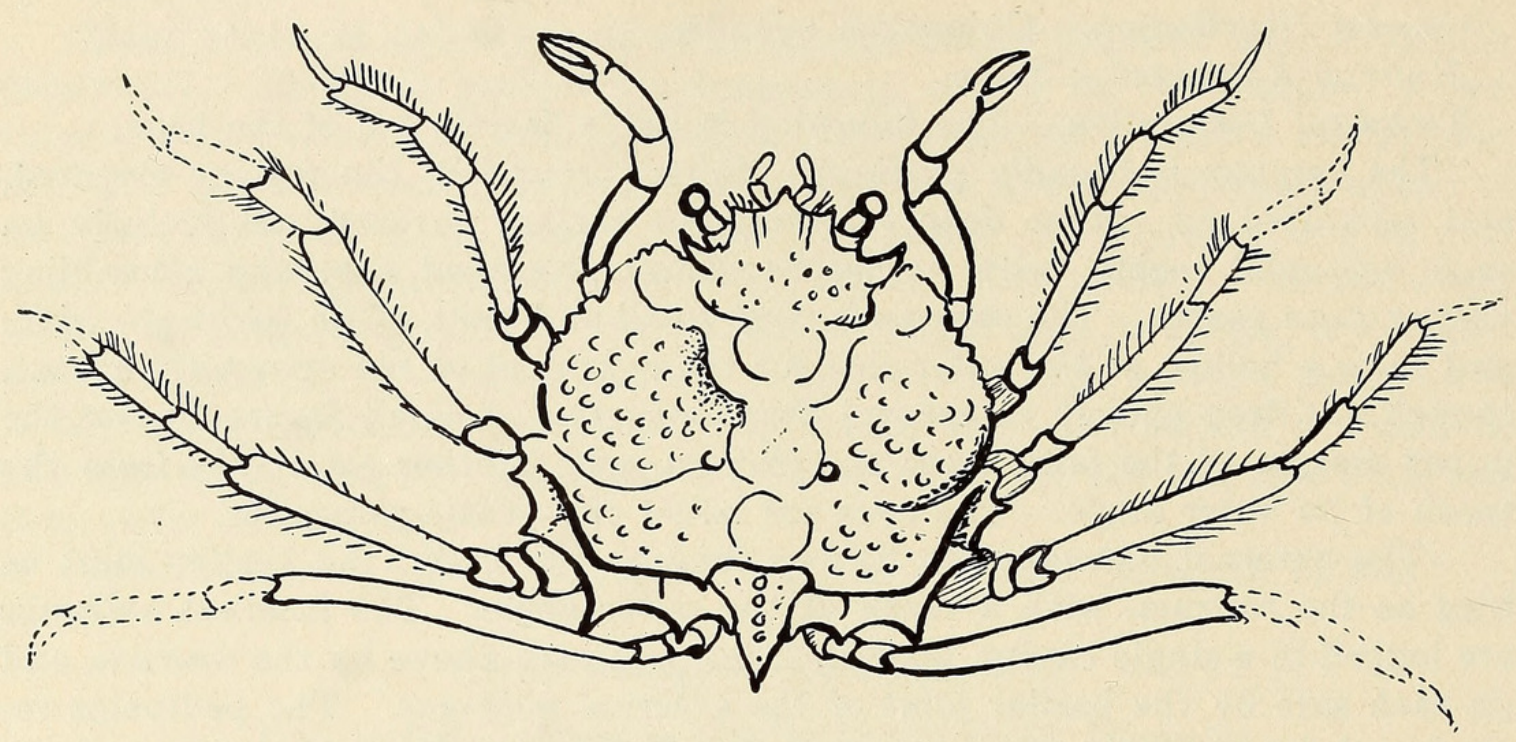

Fig. 37. Dasygyius depressus, female $\times$ about 2 (After Bell).

"This very singular species differs greatly in general form and aspect, no less than in more minute detail, from the former. The carapax is much broader, suborbicular, very depressed, although the specimen is a female, and the regions, though sufficiently distinct, are but little elevated. The surface is covered with numerous minute granular elevations, with here and there a few larger ones. The orbits resemble those of Micr. gibbosus, excepting in being much larger, as are also the eyes. The rostrum is very small, triangular, and entire, the margins minutely granulated.

The tooth of the basilar joint of the external antennae is incurved at the point. The internal antennae resemble those of the former species, but their cell is still more open. The first joint of the inner footstalk of the external pedipalps is longitudinally channelled; the second joint cordiform, but less deeply notched than in Micr. gibbosus.

The sternal disc (in the female) is almost orbicular, and not nearly covered by the abdomen, which is five-jointed. The first joint is somewhat bell-shaped, with a long central tooth or spine projecting directly backwards; the second, third and fourth, extremely short; and the fifth, consisting of a perfect union of the last three joints, forms a flat orbicular disc, having a broad, depressed, longitudinal elevation.

The first pair of legs is, in this sex, extremely small; the arms much curved; the fingers very slightly arched, and minutely toothed towards the extremity. The remaining legs are similar to those of the former species.

Colour nearly white, but with a very slight pinkish tinge.

Length of the carapax 6 lines; breadth the same.

Of this species one specimen only, a female, was procured by Mr. Cuming with the former (D. gibbosus). 


\section{Subfamily: ACANTHONYCHINAE}

Genus Acanthonyx Latrielle, 1825

Acanthonyx petiverii A. Milne Edwards. (Shield Crab; Kelp Crab).

Acanthonyx petiverii H. Milne Edwards, Hist. Nat. Crust., vol. 1, p. 343, 1834; Dana, U. S. Expl. Exped., vol. 13, Crust., pt. 1, p. 128, 1852; atlas, pl. 5, fig. 6a-d, 1855; A. Milne Edwards, Crust. Rég. Mex., pl. 27, figs. 7-7f, 1878; Rathbun, Bull. U. S. Fish Comm., vol. 20, for 1900, pt. 2, p. 60, (1901); Proc. U. S. Nat. Mus., vol. 38, p. 534, pl. 46, fig. 4, 1910 .

Acanthonyx emarginatus Milne Edwards and Lucas, d'Orbigny's Voy. l'Amer. Merid., vol. 6, pt. 1, p. 9, 1843; atlas, vol. 9, pl. 5, fig. 2, 1847.

Acanthonyx debilis Dana, Amer. Journ. Sci., ser. 2, vol. 11, p. 272, 1851: U. S. Expl. Exped., vol. 13, Crust., pt. 1, p. 127, 1852; atlas, pl. 5, fig. 5 a and $b, 1855$.

Peltinia scutiformis Dana, Amer. Journ. Sci., ser. 2, vol. 11, p, 273, 1851; U. S. Expl. Exped., vol. 13, Crust., pt. 1, p. 130, 1852; atlas, pl. 5, fig. $7 a-c, 1855$.

Acanthonyx concamerata Kinahan, Journ. Roy. Dublin Soc., vol. 1, p. 334, pl. 14, fig. 1, 1857.

Acanthonyx petiveri Stimpson, Ann. Lyc. Nat. Hist. New York, vol. 10, p. 97, 1871; A. Milne Edwards, Crust. Rég. Mex., p. 143, and synonymy, 1878 .

Pugettia scutiformis Miers, Challenger Rept., vol. 17, p. 40, footnote, 1886; Moreira, Arch. Mus. Nac. Rio de Janeiro, vol. 11, pp. 65 and 138, 1901; Bull. Soc. Zool. France, vol. 45, p. 126, footnote, 1920; Lenz and Strunck, Deutsche Sudpolar Exped. 1901-1903, vol. 15, Zool. 7, p. 276, 1914.

Acanthonyx petiverii Rathbun, Bull. 129, U. S. Nat. Mus., p. 142, pl. 44, pl. 222, figs. 1-6, 1925.

Diagnostic Characters.-Carapace shield-shaped with an obtuse preorbital tooth, a large hepatic lobe and two small branchial lobes.

Type.-Professor Milne Edwards' type specimen, which is deposited in the Paris Museum, is recorded as coming from the "Antilles."

Galapagos Distribution.-Galapagos Islands (Bell); Arcturus station 54, off Hood Island, depth 15 feet.

General Distribution. - This fascinating little dweller in the submarine plants of the tidal zone, has a wide distribution, ranging from southern Florida, through the Bahamas, West Indies, Yucatan and Carribean southward as far as Rio de Janiero on the Atlantic coast and from Lower California southward, including the Galapagos Islands, down to Valparaiso, Chile.

Material Examined.-Two male specimens of this species were secured by the director of the Expedition, William Beebe, while diving in fifteen feet of water at Station 54, off Hood Island.

Color.-This species has evolved a coloration which is a perfect mimicry of the rust-brown seaweed in which it dwells. The carapace and legs are mottled fawn-color to rust-brown and flecked with golden yellow and black maculations.

Habits. - Acanthonyx petiverii spends the greater part of its adult life cradled in the branches of seaweed and similar marine plants of the tidal zone. The secret of its ability to withstand the tremendous force exerted by wind and wave is best understood by an examination of its powerful subchelate legs, which have been so remarkably modified to meet the needs of such an existence. Experience has taught me that the only way to collect specimens of this species with the legs on is to take the plant or branch to which they cling also. They are very poor swimmers. If the plant to which they cling is snipped away with a pair of scissors and they are successfully shaken out of their aquatic "treetops," they 
will crawl and clumsily paddle their way to the nearest plant shelter. Upon attaining this they vanish with mesmeric gracefulness into the foliage and finding a point of vantage, fasten their eight anchor-toes to the twigs and pendulum with the submarine "treetops" as they sway with the waves. This little species is largely herbivorous, grazing on the algae and similar small plants, although it sometimes eats the tender new growths of the larger seaweeds. It is carnivorous, also, feeding on young amphipoda, zoea, small worms and tiny mollusks.

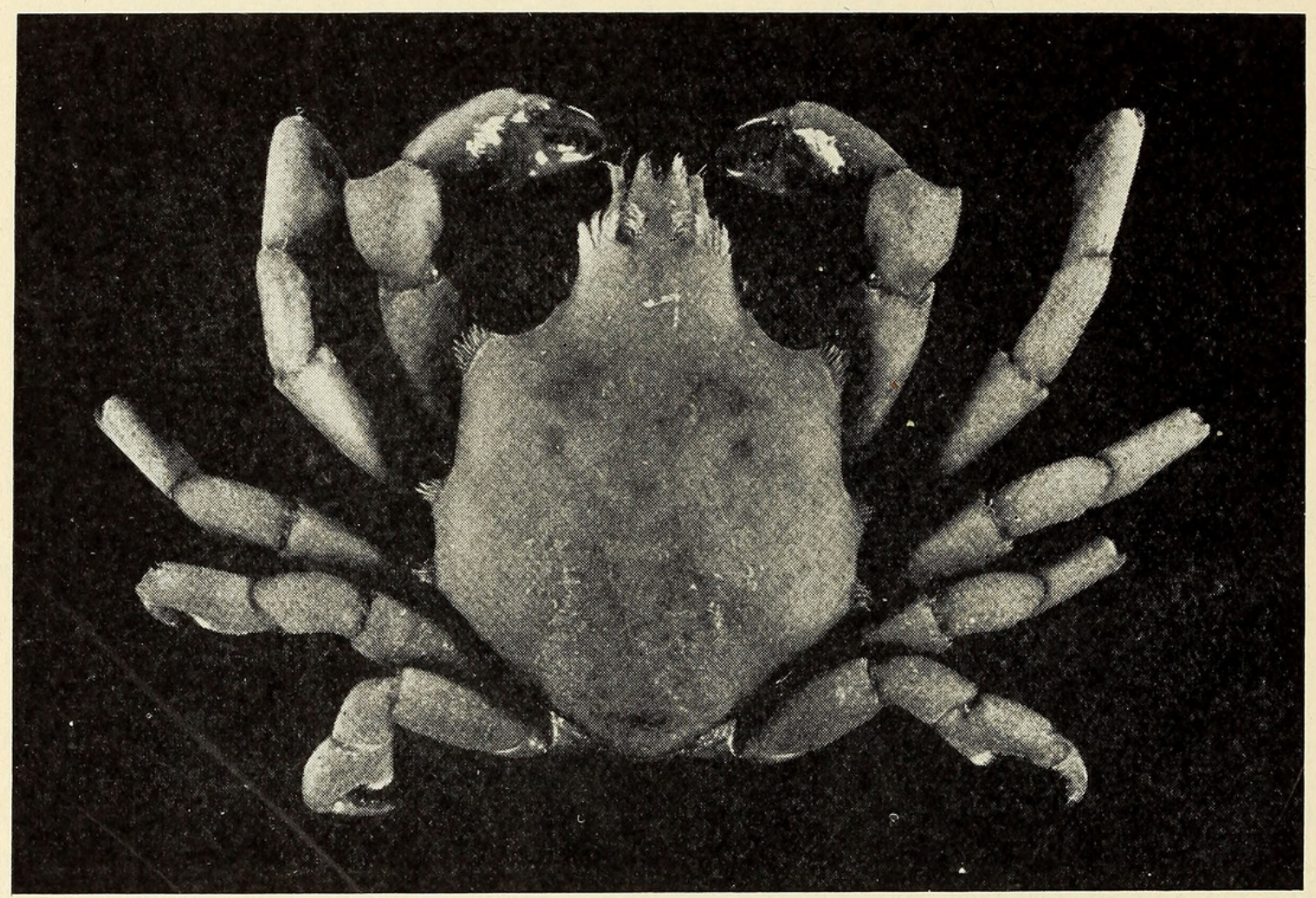

Fig. 38. Acanthonyx petiverii, $\times 3 \frac{1}{2}$.

It takes Acanthonyx petiverii about an hour and twelve to twenty minutes to cast off its old hardened shell and emerge as a "soft" crab. This is a particularly interesting process, executed by a series of unbelievably graceul movements, as the tiny legs are successively slipped from the old encasement, the carapace cracks along the line of the sternal sutures and with elfin daintiness, the little creature slips out clad in a delicate soft-hued, softtissued replica of its old dress. It seeks a sheltered branch to which it fastens the eight little anchor-toes, now relatively soft and less able to function than usual, and thus hidden, so far as it is possible to hide from the incessant menace of the keen-eyed hunger-driven enemies, the second phase in the process of ecdysis takes place. In this cumbersome, technical phrase is concealed the story of one of the most marvelous bits of natural history. Like the mythical gnome of ancient fairy lore, who emerges from the seed-pod and swells and swells and swells, until a giant stands revealed, so Acanthonyx petiverii swells and 
swells and swells,-inscrutably, inexplicably, without apparent cause or motion, but visibly enlarging, expanding until when a matter of 14 to 23 minutes of such miracle has elapsed, one discovers that Acanthonyx petiverii not only appears larger, but scientific measurement with caliphers and millimeter reveals that an increase in size of 35 to 54 per cent. has actually occurred. The next few hours are also devoted to concealment, during which time the soft shell becomes paper-like and brittle and subsequently calcifies. Nothing is eaten by the soft-shelled creature, save possibly the minutae sieved during its incessant rhythmic "bubbling" of seawater. The day after the shell has been cast or approximately 20 to 24 hours thereafter, the new carapace is quite hardened, the tips of the chelipeds especially so, and impelled by hunger, the little creature climbs from its sanctuary into the submarine treetops, there to resume the daily routine of crab existence.

In the subtropical waters of southern Florida, I have taken females bearing eggs and embryos from February through the year to the following January, but breeding seems dominant from February to April, during which period it is difficult to find an adult female without eggs. One female measuring only $8 \mathrm{~mm}$. long diameter, $5 \mathrm{~mm}$. short diameter, carried 472 fertile eggs. Another measuring $19 \mathrm{~mm}$. long diameter, $12 \mathrm{~mm}$. short diameter, carried approximately 1200 eggs. These are globular, minute, dirty yellow to brown in color. The larval stages of this species have not yet been successfully studied.

Technical Description.-Carapace shield-shaped, moderately convex, longer than wide, frontal region triangular, rostrum short, squarish, bifid, deflexed, margined with stout upward directed setae. Preorbital lobes angulated, bent upward and outward, setiferous. Anterolateral angles prominent, flaring; two small subequal teeth on the lateral margin of the branchial region, one near the anterior of the mesobranchial margin and the other near the posterior of the metabranchial margin; the posterior margin is rounded.

There are three obscure tubercles on the gastric region, one on the cardiac and one on the intestinal region. These tubercles are poorly developed, occasionally obsolete in the males and usually absent in the females. The abdomen in both sexes has the fourth and fifth segments coalesced. Eyes small, approximately under the preocular lobes; stalks stout, swollen; cornea very weak, outward directed. The antennae have the basal article smooth, simple, the second and third articles subcylindrical, extending as far forward as the apex of the rostrum, the flagellum is exceedingly slender.

The chelipeds are massive for so small a species; the basis and ischium are quite small; the merus long, three-sided, the distal apices of the lateral margins are produced as three spines - that of the dorsal being most acute. The carpus is less than half the length of the merus and is quite convex.

The ambulatory legs successively decrease in length from first to fourth pairs. All are stout, laterally compressed, have the proximal joints small, the merus long, the carpus little more than half as long as the merus and dilated distally, the propodus decidedly dilated, the distal margin concave and produced at the free angle as a blunt tooth against which the dactylus fits claw fashion; this distal margin of the propodus is densely setiferous; the dactyl is moderately stout, curved, pointed, finely spinose and setiferous on the inner margin 
which is appressed to the curved surface of the propodus. The distal margins of the basal, meral, and carpal joints are also set with tufts of setae.

Genus Taliepus A. Milne Edwards, 1878

Taliepus marginatus (Bell).

Epialtus marginatus Bell, Proc. Zool. Soc. London, vol. 3, p. 173, for 1835 (1836); Trans. Zool. Soc. London, vol. 2, p. 62, pl. 11, fig. 4, 4i, 4j, $4 k$ (female), pl. 13 (male) 1836. Heller, Reise Novara, Crust., Wien., $p 5$, 1865; Smith, Trans. Connecticut, Acad. Sci., vol. 2, p. 33, 1869; A. Milne Edwards, Crust. Rég. Mex., p. 138, 1878; Miers, Proc. Zool. Soc. London, p. 66, 1881; Ortmann, Zool. Jahrb., Syst., vol. 7, p. 42, 1893; Lenz, Zool. Jahrb., Suppl. 5, p. 7561902 ; Rathbun, Proc. U. S. Nat. Mus., vol. 38, p. 534, pl. 36, fig. 2, 1910; Aurivillius, K. Svenska Vet.-Akad. Handl., vol. 23, p. $43,1889$.

Epialtus (Antilibinia) marginatus Miers, Journ. Linn. Soc. London, vol. 14, p. 650, 1879; Rathbun, Proc. U. S. Nat. Mus., vol. 17, p. 69, 1894.

Taliepus marginatus Rathbun, Bull. 129, U. S. Nat. Mus. p. 164, pls. 52 and $53 ; p l .220$, fig. $2 ; p l .221,1925$.

Diagnostic Characters.-Rostrum narrowed anteriorly and bifid; there is a small tooth on each side in front of the orbit; post-orbital tooth obsolete; propodites of legs armed below with one tooth.

Type.-In the preliminary, synoptic diagnosis of this species the typelocality is given as "the shores of Brazil," but in the first full diagnosis of the species Bell states that the material "was taken in the Galapagos Islands by D. Cuming and on the shores of Brazil by D. Miller." This material is believed to be no longer extant.

Galapagos Distribution.-Galapagos Islands (type locality). Brazil.

General Distribution.-Galapagos Islands, Valparaiso, Chile, and shores of

Material Examined.-None.

Technical Description.-The following is Mr. Bell's description of the type:

"The carapace is rounded behind but angular and produced forwards; the surface even, punctate; and the regions divided by impressed lines. The upper and under surfaces are separated by a distinct marginal line, on which are two small tubercles, of which the posterior is obsolete, or marked only by a slight turn in the marginal line. The anterior margin has two acute prominent teeth. The rostrum is narrowed forwards and bifid; and there is a small tooth on each side in front of the orbit. The orbits are circular and entire, and the eyes globular, accurately fitting the orbits and scarcely projecting beyond them.

The internal antennae are lodged in a large fossa, which is open and undivided anteriorly, but divided from behind forward by a long narrow spine. The external antennae are concealed by the rostrum; the basilar joint broad and much produced forwards; the moveable portion cylindrical, shorter than the rostrum. Pedipalps with the outer footstalk having parallel sides, except at the apex, which is triangular; inner footstalk smooth and polished, with the second joint truncated at the inner and posterior angle.

Abdomen of both sexes with seven joints.

Anterior feet of the male very robust, nearly twice as long as the carapax, very minutely granulated: the arm with two tubercles above and two beneath: the hand rounded, smooth; the fingers strongly tuberculated through their whole length, meeting only at the points, which are somewhat excavated; the 
movable finger longer than the other. Posterior feet cylindrical, the joints tumid: the second pair longer than the hinder ones, which decrease in length to the fifth. A tooth on the inferior side of the penultimate joint, which is hairy at the point: it is smallest on the second pair and longest on the fifth. The last joint is curved, acute, and finely toothed beneath.

Colour of the adult, dark brown; of the young female, paler and reddish.

Length of the carapax 4 inches; breadth 3 inches 3 lines.

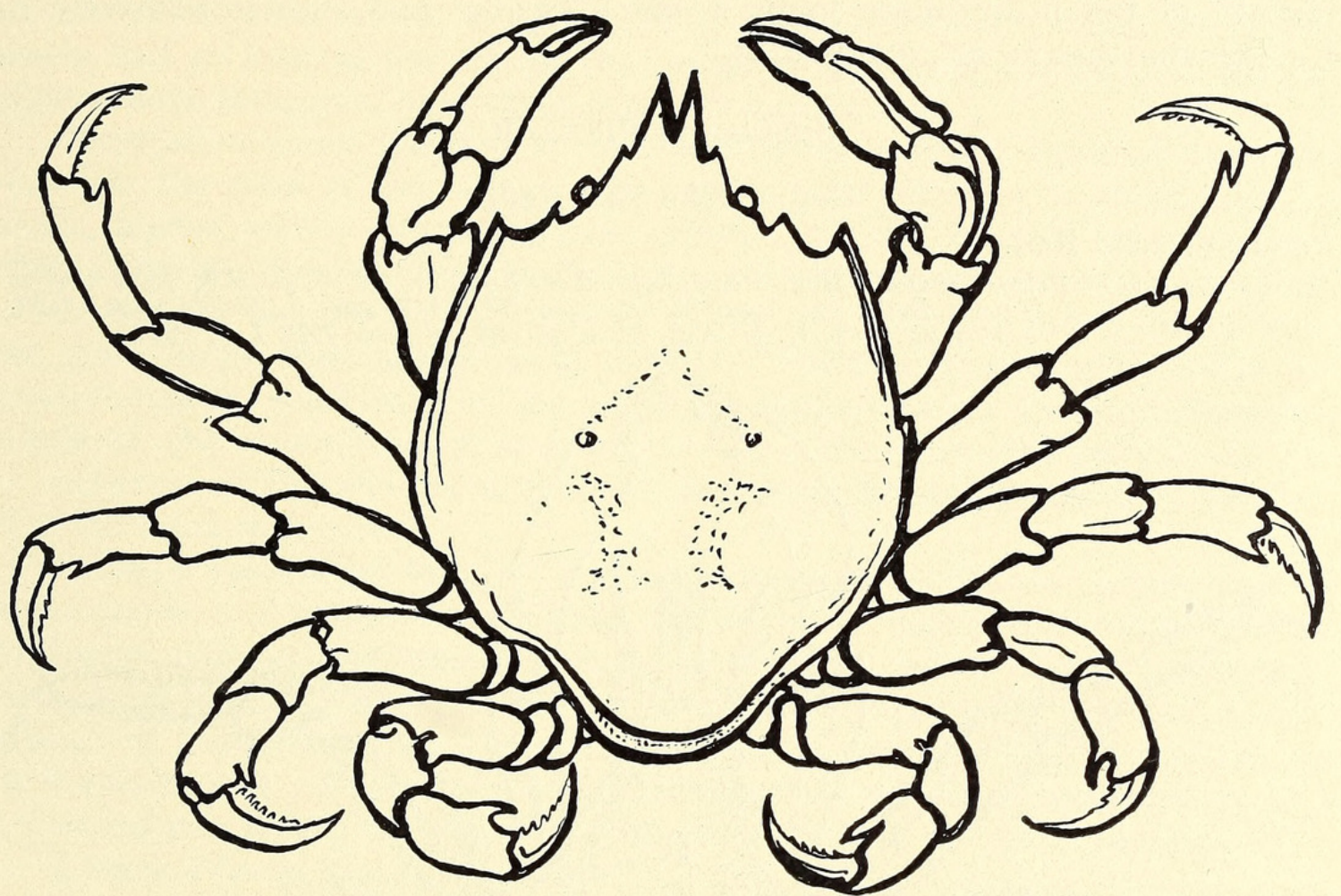

Fig. 39. Taleipus marginatus, slightly reduced (After Bell).

The large male specimen was found by Mr. Cuming with $E$. dentatus at Valparaiso in crevices of rocks. The young female specimen was brought by Mr. Miller from Rio Janeiro.

It is not without considerable hesitation that I have decided on giving to these Crustacea the characters of distinct species. I was first led to the opinion that they were so, by comparing with Mr. Cuming's specimens of Epialtus one of an immature female which was kindly presented to me by Mr. Miller, and which he had taken at Rio: and a subsequent more particular examination of the former specimens has tended greatly to confirm this view, as the largest and finest of them, a very fine adult male, posesses all the characters which had led me to consider Mr. Miller's specimen as distinct. I have thought it desirable to offer a figure of each of these two individuals, and as they differ from $E p$. dentatus only in slight characters, which are easily appreciated, it appeared unnecessary to figure that species, especially as it had been described by my friend Dr. Milne Edwards, and will I hope shortly be figured by him.

The characters upon which I have founded this distinction are these. In $E p$. dentatus the lateral margin is rounded, the sides of the carapax passing off 
from above to beneath in a continuous rounded surface: in Ep. marginatus the upper and under surfaces are separated by a distinct slightly salient margin; the posterior tubercle, which in the former is very distinct, is in the latter only indicated by a very slight degree of prominence in the marginal line; and the lateral spine of the former is in the latter supplied by a tubercle. The very great difference in the size of the anterior feet probably depends on age: but it is worthy of notice that in the rest of the feet the inferior spine near the extremity of the penultimate joint, is much smaller and shorter relatively in $E p$. dentatus than in Ep. marginatus."

\section{Subfamily: PISINAE}

Pelia pulchella Bell.

Genus Pelia Bell, 1835

Pelia pulchella Bell, Proc. Zool. Soc. London, vol. 3, p. 170, 1835 (1836); Trans. Zool. Soc. London, vol. 2, p. 45, pl. 9, figs. 2, 2d-2f, 1836; Rathbun, Bull. 129, U. S. Nat. Mus. p. 284, pl. 241, figs. 1-4, 1925.

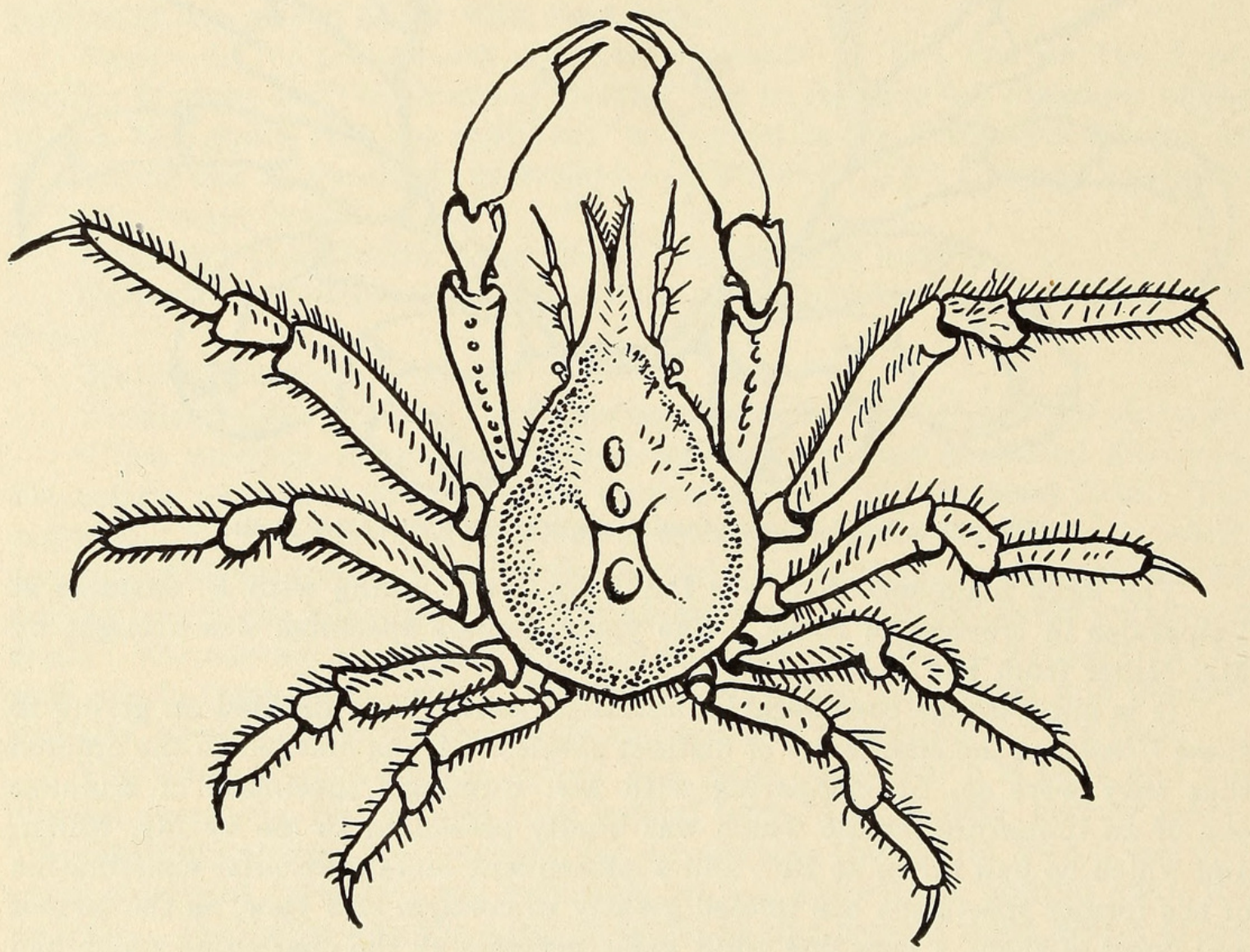

Fig. 40. Pelia pulchella, male $\times$ about 4 (After Bell).

Diagnostic Characters.-Rostrum much produced, nearly half as long as the rest of the carapace, bifid at the extremity. Basal joint of the external antennae prominant dorsally.

Type.-Bell's type was taken in the Galapagos Islands by D. Cuming; it is no longer extant. 
Galapagos Distribution.-Known only from the type specimen taken in the Galapagos Islands.

Material Examined.-None.

General Distribution.-Galapagos Islands.

Technical Description.-The following is Mr. Bell's description of the type:

"Carapax pyriform, gibbous, rounded, polished, somewhat hairy: the regions elevated, particularly the gastric and cardiac, the latter of which forms a rounded tubercle: lateral margin entire. Rostrum straight, much produced, nearly half as long as the rest of the carapax, bifid at the extremity, with a slight groove continued backwards from the bifurcation.

Internal antennae inserted at the base of the rostrum: external antennae placed at the sides of the rostrum; the basilar joint reaching to about half its length, almost wholly exposed above, slightly tapering towards its extremity, where there is a small external tooth; the moveable portion setaceous, extending a little beyond the apex of the rostrum, the second and third joints cylindrical, and much larger than the terminal portion. External pedipalps with the external footstalks semifusiform; the first joint of the internal footstalk elongate, rhomboid; the second joint of an irregular four-sided figure, the margins entire.

Abdomen in the male seven-jointed, the joints becoming gradually smaller from the third to the last.

Anterior feet longer than the body; the arm three-sided, having a toothed carina above, and two carinae beneath, the outer of which is minutely serrated; the hands slightly compressed, smooth: the fingers, when closed, in contact throughout their whole length, the half towards the apex being serrated, and a tubercle of the immoveable finger received into a corresponding excavation in the moveable one. The remaining feet compressed, carinated and hairy above, the second pair longer than the first, the rest becoming gradually shorter.

Length 4 lines; breadth $2 \frac{1}{2}$ lines.

A single male specimen was taken by Mr. Cuming from sandy mud, at a depth of sixth fathoms."

Genus Pisoides Milne Edwards and Lucas, 1843

Pisoides edwardsii (Bell).

Hyas edwardsii Bell, Proc. Zool. Soc. London, vol. 3, p. 171, 1835; Trans. Zool. Soc. London, vol. 2, p. 49, pl. 9, fig. 5, 1836.

Pisoides tuberculosus Milne Edwards and Lucas, d'Orbigny's Voy. l'Amer. Merid., vol. 6, pt. $1, p_{1} 11,1843$; vol. 9, atlas, pl. 5, figs. 1-1d, 1847; Nicolet, in Gay, Hist. Chile, Zool., vol. 3, p. 134, 1849; A. Milne Edwards, Crust. Rég. Mex., p. 75, pl. 16, figs. 5-5b, 1880; Lenz, Zool. Jahrb., Suppl. 5, vol. 2, p. 757, 1902; Rathbun, Proc. U. S. Nat. Mus., vol. 38, pp. 572 and 616,1910 .

Pisoides edwardsii Dana, U. S. Expl. Exped., vol. 13, Crust., pt. 1, p. 87, atlas, pl. 1, figs. $2 a$ and 2b, 1855; Miers, Proc. Zool. Soc. London, p. 63, 1881; Rathbun, Proc. U. S. Nat. Mus., vol. 38, pp. 672 and 613, 1910; Bull. 129, U. S. Nat. Mus., p. 285, pl. 236, 1925.

Diagnostic Characters: Carapace pyriform; preocular spine wanting; postocular spine prominent, acuminate. Rostral horns flat, basal antennal article with a prominent tubercle at its external distal angle; squarish.

Type.-Valparaiso, Chile and the Galapagos Islands; types not extant.

Galapagos Distribution.-Galapagos Islands (type locality).

General Distribution.-West Panama; Chile, southward to the Straits of Magellan; also the Galapagos Islands. 
Material Examined.-None.

Technical Description.-The following is Mr. Bell's description of type:

"Carapax pyriform, elevated, posteriorly rounded, anteriorly narrow, but without a distinct contraction behind the orbits; covered with brown hair. Rostrum formed of two elongated compressed teeth slightly converging at the apex. Orbits spacious, without spines, having a triangular tooth of moderate side at the outer canthus. Eyes globular, larger than their peduncles.

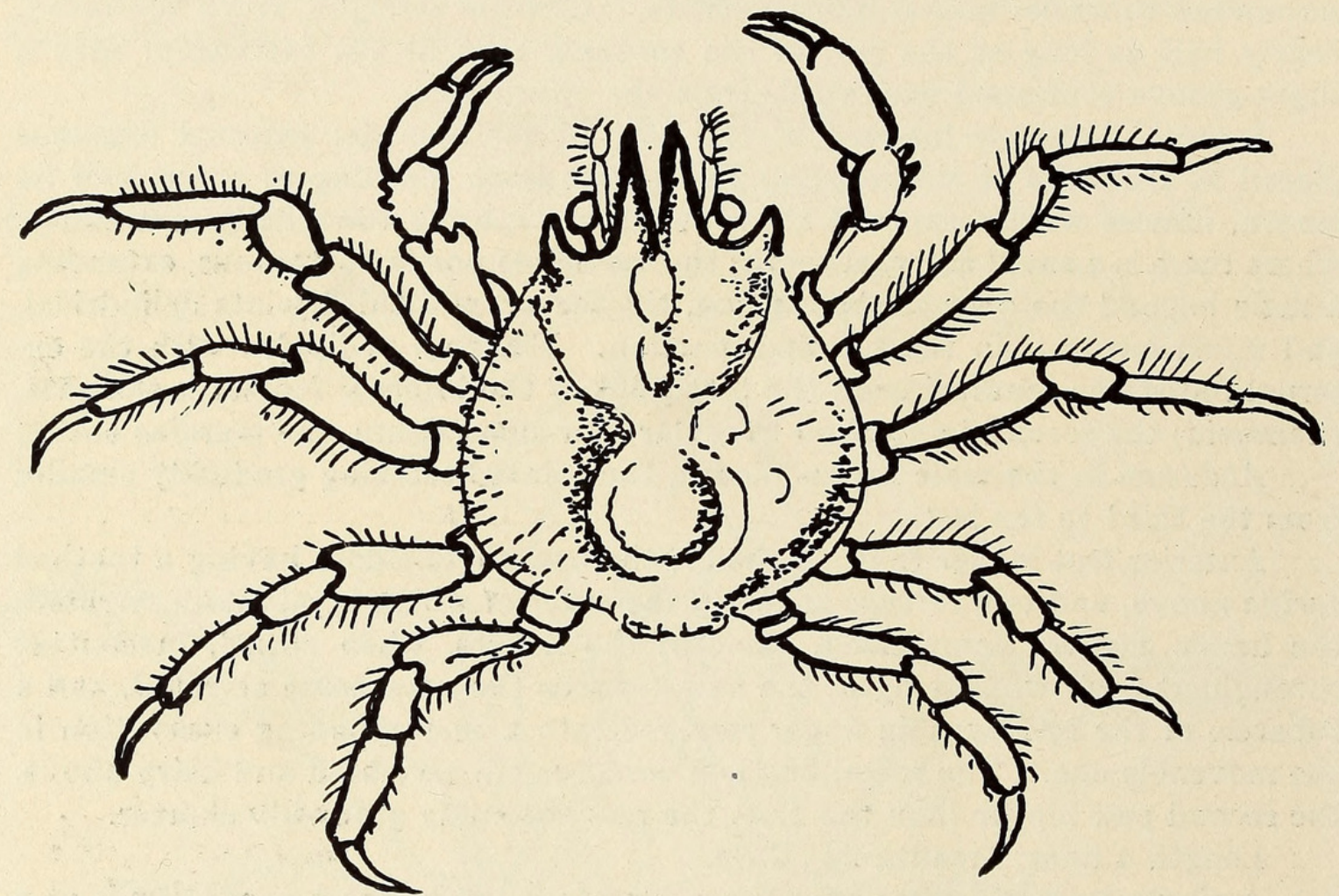

Fig. 41. Pisoides edwardsii, $\times$ about 2 (After Bell).

Interior antennae lodged in a fossa at the base of the rostrum, which is open anteriorly, and undivided. Exterior antennae longer than the rostrum, very hairy, the basilar joint with raised margins; the second and third less expanded than in the other species of the genus. The pedipalps offer no peculiarity. side.

Abdomen of the male with the penultimate joint with a small tooth on each

Anterior legs in the adult male rounded, the hand much thicker than the arm, and terminated by curved fingers, which touch each other only at the apex, which is serrated; moveable finger with a single tubercle near the base. In the female the hands are scarcely longer than the arms, the fingers are less curved, and there is no tubercle. The remaining legs are somewhat flattened above, obtusely carinated beneath, and very hairy: the second pair is the longest, and they diminish regularly to the fifth.

In size the specimens from the two localities differ exceedingly. There are adult males from the Gallapagos Islands, of which the length is 6 lines and the breadth 4 lines. From Valparaiso I have examined a specimen of an im- 
mature male, as appears by the want of development of the anterior feet, the length of which is 9 lines and the breadth 7 lines. This remarkable discrepancy led me at first to expect that I should discover some specific differences; but the most careful examination has convinced me that they are all of one species."

Genus Herbstia H. Milne Edwards, 1834

Merus of ambulatory legs armed with spines. Superior orbital margin with one tooth between the preorbital and postorbital teeth.

edwardsii

Merus of ambulatory legs unarmed. Lateral margin of carapace armed with four minute teeth.

pyriformis

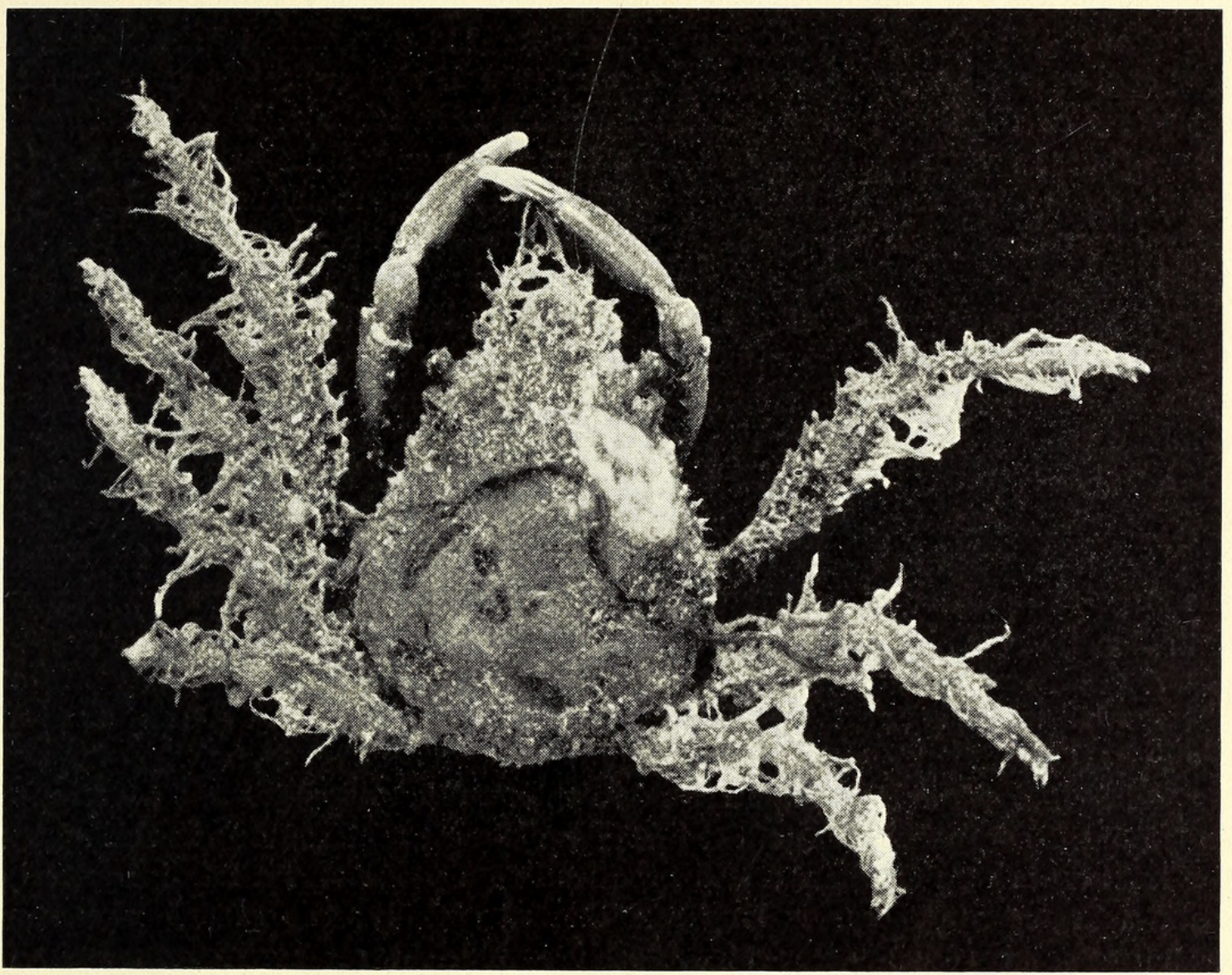

Fig. 42. Herbstia edwardsii, $\times 3$.

Herbstia edwardsii (Bell).

Herbstia edwardsii Bell, Proc. Zool. Soc. London, vol. 3, p. 170, 1835; Trans. Zool. Soc. London, vol. 2, p. 46, pl. 9, figs. 3, 3g-3i, 1836; Rathbun, Bull. 129, U.S. Nat. Mus., p. 300, pl. 105, figs. 3 and 4; pl. 240, figs. 1-4,

Herbstiella edwardsii Stimpson, Ann. Lyc. Nat. Hist. N. Y., vol. 10, p. 93, 1871.

This species was dedicated to Prof. A. Milne Edwards by Mr. Bell.

Diagnostic Characters.-Carapace depressed; superior orbital margin with 
one tooth between the preorbital and postorbital teeth. Chelipeds of male more than twice as long as the post-frontal part of the carapace; palms smooth.

Type.-The type material, which is no longer extant, was taken in the Galapagos Islands by D. Cuming.

Galapagos Distribution.-Galapagos Islands (type-locality) also James Island (Hassler Expedition); off Hood Island, station 54, depth 15 feet, Arcturus Expedition.

General Distribution.-Known only from the Galapagos Archipelago.

Material Examined.-Four females, three of which are ovigerous, one male and one very young specimen were obtained by Dr. William Beebe while diving in 15 feet of water in Gardner Bay, off Hood Island.

Technical Description. - Carapace depressed, almost subcircular but somewhat narrowed in the postfrontal region; surface finely punctate, sparsely setigerous. There are four small tubercles placed in a transverse row on the higher part of the gastric region and several similar tubercles elsewhere on the carapace, especially on the high points of the branchial region and along the lateral margins. There are two transverse rows of tubercles on the intestinal region, the anterior row consisting of three tubercles. The frontal region is distinctive, the rostral horns are small, triangulate, pointed, somewhat flattened, being distinctly longer than the external spine of the basal antennal article and separated from each other by a deep V-shaped sinus. There is a longitudinal row of long hooklike hairs subparallel to their inner lateral margins. The orbit is large, defined by a superior preorbital tooth, a postorbital tooth and with a third small, rounded tooth beneath; there is a clearly defined hiatus between the latter and the basal antennal article. The basal antennal article is broad with the anteroexternal angle produced to an acuminate process which is outward and forwarddirected and is not as long as the rostral horns; there is a smaller tooth behind the large one on the lateral margin; the second and third antennal articles are cylindrical, the last one reaching beyond the rostrum; the flagellum is composed of about sixteen rather long articles which are set with long spinose setae. 'The antennulae are rather stout and fold almost vertically within the septum beneath the rostral hood.

The chelipeds of the male are more than twice as long as the postfrontal region of the carapace; those of the female are almost twice as long as this region; the ischium is well developed and produced to a point on its inferior anterior distal margin; the merus is long and dilated distally; the carpus is convex, smooth; the propodus is elongated, nearly cylindrical, almost smooth, sparsely punctate; the fingers are less than half the total propodal length and are subequal with a wide gape; the basal finger has a strong tooth which fits between two teeth of the hinged finger. In the very young specimens and in the females these teeth are absent or much reduced in size.

The ambulatories are similar and successively decrease in length from the first to fourth pairs; all have the meral joint long and set with a row of small spines above; the carpus is elongated; the propodus is very slender and approximately as long as the merus; the distal end is produced on its posterior distal margin into an elongated rounded process which interfits and articulates with a similar but shorter, backward-directed process which arises from outer 
proximal side of the dactyl; the dactyl is about two-thirds as long as the propodus and is slender, curved, acuminate. All the legs are sparsely setigerous.

Herbstia pyriformis (Bell).

Rhodia pyriformis Bell, Proc. Zool. Soc. London, vol. 3, p. 170, 1835 (1836); Trans. Zool. Soc. London, vol. 2, p. 44, pl. 9, figs. 1-1c, 1836.

Herbstia pyriformis Stimpson, Ann. Lyc. Nat. Hist. N. Y., vol. 10, p. 93,

1871; Rathbun, Bull. 129, U. S. Nat. Mus., p. 301, pl. 104, figs. 2 and $3 ; p l$. 240, figs. 5-8, 1925.

Diagnostic Characters. - Carapace pyriform, posterior margins decidedly produced; lateral margin with four minute teeth. Propodus of chelipeds with one spine. Ambulatory legs without spines or tubercles.

Type.-Bell's type was taken in the Galapagos Islands.

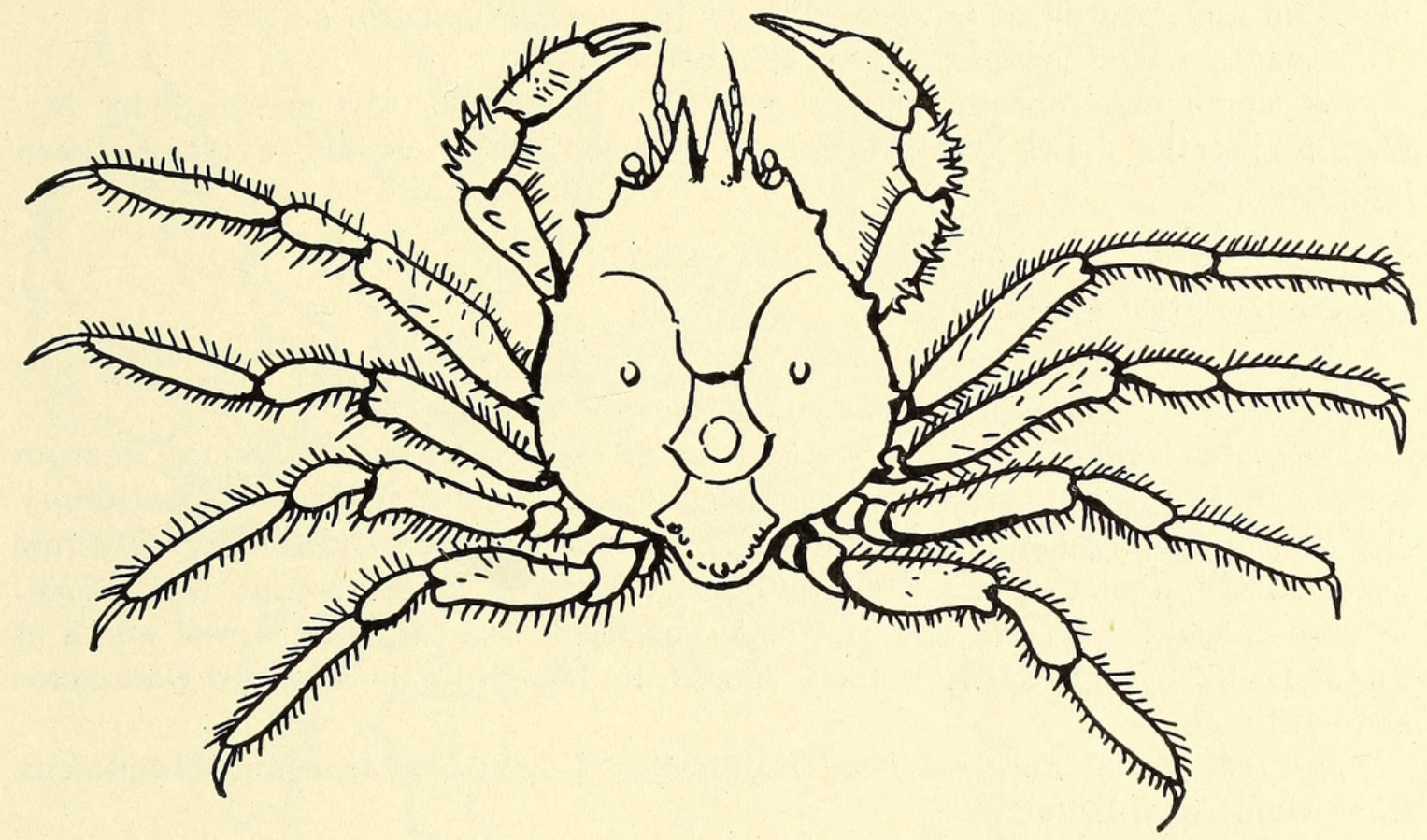

Fig. 43. Herbstia pyriformis, $\times$ about 2 (After Bell).

Galapagos Distribution.-Galapagos Islands, type-locality, also James Island, (Hassler Expedition).

General Distribution.-Galapagos Islands and James Island.

Material Examined.-None.

Technical Description.-The following is Mr. Bell's description of the type:

"Carapax pyriform, somewhat depressed, the regions slightly and evenly elevated: rostrum about as broad as it is long, small, consisting of two pointed teeth; lateral margin with four distant, minute teeth: posterior margin produced. Orbits large, with a triangular hiatus above, and a tooth at the outer and inner canthus. Eyes large, globose, fixed on very short peduncles, which are small at their junction with the eyes, but larger at their insertion into the orbit.

Internal antennae lying in deep, circumscribed, longitudinal, somewhat lunulate cavities. External antennae twice as long as the rostrum, the basilar joint broad, bidentate, the outer tooth being the shortest, and placed further back, at the inner canthus of the orbit. The pedipalps were so much injured in the specimen as not to admit of description. 
Abdomen of the male seven-jointed, decreasing in breadth from the third joint to the last.

The anterior pair of feet rather thicker but shorter than the others; the arm and wrist hairy and beset with small spines; the hand hairy above, but without spines; the fingers are slender, and are in contact throughout their whole length, and the margin is very minutely serrated. The remaining feet are longer than the carapax, the second pair by nearly one third; the remainder diminishing gradually to the fifth. They are nearly cylindrical, hairy but without spines or tubercles, and terminate in a small, slightly curved claw.

The colour of the only specimen known is pink, the hairs brown; the legs are whitish with pink annuli or bands; but as the specimen is considerably bleached and injured, it is impossible to judge of its natural colour.

Length of the carapax 8 lines; breadth 6 lines.

A single male specimen only, probably immature, was procured by $\mathrm{Mr}$. Cuming, at the depth of six fathoms, on coral sand. It had evidently been long dead."

\section{Genus Lissa Leach, 1815}

\section{Lissa aurivilliusi Rathbun.}

Lissa aurivilliusi Rathbun, Proc. U.S. Nat. Mus., vol. 21, p. 575, pl. 41, fig. 4, 1898; Proc. Wash. Acad. Sci., vol. 4, p. 284, 1902; Bull. 129,
U. S. Nat. Mus., p. 333, pl. 246, fig. 2, 1925.

Diagnostic Characters. - "Branchial ridge narrow; postero-lateral margin concave; one crest on carpus of first three pairs of ambulatory legs." (Rathbun).

Type.-One male from off Cape St. Lucas, Lower California, Albatross Station 2829; deposited in the United States National Museum (Cat. No. 21575).

Galapagos Distribution.-One male specimen was taken on a reef north of Tagus Hill, Tagus Cove, Albemarle Island, by the Hopkins-Stanford Galapagos Expedition.

General Distribution.-Lower California, off Cape St. Lucas and Magdalena Bay; Galapagos Islands.

Technical Description: (After Rathbun): “Gastric prominence small, angular; oblique ridges leading from it sharp, finely tuberculate, with only a shallow tooth at middle in place of the round knob in Lissa tuberosa and terminating in a raised tooth at postero-lateral angle. Cardiac hump small, median ridge extending back from it narrow. Lateral margins tuberculate, a shallow tooth at middle and one farther back. Postero-lateral margin with a shallow sinus extending its whole length. Median notch of front shallow, outer teeth prominent."

"Chelipeds much as in Lissa tuberosa. Ambulatory legs with only one crest on the carpus of the first three pairs, the anterior crest of Lissa tuberosa being represented by a tooth.* Measurements: Male, holotype, length of carapace 12.5, width $13 \mathrm{~mm}$. Immature female, length of carapace 9.8, width 10 mm."

*Dr. Rathbun gives the following description of the chelipeds of Lissa tuberosa:

"Chelipeds heavy in male; ischium with tooth on inner margin; merus with tridentate crest on superior margin; carpus with surface uneven, tubercle at 


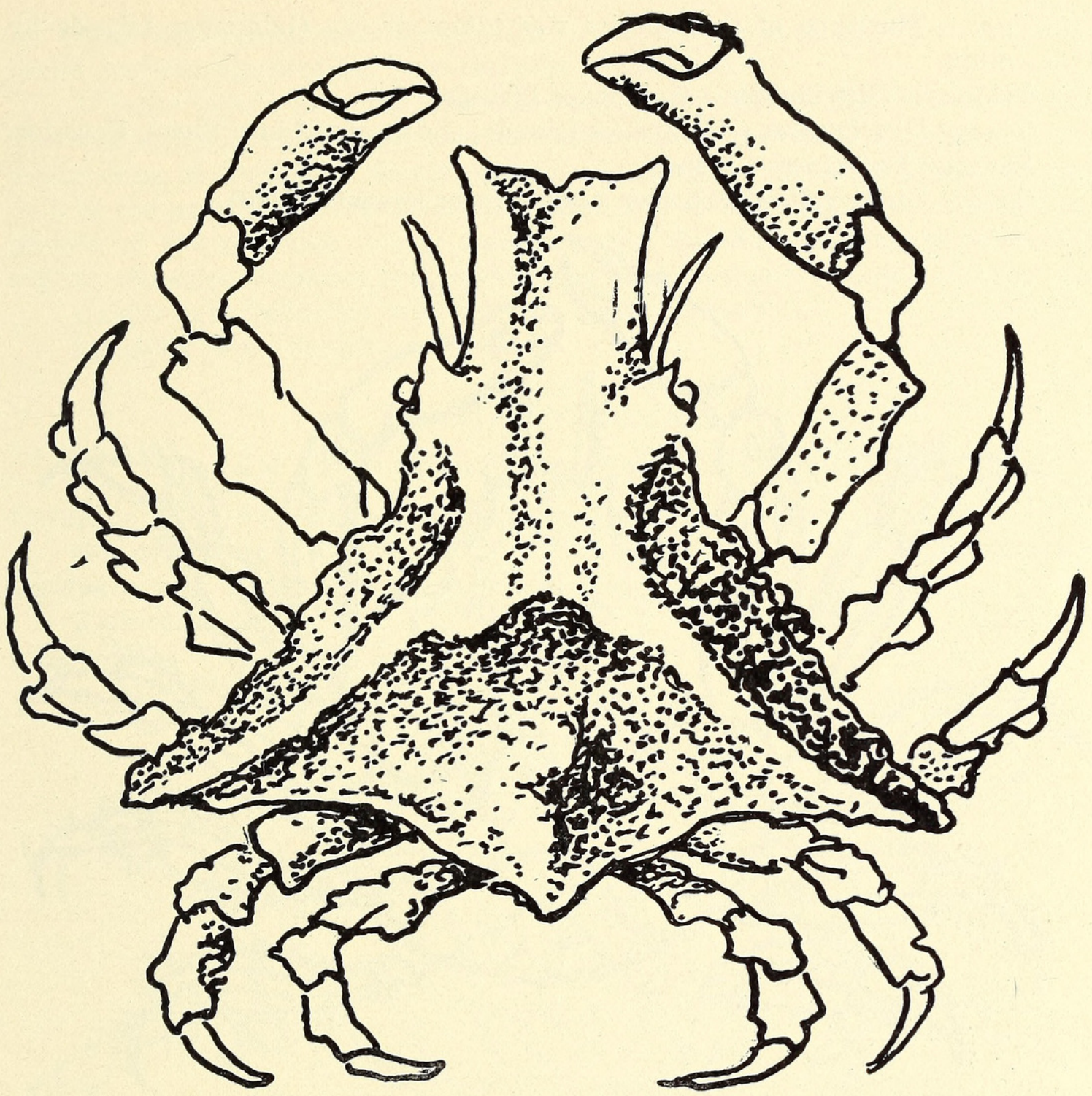

Fig. 44. Lissa aurivilliusi, $\times 3 \frac{1}{3}$ (After Rathbun).

inner angle. Hands broad, compressed, widening distally, inner surface tuberculate; lower margin of propodus with a sinus near its middle; dactylus with acute upper margin; fingers gaping for basal half. Chelipeds of female much smaller."

\section{Subfamily: MAJINAE}

Genus Thoe Bell, 1835

Thoe erosa Bell.

Thoe erosa Bell, Proc. Zool. Soc. London, vol. 3, p. 171, 1835; Trans. Zool. Soc. London, vol. 2, p. 48, pl. 9, figs. 4, 4k-4o, 1836; Nobili, Boll. Mus. Zool. Anat. Comp. R. Univ. Torino, vol. 16, No. 415, p. 30, 1901; not A. Milne Edwards, Crust. Rég. Mex., pl. 19, figs. 4-4d; 1875; p. 121, 1878, nor Rathbun, Mem. Mus. Comp. Zool., vol. 35, p. 74, 1905; Bull. 129, U. S. Nat. Mus. p. 351, pl. 249, figs. 1-6, 1925.

Diagnostic Characters.-Basal segment of external antennae with one anterior tooth. Merus with two rows of deep excavations. 
Type.-The type of this species was taken at the Galapagos Islands by D. Cuming.

Galapagos Distribution.-Galapagos Islands.

General Distribution. - Galapagos Islands; and Bay of Santa Elena, Ecuador. Material Examined.-None.

Color.-Light yellowish brown above, paler beneath (Bell).

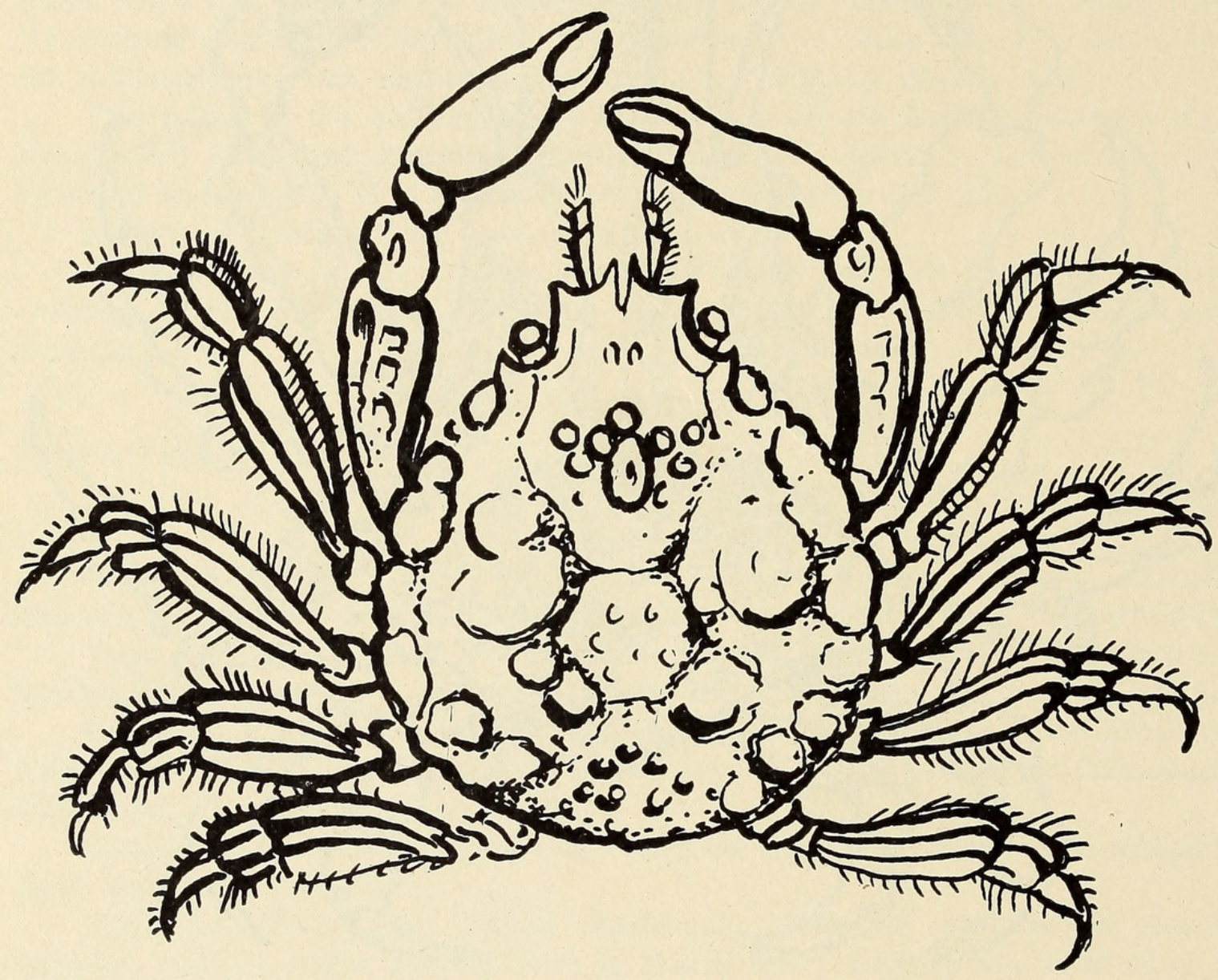

Fig. 45. Thoe erosa, $\times$ about 2 (After Bell).

Technical Description.-The following is Mr. Bell's description of the type: "Carapax somewhat triangular, longer than it is broad, rounded behind, depressed, horizontal, covered with low tuberosities; the lateral margin without teeth, perpendicular. Rostrum minute, tapering to the point, which is slightly divided. Orbit nearly round, without teeth, with three small fissures, one above the inner canthus, another at the outer angle, and the third beneath. Eyes subretractile, globose, smaller than the base of the peduncle.

Internal antennae lodged in a fossa, which is anteriorly divided by a tooth projecting backwards and longitudinally excavated. External antennae with the basilar joint very broad, produced forwards and backwards, the moveable portion three times as long as the rostrum, ciliated on the inner side. External pedipalps with the outer footstalk expanded at the outer margin; first joint of the inner footstalk nearly rhomboidal, with entire margins, ciliated on the inner margin; second joint without any emargination for the insertion of the palp. 
Abdomen in both sexes seven-jointed. In the male, the third to the sixth joints are scarcely broader than the first and second.

Anterior legs in the male longer and much more robust than the remainder. The arm with a series of quadrilateral excavations on the upper and outer surface diminishing backwards. Hands smooth, carinated beneath, the fingers meeting only at the point, not excavated or serrated, but with a single tubercle near the middle of the movable finger: remaining feet flattened above, longitudinally rugose, the sides furnished with rather long hairs; beneath rounded and smooth.

Colour light yellowish brown above, paler beneath.

Length 6 lines; breadth 5 lines."

\section{Genus Pitho Bell, 1835}

Key to the Galapagos species of the genus Pitho.

Carapace with five distinct anterolateral teeth in addition to the postorbital tooth.

quinquedentata

Carapace with six distinct anterolateral teeth in addition to the postorbital tooth.

sexdentata

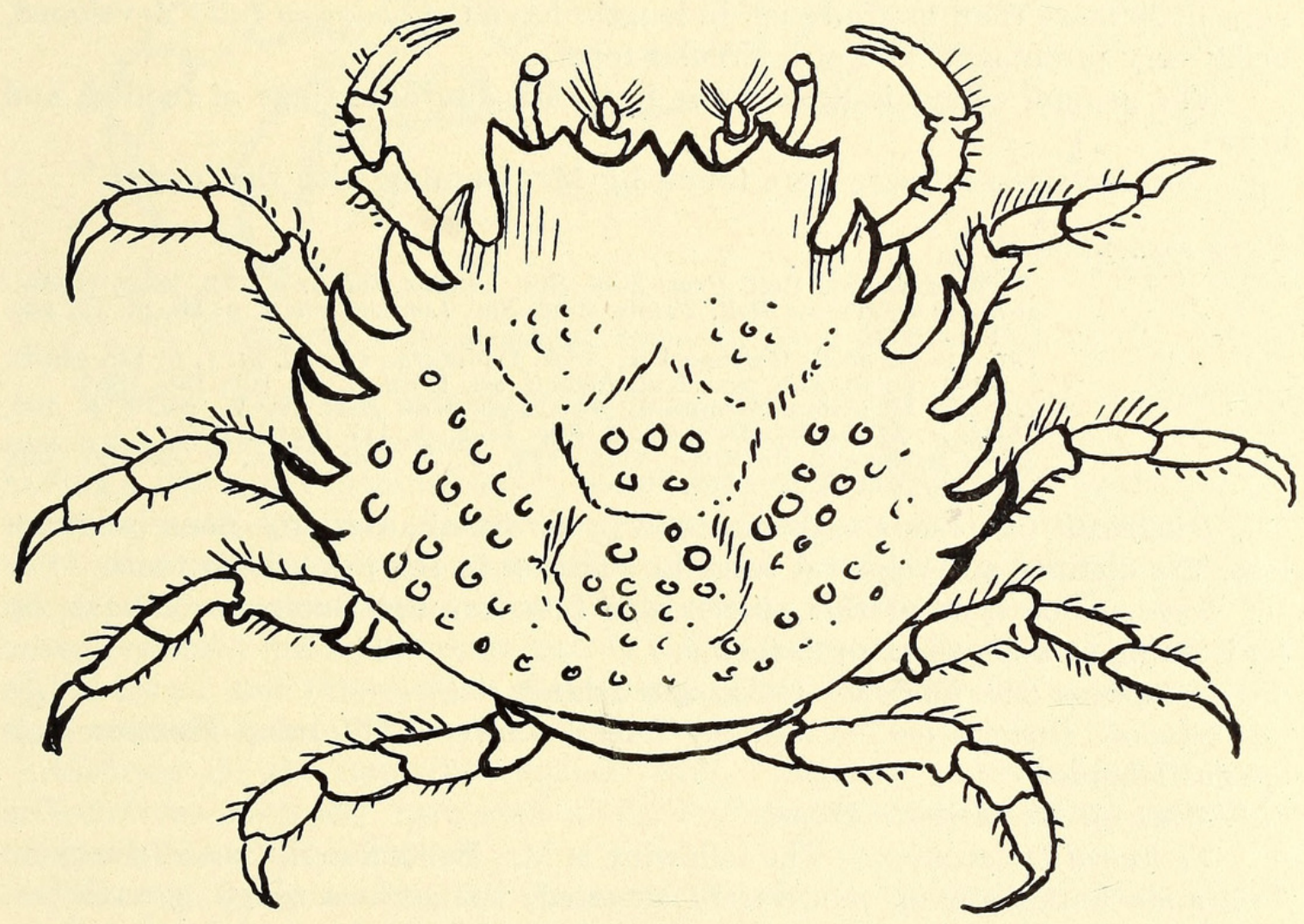

Fig. 46 Pitho quinquedentata, male $\times$ about 3 (After Bell).

Pitho quinquedentata Bell

Pitho quinquedentata Bell, Proc. Zool. Soc. London, vol. 3, p. 172, 1835 (1836); Rathbun, Proc. U. S. Nat. Mus., vol. 38, p. 573, 1910.

Othonia quinque-dentata Bell, Trans. Zool. Soc. London, vol. 2, p. 57, pl. 12, fig. $2,1836$.

Othonia mirabilis Gerstaecker, Arch. f. Naturg., vol. 22, pt. 1, p. 113. (part), 1856. 
Othonia quinquedentata A. Milne Edwards, Crust. Rég. Mex., p. 118, pl. 24 , figs. 3-3c, 1875.

?Othonia aculeata Cano, Boll. Soc. Nat. Napoli, ser. 1, vol. 3, p. 181, pl. 7, fig. 6, 1889.

Pitho quinquedentata Rathbun, Bull. 129, U. S. Nat. Mus., p. 361, pl. 250, figs. $1-4,1925$.

Diagnostic Characters. - First movable segment of the external antennae narrowed. Cheliped with palm compressed, wide.

Type.-The type of this species was taken at the Galapagos Islands by D. Cuming.

Galapagos Distribution.-Galapagos Islands.

General Distribution.-Galapagos Islands and Bay of Panama.

Material Examined.-None.

Technical Description.-The following is Bell's description of the type:

"This species resembles the former one in most of its characters. It differs, however, in the number of teeth on the lateral margin, and very considerably in size. The frontal portion of the carapax is more produced, and the surface more scantily granulated, and without spines. The two specimens of the former species are nearly an inch long, and are both evidently immature, as the $a b$ domen is but very little developed. Those of the present species, which are very little more than half an inch in length, have the abdomen fully developed, being very prominent, and of a circular form.

The general colour is brown; the feet with alternate rings of reddish and brown.

Two female specimens were found by Mr. Cuming with the former."

Pitho sexdentata Bell.

Pitho sexdentata Bell, Proc. Zool. Soc. London, vol. 3, p. 172, 1835, (1836). Othonia sexdentata Bell, Trans. Zool. Soc. London, vol. 2, p. 56, pl. 12, figs. $1-1 d, 1836$.

Othonia mirabilis Gerstaecker, Arch.f. Naturg., vol. 22, pt. 1, p. 113 (part), 1856; Cano, Boll. Soc. Nat. Napoli, set. 1, vol. 3, pp. 102, 182, 1889.

Othonia sexdentata Stimpson, Ann. Lyc. Nat. Hist. N. Y., vol. 7, p. 192 1860; A. Milne Edwards, Crust. Rég. Mex., p. 117 (part), 1875.

Pitho sexdentata Rathbun, Bull. 129, U. S. Nat. Mus., p. 367, pl. 130, fig. $1 ; p l .250$, figs. 5-9, 1925.

Diagnostic Characters.-Carapace oval, narrowed anteriorly, densely granulose. Six distinct anterolateral teeth in addition to the postorbital tooth.

Type.-The type of this species was taken at the Galapagos Islands by D. Cuming at a depth of six fathoms.

Galapagos Distribution.-Galapagos Islands.

General Distribution.-Cape St. Lucas, Lower California; Mexico; Galapagos Islands.

Material Examined.-None.

Technical Description.-The following is Mr. Bell's description of the type: "Carapax broadly oval, moderately elevated, the surface rough, granulated, and slightly hairy; the lateral margin with six flattened triangular, falciform teeth, the points acute and directed forwards; a ridge of prominent granulations over the posterior margin. Rostrum very small, bifid, with a small sulcus continued backwards from the division. Orbits with a broad triangular fissure above, the tooth on each side flattened and triangular, the outer one the larger. Eyes not larger than the peduncles, which are elongated, slender, projecting forwards and slightly curved inwards. 


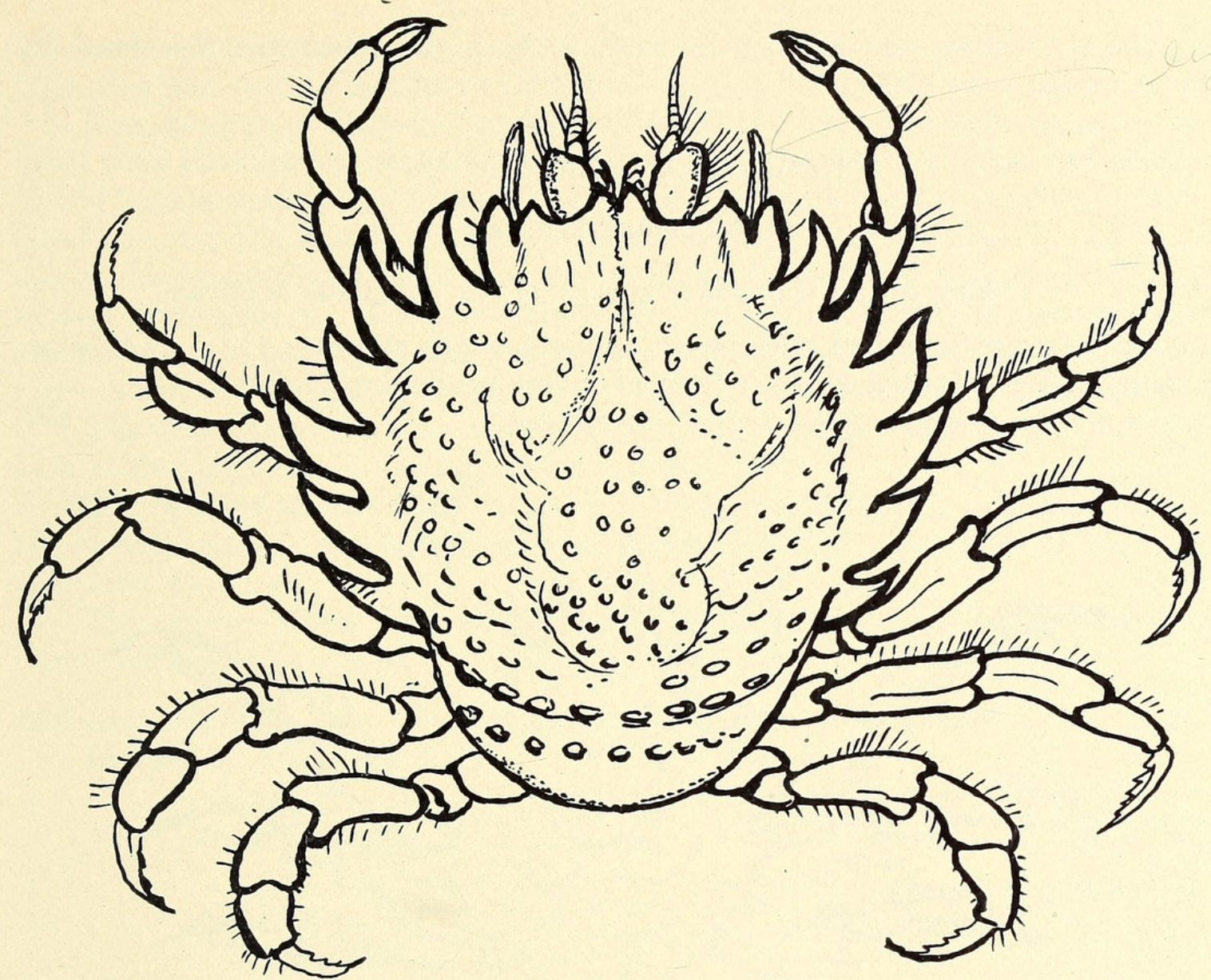

Fig. 47. Pitho sexdentata, female $\times$ about 3 (After Bell).

Internal antennae extremely minute, and placed far back behind the rostrum. External antennae hairy, short, the basilar joint broad and flat, having a triangular external tooth, which extends forwards as far as that of the orbit; second joint flat, cordate anteriorly emarginate for the insertion of the third joint, which is also compressed, and much smaller than the previous one: the remaining joints are small and cylindrical. External pedipalps with the outer footstalk gradually acuminated: the inner footstalk with the first joint rather broad and rhomboidal; the second triangular with the anterior angles somewhat produced.

Abdomen (in the immature female) oval, consisting of seven nearly equal articulations, obtusely carinated along the centre; each of them delicately ciliated at its anterior margin.

Feet of moderate length: the anterior pair (in the female) considerably smaller than the rest, slender, slightly compressed, and smooth; hand with a small obtuse tooth above and one beneath, at the base; the fingers with the margins minutely serrated. The moveable finger longer than the other, and curved over its extremity. The remaining pairs of feet decreasing in length from the second to the fifth, depressed, and slightly hairy; the antepenultimate joint has a shallow sulcus on each side; the terminal joint is minutely toothed beneath. 
Of the colour nothing can be said, as both the specimens preserved by Mr. Cuming were bleached."

\section{Genus: Mithrax Latreille, 1817}

\section{Subgenus: Mithrax}

Key to the Galapagos species of the subgenus Mithrax.

Lateral margin furnished with seven or eight sharp spines.

Lateral margin furnished with four nodulose projections. Car-

spinipes pus with five tubercles on the inner margin.

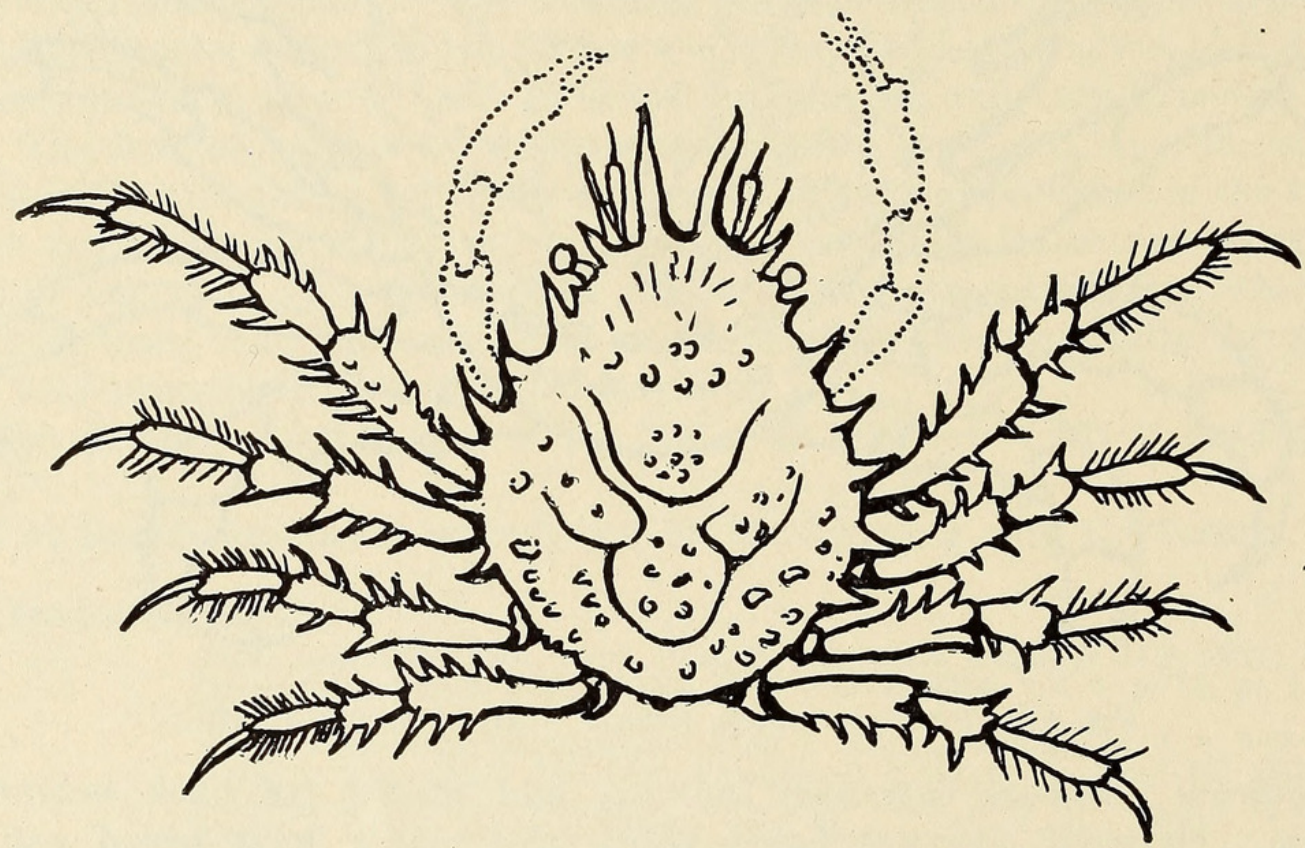

Fig. 48. Mithrax spinipes, $\times 2$ (After Bell).

Mithrax (Mithrax) spinipes Bell.

Pisa spinipes Bell, Proc. Zool. Soc. London, vol. 3, p. 171, 1835, (1836); Trans. Zool. Soc. London, vol. 2, p. 50, pl. 9, figs, 6, 6s, 6t, 6u, 1836.

Nemausa spinipes A. Milne Edwards, Crust. Rég. Mex., p. 82, 1875.

Mithrax (Nemausa) spinipes Miers, Challenger Rept., Żool., vol. 17, p. 85.

Mithrax (Mithrax) spinipes Rathbun, Bull. 129, U.S. Nat. Mus., p. 391, pl. 136, figs. 3 and $4 ;$ pl. 262, fig. 5, 1925.

Diagnostic Characters. - Lateral margin furnished with seven or eight sharp spines.

Type.-The type of this species was taken at the Galapagos Islands by D. Cuming, at the depth of sixteen fathoms.

Galapagos Distribution.-Galapagos Islands.

General Distribution.--From Gulf of California to Galapagos Islands and St. Elena, Ecuador.

Material Examined.-One female, from station 54, off Hood Island, Galapagos, taken by William Beebe, while diving in 15 feet of water.

Technical Description.-The following is Bell's description of the type: "This is an elegant little species, bearing considerable resemblance to young 
specimens of Pisa tetraodon Leach, but differing in many essential particulars from this and every other known species.

The carapax is depressed and granulated; the lateral margin on each side beset with about seven or eight sharp spines, which are much smaller and shorter in the female than in the male. The former sex has a strongly-marked granulated line over the posterior margin, which is much less conspicuous in the male; a circumstance which I have observed in many species, not only of this but of several other genera. The tooth above the orbit, unlike many other species, is shorter than that of the basilar joint of the exterior antennae. The horns of the rostrum are separated throughout their length, and are somewhat divergent.

The abdomen of the male specimen was lost: that of the female is as broad as it is long, and has a low longitudinal carina.

The feet are all furnished with small spines, particularly on the third joint; the anterior pair in the female scarcely larger than the rest: those of the male specimen were lost.

This species differs from all the others, excepting Pisa styx Latr., in having numerous spines on the legs."

Mithrax (Mithrax) belli Gerstaecker (Purplish-brown Galapagos Spider Crab; Moss-back Spider Crab).

Mithrax ursus Bell, Proc. Zool. Soc. Lond., vol. 3, p. 171, 1835 (1836); not Cancer ursus Herbst, 1788; Trans. Zool. Soc. London, vol. 2, p. 52, pl. 10, figs. 2, 2c, 2d, 2e, and 3, 1836; A. Milne Edwards, Crust. Rég. Mexico, p. 103, 1880.

Mithrax bellii Gerstaecker, Arch. f. Naturg., vol. 22, pt. 1, p. 112, 1856; name substituted for Mithrax ursus Bell; Rathbun, Bull. 129, U. S. Nat. Mus. p. 403, pls. 142 and 143, 1925; Zoologica. N. Y. Zool. Soc., vol. 5, No. 14, p. 153, 1924.

Diagnostic Characters.-Color: Adults purplish brown; young, light brown, with reddish tinge. Dorsal surface of carapace mosaiced with flat granules; four projections of anterolateral margin nodulose; carpus with five tubercles on the inner margin.

Type.-The type locality given by Bell is "Galapagos Islands"; this type is said to be no longer extant.

Galapagos Distribution.-Galapagos (type-locality); Black Bight, Albemarle Island; Chatham Island; Eden, Hood and Tower Islands.

General Distribution. - The recorded distribution of this species is restricted to the Galapagos Archipelago, where it has been taken by several expeditions, and a single record by Miers from Chile.

Material Examined.-Thirteen small, young specimens, secured by William Beebe, director of the Arcturus Oceanographic Expedition, while diving in 15 feet of water, at Station 54, Hood Island, Galapagos. One male specimen, taken at Station 37, in shore zone D to E, Tower Island, Galapagos Islands.

It was also taken by the Harrison Williams Galapagos Expedition.

Technical Description.-Carapace convex, subpyriform, maximum width a trifle more than length; the margins are thick, the protuberances nodulose; the dorsal surfaces mosaiced with flattened granules and irregular tubercles. The rostrum is bifurcated into two thick horns which are separated by a Vshaped sinus: two pairs of dorsal tubercles are present on the proximal part of the rostrum. There is a protrusion at the outer distal angle of the basal article 
of the external antennae which is slightly incurved and somewhat higher and larger than either rostral horn. There is an inconspicuous preorbital lobe present, and two smaller tubercles on the orbital margin, one at the outer angle and one below. There are six tubercles on the lateral margin the first and second of which are quite large and each of which bear a smaller anterior tubercle, the hepatic tubercle is the second largest of the series; the most anterior of the simple tubercles is the largest, the fourth is the smallest, the fifth is of medium size and the sixth is postlateral. Behind the sixth tubercle there is a row of minor

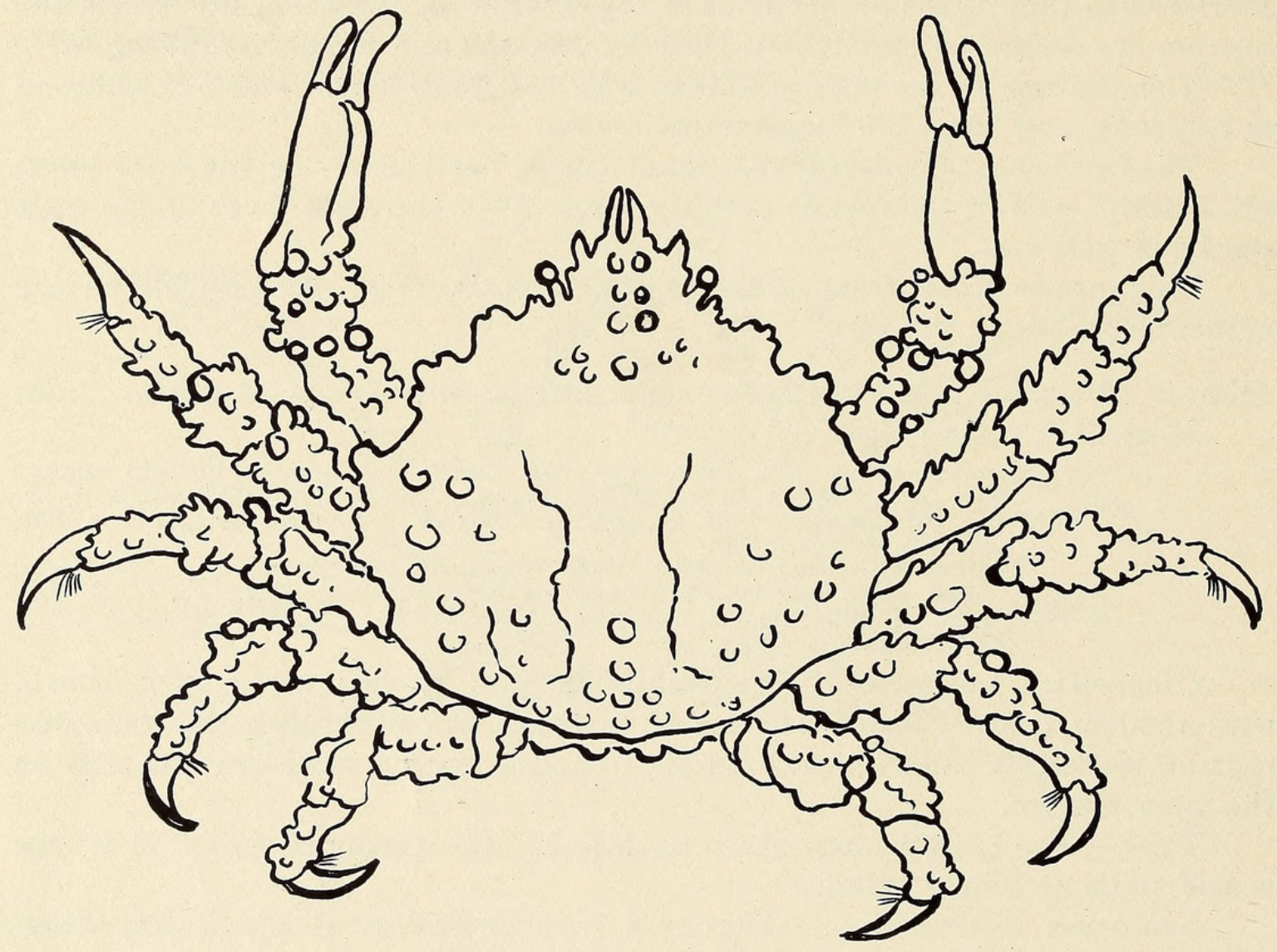

Fig. 49. Mithrax belli, $\times 2$.

tubercles on the posterolateral margin. There are two longitudinal rows, consisting of two or sometimes three small tubercles each, situated between and behind the orbits. Posterior to these there is a transverse row of five tubercles on the mesogastric region. There is also a row of tubercles on the lateral walls of the carapace, some of these are visible in a dorsal view. The pterygostomian ridge is coarsely granular or tuberculate. The regions of the carapace are distinctly delineated. The male abdominal belt is seven-segmented, triangulate with a rounded apex; the first pair of male appendages are moderately thick rods, curved basally, and directed straight forward within the cavity.

The external maxillipeds are rectangular, almost square, being only a little wider than long, and having the median and anterior portions decidedly protruberant. The exognath is not quite half as wide basally as long, extends to outer distal margin of the merus but is distinctly narrower and tapering for 
its distal fourth; it bears a slender whip internally. The ischium is broadly rounded on the inner distal margin for more than half its width and produced beyond the outer distal angle, which is practically right-angled and gives rise to the merus which fits closely to the margin of the ischium, has its outer distal angle produced and its inner margin rounded. There is a strong depressed spine on the anterior margin of the merus, which is directed inward. The palp arises from an angulation about midway the anterior margin of the merus, and consists of three articles which successively decrease in size. The first and second articles curve around the margin of the merus; the third joint is very small and bears a brush of long setae. The inner lateral margins of the ischium are also finely setigerous.

The inner antennae are folded in the fossett beneath the rostrum; the basal joint is almost invisible; the first free joint is elongate, dilated, distally rounded on its outer surface and hollowed on its inner side for the reception of the next joint when folded; the second free joint is more robust than the first and is also convex on its outer surfaces and flat on the inner side; it bears distally the brief two-branched flagellum; the inner, stouter branch is about as long as the preceding article, and consists of a number of closely fused, tapering articles that bear on their outer side a dense brush of fine plumose setae; the slenderer, ventral branch is also shorter, consisting of six tapering articles each of which bears a few isolated setae on its distal margin.

The outer antennae have the basal article fixed, its outer distal angle is produced in a protuberance which is as large as either of the rostral horns; the first free joint is rectangular, about half as wide as the preceding segment and its width is equal to half of its own length; the third segment is slightly longer and distinctly narrower than the second segment; the flagellum is composed of five small articles, which taken together are conspicuously shorter than the club-like tactile organs which are borne along the distal and inner margin of the two free antennal segments. These organs are elongate, cylindrical, distally dilated and appear to have a central hollow cone within; the outer surface is finely setigerous.

The eyestalk is short, constricted below the cornea and produced beyond this constriction on the outer anterior side into a small rounded process which projects upon the cornea. The cornea is terminal, with its major range of vision a lateral one. The facets of the cornea are exceedinlgy fine and numerous.

The chelae (male) are slender, the three basal joints are subequal, not visible in a dorsal view. The merus is about one and one-half as long as the ischium and is dilated distally with the outer distal angle produced to a triangulate process; there is a prominent granulose tubercle on the upper surface near the inner distal margin and six tubercles on the inner distal margin; the carpus is short with the inner distal angle produced to a toothlike process, and the upper surface ornamented with six granulose tubercles; the propodus is slender, cylindrical, convex outwardly and slightly dilated and granulose near the base; the propodal finger is almost one-third of the length of the propodus and is spoon-shaped distally with this margin finely crenulate. The hinged finger is similar and subequal to the propodal finger; their tips are closely appressed on each other; there is a small gap between the cutting edges which are finely dentate. 
The ambulatory legs are similar in structure. The first pair are sa long as the chelae, the remaining pairs respectively decrease in size posteriorly, the second pair being shorter than the first by the combined length of one-half the length of the propodus and the dactyl; the third pair is shorter than the second pair and the fourth pair is shorter than the third by about this same ratio. Each leg terminates in a sharp curved dactyl and bears many club-like tactile organs along the outer and inner lateral margins. These are similar to those on the antennae. The larger adult crabs are said to be devoid of this growth.

\section{Subgenus Mithraculus White}

Mithrax (Mithraculus) nodosus Bell (Nobuled Crab).

Mithrax nodosus Bell, Proc. Zool. Soc. London, vol. 3, p. 171, 1835; Trans. Zool. Soc. London, vol. 2, p. 53, pl. 11, figs. 1-1b, 1836. Mithraculus nodosus White, List Crust. Brit. Mus., p. 7, 1847; A. Milne Edwards, Crust. Rég. Mex., p. 108, pl. 23, figs. 5-5d, 1875. Mitraculus ruber Cano, Boll. Sov. Nat. Napoli, ser. 1, vol. 3, p. 185, 1889. Not Mithraculus ruber Stimpson. Mithrax nodosus Rathbun, Bull. 129, $U$. $S$. Nat. Mus., p. 429, pl. 155, 1925.

Diagnostic characters. - Anterolateral margin with three large lobes. Posterior part of carapace rugose, worn-looking. The basal half of the inner margin of the cheliped is very thin and sharp.

Type.-Bell's type, which is no longer extant, came from the Galapagos Islands.

Galapagos distribution.-This species has been taken by the Hassler, the Albatross, the Hopkins-Stanford and the Harrison Williams Galapagos Expeditions and by Dr. W. G. Jones of the U.S. Navy, at James, Albemarle, Chatham, Hood, Charles, Duncan and Eden Islands of the Galapagos Archipelago.

General distribution.-Galapagos Islands; Miers also reports that there is a specimen of this species from Chile in the British Museum.

Material examined.-Six males, one of which is only $1.7 \mathrm{~mm}$. wide, and one ovigerous female were collected at Station 54, off Hood Island, Galapagos, in 15 feet of water, by William Beebe.

Color.-Bell states that this species is brown above, paler beneath, with the hands dark plumbeous.

Habits. - It lives in the crevices of the coral rock and feeds upon amphipods, hermit crabs and other organisms. One specimen was captured eating a hermit, another with a half-devoured Hyperid amphipod.

Technical description.-Carapace $19 \mathrm{~mm}$. wide, $16 \mathrm{~mm}$. long. Rostral horns short, broad, rounded, separated by a deep V-shaped sinus which is fringed on both margins by long setae; there are a pair of subacute, submedian tubercles behind the rostrum and on a slightly higher plane situated between and in line with the anterior margin of the superior orbital lobes; between the bases of these orbital lobes there is a median node surmounted by a second pair of low submedian tubercles; posterior to these on the summit of the mesogastric area there is a transverse row of five subequal and subequally spaced tubercles. The anterolateral margin is divided into three node-like lobes, the first of which is close to the orbital angle, the second is slightly larger and the most prominent of the series. There is a small, subacute posterolateral lobe situated about as far behind the third anterolateral lobe as it is from the second 
lobe. The cervical grooves are deeply delineated and sulci arising between the lateral nodes and running diagonally backward toward the outer give the carapace an eroded, granulose appearance. There are a number of rather large granulose tubercles on the posterior region of the carapace which bear elongated, club-shaped tactile organs. These latter have a central cone of deeper golden brown spongy fiber.

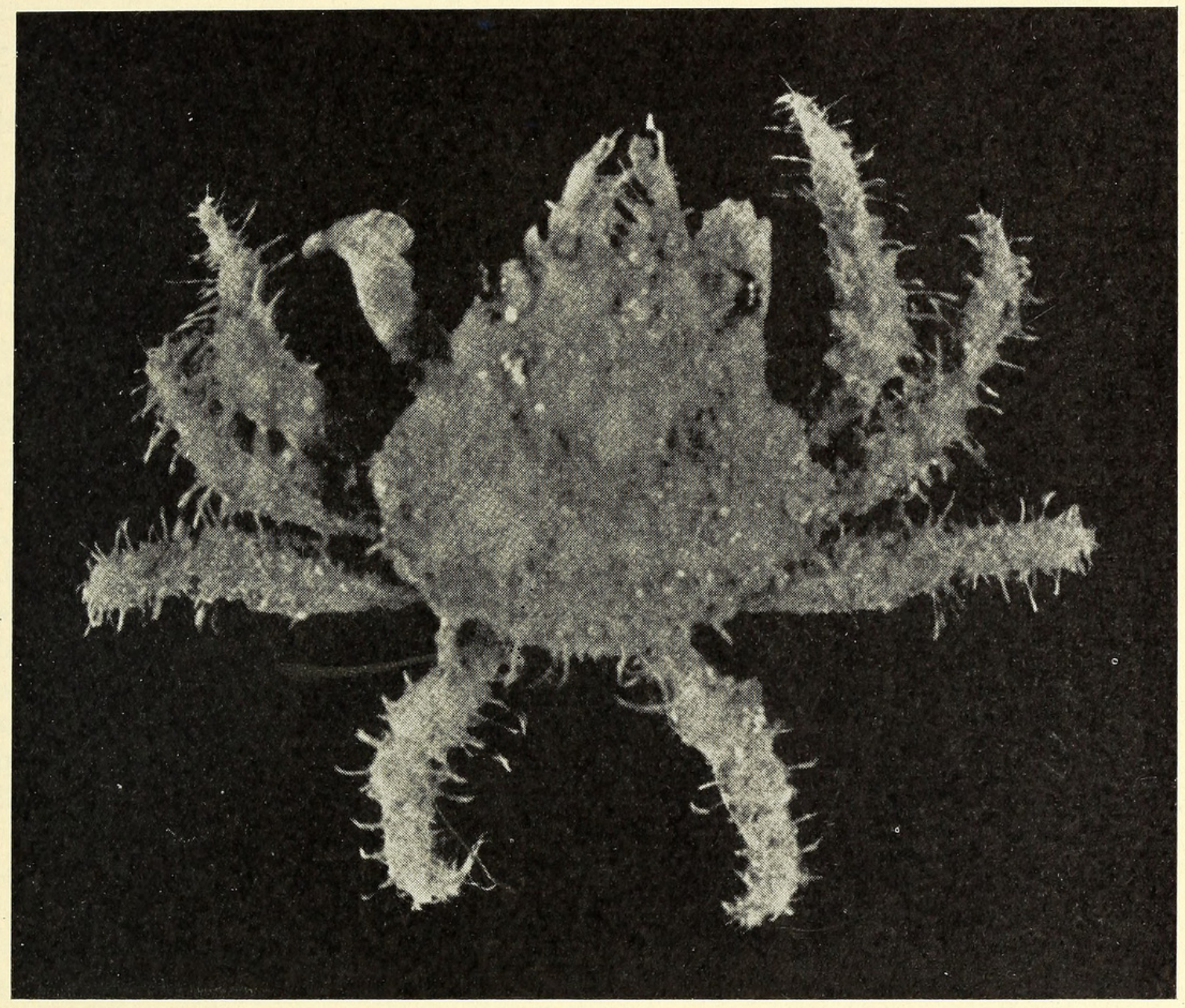

Fig. 50. Mithrax nodosus, young $\times 4$.

The female abdomen is seven-segmented, very broad, almost covering the entire sternal area between the legs; the second to fifth segments inclusive each bear paired biramose appendages, the outer branch of which is very heavily fringed and curves around the outer margin of the brood-pouch, forming a sieve-like wall around the eggs. The inner branch is shorter, two-jointed and beset with long setae to which the eggs are fastened.

The male abdomen is narrow, triangulate with the apex rounded, sevensegmented. The first pair of male appendages are slender rod-like processes which taper distally and are flattened into a minute two-pointed process which is channelled by a groove. 
The eyestalk is rather small for the socket and is longitudinally striped with alternate bands of light and dark coloring. On its posterior distal margin it bears a long thick fringe of close-set setae which form a brush-like eye-lash; on its anterior distal margin it is produced to a narrow, rounded, tongue-like projection which does not reach to the middle of the cornea and is tufted with coarse setae at its apex; the cornea is spherical, composed of minute, hexagonal facets.

The internal antennae are rather small and fold vertically within the fossett which lies under the postrostral lobe. The basal joint is scarcely visible; the first and second free joints are subequal, rather compressed and dilated distally; the flagella are minute, the smaller branch consisting of four tapering rings and the larger one, of fourteen tapering annulations and a heavy brush of setae.

The external antennae have the basal joint anchylosed and its external distal angle produced to a prominent rounded nodule which is only slightly smaller than the rostral horns. The second (first free) segment arises from the inner half of the basal segment, is about half as wide as the latter, and is compressed cylindrical, somewhat dilated distally, with the inner distal angle slightly produced and bearing a fanlike arrangement of clublike organs which appear to be tactile; the third (second free) segment is about half as wide as and slightly longer than the second segment; it is laminate and armed with clublike organs similar to those of the preceding segment.

The external maxilliped have the exognath about three-fourths as wide basally as the ischium and narrowing a little distally and bearing an internal, slender, heavily fringed palp. The ischium is subrectangular but with the external distal border notched for the reception of the merus, and the internal distal fourth of the ischium broadly rounded and closely interfitting with the merus is declivous with its outer distal margin roundly produced and its inner margin evenly rounded; the palp arises from near the middle of the merus and consists of a broad, curved basal joint, a subcircular second joint and a small distal joint which is furnished with long plumose setae.

The chelipeds have the ischium produced triangularly on its anterior distal angle extending to the base of the big internal node of the inner meral margin; the merus is rather short and in addition to the inner node bears an outer forward-projected distal node and a rounded upper distal node, also two smaller upper nodes midway its length; the carpus is convex on its upper surface and bears six subequal nodes on this surface and has a node-like process midway on its inner margin; the propodus is somewhat compressed, laminate on the basal half of its inner margin, one-lobed; two lobes on its outer margin, and a tubercle on its upper surface; the fingers gape moderately, but meet at the weakly crenulated tips; the propodal finger is horizontal in position; the hinged finger has a single tooth about two-fifths of the distance from its base.

The ambulatories are similar in structure, but successively decrease in size posteriorly. They are coarsely nodulose, each nodule bearing a tuft of club-shaped organs which appear to be tactile, similar to those of the carapace and antennae. 
Mithrax (Mithraculus) denticulatus Bell.

Mithrax denticulatus Bell, Proc. Zool. Soc. London, vol. 3, p. 172, 1835; Trans. Zool. Soc. London, vol. 2, p. 54, pl. 11, fig. 2, 1836; Nobili, Boll. Mus. Zool. Anat. Comp. R. Univ. Torino, vol. 16, No. 415, p. 31, 1901. Mithraculus denticulatus White, List. Crust. Brit. Mus., p. 7, 1847; A. Milne Edwards, Crust. Rég. Mex., p. 109, pl. 23, fig. $4 m, 1875$.

Mithrax (Mithraculus) denticulatus Rathbun, Bull. 129, U. S. Nat. Mus., p. 428, pl. 154, figs. 2 and 3, 1925.

Diagnostic characters. - Carapace nearly half wider than long. Two lobes and one spine on anterolateral margin. Two lobes of basal antennal segment equally advanced. Inner edge of wrist laminate.

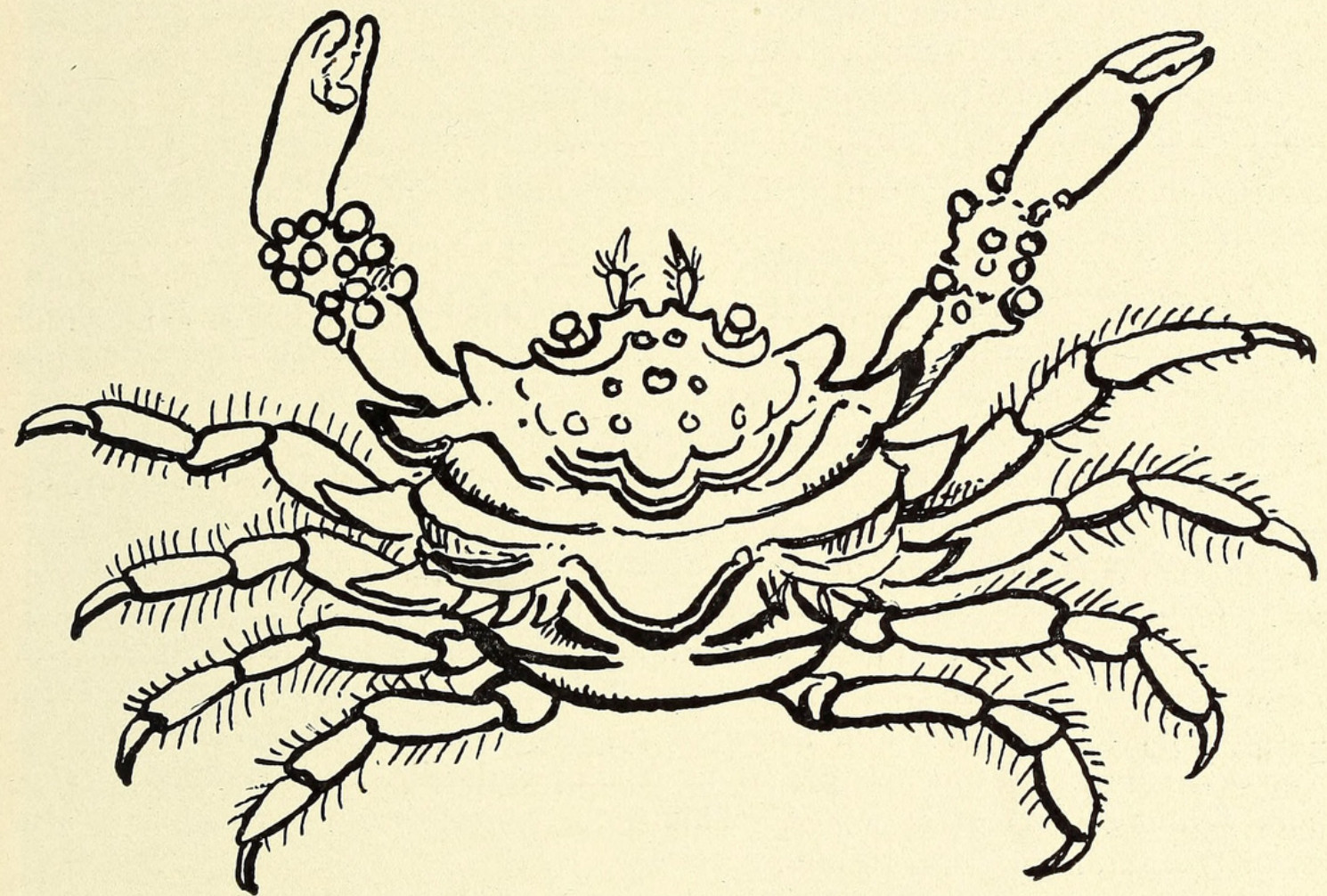

Fig. 51. Mithrax denticulatus, $\times 2$ (After Bell).

Type.-Galapagos Islands, under stones. The type is no longer extant.

Galapagos distribution.-Galapagos Islands.

General distribution.-Lower California to Ecuador.

Material examined.-One taken at Cocos Island, May, 1925, by the Arcturus.

Technical description.- "A small species resembling in most of its characters the former one ( $M$. nodosus), though differing sufficiently to be distinguished from it at the first glance. The markings on the carapax, though similar in situation, are much more distinctly and deeply incised; the teeth on the lateral margin, though rather obtuse, have not the rounded, tubercular character of the same appendages in Mithr. nodosus. The arms and the feet also are more sharply spined. But the character which at once distinguishes them, on a closer inspection, is the form of the second joint of the inner footstalk of the external pedipalp, which is Mithr. nodosus is crescent-shaped, and 
much broader than it is long; and in the present species is cordate, and as long as it is broad.

Colour plumbeous, passing into fuscous.

Length 5 lines; breadth 6 lines.

Found by Mr. Cuming in considerable numbers with the former." The foregoing is taken from Mr. Bell's description.

\section{Genus: Teleophrys Stimpson, 1860.}

Key to the Galapagos species of the genus Teleophrys.

Three pairs of submedian tubercles forming a longitudinal series on the postrostral region. Four squamose tubercles forming a transverse row on the mesogastric region.

Granules of carpace abundant, but not forming a definite pattern, one or two anterolateral, branchial, marginal spines present.

\section{Teleophrys diana, sp. nov.}

Diagnostic characters. - Three pairs of submedian tubercles forming a longitudinal series on the postrostral region. Four squamose tubercles forming a transverse row on the mesogastric region.

Type.-The type, an adult male and a female specimen, with additional material, were collected at station 54, off Hood Island, Galapagos Islands, by William Beebe, while diving in 15 feet of water.

Galapagos distribution.-Arcturus station 54, off Hood Island.

General distribution.-Known only from the type locality.

Material examined.-The type, an adult male and a female specimen, and 112 additional specimens, i. e., 50 males, 38 females, and 25 ovigerous females containing eggs, embryos and zoeae in practically all stages of development were collected at station 54, off Hood Island, Galapagos, by William Beebe, while diving in 15 feet of water. This series contains adults ranging in size from $1.9 \mathrm{~mm}$. diameter to $10 \mathrm{~mm}$. diameter.

Technical description.-Carapace $9.1 \mathrm{~mm}$. long, $9.2 \mathrm{~mm}$. greatest width, (across the urogastric sulcus); subovate, nearly subcircular; regions of the carapace deeply delineated, gastric, hepatic, branchial and cardiac regions tumid. Dorsal surface finely granulate, these granulations becoming coarser near the lateral margins and especially along the posterior margin where they form a submarginal row. There are four squamose tubercles forming a transverse row across the middle of the highest part of the mesogastric region; the distance between the inner pair is one and one-half times as long as that between the inner and outer tubercle. The rostrum is broad and short in the smaller adults; the interspace dividing the horns is small, shallow, triangular; the horns are broad, short, triangular, the apex being rounded and the outer margin sloping, more than twice as long as the inner margin; the rostral lobes are convex on the upper surface and separated by a median sulcus, a second slightly diagonal sulcus extends backwards from behind the outer antennal base between the rostral lobe and orbital border. In the larger adults $(9 \mathrm{~mm}$. greatest width) the rostral horns are not triangulate but are truncate, rounded, and the interspace is reduced, being more linear than triangular. There are three pairs of submedian tubercles 
forming a longitudinal series, the first pair being adjacent to the rostral margin; the second pair about in line with the inner superior orbital angle, the third pair are about opposite the posterior orbital margin. The outer distal angle of the external basal antennal article is produced into a rugged triangulate process which is visible in a dorsal view as the inferior inner orbital angle, reaching nearly as far forward as the rostral horn. The superior orbital angle forms a raised, rounded tubercle stouter than and opposite to the second pair of rostral

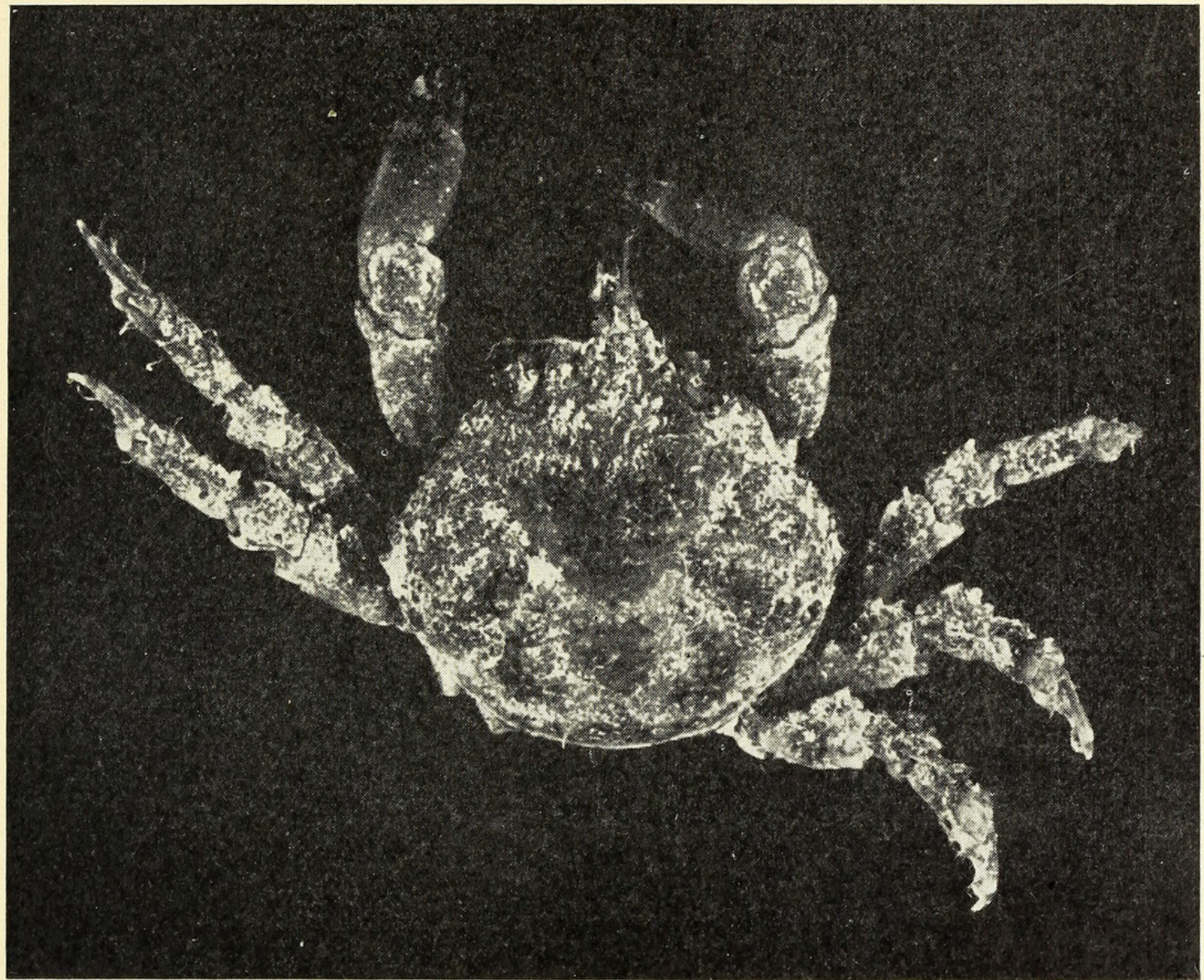

Fig. 52. Teleophrys diana, $\times 2$.

tubercles. In the younger adults there are two linear fissures in the superior orbital border; these are obsolete in the larger adults. The hepatic lobe is moderately tumid and bears a variable series of coarse granulations on its lateral margin, and a single larger squamose tubercle above these granulations, in line with the three lateral teeth of the margin of the branchial region. These latter have the anterior margin short, the apex sharp and strongly forwarddirected and the postlateral margin convex and broadly rounded. The first and second teeth are almost subequal, the second tooth occasionally being a trifle larger than the first; the third or posterior tooth of the series is constantly the smallest. There is a large tubercle on the high posterior part of the branchial region, situated inward from and just posterior to the third branchial tubercle. 
The eyestalk is stocky, slightly swollen, but constricted distally and produced on the upper dorsal surface into a rounded, tongue-like process that extends a little way onto the cornea but not to the distal region of the cornea. The cornea is subspherical, prominent; composed of many facets.

The external antennae have the basal article fused, large with the outer distal angle produced into a triangular tooth which is visible dorsally, appearing as the inferior orbital angle; there is a smaller sharp tubercle just below the external proximal angle of the basal antennal joint. The second (first free) joint of the external antennae is not quite half as wide as the distal end of the first joint, and arises from the inner distal angle of the basal joint; it is subcylindrical, dorso-ventrally compressed and furnished with a fringe of long curved setae along the distal half of the inner lateral margin; the third joint is slightly longer and narrower than the second; it is somewhat dilated distally and bears a cluster of setae nearly as long as the joint itself, on the inner distal angle; it also supports a flagellum composed of thirteen tapering articles each of which bears one or two long setae on its distal margin; the flagellum is about 2 $\mathrm{mm}$. long, or one and one half times as long as the two free peduncular segments taken together.

The inner antennae are situated within the fossett beneath the rostral horns, into which they fold almost vertically; the basal joint is scarcely visible, the two free joints are stocky, cylindrical, subequal, about half as wide as long; the distal one bears on the ventral side of its distal end a minute flagellum composed of six small tapering articles, and a cluster of setae on each side of the flagellum; the larger stouter flagellum is adjacent and dorsal to the smaller one and about the same length. It consists of eight short tapering rings and bears a heavy, long brush of close-set setae which project considerably beyond the flagellum and cause it to appear much longer than it actually is.

The external maxillipeds have a small basal article; the exognath is about two times as long as wide and has its distal end triangulate, its apex reaching almost to the anterior border of the merus; it bears a very slender, multiarticulate palp which is as long as the exognath and finely setigerous. The ischium is two-thirds as broad as long, has the inner margin straight, finely setigerous, the inner half of the distal region produced in a rounded lobe; the merus arises from the outer half of the distal margin of the ischium; the merus is not quite as long on its inner lateral margin as it is wide, but is about as long on its outer lateral margin as it is wide and has the inner distal margin oblique and the external distal margin widened and rounded. The palp arises from a notch on the inner distal angle and consists of three articles which are subequal in length but the middle joint is less than half as wide as the proximal joint, and the distal joint is less than half as wide as the middle one; all three joints are heavily fringed with setae. There is a narrow space between the halves of the maxilliped, which is guarded by long fringes of setae.

The female abdomen is very broad and subcircular, covering the entire sternal region between the legs and reaching forward almost to the base of the external maxilliped. It consists of seven segments of which the first and second are subequal, forming the hinge and being narrower and shorter than the remaining segments. The third, fourth, fifth, sixth and seventh segments are 
subequal in length but of varying width, forming the subcircular, broad pouch, the fifth segment being the widest. The second to fifth segments inclusive each bear paired appendages to which the eggs are attached. Each appendage consists of a long, curved, almost semicircular outer branch which is quite strong and fringed with fine close-set setae and lies subparallel to the outer margin of the pouch or when the pouch is filled with eggs, the outer branch of each of the four appendages spreads outside the margin of the pouch, somewhat like the sticks of a fan, forming a protective border. The inner branch of each appendage is very fragile; only about half as long, or less, than the outer branch and consists of two articles, the basal, which is almost two-thirds of the total length of the branch and the distal article, which is only one-half as long as the basal article and much frailer; the inner branch bears long silky setae to which the eggs are attached.

The male abdomen is also seven-segmented; it is triangular with the apex of the distal segment rounded. The first and second segments cover the sternal plate between the last pair of ambulatory legs. The first pair of male appendages are strong laminar processes which are flattened, having the outer third of the width of the process bent over upon the inner two-thirds, with a longitudinal hollow channel under this fold; the tip of the outer half is produced into a shape like that of a calla-lily blossom; the distal end of the inner third of the margin terminates somewhat below the outer angle and bears an oval membraneous process which reaches almost as far as the outer process.

The chelipeds have the coxa small; the basis stout and produced to a toothlike process on its posterior distal angle; the ischium is somewhat longer than the two preceding joints taken together and is produced on the anterior distal margin to a long triangulate process which extends nearly halfway the length of that margin of the merus; the merus is dilated distally and rounded on its upper surface which is ornamented with three subequally spaced longitudinal rows, composed of four or five tubercles each; the distal margin is produced into an enlarged node on the inner side and into a still larger toothlike node on the outer distal angle; the carpus is not quite one-half as long as the merus, is rounded on the upper side and has its edges cristate and four tubercles forming a diamond-shaped figure on the upper surface; the propodus is about a third longer than the merus and is half as high as it is long, with the upper edge carinate; a single low tubercle occurs near the middle of the proximal margin of the propodus. The propodal finger is about one-third of the entire length of the propodus and is spoon-shaped distally, crenulated around the distal margin and furnished with two tufts of setae inside the cutting edge. The hinged finger is similar to the propodal finger but is a trifle stronger and slightly curved downward distally with its crenulated margin meeting upon that of the propodus; there is a gap between the fingers which meet only at the tips. The hinged finger has a large rounded tooth on the cutting edge near the base.

The four pairs of cristate ambulatory legs are similar in structure but successively decrease in size posteriorly. The coxa and basis are small; the ischium is small and is produced on its anterior distal margin to a triangulate process; the merus is dilated distally and has its lateral and distal edges serrulate and a slightly less prominent longitudinal row of serrulations on the upper surface; 
the carpus is about half as long as the merus, and is similarly cristate; the propodus is rather stocky, of about the same width throughout its length, with two rows of serrulations and with the posterior distal margin produced into a prominent rounded disc which interfits with a smaller, elongate rounded process which arises from the outer lateral surface of the dactyl, is directed backward and fits over the rounded projection of the propodus upon which it articulates. The propodal disc-like projection extends onto the dactyl for about one-third of its length. The dactyl is very strong and decidedly curved apically and armed with several rows of spinose setae, but devoid of serrulations.

Eggs.-The ovigerous females carry from about 150 to 200 eggs which are attached to the setae of the inner branches of the abdominal appendages. The eggs fill the brood pouch which becomes greatly distended, the outer branches of the pleopoda forming a side-wall between the margins of the abdominal belt and the sternal plastron. The eggs are spherical, golden yellow, their diameter being less than that of a medium-size sewing needle.

Embryos. - The largest embryos in the series at hand are about two and a half times as large as the diameter of the undeveloped eggs. They show huge elliptical black eye-spots whose long diameter appears to be about two-thirds of the height of the embryo and whose short diameter is about one-third of the width of the embryo.

Young.-Young adults of both sexes whose maximum diameter is scarcely $2 \mathrm{~mm}$. show the specific characters unmistakably. The legs are cristate in miniature, and the minute granulations, visible only under high magnification, represent the tubercles of the dorsal surface of the carapace.

Remarks.-An adult male specimen whose maximum diameter is $6 \mathrm{~mm}$. is a remarkably interesting example of the capacity for regeneration of lost appendages possessed by even the tiniest crabs. The present specimen has lost all four ambulatory legs on one side and the second and third ambulatory legs on the opposite side. Apparently all of these were lost at one time, for the six budded successors are in the same early stage of development, showing the same relative differences in size as do the full-grown legs.

\section{Teleophrys tumidus (Cano)}

Mitraculus tumidus Cano, Boll. Soc. Nat. Napoli, ser. 1, vol. 3, p. 186, pl. 7 , fig. 7,1889 .

Mithrax tumidus Rathbun, Proc. U. S. Nat. Mus., vol. 38, p. 575, 1910.

Teleophrys cristulipes Rathbun, Proc. U. S. Nat. Mus., vol. 38, p. 536, (part; not pl. 46, fig. 2), 1910.

Teleophrys tumidus Rathbun, Bull. 129, U. S. Nat. Mus. p. 442, pl. 159, figs. 8 and 9,1925 .

Diagnostic characters. - Ambulatory legs with a lateral and a dorsal lobe on the posterior side of the propodus. Anterolateral spines one or two, branchial and marginal in position.

Type.-Cano's type came from Payta, Peru, and is deposited in the Naples Museum.

Galapagos distribution.-Arcturus station 54, Gardner Bay, off Hood Island, 15 feet; reef north of Tagus Cove, Tagus Hill, Albemarle Island.

General distribution.-Peru, Cocos Island and Galapagos Islands.

Habits. - This species dwells in the crevices of coral rock bottoms in the Galapagos. 
Material examined.-Six from Arcturus station 54 Hood Island.

Technical description. - The front is subtriangulate, the rostral horns of moderate length, separated from each other by a very narrow sinus. The superior orbital margin has two weak emarginations. The outer margin of the basal article of the external antenna is not dentate, but forms a very faint lobe posteriorly; the second free article is short and stout, being more than onehalf as wide as long. The antennules are well-developed and fold within the septum.

The external maxillipeds have the ischium subrectangular, with the inner distal angle roundly produced; the merus is more than one-half as long as the ischium and has the inner distal angle deeply notched for the reception of the three-jointed palp.

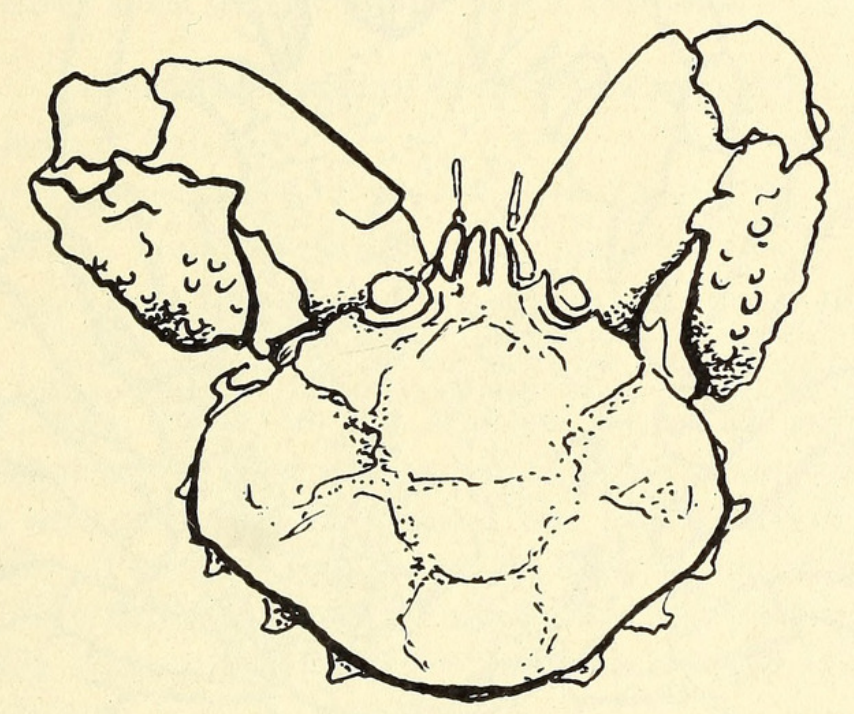

Fig. 53. Teleophrys tumidus, $\times 1 \frac{1}{2}$ (After Rathbun).

Carapace longer and more triangular than Teleophrys diana or T. cristulipes; dorsal surface with granulations abundant but not forming a definite pattern as in diana; with fewer tubercles and spines than in cristulipes. Branchial region unusually elevated on either side of the cardiac region. Anterolateral margin with an hepatic tubercle, followed by a branchial tubercle, which is succeeded by a branchial spine placed just in advance of the second spine which is situated at the lateral angle and is followed by a tubercle and the postlateral spine.

The chelipeds are less rugose than those of cristulipes but more so than those of diana. There is a tubercle near the middle of the margin of the palm. The fingers are rather stout and tapering.

The ambulatories are very stout, especially the propodus which has a lateral as well as a dorsal lobe; the dactyl is short, stout and distinctly curved.

Genus: Stenocionops (Leach, Mss.) Desmarest, 1823

Stenocionops ovata (Bell).

Pericera ovata Bell, Proc. Zool. Soc. London, vol.. 3, p. 173, 1835 (1836); Trans. Zool. Soc. London, vol. 2, p. 60, pl. 12, figs. 5, 5 o, 5 p. 5 q, 1836. 
Stenocionops ovata Rathbun, Proc. U. S. Nat. Mus. vol. 38, p. 574, 1910; Bull. 129, U. S. Nat. Mus. p. 459, pl. 264, figs. 5-7, (after Bell), 1925.

Diagnostic characters. - Rostral horns divergent; carapace elongate-oval with eight median spines, and four or five lateral marginal spines.

Type.-Mr. Bell's type, which is believed to be no longer extant, was collected in the Galapagos Islands, in six fathoms.

Galapagos distribution.-Galapagos (type locality).

General distribution.-Known only from the type locality.

Material examined.-None.

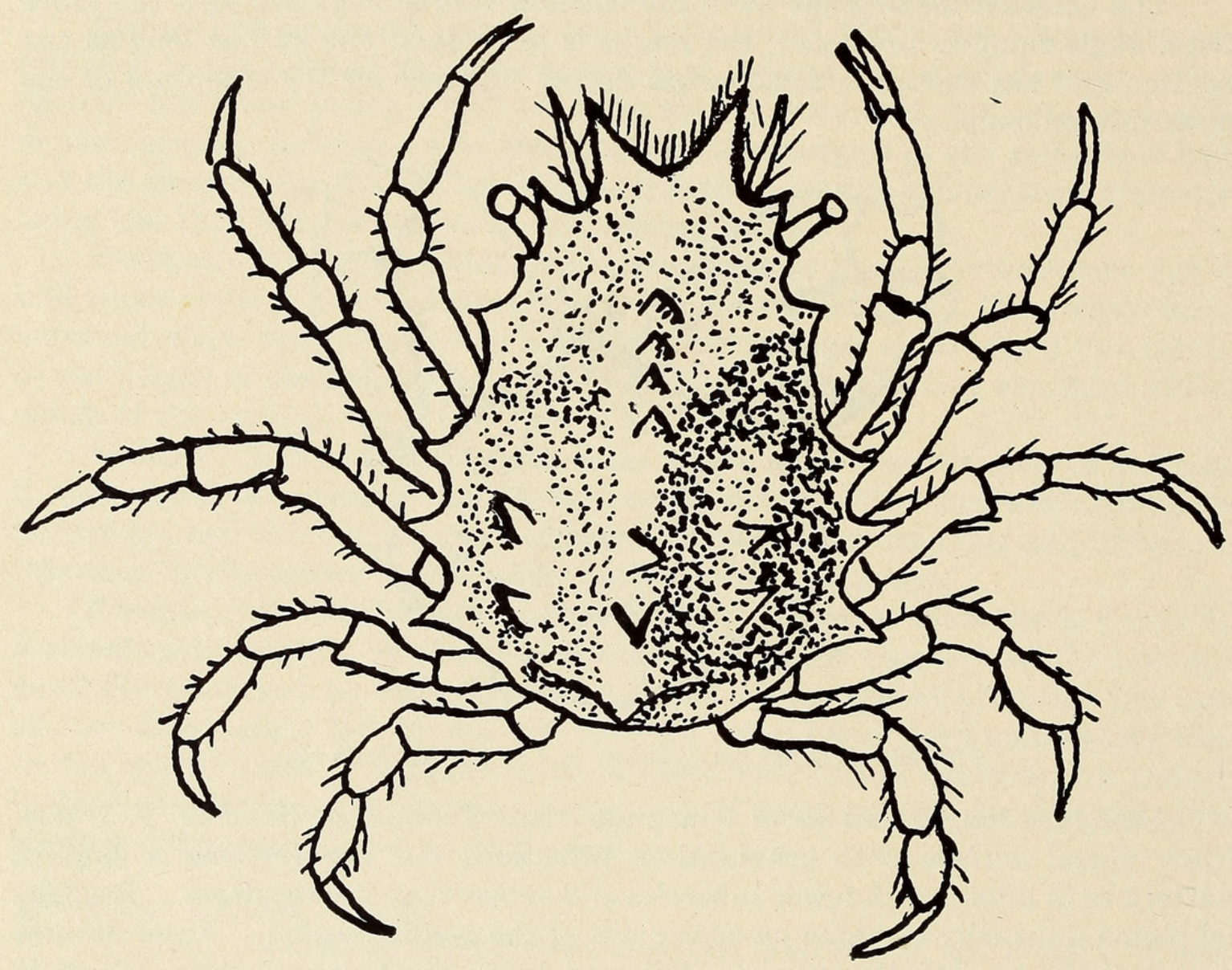

Fig. 54. Stenocionops oṽata, $\times 2$ (After Bell).

Technical description. - "The carapace of this species is oval, longer in proportion to its breadth than many others, considerably elevated, at least in the female, the only six as yet observed, sparingly covered with short close hair, and furnished with numerous spines of various length and size, of which there are four small ones on the median line of the gastric region, three on the cardiac and genital, of which the middle one is the largest, one on the intestinal, a very small one on each hepatic, three on the branchial, and four or five on each lateral margin. The orbit is formed nearly as in the other species, the upper and anterior spine extending much beyond that of the basil joint of the external antennae, is very broad; its outer spine is short and triangular, and there is a very small tooth beneath the insertion of the second joint. The moveable portion is as long as the rostrum, and beset with a double series 
of bristles. The second joint of the internal footstalk of the outer pedipalps is triangular, the anterior margin rounded and scarcely notched.

The abdomen of the female is oval, seven-jointed, and has an obtuse interrupted carina running its whole length, formed by a tubercle on the center of each joint; the first joint has a small tooth.

The legs are without spines, but covered with close hair; the first pair in the female is not larger than the others, and shorter than the second and third, which are the longest of the whole. The hand is simple, naked and slender; the claw small and furnished with extremely minute teeth.

The colour is a rich rather light reddish brown.

Length 1 inch, breadth six lines.

Two specimens, both females, were dredged by Mr. Cuming at the Galapagos Islands on coral sand at the depth of six fathoms." (After Bell.)

\section{Genus Microphrys Milne Edwards, 1851}

Microphrys aculeatus (Bell).

Pisa aculeata Bell, Proc. Zool. Soc. London, vol. 3, 1835 (1836), p. 171; Trans. Zool. Soc. London, vol. 2, p. 50, pl. 9, fig. 7, 1836.

Milnia aculeata Stimpson, Ann. Lyc. Nat. Hist. New York, vol. 7, p. 52. 1860.

Microphrys aculeatus A. Milne Edwards, Crust. Rég. Mex., p. 63, 1875; Rathbun, Proc. U. S. Nat. Mus., vol. 38, pp. 546 and 574, pl. 45, fig. 4, 1910 ; Bull. 129, U. S. Nat. Mus., p. 500, pl. 271, fig. 1, 1925.

Microphrys platysoma Rathbun, Proc. Wash. Acad. Sci., vol. 4, p. 285, 1902; Proc. U. S. Nat. Mus., vol. 38, pp. 535 and 574, 1910.

Diagnostic characters. - Two prominent raised disks on the anterolateral wall. There is no tooth or lobe behind the anterolateral spine of the basal antennal segment. There are four spines on each branchial region, two of which are marginal. Five tubercles form an arc across the gastric region.

Type.-Bell's type, which came from the Galapagos Islands, is believed to be no longer extant.

Galapagos distribution.-Bell's type locality is given as "Galapagos Islands"; this species has also been taken on the reef north of Tagus Hill, Tagus Cove, Albemarle Island, by the Hopkins-Stanford Expedition and taken off Hood Island, depth 15 feet, Arcturus station 54, by William Beebe.

General distribution.-Galapagos Islands, Ecuador and Peru.

Material examined.-Two female specimens and one young specimen from off Hood Island, station 54, collected by William Beebe while diving in 15 feet of water.

Technical description.-The carapace, which is broadly pyriform, measures $8 \mathrm{~mm}$. long from base of rostrum to posterior margin, $7 \mathrm{~mm}$. greatest width, and is very well furnished with clusters of very high fish-hook-shaped setae many of which have tubercles or granules at their base; there are many small hairs between these hooks; the surface of the carapace is pitted. The paired rostral horns are long, acuminate, separated by a deep V-shaped sinus which is three-fourths as wide distally as the horns are long. The slender anterolateral spine of the basal antennal segment is directed outward and is two-thirds as long as the rostral spine. The superior orbital border is marked by closed fissures; the postorbital cup is flat, disk-like; there are two large, prominent, oval disks, situated on the anterolateral wall, one being hepatic and one bran- 
chial in position. Five tubercles form an arc across the summit of the gastric region; two tubercles, one behind the other, on the gastric region are placed posterior to the median one of the five tubercles forming the arc. There are two tubercles near the outer edge of each branchial region. There are normally four spines on each branchial region, three of which form a transverse row on the cardiac region; the outer spine of this series is marginal, the fourth spine is lower and more anterior than the third and is also marginal. There is said to

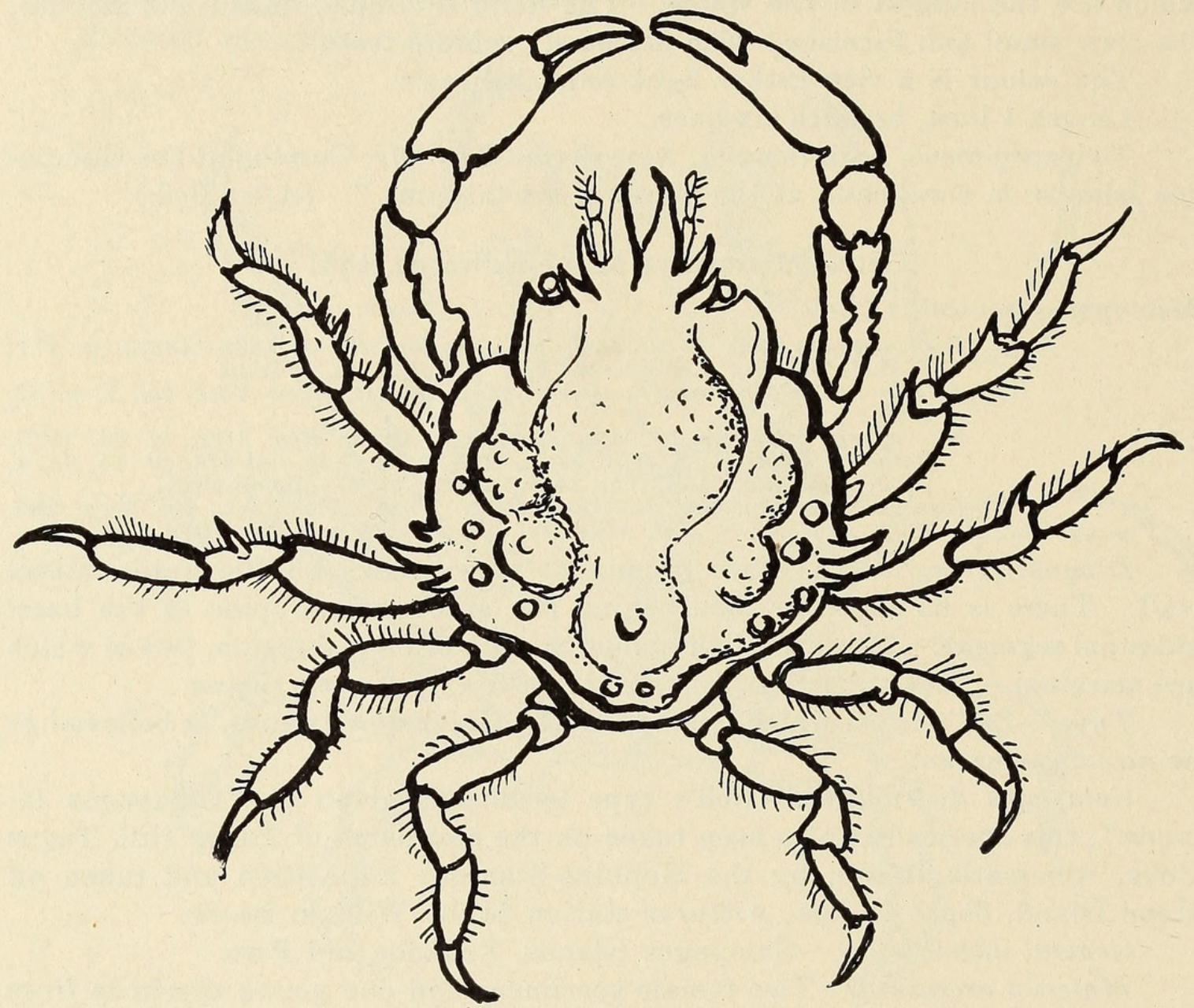

Fig. 55. Microphrys aculeatus, $\times$ about 2 (After Bell).

be an occasional variation in this row of spines, the innermost one sometimes being reduced or absent; sometimes a secondary spine occurs between the second and third branchial spines. There is a row of twelve prominent tubercles forming an arc just above the posterior margin. Each tubercle bears a tuft of long curled hairs; there is a row of similar hairs along the anterolateral regions; and another on the gastric region running forward almost to the tips of the rostral horns.

The female abdomen is seven-segmented and is quite narrow.

The antennulae are small, placed beneath the rostral hood and fold diagonally within the M-shaped fossett

The external antennae have the basal joint greatly dilated and armed at 
the outer distal angle with a long slender spine, which is visible dorsally; the free second and third joints are long and slender, and lie beside the rostral spine, the two together almost reaching the apex of the spine; the flagellum is long and slender, consisting of seven or eight long rings and reaching beyond the tips of the extended cheliped.

The external maxillipeds are rectangular; the long second joint of the exognath is convex on its inner lateral margin and is two-thirds as wide as the ischium; the ischium is cleaver-shaped with the inner distal angle produced; the merus is a little more than half as long as the ischium, with the distal margin truncated, the external distal angle produced and rounded, and the inner distal angle emarginate for the reception of the three-jointed palp; the basal joint of the palp is quite robust, the second and third joints are small and tapering.

The chelipeds (female) are equal and are only slightly larger than the first pair of ambulatories. The merus of the chelipeds is elongate, compressed, and has three triangulate teeth above; the carpus is rounded and nodulose; the palm is moderately enlarged and compressed; the fingers are slender, compressed, curved, hollowed at the tip and shallowly dentate.

The four pairs of ambulatory legs successively diminish in size posteriorly. The most anterior leg has a long sharp spine on the carpus and another subdistal spine on the merus. The next (second) leg has a spine on the carpus only. The dactyli are well developed, curved and sharp-pointed.

Microphrys triangulatus (Lockington).

Mithraculus triangulatus Lockington, Proc. California Acad. Soc., vol. 7, p. 73,1876 (1877).

Mithrax triangulatus Rathbun, Proc. U. S. Nat. Mus., vol. 21, p. 578, 1898. Microphrys branchialis Rathbun, Proc. Washington Acad. Sci., vol. 4, p. 285,1902 .

Microphrys triangulatus (Rathbun), Bull. 129, U. S. Nat. Mus., p. 504, pl. 177, 1925.

Diagnostic characters. - Carapace short and broad, nodulose, nodules almost smooth. Three marginal teeth or lobes on basal segment of antenna. Chelipeds of male very long and strong, palms high.

Type.-Gulf of California (type-locality); the type is not extant.

Galapagos distribution.-Galapagos Islands.

General distribution.-Lower part of Gulf of California; Galapagos Islands. Shallow water to 10 fathoms.

Material examined.-None.

Technical description.-The following is Miss Rathbun's description: "Carapace a little longer than broad, thick and nodulose, the nodules ornamented sparingly with low granules, so as to appear almost smooth. The largest nodule is the anterior branchial, which is oblique, elongate and overhangs the lateral wall of the carapace. Behind and below this lobe there is a short blunt spine or lobe at the lateral angle of the carapace. The most prominent granules are on the anterior portion of the carapace, namely, two on the summit of each protogastric lobe, a row of three on each epigastric lobe, one or two at base of each preorbital tooth. Two large tubercles on intestinal region, from each of which a submarginal line of granules extends outward.

Rostrum short, deeply divided; horns broad, inner margin straight, outer 
margin convex, sinus narrow. Preorbital lobe little advanced, blunt, granulate; postorbital cup also little advanced. Basal antennal segment broad, bearing two broad blunt lobes on the margin, each lobe outwardly arcuate, also a small subacute tooth at the base of the next or movable segment, and a tubercle on the ventral surface near the postero-external angle.

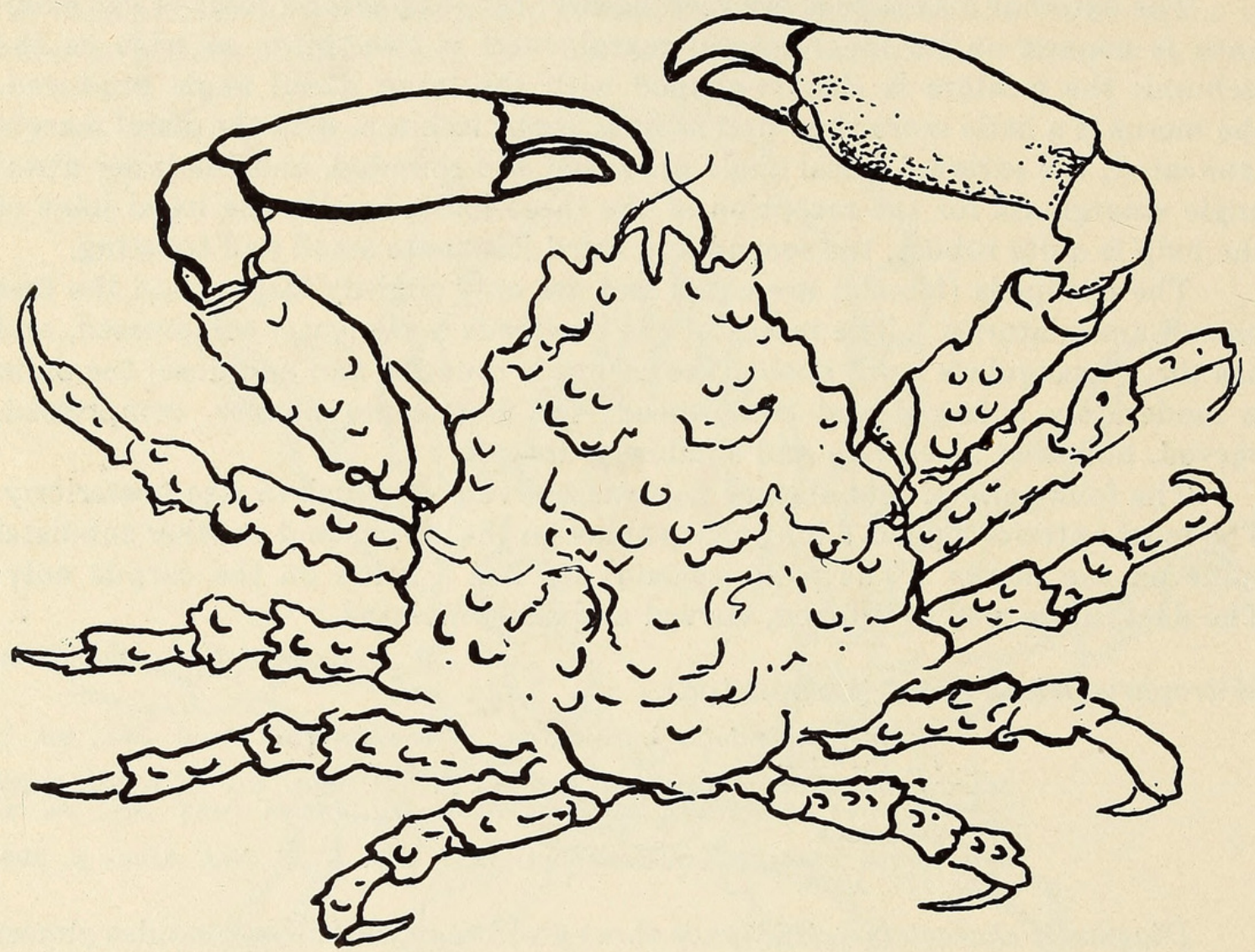

Fig. 56. Microphrys triangulatus, $\times 3$ (After Rathbun).

Chelipeds of male very strong, one and two-thirds times as long as carapace. Arm tuberculate on upper margin and inner and outer surfaces; wrist nearly smooth; palm unusually high, its upper length about one and two-thirds times its height; immovable finger a little convex below, a large tooth on the dactyl a little behind middle of gape. Merus joints of legs with about two rows of large tubercles some of which are conical and subacute; a few of the same are on the carpus, from one to three of these being enlarged; two tubercles on each propodus.

Color.-In spirits, uniform reddish (Lockington).

\section{Family: PARTHENOPIDAE}

\section{Subfamily: PARTHENOPINAE}

Genus Parthenope Weber, 1795

Parthenope (Platylambrus) exilipes (Rathbun).

Lambrus (Parthenolambrus) exilipes Rathbun, Proc. U. S. Nat. Mus., vol. 16, p. 234, 1893. 
Lambrus hassleri Faxon, Bull. Mus. Comp. Zool., vol. 24, p. 152, 1893.

Parthenope (Platylambrus) exilipes Rathbun, Bull. 129, U. S. Nat. Mus. p. 523, pls. 184 and $185 ;$ pl. 277 , figs. 1 and $2,1925$.

Type.-The type, a male specimen, was collected off San Domingo Point, Lower California, Mexico, and is deposited in the United States National Museum.

Galapagos distribution.-Off Charles Island, 78.5 fathoms, one female specimen.

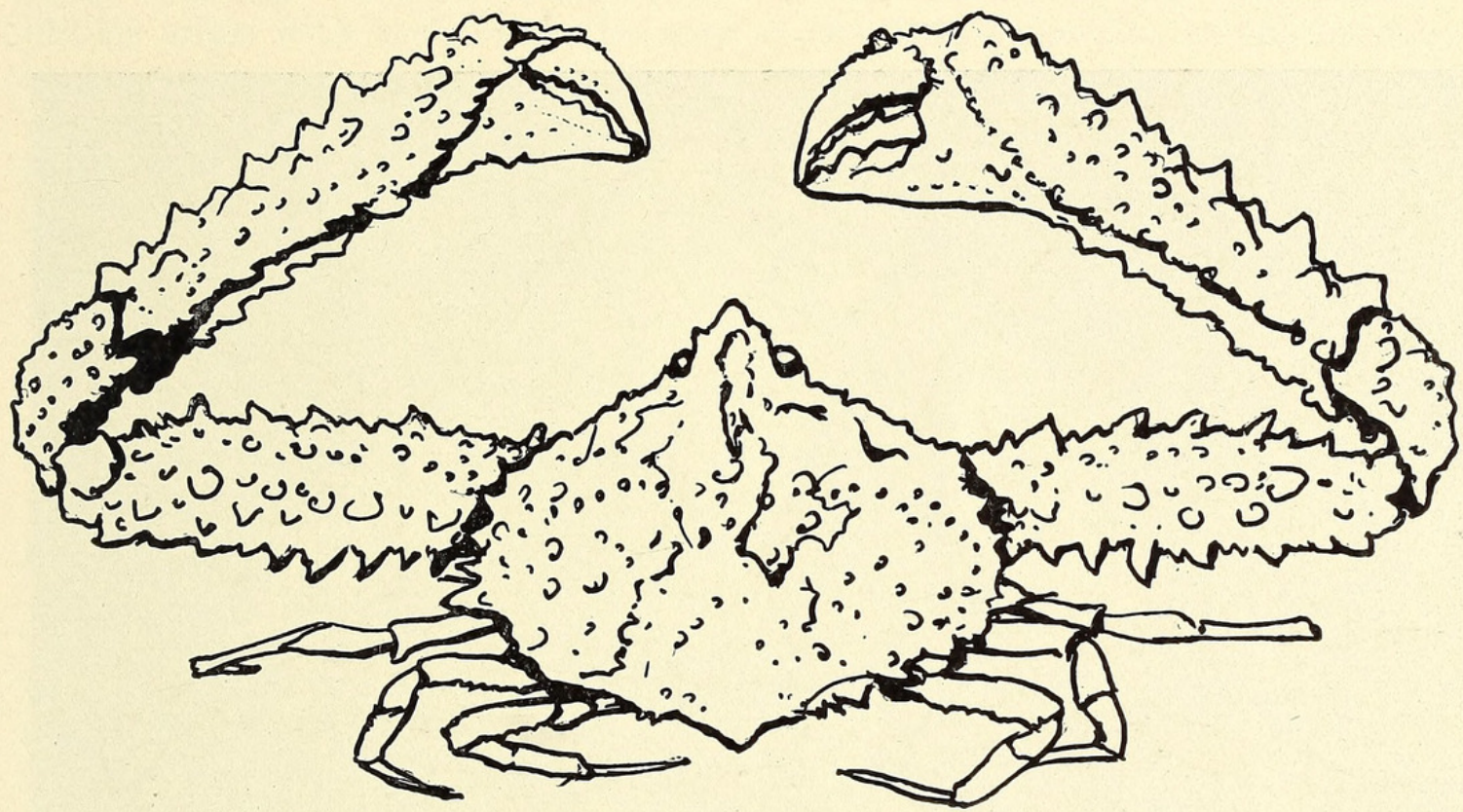

Fig. 57. Parthenope (Platylambrus) exilipes, natural size.

General distribution.-West coast of Mexico; Panama Bay; off Cocos Island; Galapagos Islands. From depths ranging from 31 to 80 fathoms.

Material examined.-None.

Technical description.-The following is Dr. Rathbun's diagnosis: "Near pourtalesii; carapace broader; branchial regions more expanded and inflated, the inflation extending farther in toward the cardiac area so as to involve the oblique row of small tubercles, which in pourtalesii lies low in the fossa between branchial and cardiac regions; inter-regional depressions shallower; branchial pits deeper; a transversely-oblique line of tubercles across anterior branchial region more conspicuous, spines and teeth of carapace and chelipeds shorter and stouter, those on chelipeds not laciniated to such a degree; anterior margin of carpus and propodus of all the legs finely spinulous or denticulate.

Measurements.-Female (21966) length of carapace 29.7, width of same 40.3, length of cheliped $76.4 \mathrm{~mm}$."

\section{Subgenus Pseudolambrus Paulson, 1875}

Parthenope (Pseudolambrus) excavata (Stimpson) (Hexagonal Crab).

Lambrus excavatus Stimpson, Ann. Lyc. Nat. Hist. New York, vol. 10, p. 98, 1871; A. Milne Edwards, Crust. Rég. Mex., p. 154, 1878.

Parthenope (Pseudolambrus) excavata Rathbun, Bull. 129. U. S. Nat. Mus., p. 529, pl. $189,1925$. 
Diagnostic characters.-Carapace triangulate with five deep depressions on the anterior half of body. Anterolateral margins angulate. "Chelipeds deeply concave above, the concavity defined by prominent dentate crests" (Stimpson).

Type.-Professor Stimpson's type material consisted of two specimens collected at Manzanillo, Mexico, by John Xantus. They were lost in the great Chicago fire.

Galapagos distribution.-Off Hood Island, Arcturus station 54, in 15 feet of water.

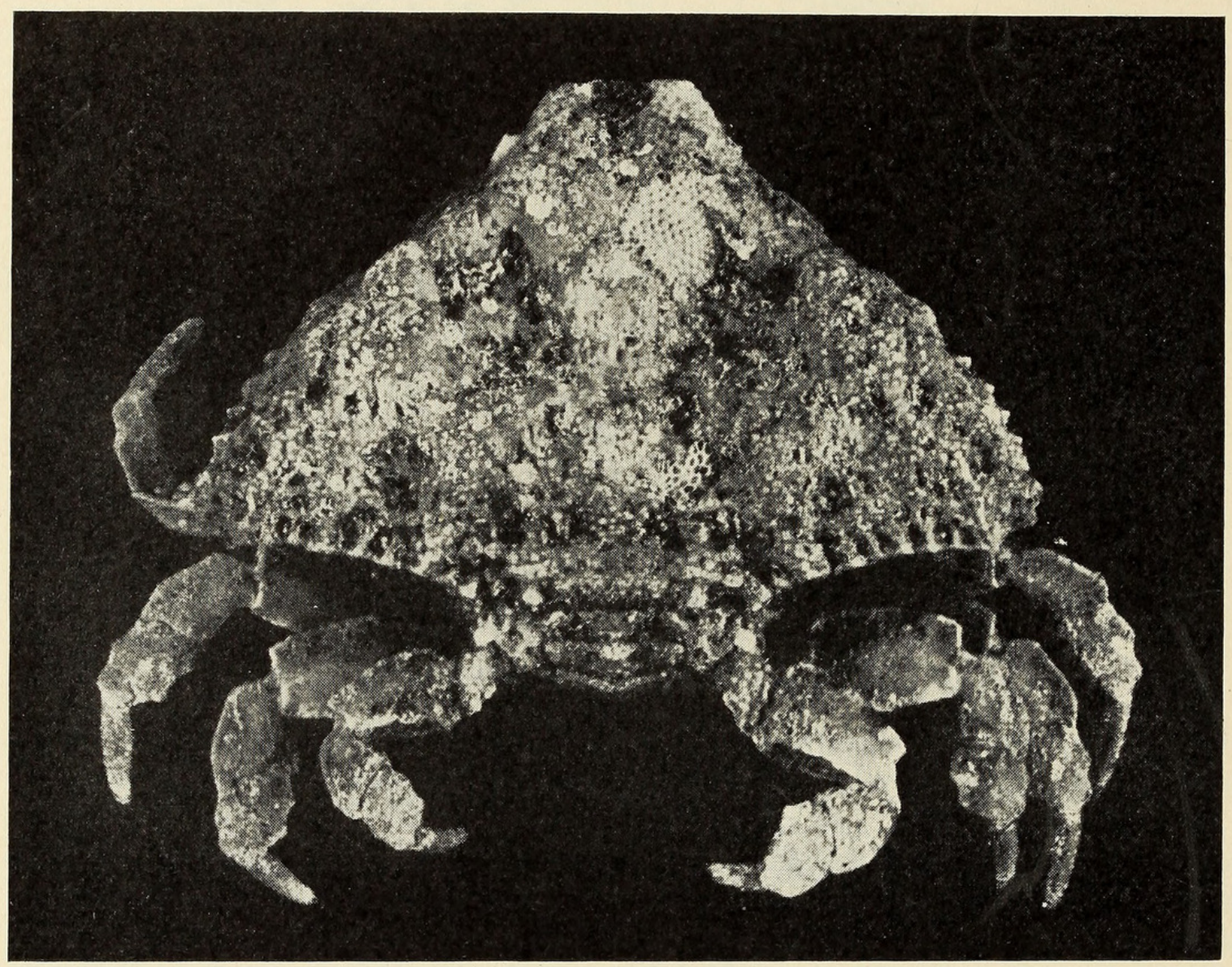

Fig. 58. Parthenope (Pseudolambrus) excavata, $\times 3$.

General distribution.-In addition to the type-locality, Manzillo, Mexico, I find only one specimen from Panama, collected by Captain John M. Dow, recorded. The Arcturus Expedition has extended the known range of this species to the Galapagos Islands.

Material examined.-One female specimen was taken at Station 54, Hood Island, Galapagos Islands, by William Beebe, while diving in fifteen feet of water. This is the first record of this species from the Galapagos Islands.

Habits.-Little is known of the habits of this rare crab. It was found in the crevice of the coral rock, which it so much resembles in the sculpturing of its carapace. The eroded and nodulose surface of the carapace of the Galapagos specimen is rendered even more inconspicuous by the patch-like colonies of two 
species of Bryozoa, two kinds of algae, one species of tube-dwelling worm, and one species of sponge which adhere to it.

Technical description.-Carapace $27 \mathrm{~mm}$. greatest width; $18 \mathrm{~mm}$. long; irregularly hexagonal, its greatest width being through the posterior region. The rostrum is prominent, though sharply deflexed, triangulate, with the margin irregularly, vaguely dentate. The anterolateral margins are concave, forming an angle with the outer lateral margin, and terminate posteriorly in a decided projecting angle; the posterolateral are but little concave forming a decidedly obtuse angle with each other, because of the little projection of the intestinal region. The posterior margin is narrow. The margins are cut into small teeth which are short, triangular and more regular on the anterior and outer lateral margins, being prominent at the lateral angle; on the postlateral margins these teeth are less triangulate and more irregular. There is a deep concavity on the frontal region which extends backwards a little ways. In addition to the normal delineation of the branchial and cardiac regions there are four deep cavities or depressions in front of the branchial region; two of these separate the branchial and hepatic regions and the other two separate the branchial from the gastric regions. The dorsal surface of the carapace is rough; the raised areas are covered with well developed low granules or tubercles. Three flat triangular denticles form a row on the ventral surface behind the cheliped.

The female abdomen is seven-segmented, oval, of moderate width and with the distal segment broadly rounded; the lateral margins are densely fringed with short plumose setae. The external surface of the abdomen is very rugose, the middle of each segment being occupied by a ridge-like, setose tubercle which is as long as the segment; several smaller tubercles are placed on each side of the central one, the second to fifth segments inclusive respectively bear the paired biramose appendages. Each appendage consists of a short basal joint and two, long, curved, subequal branches, each of which is heavily fringed with exceedingly long plumose setae.

The male abdomen has not been described.

The eyestalks are very convex and are covered with a calcareous granulose substance similar to the carapace. The cornea is terminal, subspherical, shining black, composed of numerous hexagonal facets.

The inner antennae have an enormous basal joint which is very rough on its outer surface; the first free joint is long, moderately slender and granulose externally, the next joint is slightly shorter and is cylindrical and bears distally the two small flagella.

The external antennae are small; the distal inner angle of the basal joint does not reach the front; the outer distal angle reaches as far as the inner inferior orbital angle; the second antennal joint is small and is in the orbital hiatus; the third joint is scarcely larger than the flagellum, which consists of nine, short, slender, tapering articles.

The external maxillipeds fit closely in the buccal cavity; the exognath is long, tapering, thin on the inner distal margin and bearing a very slender palp; its outer surface bears a row of three or four granules. The ischium is subrectangular with its inner distal margin slightly produced; its outer surface granulose and channelled by a median longitudinal sulcus; its inner edges are crenulate 
and furry with very short setae. The merus is as wide as long, and is about onehalf as long as the ischium, with its outer distal lobe rounded and its inner distal lobe deeply incised for the reception of the three-jointed palp. The first joint of the palp is large and completes the outline of the merus, the second and third joints are cylindrical, tapering, fringed with long setae; they are bent downward and lie between the meral joints.

The chelipeds in the present specimen have been broken off and the regeneration of these appendages has begun. These folded, budded chelae do not quite reach to the margin of the carapace but the diagnostic features cited by Stimpson may be clearly discerned.

The following is Professor Stimpson's description of the chelipeds:

"The chelipeds are much shorter and stouter than in the typical forms of the genus, and are deeply concave above, the concavity being smooth or nearly so, and defined by prominent marginal crests, which, except on the carpus, are strongly toothed. The meros joint of the cheliped is particularly short; its anterior crest is armed with three or four teeth, and its superior one with only two large teeth, the outer one of which is much the largest. In the hand the crest of the superior margin is armed with six unequal, approximated, triangular teeth; and that of the outer margin with two conical distant teeth, besides the knob at each extremity. The lower surface of the hand is ornamented with four or five rows of granulated tubercles, those of the middle row being largest and most conspicuous; inner margin serrated with granulated teeth.

Length of the carapax in a female, 1.20 ; breadth, 1.38 inch; proportion $1: 1.15$; length of meros-joint of cheliped, 0.68 ; length of greater hand, 1.20 inch.

It is distinct from all other known species with the carapace broader than long, in the shortness of its chelipeds. In one of the specimens before me the right hand is nearly twice as broad as the left."

The four pairs of ambulatory feet of the specimen secured by Mr. Beebe are of similar shape but successively decrease in size posteriorly. The first and second pairs are almost equal, the third pair only reaches to the base of the dactyl of the second pair and the fourth pair is conspicuously smaller reaching only to the distal end of the propodus of the third pair. All of the legs are decidedly compressed, crested above, the margins are dentate and the outer surfaces of the legs are granulose. The three proximal joints are small; the meral joint is the longest joint of the appendage, and is three-sided, the ventral face being narrow, excavate between the carina-like margins, the upper portion is very compressed and its margin crested and dentate; the carpus is about half as long as the merus; the propodus is a little longer than the carpus and has one or two angulations on its ventral margin made by large granules; the dactyl is as long or a trifle longer than the propodus and is stout, sub-cylindrical, tipped with a strong spine and covered with granules and short furry setae. 


\section{Superfamily: BRACHYRHYNCHA}

\section{Family: PORTUNIDAE}

Subfamily: PORTUNINAE

Genus Portunus Weber, 1795

Subgenus Achelous DeHaan

Key to the Galapagos species of the subgenus Achelous.

Arm and hand very short; carpal spine unusually long, reaching halfway to the upper marginal propodal spine when the hand is flexed.

brevimanus

Lateral teeth alternately large and small; lateral spine only slightly longer than seventh tooth; one small spine on posterior distal angle of merus of swimming feet.

angustus

Carapace with frontal border unusually prominent; ridges and rugosities of carapace decidedly pronounced. One strong spine on merus of swimming feet.

Portunus (Achelous) brevimanus (Faxon).

Under Achelous spinimanus Faxon, Mem. Mus. Comp. Zool., vol. 18, p. 23, 1895 (not Portunus spiniamanus Latreille) is described Ächelous brevimanus Faxon (in text).

Portunus (Achelous) brevimanus Rathbun, Proc. U. S. Nat. Mus., vol. 21, p. 593, 1899; Proc. U. S. Nat. Mus., vol. 38, p. 578, 1910.

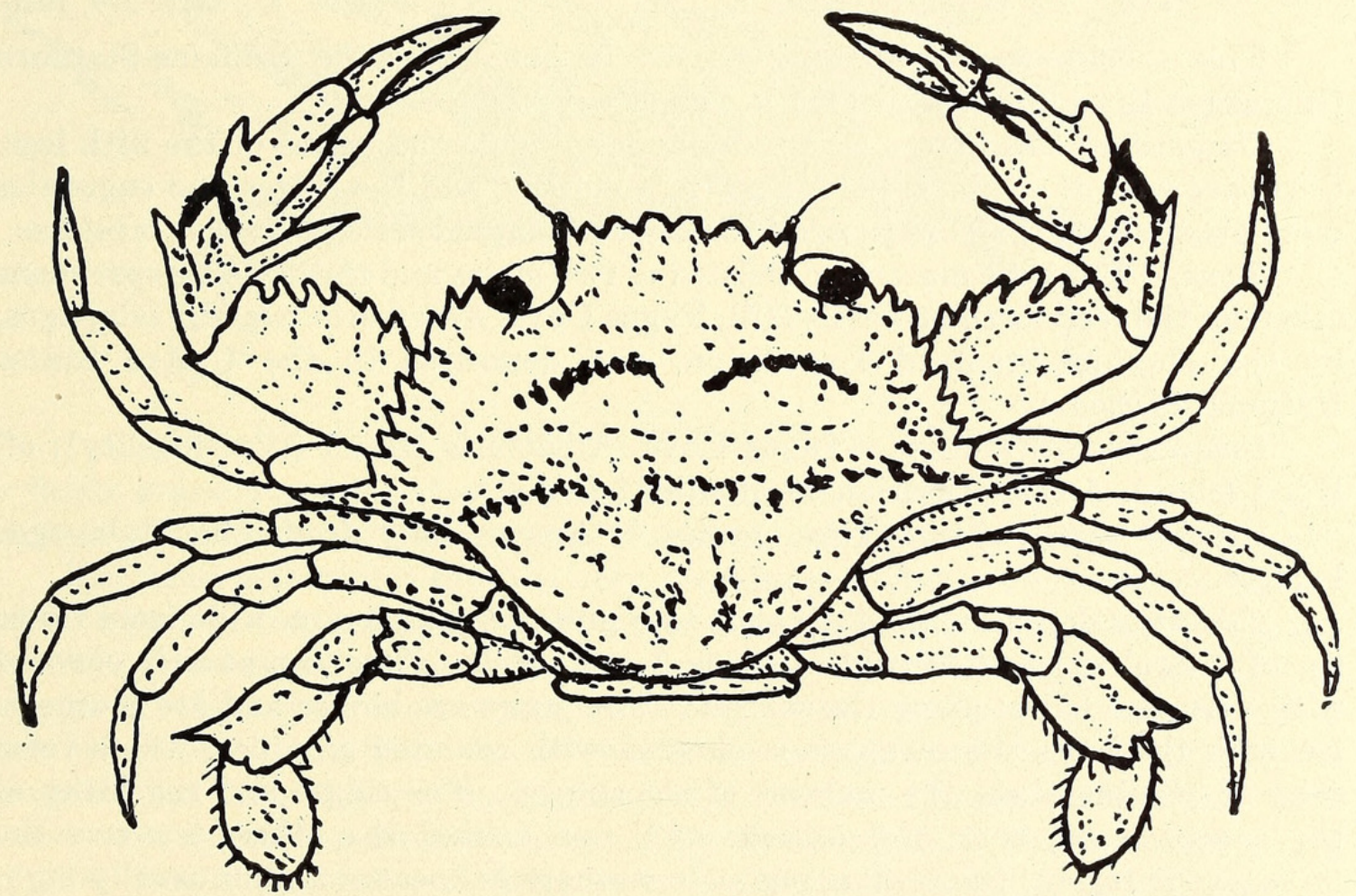

Fig. 59. Portunus (Achelous) spinimanus, natural size.

Diagnostic characters.-Arm and hand shorter than in related species; a longer spine on the inner side of the carpus. 
Type.-Two male specimens from off Cocos Island, Albatross station 3368, furnished the material upon which this species is founded; they are deposited in the Museum of Comparative Zoology, Cambridge, Mass. Island.

Galapagos distribution.-Off Hood Island 20 and 40 fathoms, Albemarle

General distribution.-Pacific, off Cocos Island; Galapagos Islands.

Material examined.-One broken.

Technical description.-The following is Dr. Faxon's description of the species: "These specimens differ from the typical form in having a shorter arm and hand, a longer spine on the inner side of the carpus; in having a short spine at the distal end of the superior border of the propodus and two small spines at the distal end of the merus of the last pair of legs. Of these two spines the larger is on the posterior lateral angle of the segment, the smaller one just above it. The carpal spine reaches halfway to the extremity of the spine on the upper margin of the propodus when the hand is flexed. The length of the carapace is $44.5 \mathrm{~mm}$; breadth, $69.5 \mathrm{~mm}$.; length of merus, $33 \mathrm{~mm}$.; length of chela, $47 \mathrm{~mm}$.; breadth, $15 \mathrm{~mm}$.; length of dactylus $25 \mathrm{~mm}$.; length of carpal spine, measured from the anterior border of the carpus, $10.5 \mathrm{~mm}$.

If these differences prove to be constant in specimens from this region the form may be called Achelous brevimanus."

Portunus (Achelous) stanfordi Rathbun.

Portunus (Achelous) stanfordi Rathbun, Proc. Washington Acad. Sci., vol. 4, p. 282, pl. 12, fig. 11, 1902 ; Proc. U. S. Nat. Mus., vol. 38, p. 578, 1910.

This species was apparently named in honour of the Hopkins-Stanford Galapagos Expedition, by which it was discovered.

Diagnostic characters.-One prominent spine on the merus of the fifth legs. Carapace with the frontal border more prominent and the ridges and rugosities more pronounced than are those of the closely related species Portunus minimus.

Type.-The type material consisted of two males and three young specimens taken on the reef north of Tagus Hill, Tagus Cove, Albemarle Island, Galapagos, by the Hopkins-Stanford Expedition, and deposited in the United States National Museum.

Galapagos distribution.-Tagus Cove, Albemarle Island (type-locality); off Hood Island, Arcturus station 54, depth 15 feet. Islands.

General distribution.-This species is known only from the Galapagos

Technical description.-Carapace $13.5 \mathrm{~mm}$. long; $22.5 \mathrm{~mm}$. wide from tip to tip of lateral spine; interorbital space $7 \mathrm{~mm}$. wide. The carapace is covered with very fine hairs; along the margins these hairs are longer and are plumose. Beneath the hairs the carapace is covered with rounded granules, which form rows of beading along the margins of the spines. The ridges and rugosities of the carapace are very pronounced; two, one behind the other, traverse the mesogastric region; the cardiac region is strongly delineated and unusually high, appearing as two lobes, forming a heart-shaped protuberance; the inner area of the branchial region is emphasized by two rounded tubercles, the anterior of which is contiguous with a prominent ridge that curves out toward the lateral 
border and forms a slender beaded median rib on the lateral spine. Behind the second tubercle there is a short prominent ridge. The interorbital border is prominent and is divided into eight teeth; the inner four are subequal, triangular; the inner pair a little longer and are slightly narrower at the base than the outer and are separated from each other by a V-shaped sinus and from the outer pair by a U-shaped sinus; the outer four teeth are quite small, blunt, two situated above each antenna, separated from each other by a shallow concavity and from the inner four by shallow V-shaped sinus. The superior orbital margin

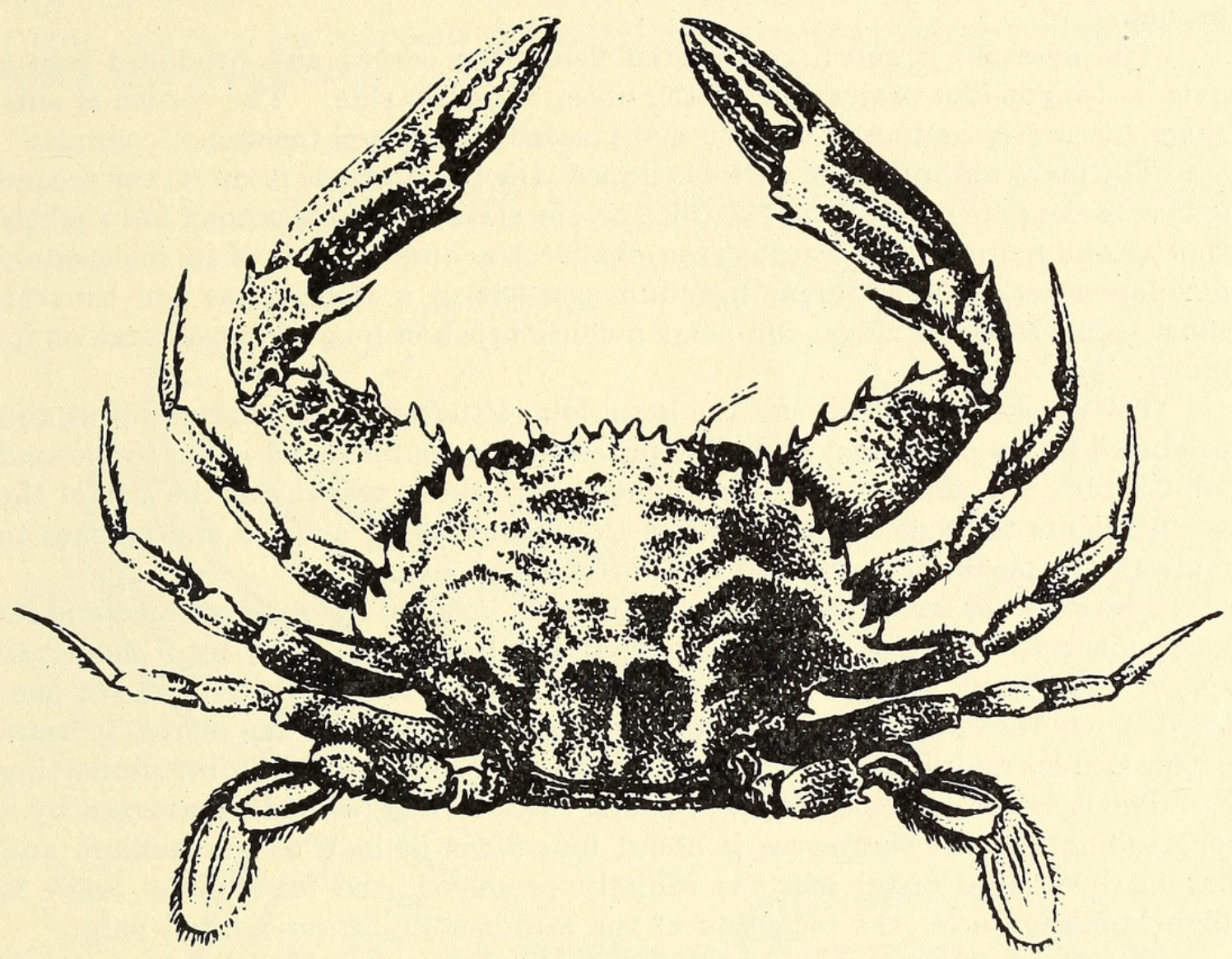

Fig. 60. Portunus (Achelous) stanfordi, $\times 1 \frac{1}{4}$ (After Rathbun).

is finely granulate, fringed with plumose setae and broken by two fissures, the inner of which is linear, the outer is $\mathrm{V}$-shaped and has its inner angle produced.

The inner suborbital tooth is very prominent and is produced as far as the median pair of frontal teeth. The outer sinus is small, V-shaped. The postorbital tooth is well developed and is equal to the teeth of the anterolateral margin of which there are seven in addition to the postorbital; all are decidedly forward-directed and have the short anterior margin coarsely beaded, and the long, convex outer margin finely granulose; the first and second teeth are subacute, the remaining six are acute. The second, fourth and sixth teeth are smaller than the others, and decrease in the sequence named; the fifth tooth is the widest of the series. The ninth or lateral spine is about two and three-fifths as long as the eighth spine and is very acuminate, ribbed by a beadlike ridge and directed outward and upward. The posterior margin is carina-like. 
The male abdomen is triangulate, five-segmented, the third segment being composed of three fused segments. The first pair of male appendages are paired, slender, tapering rods.

The female abdomen is broadly subtriangulate with the lateral margins of each segment forming a separate curve; it is six-segmented; the terminal segment is much smaller than any of the preceding segments. The four pairs of biramose appendages are long and heavily fringed. Each appendage consists of a short basal joint, a two-jointed inner branch and a slightly longer outer branch.

The eyestalk is short, constricted below the cornea and produced into a narrow tongue-like projection on the outer (frontal) side. The cornea is subspherical and is composed of very many small, hexagonal facets.

The inner antennae are well-developed; the basal article is short; the second article is elongate cylindrical; the third article is similar to the second but slightly shorter and more dilated distally; the smaller flagellum consists of six moderately developed articles; the larger flagellum consists of a stout basal and thirteen short stout, tapering rings, and bears a dense brush of long plumose setae on its under side.

The external antennae has the basal joint situated in the orbital hiatus and produced into a prominent node-like process on its outer distal joint; the second joint is long and slender; the third joint is only about two-thirds the size of the second joint; the flagellum consists of thirteen tapering articles and reaches to midway the posterior margin of the postorbital tooth.

The external maxilliped is very setigerous both on its outer surface and its inner margin. The two halves are separated from each other by a moderate space. The basal joint is short; the second joint of the exognath is about onethird as wide as long, and reaches to the outer distal angle of the merus; it bears a very slender multiarticulate palp which is nearly as long as the joint supporting it. The ischium is subrectangular, about twice as long as wide, traversed by a longitudinal sulcus; the merus is about four-fifths as long as the ischium and has its inner and distal margins roundly produced; the inner distal angle is slightly excavate for the reception of the rather stout, three-jointed palp.

The chelipeds are equal in both sexes. The three proximal joints are small but strongly developed; the merus is approximately as long as half the width of the carapace and furnished with five acute spines along the anterior margin; the proximal two of which are weaker. The upper posterior margin of the merus is rough with denticle-like granulations and there is a larger, sharp spine at the outer distal angle; the carpus is convex on its outer surface and traversed by two curved lines of beading; the outer distal angle is produced into an acute spine and the inner distal angle is produced into a very long sharp spine which is about three and a half times as long as the one on the outer angle. The propodus is about one-third longer than the merus, the fingers comprising almost one-half of this length; the palm is carinated on both its upper and lower margins; the upper carina terminating distally in an acute spine. Two more longitudinal carinae composed of denticle-like tubercles traverse the outer surface of the palm, the areas between, above and below the carinae being somewhat concave and finely setigerous. There is another acute spine on the 
upper, outer proximal part of the palm, adjacent to the distal angle of the carpus. The fingers are subequal, long and slender, with the tips curved and crossing. The cutting edges are serrated with alternately large and small teeth, which fit closely upon each other; the upper finger bears a greatly enlarged, blunt basal tooth. Both fingers are fluted on the outer surface by carinae.

The first, second and third ambulatory legs are similar, slender, with long, acuminate, fluted dactyli, and decrease in length in the order named. The fifth pair of legs have a prominent spine on the posterior subdistal margin of the merus, and have the propodus and dactyl flattened into oval swimming paddles which have fringed setae.

\section{Portunus (Achelous) angustus Rathbun.}

Portunus (Achelous) angustus, Rathbun, Proc. Nat. Mus., vol 21, p. 594, pl. 44, fig. 2, 1899; Proc. Washington, Acad. Sci., vol. IV, p. 287, 1902; Proc. U.S. Nat. Mus., vol. 38, p. 578, 1910.

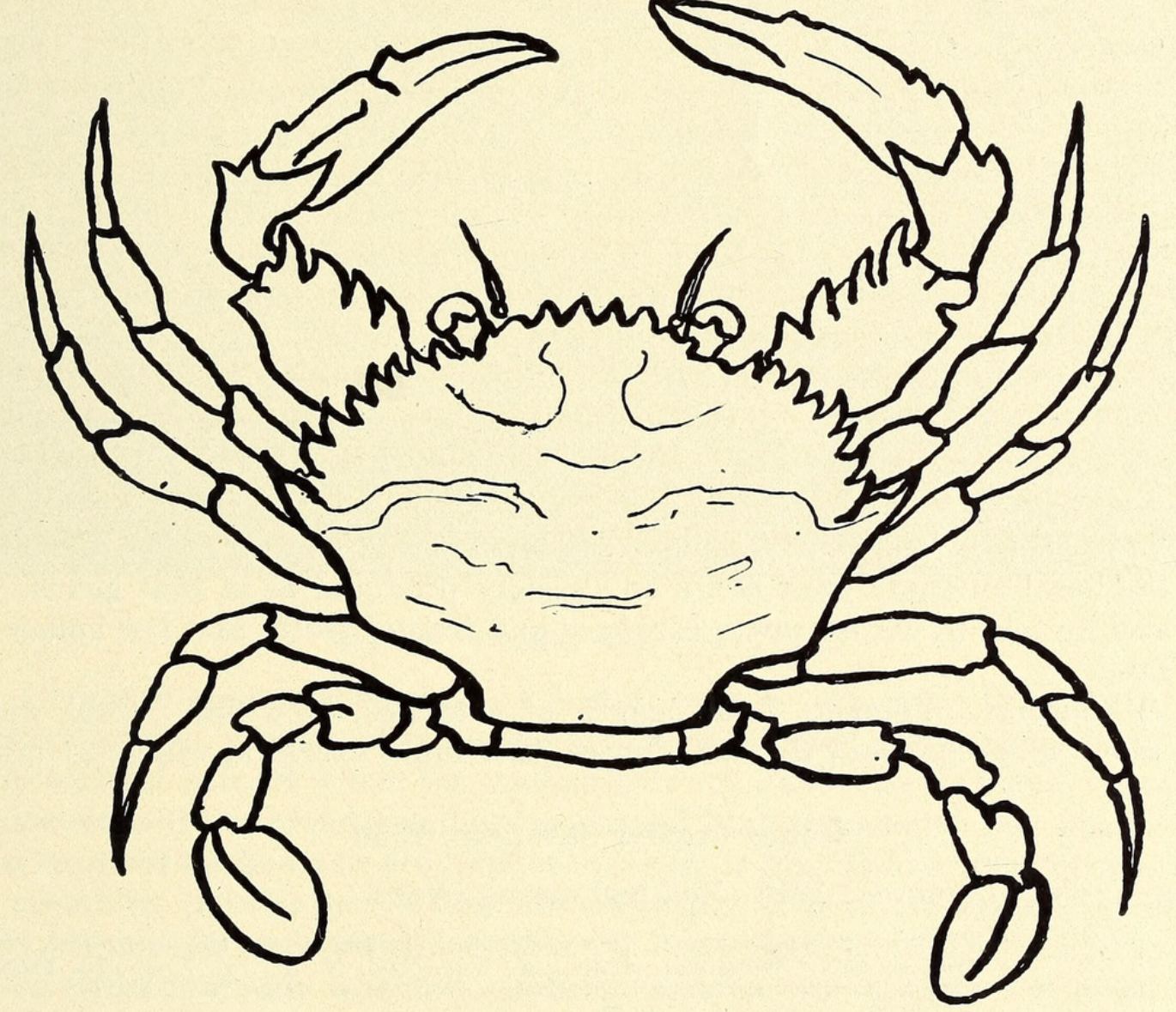

Fig. 61. Portunus (Achelous) angustus, $\times 1 \frac{1}{2}$ (After Rathbun).

Diagnostic characters.-Front advanced, 8-toothed; lateral teeth alternately large and small; lateral spine only slightly longer than seventh tooth; a spine at posterior distal angle of merus of swimming feet.

Type.-One female taken off Hood Island, Galapagos, 20 fathoms, Albatross station 2812, which is deposited in the United States National Museum.

Galapagos distribution.-One female taken off Hood Island, Galapagos, Albatross station 2812. 
General distribution.-One female taken off Hood Island, Galapagos.

Material examined.-None.

Color.- "Although this crab has been for a long time in alcohol, it seems to be of a reddish hue. The basal half of the fingers is red, the next quarter is white, the remainder is brown, except the tips, which are white." (Rathbun.)

Technical description.-(After Rathbun): "Carapace narrow, pubescent except upon the transverse granulated lines; in shape resembling Portunus ordwayi (Stimpson). Front advanced; four middle teeth subacute, the outer pair broader at base than the inner, and separated from the inner pair by wider sinuses than the median sinus, and from the supra-antennal angle by a deep V-shaped sinus. Supra-antennal lobe bidentate; teeth acute. Antero-lateral teeth alternately large and small, the last tooth or lateral spine very little longer than the seventh. The inner suborbital tooth is acute and equally advanced with the second pair (reckoning from the middle) of frontal teeth; there are no teeth on either side of the outer orbital fissure.

The merus of the cheliped of the type specimen, a female, has four spines on its inner margin, graduated from a large one near the distal end to a small one near the ischium; a very small spine on the outer margin at the distal end. Carpus with a small external distal spine and a long inner spine reaching, when the arm is flexed, to the spine next to the smallest on the merus. The hand has two large spines, one next the carpus and one on the superior margin at one-third its length from the dactylus. The ridges on the carpus, propodus, and dactylus are very coarsely granulated with acorn-shaped granules. The depressions are pubescent. The extero-superior surface of the merus is crossed by a longitudinal ridge. The inferior margin of the merus of the left natatory foot is armed with a sharp spine near the distal end; on the right foot there are two smaller spines in the same position.

This species has considerable resemblance to Charybdella (= Cronius), but the basal antennal joint is not so strongly produced as in that genus. It can also be told by its narrower carapace and frontal teeth, and few spines on the hand.

Dimensions.-Female: Total length of carapace, $25.5 \mathrm{~mm}$.; total width $37.2 \mathrm{~mm}$.; width between the last sinuses, $33.5 \mathrm{~mm}$.; exorbital width, $21 \mathrm{~mm}$."

\section{Genus Cronius Stimpson, 1860}

Cronius ruber (Lamarck) 1818 (Red Swimming Crab).

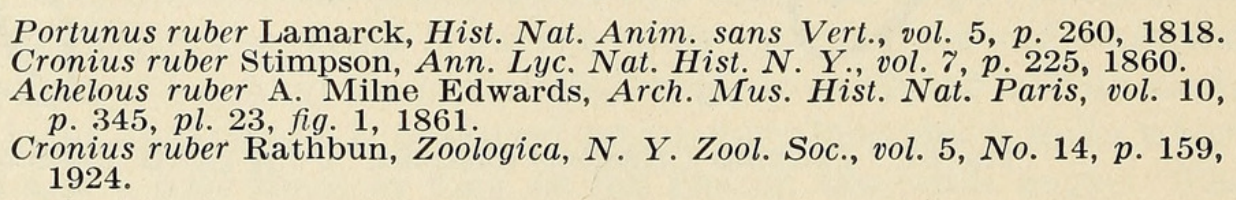

Diagnostic characters. - Carapace subcircular; postorbital spine wider basally than any of the succeeding anterolateral spines.

Type.-Lamarck's type which is believed to be no longer extant, came from the "Antilles."

Galapagos distribution.-Off Eden Island, 5 fathoms (Harrison Williams Expedition), three young specimens. 
General distribution.-This species ranges from Charleston, South Carolina, to Rio de Janeiro, Brazil, on the Atlantic coast and from Lower California to Ecuador on the Pacific coast.

Material examined.-One young specimen collected off Eden Island, in five fathoms, April 1, 1923, by the Harrison Williams Galapagos Expedition (tag 2075).

Technical description.- (The following notes were made from a young specimen which is only $6.5 \mathrm{~mm}$. long.)

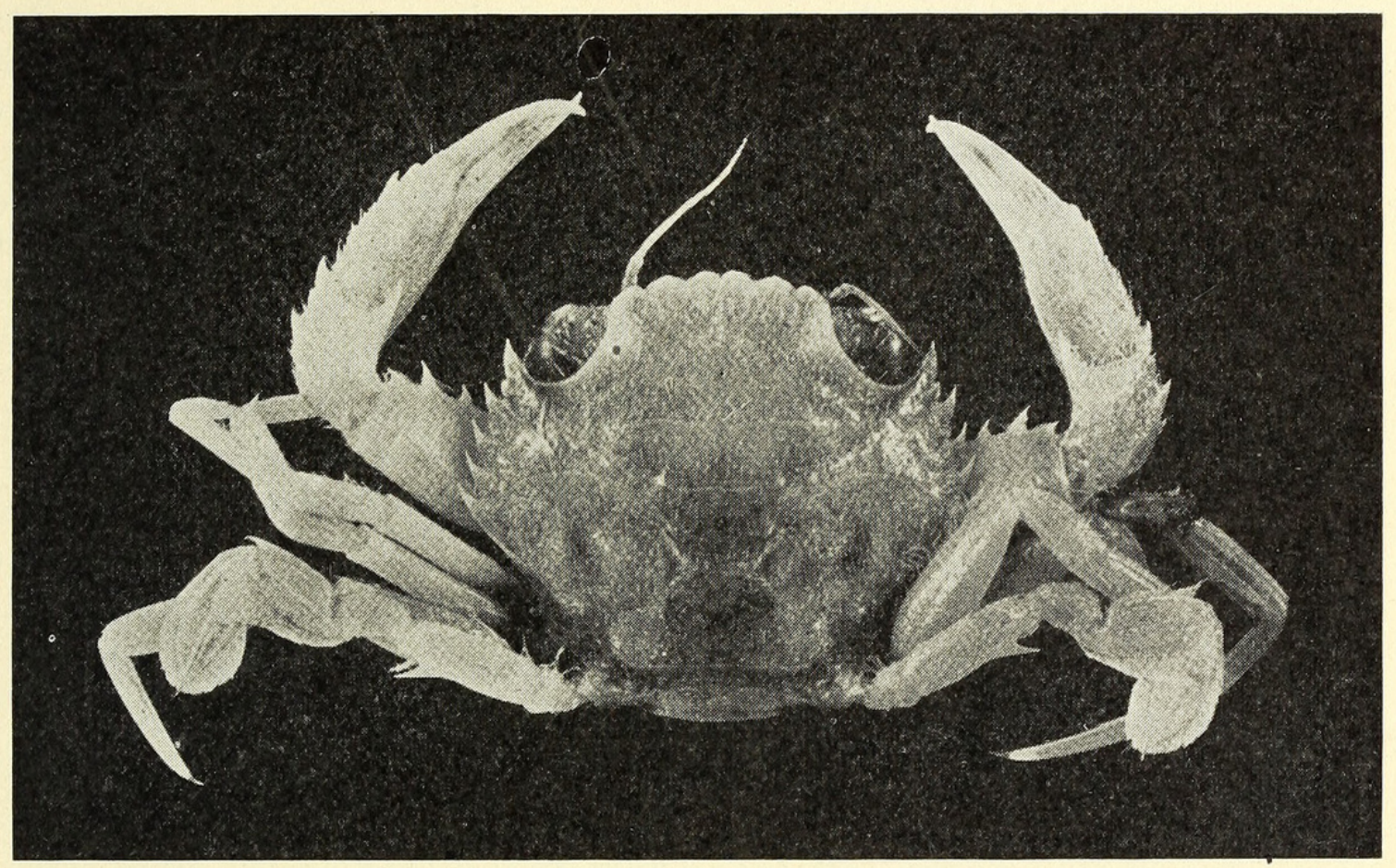

Fig. 62. Cronius ruber, young $\times 5$.

Carapace almost subcircular, $6.5 \mathrm{~mm}$. long, $7 \mathrm{~mm}$. wide from tip to tip of lateral spines. Interorbital space $3 \mathrm{~mm}$. wide, divided into six lobes including the preorbital pair, of which the median pair are smallest and closest together; the second pair are broader and are separated from the median pair by a wider sinus than the median pair are from each other, or than the second pair are from the preorbital pair, to which they are subequal. The entire frontal margin is finely crenulated and sparsely setigerous. The orbit is subelliptical; marked on the superior margin by three suture lines indicating sinuses. The outer half of the superior orbital margin is fringed like an eyelash. The postorbital spine is triangular, acute, wider basally than any of the other orbital spines; there is a small, inferior, blunt spine on the base of the posterior margin of the postorbital spine. The postorbital spine is followed by similar, subequal, acute, triangular spines, each of which is narrower basally than the postorbital spine. The first spine behind the postorbital spine bears a smaller rudimentary blunt tooth at the base of its posterior margin. All the anterolateral spines are forwarddirected. The dorsal surface of the carapace is finely setigerous. There is a 
beadlike line on the median gastric area behind and subparallel to the interorbital space. Another beadlike line curves inward between the bases of the third and fourth lateral spines and vanishes approximately opposite and posterior to the outer ends of the above-mentioned median gastric line. Both bear an anterior fringe of fine short setae. The postlateral margins of the carapace are convergent.

The cheliped has three large and two minute (basal) spines on its superior anterior margin; the carpus bears a strong, sharp spine at its inner distal angle, an obtuse, beaded outer distal angle, below which there is another sharp, subdistal spine which is followed posteriorly by a small, sharp spine on the upper surface of the carpus; the inferior distal angle of the carpus also bears a small sharp spine. The propodus is finely granulose; its inner upper margin bears two large acute spines one of which is almost midway its length, the other, smaller one is subdistal; a second carina of denticle-like tubercles extends along the outer margin and terminates in an acute subdistal tooth; the convex outer surface is traversed by three longitudinal carinae, the upper one is composed of sharp denticles and ends approximately above the base of the hinged finger; the second carina is composed of smaller granules and is approximately parallel to the upper one, but ends between the fingers; the third carina is the longest, extending almost to the distal end of the propodal finger. The fingers are subequal, comprising two-fifths of the propodal length; fluted on the outer surface; tips acuminate, crossing upon each other.

\section{Family: XANTHIDAE}

\section{Subfamily: XANTHINAE}

Genus Liomera Dana, 1851.

Liomera cocosana, $s p$. nov.

Name.-This species takes its name from Cocos Island, where it was first discovered.

Diagnastic character.-Carapace barrel-like, convex, anterolateral margins four lobed. Male chelipeds with black fingers and a heavy median black band on the propodus.

Type.-The type, an adult male and female specimen were taken at Cocos Island, May 9, 1925, by the Arcturus Oceanographic Expedition. It is deposited in the collections of the New York Zoological Society.

Galapagos distribution.-Arcturus station 54, Gardner Bay, off Hood Island, $15 \mathrm{ft}$., coral rock bottom.

General distribution.-Cocos Island and Hood Island, Galapagos Islands.

Technical description.-Carapace barrel-like, strongly convex in both directions; surface enamel-like, shining, with numerous rather coarse punctae irregularly scattered over the surface; the frontal margin is bilobed by a definite median notch and short sulcus, on either side of which it is sinuate forming a broad rounded submedian lobe which is succeeded by a less produced outer lobe which is almost right-angled and closely appressed to the eye-stalk. The anterolateral margin is divided into four rounded lobes of which the first, or 
postorbital is almost colaesced with the second lobe, only a short marginal sulcus which is scarcely visible dorsally indicating the division; the third lobe is more definitely rounded than the preceding one, from which it is separated by a decided sulcus which extends inward on the branchial region; the fourth lobe is slightly larger than the third from which it is separated by a sulcus similar to that between the second and third lobes; pösteriorly the fourth lobe is contiguous with the posterolateral margins which are decidedly concave

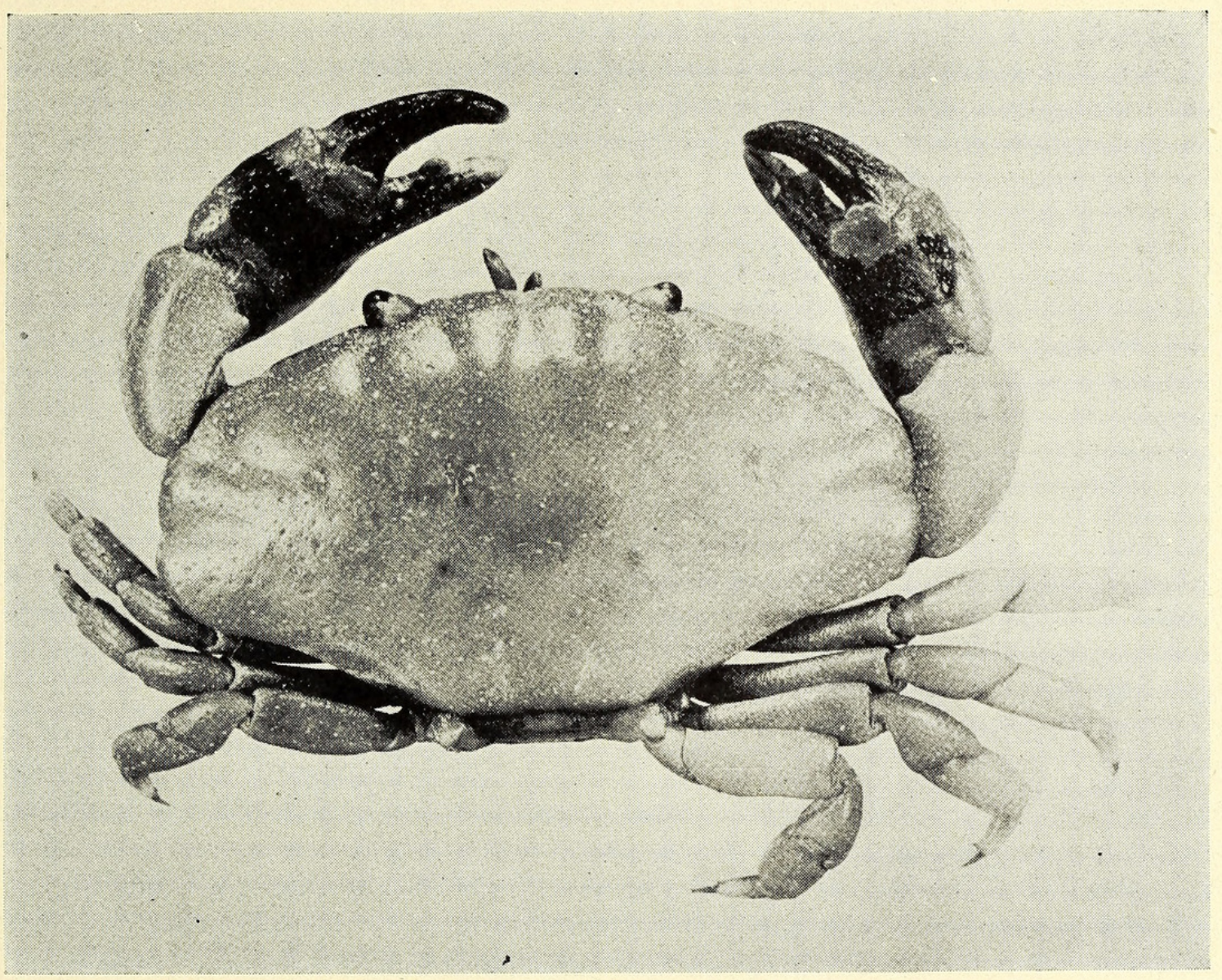

Fig. 63. Liomera cocosana, male $\times 3$.

and convergent. The male abdomen is five-segmented, the first and second segments being successively narrower but subequal in length; the third, fourth and fifth segments are anchylosed forming the third segment which narrows distally; the penultimate segment is squarish, half as long as the preceding segment; the terminal segment is triangular with the apex rounded. The female abdomen is broadly oval, seven-segmented, the sixth and seventh segments being the longest.

The superior orbital margin is closed, with two very faint suture lines indicating closed sinuses.

The eye-stalk is short and stout and produced distally on the inner side as far as the cornea, which latter is quadrispherical, shining black; apparently with a very limited range of vision. 
The antennulae are stocky and fold nearly transversely within the septum.

The antennae have the basal joint short and wide, tapering distally, just touching the frontal margin; the flagellum lies within the orbital hiatus. and extends almost to the distal margin of the eyestalk.

The external maxillipeds have the exognath half as wide as the ischium basally, tapering moderately distally to a point at the outer distal angle of the merus, and supporting a small slender multiarticulate whip, which is internal; the ischium is rectangular, two-thirds as wide as long, with a median longitudinal groove on the outer face, and with the distal margin slightly oblique; the merus is approximately half as long as the ischium, with the distal margin moderately oblique and the inner distal angle notched for the reception of the three-jointed palp which is stocky and $\mathrm{se}_{\llcorner}^{t}$ with numerous long setae.

The chelipeds are subequal in both sexes with the three proximal joints small, the merus much longer reaching almost to the outer edge of the carapace, trigonal; the carpus is almost as long as the merus with the upper and outer surfaces rounded; the propodus is distinctly the largest joint of the limb, the palm being somewhat longer and higher than the carpus, and having a proximal ball-like base separated from th rest of the palm by a sharply defined crescentic margin; the remaining outer surface of the palm is moderately convex with a longitudinal groove somewhat below the upper margin, and a second less pronounced groove approximately halfway the distance below the first groove; the propodal finger is about half as long as the palm and is quite slender and tapering, armed with a single median tooth on the cutting edge, and having a prominent groove on outer face which in the male extends back a short distance on the propodus. The hinged finger is somewhat thicker and more curved than the propodal and has two deep grooves on its outer surface.

The chelipeds of the male type, have both fingers a rich black, this color being continued from the base of the propodal finger backward on he palm for half its length and upward to the dorsal margin as a slightly narrowing band, on both the inner and outer faces of the propodus; a bright orange-red area separates this black band from the base of the hinged finger. In the female type only the fingers are black, the entire propodus being of the same color as the carapace. The female chelipeds seem a trifle less robust than those of the male.

The ambulatory legs are similar but successively decrease in length from the first to fourth pairs. Each has the meral, carpal and propodal joints stout and the dactyl slender, long, a little curved and banded with cream-color just before the tip which is black.

\section{Genus Leptodius A. Milne Edwards, 1863}

Key to the Galapagos species of the genus Leptodius

Anterolateral margin obtuse and rounded; postorbital and first marginal tooth obscure, coalesced; the second, third and fourth teeth are raised lobes. Carapace deeply areolated.

Anterorlateral margin broken into four well marked teeth, besides the postorbital tooth; carapace deeply areolated on the anterior two-thirds.

cooksoni.

snodgrassi 
Leptodius snodgrassi Rathbun.

Leptodius snodgrassi Rathbun, Proc. Wash. Acad. Sci., vol. 4, No. 8, p. 279 pl. 12, figs. 7 and 8, 1902; Proc. U. S. Nat. Mus., vol. 38, p. 582, 1910.

Name: This species appears to have been named for Mr. Robert E. Snodgrass, one of the naturalists of the Hopkins-Stanford Galapagos Expedition.

Diagnostic characters. - Frontal border bilaminar; anterolateral border with four well-marked teeth besides the orbital tooth; carapace deeply areolated on its anterior two-thirds.

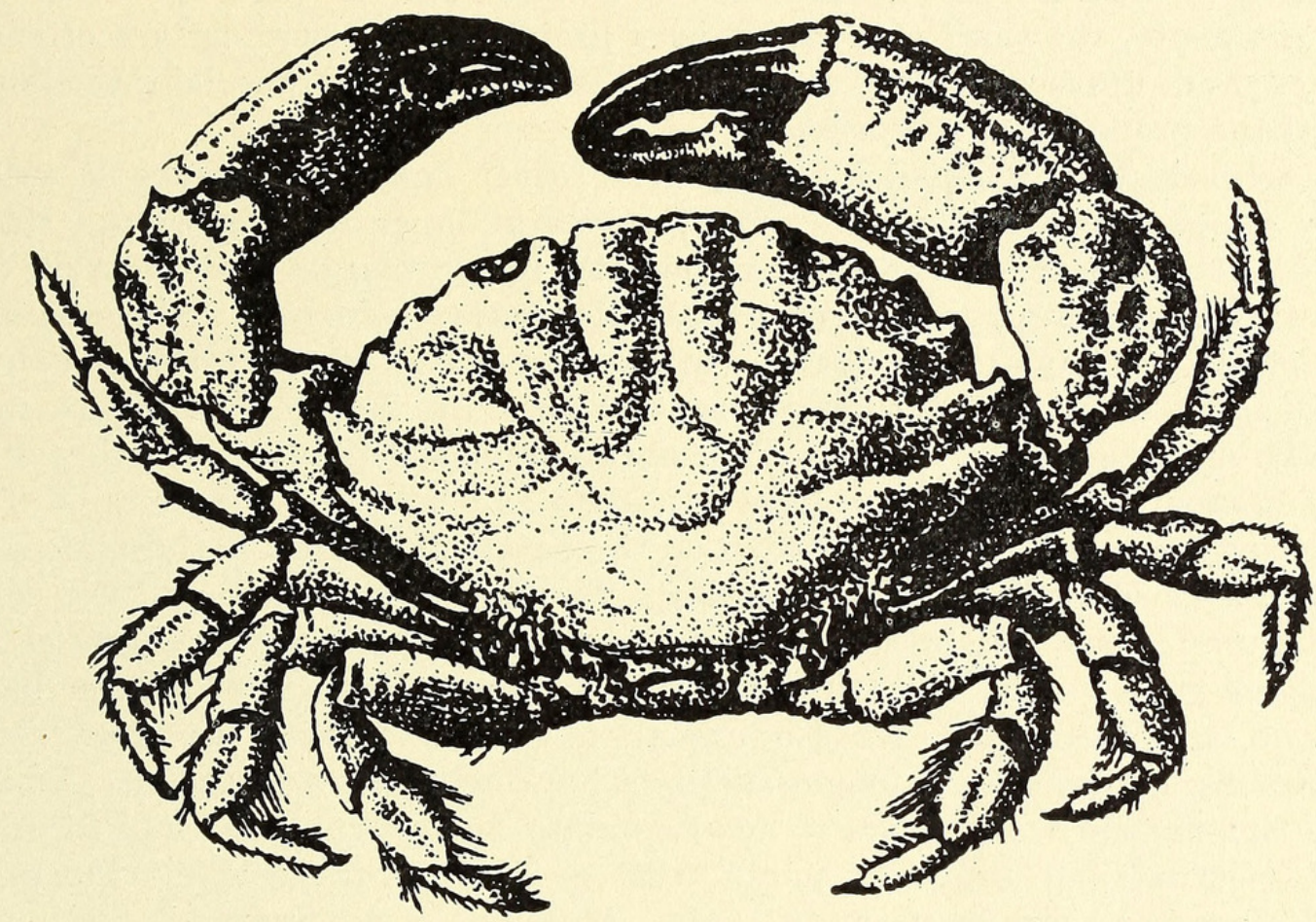

Fig. 64. Leptodius snodgrassi, $\times$ about 3 (After Rathbun).

Type.-The type of this species and a fragment of a smaller specimen was secured at Black Bight, Albemarle Island; one small cheliped of a small specimen was taken at Tagus Cove, Albemarle Island.

General distribution.-Known only from Galapagos.

Material examined.-None.

Technical description. - I have not been able to secure a specimen of this species for examination and am therefore quoting Dr. Rathbun's description of the type:

"Carapace moderately convex and deeply areolated in its anterior twothirds, flat and smooth in its posterior third. Behind each lobe of the frontal margin a small lobule; behind each of these a larger and very prominent rectangular lobule; still further back a transverse line of four high gastric lobules, the outer pair about one and a half times as wide as the inner; and behind these a granulated line of granules interrupted at the middle, across the widest part of the mesogastric region. The lateral portions of the carapace have each four prominent elevations, one of which is nodular and situated at the base of the fourth antero-lateral tooth, and three of which are surmounted by broad trans- 
verse ridges; of the three ridges the anterior is in a line with the third lateral marginal sinus, the second ridge is in a line with the fourth sinus, while the third is posterior to the last marginal tooth. Front not very prominent, but projecting beyond the inner angle of the orbit, from which it is separated by a notch; bilaminar, the lobes with a slightly concave margin, and most prominent at the inner end. Antero-lateral border cut into four well-marked teeth besides the orbital angle; the first tooth is blunt and situated below the level of the orbital tooth, with which it is connected by a blunt superior ridge; the remaining teeth are acute, the third and fourth very prominent. Lower surface of carapace, edges of upper surface of arm and edges of legs hairy, especially the lower edge of the propodus of the last pair.

Chelipeds very unequal in the male. Upper and outer surface of wrists deeply dimpled or wrinkled; a strong tubercle at inner angle of wrist. Hand with blunt longitudinal carinae, two on the upper margin and three on the outer surface. The upper carina of the outer surface is broad and has a row of deep pits or dimples; the lowest carina is at the inferior third of the outer surface and is continued along the upper margin of the thumb. The upper part of the inner surface is also pitted. The entire surface of the chelipeds as well as of the carapace is finely and closely granulate and irregularly punctate. The fingers are carinated, the lower carina on the outer surface of the thumb is continued one-third the length of the palm. The fingers are black and the color of the thumb is extended on the palm, ending in a zigzag line. The fingers of the large hand gape widely, those of the small hand slightly; dactylus of large hand with two large teeth and a small intermediate one; pollex with two large teeth; tips broadly hollowed out, fingers of small hand with wavy margins. Ambulatory legs flattened, and more or less granulate, the granules fine and forming rugae. Carpal and propodal joints with a longitudinal groove. Dactylus furred along the edges as far as the nail. Abdomen of male five-jointed."

"Dimensions.-Length $13.1 \mathrm{~mm}$. width 20.4, fronto-orbital width 11.8 , width of front 5.5."

Leptodius cooksoni Miers.

Leptodius cooksoni Miers, Proc. Zool. Soc. London, p. 73, pl. 12, figs.1-1d, 1877; Rathbun, Proc. U. S. Nat. Mus. vol. 38, p. 582, 1910.

Diagnostic characters. - Carapace finely punctate, anterior region distinctly areolated. Frontal margin bifid; anterolateral margins obtuse and rounded, the postorbital tooth and the first marginal tooth are obscure, coalesced, the second, third and fourth teeth are raised lobes.

Type.-Miers founded this species on an adult male and a smaller female specimen taken at Charles Island.

Galapagos distribution.-Charles Island (type-locality); Arcturus station 54, off Hood Island, depth 15 feet.

General distribution.-Known only from the Galapagos Islands and Cocos Island.

Material examined.-Seven females, three of which are ovigerous and nine males from Cocos Island; five males and six females taken at station 54, off Hood Island, by William Beebe, while diving in 15 feet, of water. 
Carapace ovate, convex, deeply areolated; regions clearly defined; $16 \mathrm{~mm}$. long, $27 \mathrm{~mm}$. wide; interorbital space one-third of width of carapace, with frontal margin raised, slightly produced and minutely bilobed in the median line; frontal edge arcuate with the angle near the orbit bent downward. The orbit is subcircular with an internal hiatus; the dorsal rim is raised. The anterolateral margins are broadly rounded, broken into five teeth, the first and second of which are long, obtuse, coalesced except for a faint dorsal constriction; third

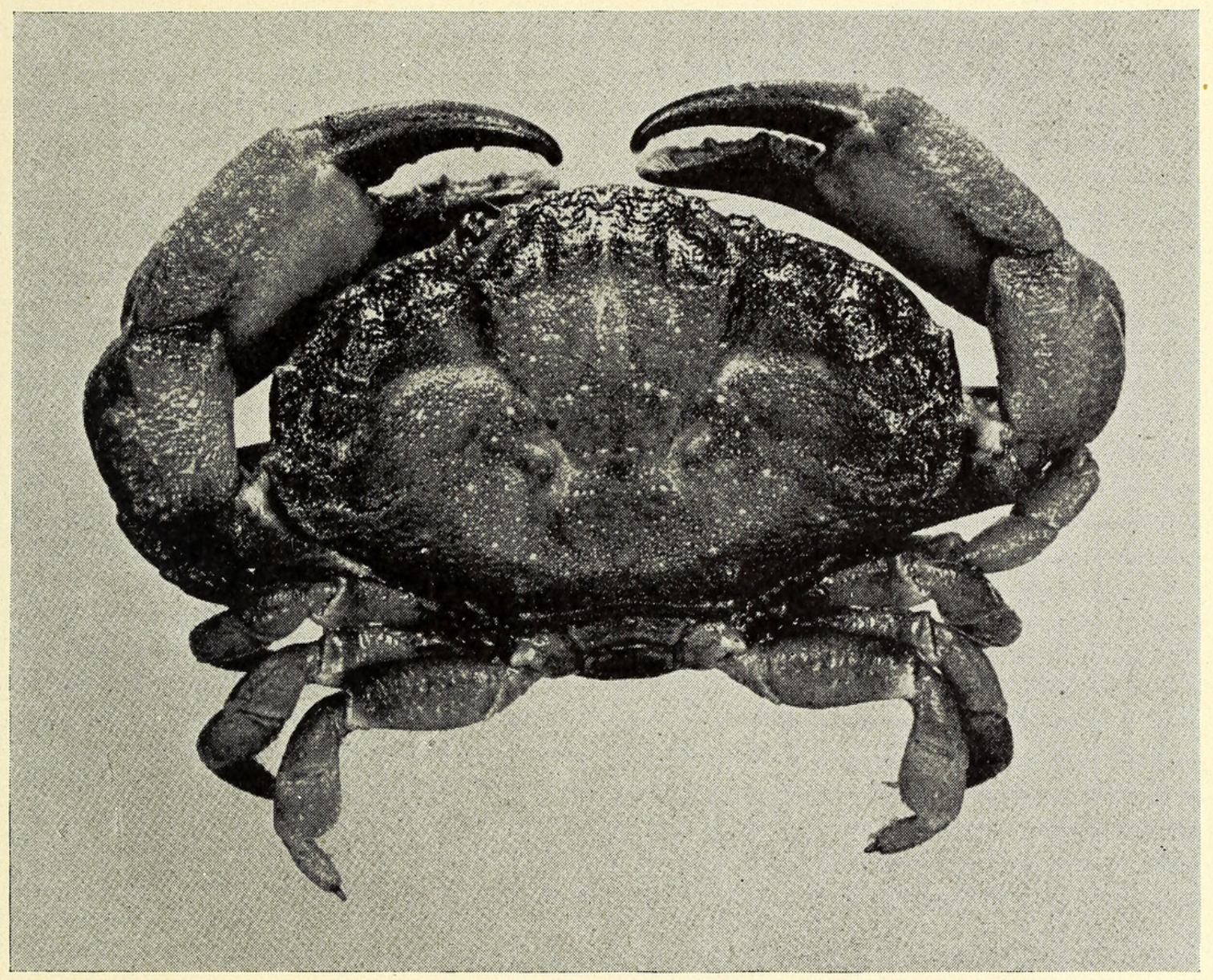

Fig. 65. Leptodius cooksoni, $\times 2$.

tooth is about as long as second, but is raised and produced anteriorly to a triangulate tooth; the fourth tooth is also raised to form a triangulate tooth but is not so wide as the third one; the fifth one is raised but is much less prominent than the preceding one. There is a groove-like line just inside these teeth paralleling the lateral margin, which accentuates the lobes of the carapace. The gastric region is delineated by deep grooves which run back from near the outer edge of the orbit to the join urogastric groove. The groove running back from the median frontal notch bifurcates to outline the mesogastric area. A short groove runs from the inner orbital angle back a short ways bilobing each half of the gastric region. A curved groove runs inward from between the second and third lateral teeth, the cervical groove-defining the hepatic 
lobe; a second groove runs inward from between the third and fourth teeth and fuses with the above described groove about midway its length. A more deeply delineated groove runs inward from between the fourth and fifth teeth and fuses with the urogastric depression, thus forming a complete transverse sulcus across the carapace. The postlateral margins are slightly arcuate, convergent. The posterior margin is a flat, raised carina; paralleling it, separated only by a narrow groove is a raised, slightly wider ridge which terminates into a rounded, low tubercle at each end.

The male abdomen consists of five segments; the first and second segments are narrow, dorsal in position; the second is one half as long as the first segment; the third, fourth and fifth segments are fused into one which is produced laterally at the basal end completely covering the sternum between the first and second legs, thence curving inward and narrowing as it goes forward, uniting with the sixth segment midway the basis of the second ambulatories; the sixth segment is squarish with the frontal border arcuate; the seventh segment is only about half as long as the sixth and forms a smal! triangle whose apex is blunt. There is a median longitudinal slit-like depression on the sternal plate, just a little in front of this apex of the abdomen. The first pair of male appendages are stout, basally curving inward and proceeding forward as strong, slender rods, laterally compressed and channeled on the inner side. This channel is margined on either side by a row of finely denticulate granulations; the tip of the organ is flattened, rounded and produced outwardly into a transparent, corneous, subspatulate process whose edge is finely crenulate. There is a long brush of setae on the inner margin of the rod near the base of this process. The second male appendages are very short, produced basally into a curious winglike process which is fringed outwardly with setae and continues distally as a fine curved rod that only reaches forward to the beginning of the rod of the first appendages.

The outer antennae have the basal articles closely fused with the epistome; the three free peduncular articles cylindrical, successively decreasing in size distally; the flagellum is minute, consists of eight tapering articles and reaches only to the base of the cornea. The first basal antennal segment forms a balllike movable aperture for the antennal gland - the free margin of this segment is finely setose and fits tightly upon the epistome when closed; when opened it reveals its inner wall and cuplike cavity.

The inner antennae are stout, clavate and fold obliquely within the septum. The orbit is subcircular; the eyestalk is dilated basally, constricted distally on the outer surface and its margin is finely granulate; on the upper surface the margin is produced into a rounded piece which projects on the cornea, is small, convex, elliptical, placed transversely at outer end of the stalk.

The external maxilliped is rectangular, close-fitting except for an irregularly shaped slit at the efferent aperture. The exognath has a very small base, a long rod-like merus and an internal whip. The endognath has a rectangular ischium marked by a longitudinal sulcus; a squarish depressed merus which has the outer distal angle somewhat produced and the inner angle deeply incised for the reception of the rotund basal joint of the three-jointed palp whose tapering second and third joints are bent downward beside the inner meral margin. The inner margin of the ischium, and the upper margin of the merus and the 
palp are fringed with setae. The outer surface of the maxilliped, especially of the merus, is finely granulose,- that of the merus is also setigerous.

The sidewalls of the carapace under the legs bear dense tufts of long plumose hairs.

The male chelipeds are moderately subequal, both being massive. The large cheliped has the basis and ischium small; the merus long, three-sided, exceedingly compressed laterally except at the distal end which is produced at its inner dorsal angle into a curious rounded socket-like process into which a knob of the carpus fits; a crooked sulcus round this process and extends inward on the inward side of the merus; the carpus is very prominent, swollen distally, rugose and convex on the upper and outer surfaces, and produced to a blunt knob at the inner dorsal angle; the propodus is massive, twice as long including the finger, as the carpus, and as high as the carapace; rugose on the dorsal and upper half of the outer surface, small on the lower; the finger is two-fifths the total length of the propodus, and tapers to a rounded point which is hollowed, spoon-shaped and bears a tuft of hairs in the concavity. In addition to this there are three small distal teeth and two large basal molars. The finger is slaty black and carinated longitudinally on the outer surface. The hinged finger is more curved distally but otherwise resembles the propodal except that it has only one very large molar which is followed by two medium sized and eleven insignificant teeth and a tuft of setae in the concavity of the spoon-tip. The fingers are gaping, except at the tips which fit perfectly upon each other. The inferior chela differs only from the superior in size and in having the fingers longer, slenderer not gaping; they comprise about one-half the length of the propodus.

The ambulatories are similar, subequal, gradually decreasing slightly in length posteriorly. The first pair has the merus arched toward the front, the second, third and fourth pairs curve posteriorly. The merus is the longest. joint and is compressed; the carpus and propodus taken together are about as long as the merus but are stouter and more dilated; the dactyl is slenderer, compressed cylindrical, tipped with a strong horny nail and covered with coarse setae, which also form a brush on the under margin of the propodus.

Genus Xanthodius Stimpson, 1859

Key to the Galapagos species of the genus Xanthodius

Anterolateral margin deeply quadridentate.

occidentalis

Anterolateral margin divided into four prominent lobules; carapace deeply lobulated, sulci between the lobules deep and wide.

lobatus

Xanthodius lobatus (A. Milne Edwards). One of the group known as "pebble" crabs.

Leptodius lobatus A. Milne Edwards, Crust. Rég. Mex., p. 271, pl. 49, fig. 4,1880 .

Xanthodius lobatus Rathbun, Proc. U. S. Nat. Mus., vol. 38, p. 582, 1910; Zoologica, N. Y. Zool. Soc., vol. 5, no. 14, p. 158, 1924.

Diagnostic characters. - Carapace deeply lobulated, sulci between the lobules deep and wide. In life a broad band of contrasting color (white in preserved specimens) down the middle of the back. 
Type.-Professor Milne Edwards' type material came from the "coasts of Chile" and is deposited in the Paris Museum.

General distribution.-In addition to the type-locality, Chile, this species is known from the Galapagos Islands, Cocos Island, and Clarion Island, Mexico.

Material examined.-One female and six males from Station 54, off Hood Island, taken by William Beebe, while diving in 15 feet of water; five males and

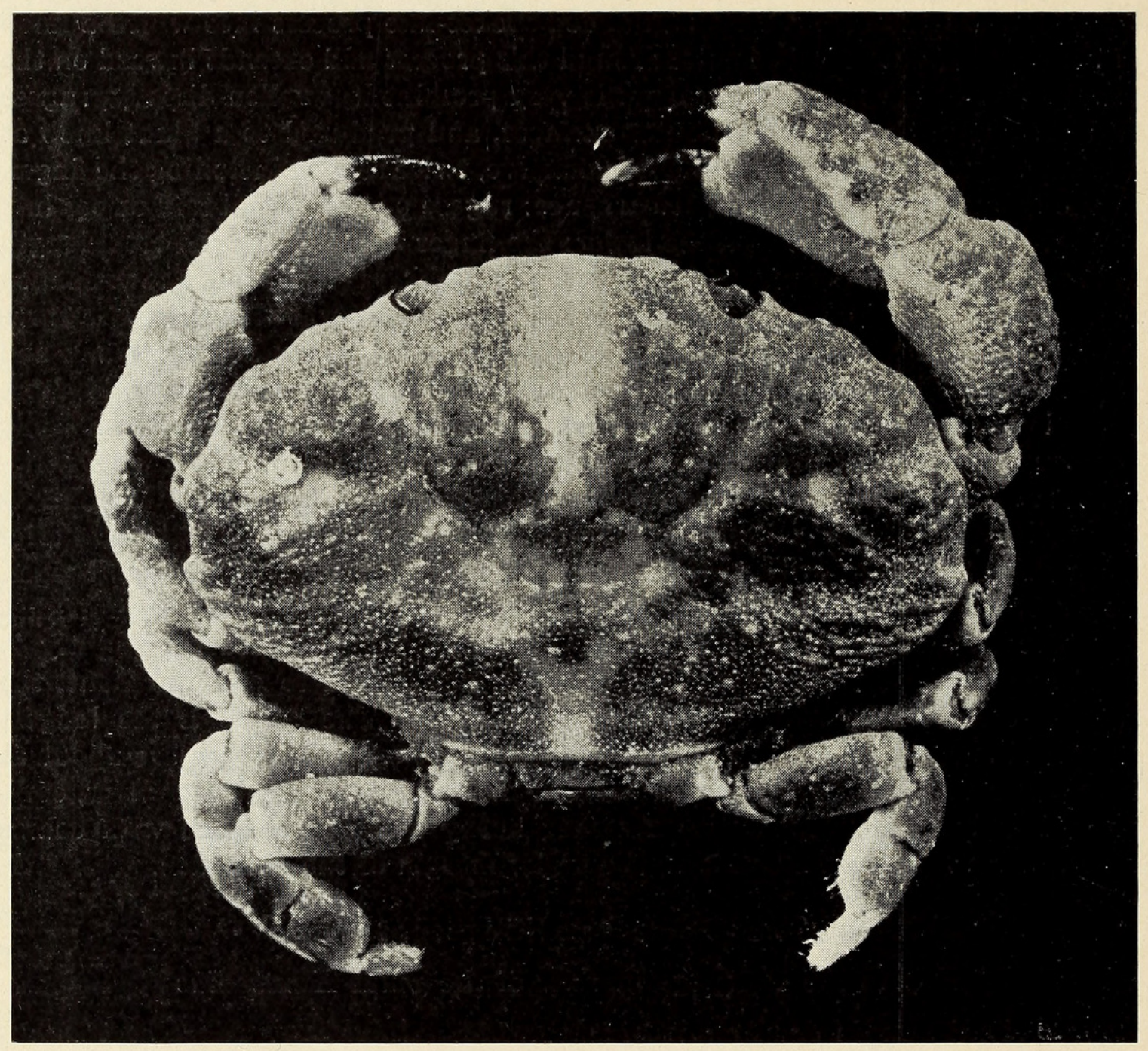

Fig. 66. Xanthodius lobatus, $\times 4 \frac{1}{4}$.

six females (one of which is ovigerous) also one fragment, from Cocos Island; one female (photographed, fig. 66) from Station 37, shore zone, D to E, Tower Island, April 10, 1925.

Habits.-This species dwells in the crevices of the coral rock bottoms.

Technical description.-Carapace $11 \mathrm{~mm}$. long, $17.6 \mathrm{~mm}$. wide, very convex and deeply lobulated with the depressions between the lobes deep and wide. Interorbital border $6 \mathrm{~mm}$. wide, deflexed, sinuate, carinated and separated from the median lobes by a sinuate depression which is confluent with a median groove that runs back posteriorly between the median lobes and bifurcates 
outlining the mesogastric region. There is a deep longitudinal sulcus bisecting each median lobe, which is confluent with a curved sulcus behind the raised superior orbital margin. The cervical grooves are very deep, they arise behind the eye, bisect the postorbital sulcus, outline the outer pair of median lobules and converge with the grooves delineating the cardiac region. The anterolateral border is divided into four prominent lobes; the hepatic lobe is moderately developed; the second lobe is a trifle larger; the third lobe is the largest and most prominent; the fourth lobe is small and somewhat pointed. Subparallel to the anterolateral margin are a series of pit-like depressions which accentuate the rugose appearance of the first, second and third lobes. A curved depression passes inward from between the first and second lateral lobes and unites with the postorbital depression. A second broken depression passes inward from between the second and third lateral lobes and unites with the cervical groove. A more incisive depression passes inward from between the third and fourth grooves, and uniting with the urogastric groove, forms a complete transverse depression across the carapace. Two short oblique grooves cross the third lobe uniting with the second and third grooves and cutting the third lateral lobe into three lobes. Posterior to the fourth lateral tooth are three or four granulose striae, separated by short, broken depressions. The posterior margin is sinuous, granulose, carinated, paralleled by a groove followed by a second, broken raised carina. The under sides of the carapace are heavily granulose.

The female abdomen is oval, rather narrow, seven-segmented and fringed with short thick setae. The first and second segments are visible dorsally and are rather narrow; the third, fourth and fifth segments are a trifle longer than the second and are subequal; the sixth segment is one and one-half times as long as the fifth; the seventh segment is about two-thirds as long as the sixth and has its anterior margin bluntly rounded. The second to fifth segments inclusive respectively bear paired biramose appendages to which the eggs are attached. The outer branch is curved; the inner branch consists of a basal joint which is obliquely directed toward the center and which supports a sixsegmented joint which is forward-directed and heavily fringed.

The male abdomen is narrow, triangulate and consists of five articulations, the third articulation being composed of three anchylosed segments; the terminal segment is rounded distally.

The first pair of male appendages are very stout basally tapering into a substantial rod which is grooved on its outer surface, each raised edge, or side, of the groove being finely serrate; distally the process widens into a spoonlike process which is convex and heavily spinose on its under side, produced to a twisted tip distally, and concave on its upper surface, this concavity being confluent with the groove of the rod.

The eyestalk is short and bulbous, filling the orbit; constricted on its upper surface and produced distally into a small rounded process on the dorsal surface of the cornea; the cornea is small, terminal, scarcely deep enough to be called hemispherical.

The internal antennae are large and fold obliquely with the fossett which lies beneath the frontal border; the basal article is very large and of a peculiar 
shape; the two succeeding articles are cylindrical, the terminal one is swollen distally and bears the small two-branched flagellum.

The external antennae are situated in the inner inferior orbital hiatus; the immovable joint is subrectangular, twice as long as wide; the first free joint is very small, cylindrical, transversely constricted on its outer surface; the second free joint is also cylindrical, and scarcely larger than the flagellum; the latter consists of fourteen tapering articles, and extends only to the base of the cornea.

The external maxillipeds are rectangular, being one-fourth wider than long, and fit closely into the buccal cavity. The ischium is subrectangular and is traversed on its outer surface by a deep longitudinal groove; the merus is half as long as the ischium, but is wider distally with the outer distal margin produced; the outer surface is grooved irregularly; the inner distal margin of the merus is notched for the reception of the palp; the latter has the basal joint stout, the second and third joints being successively smaller and tapering to a point which bears an unusually long brush of setae. The inner margin of ischium and merus are setose; their outer surfaces are very granulose and finely setigerous.

The chelipeds are equal and are alike in both sexes. They fit closely against the sides of the carapace. The upper and outer surfaces of the meral, carpal and propodal joints are convex and deeply pitted and granulose, having a coarse, eroded appearance. The upper edge of these three joints is sharply ridged, the inner surfaces being flat, fairly smooth and closely appressed to the body. The basal three joints are small; the meral joint does not extend beyond the carapace; the carpal joint is quite large, being nearly as long as the palm, and is produced to a sharp angle on its inner subdistal margin. The palm is high, angulated on its upper margin, eroded on its upper surface and the upper half of its outer surface and coarsely granulose on the lower half of the outer surface, there being three or four longitudinal carinae composed of granules in this region. Both fingers are deep brownish black; are spoon-shaped at the apex and fit upon each other; the cutting edges nearly meet. The propodal finger is about one-third of the length of the propodus and is longitudinally traversed by continuations of the two lower carinae of the propodus; there are three large teeth on the cutting edge, the median one being the most prominent. The hinged finger is similar to the propodal but is more curved; it is traversed by two deep sulci, the more prominent of which is on the upper surface. There are three shallow triangulate teeth on the cutting edge, all being inferior in size to those of the propodal finger. Within the concavity of the spoon-like apex of both the propodal and hinged fingers there is a round cavity from which arises a tuft of long bristly setae.

The four pairs of ambulatory legs are similar, rather short and stubby. The first three pairs are subequal in length; the fourth pair is smaller, reaching only to the distal part of the propodus of the third pair. All have the basal three joints small, the meral, carpal and propodal joints stout, compressed cylindrical, and granulose on the outer surfaces; the dactyl is compressed cylindrical also, and as long as the propodus, terminating in a sharp spine. The dactyl is covered with short, furry setae in which long spinose setae are sparingly interspersed. 
Eggs.-A female $8 \mathrm{~mm}$. long carried about 340 eggs. These were pale yellow spheres.

Young.-Young specimens of Xanthodius lobatus $3.7 \mathrm{~mm}$. wide show only faint indications of the lobed carapace, but may be identified by the chelae, which correspond to those of the larger adults. Specimens 6 to $8 \mathrm{~mm}$. wide show clearly all the characteristics of the larger specimens, except that the smaller ones are finely granulose and lack the eroded appearance of the older forms.

Xanthodius occidentalis (Stimpson).

Chlorodius occidentalis Stimpson, Ann. Lyc. Nat. Hist. N. Y., vol. 10, p. $108,1871$.

Leptodius occidentalis, A. Milne Edwards, Crist. Rég. Mex., p. 269, 1880; Rathbun, Proc. U. S. Nat. Mus., vol. 21, p. 589, 1899.

Xanthodius occidentalis, Rathbun, Bull. American Mus. Nat. Hist., vol. 48, p. 622,1923 .

Diagnostic characters. - Lateral margin quadridentate (in addition to postorbital tooth); anterior two-thirds of carapace deeply areolated and lobulated.

Type.-Professor Stimpson's type material was "found at Panama by Alexander Agassiz, Esq., and at Manzanillo, Mexico, by Mr. John Xantus."

Galapagos distribution.-Galapagos Islands.

General distribution.-Manzanillo, Mexico; Aqua Verde Bay and Pichilinque Bay, Lower California; Panama and the Galapagos Islands.

Material examined.-One specimen from station 54, Gardner Bay, off Hood Island, Galapagos Islands, in 15 feet of water.

Technical description.-Carapace $17 \mathrm{~mm}$. long; greatest width $25 \mathrm{~mm}$; decidedly convex, deeply areolated and lobulated between the areolations. The frontal border is equal to a little more than one-third the width of the carapace and is relatively straight and not produced in advance of the lateral teeth. A small median notch separates the two frontal lobes; their outer angles are almost right-angled and separated from the preorbital angle by a V-shaped sinus; the superior orbital margin is elliptical and is cut by two lines indicating closed sinuses. The postorbital angle is a blunt triangulate tooth; a small submarginal hepatic tooth shows below the hiatus between the postorbital and first anterolateral tooth. The anterolateral margin is cut into four distinct teeth; the first (most anterior) tooth is three-fifths as wide as the orbit and is blunt; its anterior lateral margin being short, its posterior lateral margin long and rounded. The second tooth is of similar shape as the first and is the broadest of the series, being as wide as the long diameter of the orbit; the third tooth is almost as wide as the second tooth and is decidedly more acute, with its apex forward-directed and its longer postlateral margin rounded; the fourth tooth is also acute but is smaller than the third tooth and outward-directed, with a moderately carinated midrib running inward from the apex. The cervical, hepatic, cardiac and urogastric grooves are deep. There is also a groove running inward between the second and third teeth and another similar groove between the third and fourth teeth. A submarginal groove runs between the lateral teeth and the branchial lobules. The second and third lobules are also crossed by diagonal depressions. The posterior margin is carinated. The pterygostomian region is tomentose. The entire dorsal surface of the carapace is coarsely punctate. 


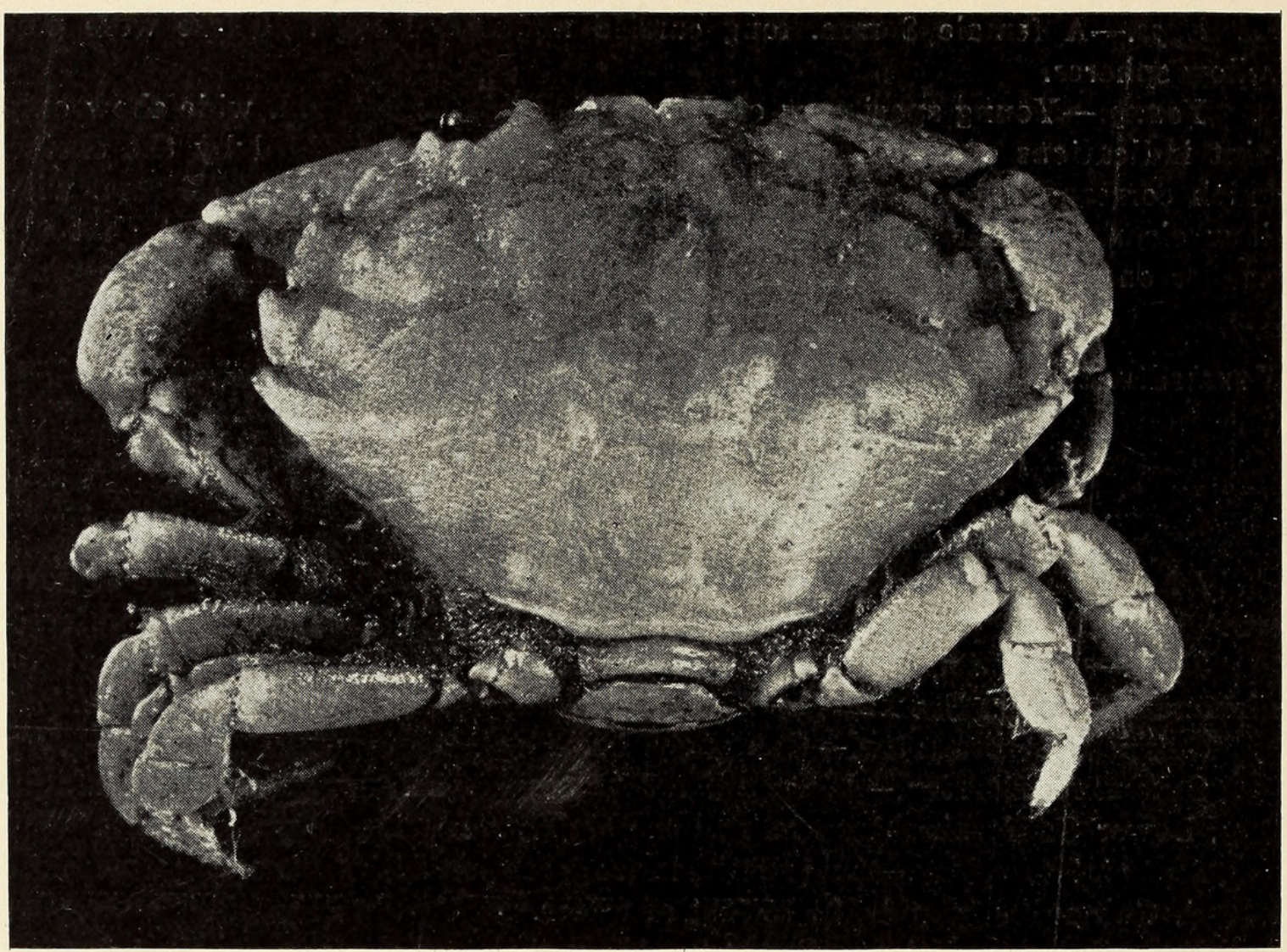

Fig. 67A. Xanthodius occidentalis, female, dorsal view $\times 2.8$.

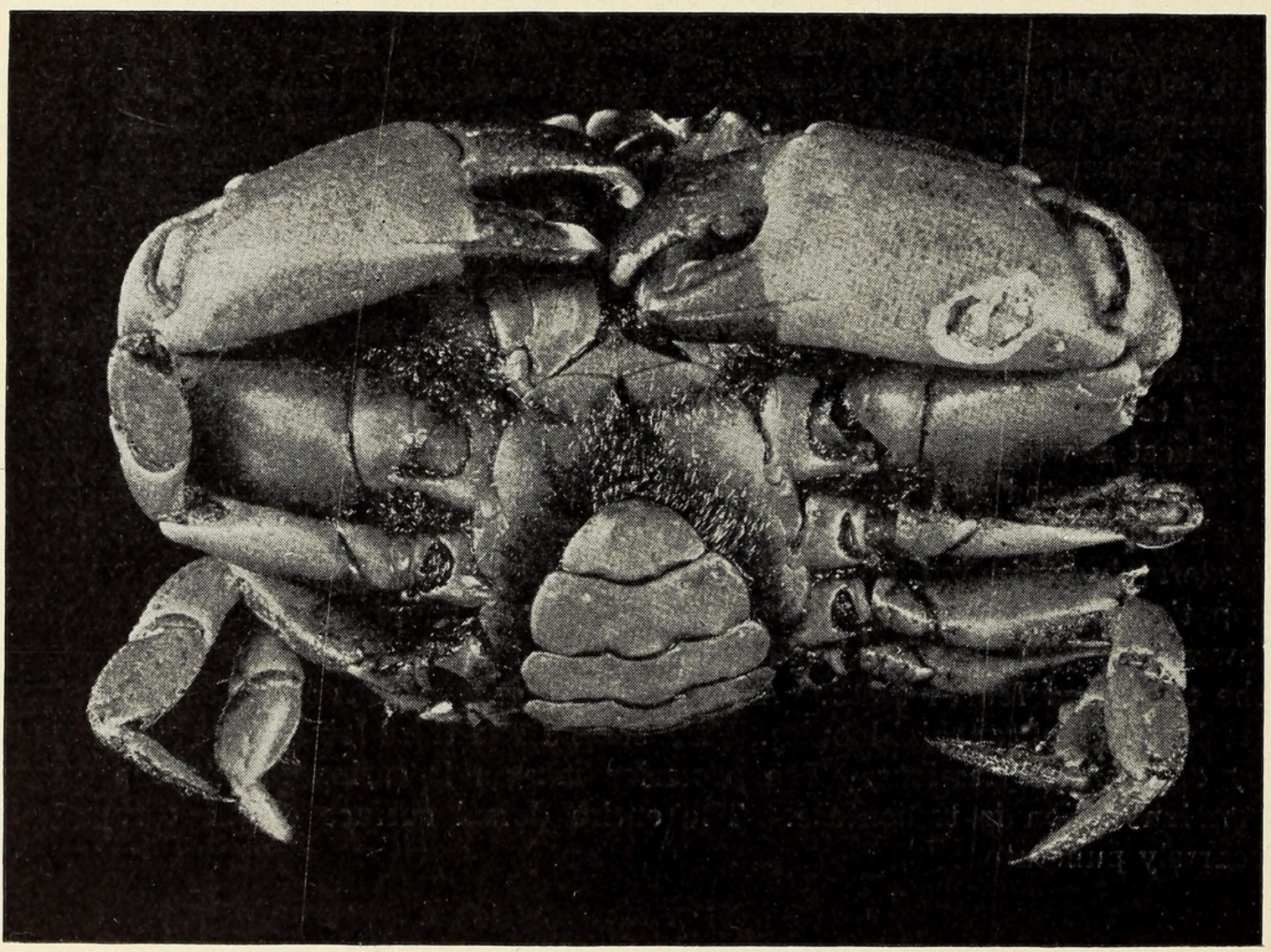

Fig. 67B. Same, ventral view. 
The eyestalk is short, cylindrical, constricted on the dorsal surface below the cornea and produced to a small subcircular process that extends upon the cornea; the cornea is subspherical, brownish-black.

The inner antennulae are well developed and fold within the fosett beneath the rostrum.

The external antennae have the basal article enlarged and closely fitted into the hiatus; the second and third articles are successively smaller; both are situated in the orbital hiatus; the flagellum is composed of eight tapering rings and extends to the base of the cornea.

The external maxillipeds offer no specific characters.

The chelipeds are slightly unequal in the female. The merus is trigonal, decidedly compressed on its dorsal surface, and curved; the carpus is quite convex dorsally, and areolated; there is an acute subdistal tooth at the inner distal angle; the propodus is long, convex on its outer face with the upper region a little roughened; the fingers are deep brown, subequal, curved, with the tips spoon-shaped. The propodal finger of the large cheliped has a large subdistal tooth.

The ambulatory legs are similar and successively decrease in length in the order 1, 2, 3, 4. Each leg has the merus, carpus and propodus dilated, the dactyl stout and covered with short bristles.

\section{Genus Cycloxanthops Rathbun, 1897}

Cycloxanthops vittatus (Stimpson) (Cameo Crab).

Xantho vittata Stimpson, Ann. Lyc. Nat. Hist., N. Y., vol. 7, p. 78, 1860.

Cycloxanthus vittatus A. Milne Edwards, Miss. Sci. au Mexico, p. 259, pl. 46, fig. 5, 1880 .

Diagnostic characters.-Frontal border equal to about one-fourth of the width of the carapace and very prominently projecting beyond the anterolateral border. Anterolateral margin with seven acute teeth; one smaller postlateral tooth.

Type.-Professor Stimpson's type material, which is no longer extant, "was found at Panama by the Rev. J. Rowell also abundantly at Cape St. Lucas by Mr. Xantus."

Galapagos distribution.-Off Hood Island, Arcturus station 54, from a depth of 15 feet.

General distribution.- Known only from the type material taken at Panama, and Cape St. Lucas, Lower California, and the material taken at Galapagos by the Arcturus.

Material examined.- One large female and four very young specimens were secured by William Beebe, while diving in 15 feet of water at station 54, off Hood Island, Galapagos. These specimens are deposited in the collections of the New York Zoological Society, New York City. They appear to be the first record of this species from the Galapagos Islands, and also the first capture of the species, since the type material, which is no longer extant, was taken.

Technical description.-Carapace ovate, moderately convex, regions clearly delineated, $12 \mathrm{~mm}$. wide, $10 \mathrm{~mm}$. long. Frontal border equal to about onefourth of the width of carapace, produced beyond the anterolateral border; 
very prominent; margin finely crenulate, minutely bilobed by a median indentation which is continued as a distinct groove back upon the gastric region. Orbit with four prominent subequal teeth forming the upper margin. Anterolateral margin with seven (in addition to the postorbital) unequal, acute, raised teeth. The first tooth is about as far behind the orbit as the width of the orbit and is acute; the second tooth is the largest of the series; the third is about equal to the first, but slightly sharper, the fourth tooth is only about half the

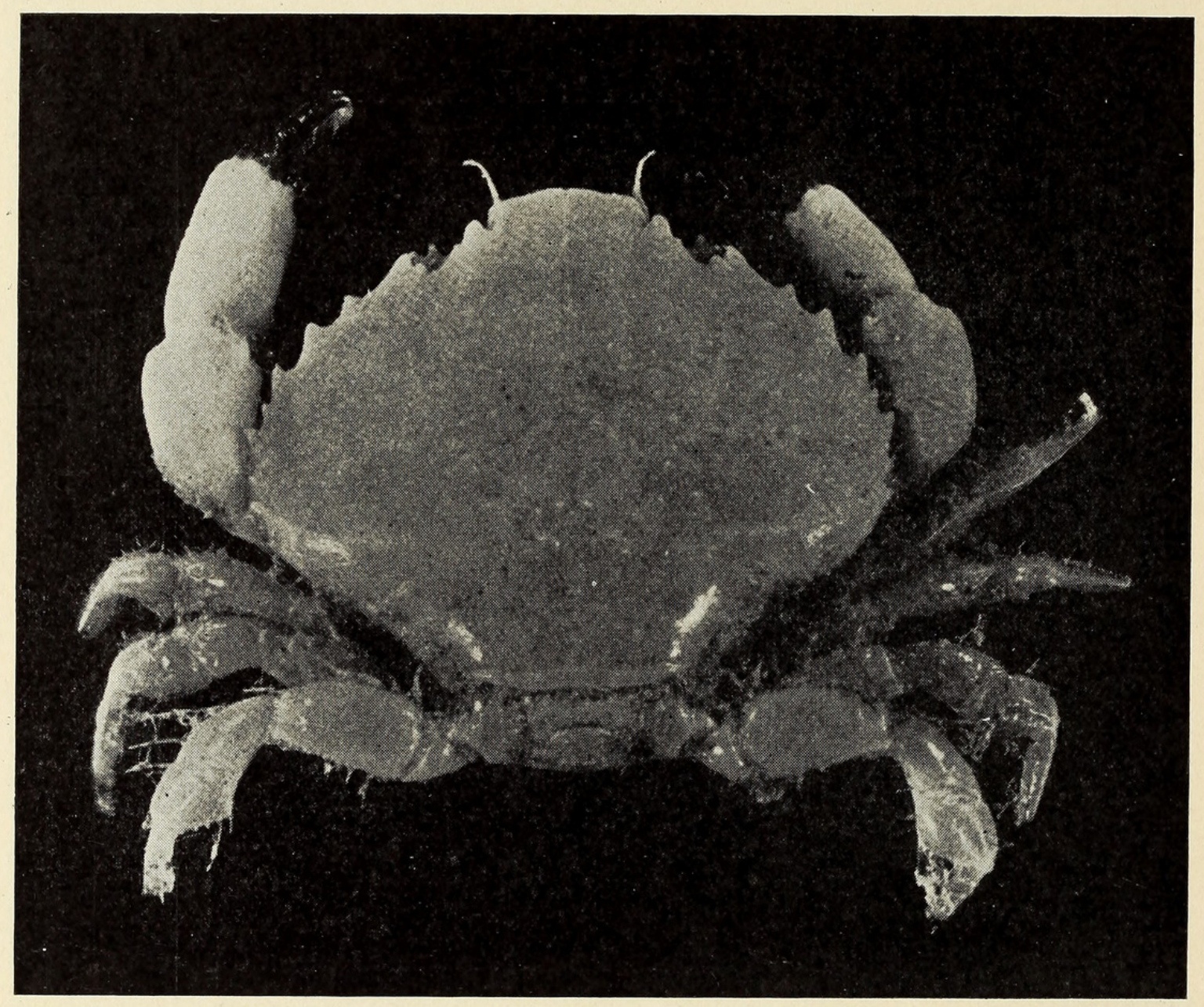

Fig. 68. Cycloxanthops vittatus, $\times 5$.

size of the third; the fifth tooth is about as large as the third, the sixth tooth is small like the fourth and the seventh tooth is only a trifle larger and sharper than the fourth. There is a minute granulation faintly resembling a tooth on the postlateral margin posterior to the seventh tooth; otherwise the postlateral margins are unornamented, slightly arcuate and decidedly convergent. In addition to the median sulcus there is a sulcus on each side running backward from the inner orbital angle and another from between the second and third orbital teeth. The anterior part of the carapace is faintly granulose. It is traversed by two broken lines of somewhat larger granulations, the anterior of which ends near the third lateral tooth; the second line is just behind the 
first one. There is also a line composed of granulations running inward from the fifth lateral tooth as far as the outermost longitudinal sulcus. A second, higher unbroken line runs inward from the sixth lateral tooth about the same distance. The pterygostomian region is traversed by a line of long setae; the sides of the carapace adjacent to the basal joints of the legs are smooth.

The lower half of the orbit consists of two teeth, the inner of which is the more prominent.

The female abdomen is seven-segmented, segments one and two being narrow, short and dorsally visible; segment three is the widest projecting beyond the other segments as triangulate formations, segments four and five are subequal; segment six is squarish, being decidedly longer than any of the preceding segments; segment seven is almost an equilateral triangle. Four pairs of biramose appendages are borne by the second to fifth segments respectively.

The outer antennae have the basal article squarish with the distal margin arcuate, fitted into the space between the orbit and epistome; the second article is cylindrical, moderately stout, the third slender; the flagellum consists of about fourteen tapering rings.

The inner antennae are fleshy and fold obliquely within the septum which is overarched by the projected frontal border.

The eyestalk is stocky, constricted on the outer side, calcareous like the carapace and produced in front to a tubercle at the edge of the cornea and a second less protuberant process projects upon the upper surface of the cornea. The latter is terminal, transversely placed, convex, black.

The external maxillipeds have a slender two-jointed exognath which bears a slender whip internally; the endognath consists of a subrectangular ischium and five-sided merus set obliquely, and supporting a palp consisting of a broad basal, a moderate second and a finely tapering third joint. The upper and inner margins of the articles of the maxilliped are very setigerous.

The chelipeds are equal. The basis and ischium are small, the merus quite long and very broad and fringed with hairs along the ventral margins. The carpus is rather long, dilated distally, convex on the outer surface and bears a tooth at the upper, inner distal angle; the propodus is massive, moderately convex on the outer surface, flattened along the dorsal margin and terminating distally in a rounded knob-like process above the hinged finger. The propodal finger is triangular, bears two linear carinations on the outer surface and four well-developed teeth along the cutting edge. The hinged finger is very similar to the lower finger in shape but bears eight small teeth along the cutting edge, a curved linear carina on the outer surface, and another carina on the outer dorsal edge. The first three pairs of ambulatories are similar and subequal, the fourth pair is conspicuously shorter than the preceding. All have the merus long and arched to conform to the body contour, the carpus and propodus short, the latter being dilated, the dactyl long and slender, being as long as the propodus, tipped distally with a horny point, finely setigerous on the upper, and coarsely so, on the lower surface. The upper and lower margins of the propodus and carpus are also setigerous.

Young.-A specimen of this species measuring $1.8 \mathrm{~mm}$. long, $2 \mathrm{~mm}$. greatest 
width, possesses all the characters of the older form, but as is usual with very young crabs, the eyes are relatively much larger and more prominent.

\section{Genus Medaeus Dana}

Key to the Galapagos species of the genus Medaeus.

Ambulatory legs with lobate crests.

Ambulatory legs without crests of any kind.

Medaeus lobipes Rathbun.

Medaeus lobipes Rathbun, Peoc. U. S. Nat. Mus., vol. 21, p. 583, pl. 44, fig. 1, 1899; Proc. U. S. Nat. Mus., vol. 38, p. 583, 1910.

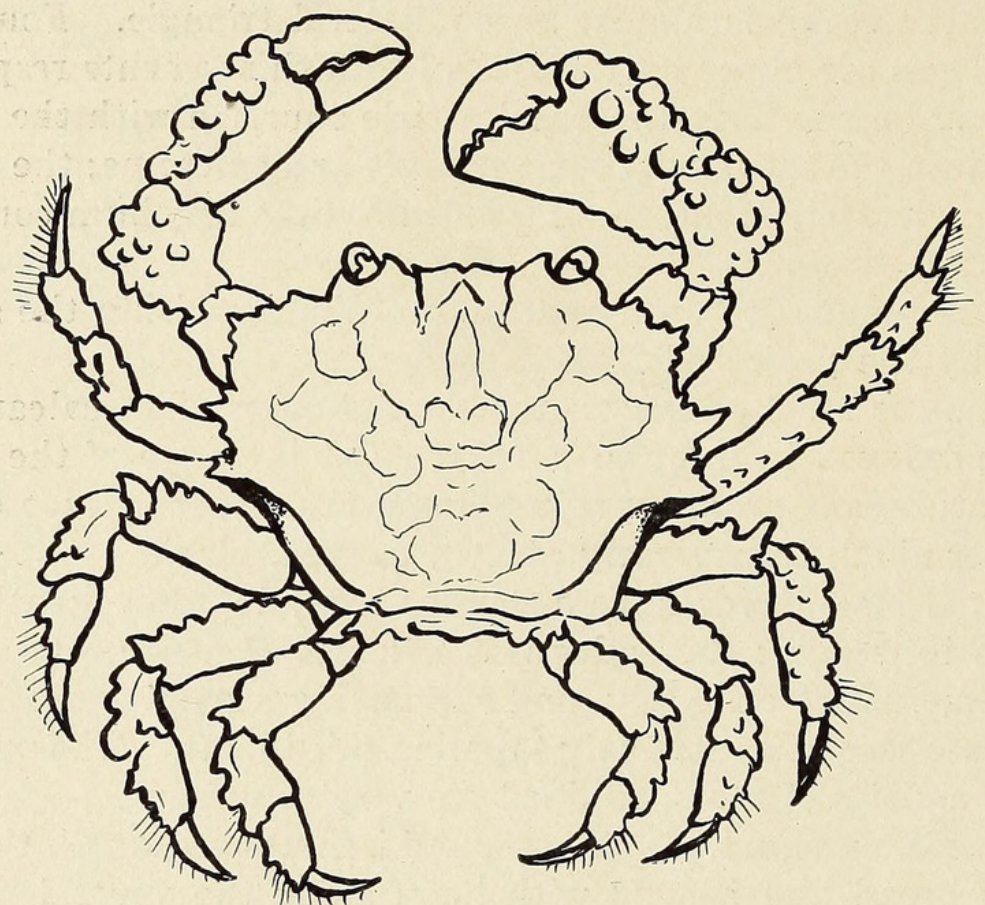

Fig. 69. Medæus lobipes, $\times 1 \frac{1}{3}$ (After Rathbun).

Diagnostic characters.-Ambulatory legs with lobate crests. (Rathbun.)

Type.-One male, from Panama Bay, Albatross station 2796, 33 fathoms deposited in the United States National Museum.

Galapagos distribution.-Off Hood Island, 20 fathoms (one female).

General distribution.-Off Cape St. Lucas, Lower California, 31 fathoms; Panama Bay, 51/2 to 33 fathoms; Galapagos Islands.

Material examined.-None.

Technical description.-The following is the original description of the species:

"Carapace shorter and broader than in Medaeus spinimanus Milne Edwards; lobules similar in shape and position to those of that species. In the largest specimen the tuberculation of the lobules is less extensive than in the somewhat larger individual of Medaeus spinimanus, with which it is compared. Posterior half of mesogastric region divided by a median sulcus into two lobules. Cardiac region also distinctly divided in the same way. Front less advanced, 
and lobes less oblique than in Medaeus spinimanus. The lateral teeth and the chelipeds offer no differences worthy of note. The ambulatory legs are, however, very distinct. They are shorter than in Medaeus spinimanus. The meral joints are armed on the upper and anterior margin with spiniform teeth, as in that species; the tubercles of the upper surface of the last pair are more depressed. The carpal and propodal joints are ornamented with lobate crests, of which there are three on the carpal joints of the first, second, and third pairs, and two on the propodal joints and on the carpal joint of the fourth pair. The middle crest of the carpal joints (the anterior crest in the last pair) is most prominent, and is composed of three rounded lobes, the interspaces as wide as the lobes. Ambulatory legs hairy, the dactyli densely so.

Abdomen of male with the first three segments tuberculous; anterior margin of each segment, including the coalesced segments, marked by a transverse band of pubescence. Posterior half of sternum tuberculous; anterior half punctate or pitted.

Dimensions.-Male, type; length, $17 \mathrm{~mm}$; width, $25.6 \mathrm{~mm}$. Female with eggs, station 2813 : length $8.5 \mathrm{~mm}$.; width $12.3 \mathrm{~mm}$."

\section{Medaeus rugosus, sp. nov. (Hooded Crab).}

Diagnostic characters. - Carapace hexagonal, anterior three-fourths, also upper surface of chelipeds coarsely granulose and very convex.

Type.-The type, an ovigerous female, was taken at station 54, Gardner Bay, off Hood Island by Dr. William Beebe, while diving in 15 feet of water, and is deposited in the collections of the New York Zoological Society.

Galapagos distribution.-Arcturus station 54, off Hood Island (type locality).

General distribution.-This species is known only from the Galapagos holotype.

Technical description.-Carapace $4.5 \mathrm{~mm}$. long, $6.5 \mathrm{~mm}$. wide, interorbital space $2.5 \mathrm{~mm}$. wide. The frontal border is more than half of the maximum width of the carapace and is a straight line whose margin is ventral in position forming a hood over the antennular fossette; the outer distal margins of the front are rounded dorsally and continuous with the superior orbital border; they are produced on the ventral side meeting the distal inner angle of the basal antennal segment. The superior orbital border is semicircular and unbroken and is continuous with the similar inferior orbital margin. The anterolateral margins are arcuate and granular; there is a faintly indicated angulation at the beginning of the postlateral margins which are sinuous and decidedly converging. The anterior three-fourths of the carapace is covered with round granulations and sparsely with a fine pubescence. This region is very convex, the frontal and gastric areas forming a pair of prominent lobules which are separated from each other by a shallow median depression and are similarly faintly defined on their outer margins by the cervical groove; the hepatic region is not especially tumid but the branchial areas are decidedly inflated and are ornamented with miniature lobules composed of granules. The cardiac region is distinctly defined but rather depressed; there are a pair of depressions, one at each end of the urogastric groove; the intestinal region is clearly defined and 
slightly higher than the cardiac region. The surface of the posterior part of the carapace is marked by broken transverse ridges which approximately parallel the posterior margin. The undersides of the carapace are finely granulate and the parts adjacent to the legs are covered with a coarse pubescence. The female abdomen consists of seven segments and is oval with the distal end rounded; the entire margin is set with long thickly plumose setae; the outer rami of the appendages project beyond the abdomen like spokes of a wheel and support the huge egg-mass which is attached to the long, silky hairs of the inner rami.

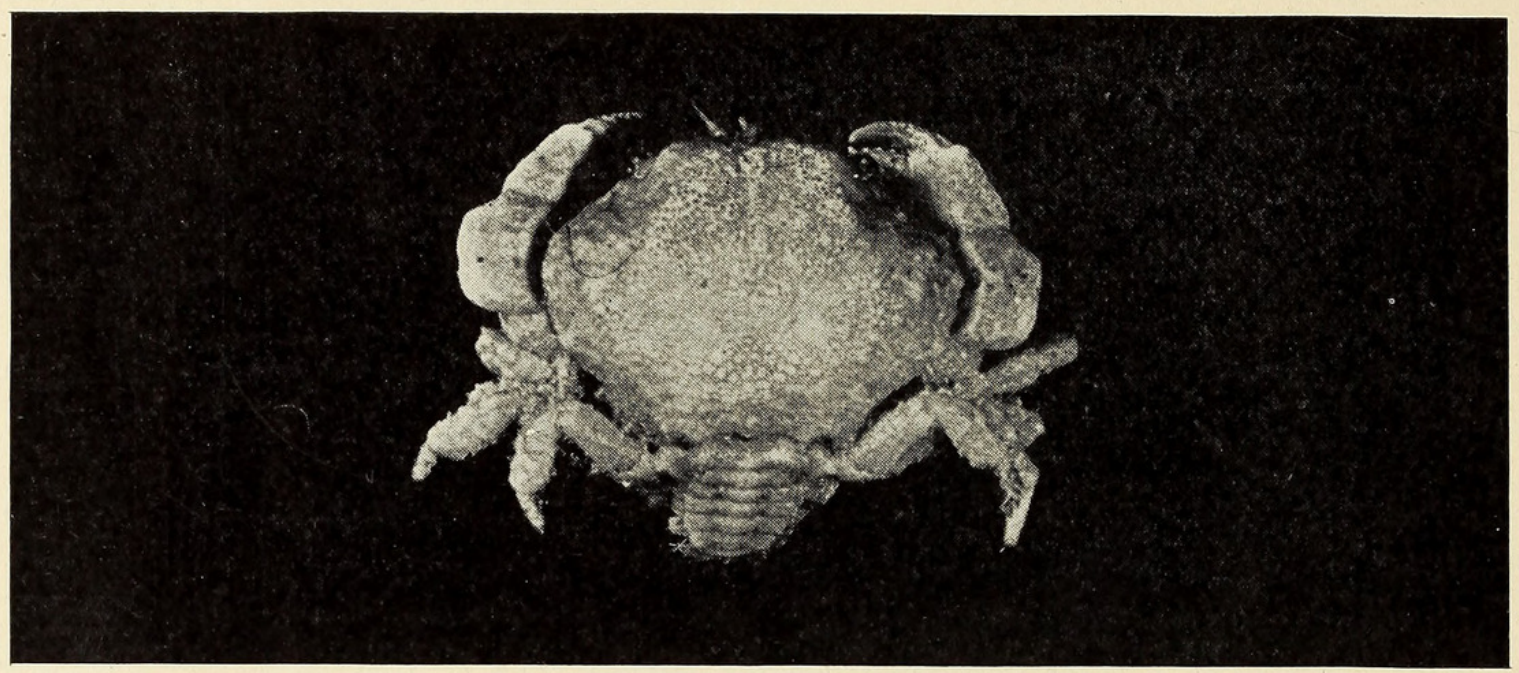

Fig. 70. Medæus rugosus, female, type $\times 4$.

The eyestalks are short and but little of them is visible; the cornea is convex, large and shining black.

The antennulae have the basal joint very wide and short, the two free joints are subequal, stout, cylindrical, and fold transversely within the septum; the flagella are short; the larger branch bears a tuft of setae.

The external antennae are rudimentary, minute, reaching only to the base of the cornea.

The external maxillipeds have the ischium subrectangular with the distal margin a little oblique; the merus is about half as long as the ischium and is a little wider than long, the inner distal margin is slightly notched for the reception of the close-fitting three-jointed palp.

The chelipeds are equal in the female; the meral joint is elongate, trigonal, closely appressed to the carapace with only the distal upper edge showing beyond it; the carpus is very large, convex and lumpy on its upper and outer surface; it is as long as the palm of the propodus; both the carpus and propodus have the upper inner margin cristate; the outer surface of the palm is convex, lumpy and granulose. The fingers are subequal, the propodal being a trifle thicker and the upper finger more curved; both fingers are fluted on the outer and upper surfaces, the ridges and also the interspaces being covered with granules; the cutting edges are coarsely dentate and fit closely upon each other. 
The four pairs of ambulatories are similar and subequal, decreasing slightly in length from the first to fourth pairs; all have the meral joint long and flattened; the carpal and propodal joints are short, stout, thick and roughened on the upper surface; the dactyl is as long, or a little longer, than the propodus but is much slenderer, cylindrical, and tipped with an acuminate spine.

\section{Subfamily Actaeinae}

Genus Actaea de Haan, 1883

Key to the Galapagos species of the genus Actaea.

Carapace with anterolateral margins evenly rounded, quadri-

lobate; finely granulose and coarsely setiferous.

dovii

Carapace with anterolateral lobes dentiform; lobulated pos-

teriorly as well as anteriorly.

angusta

Actaea dovii Stimpson.

Actaea dovii Stimpson, Ann. Lyc. Nat. Hist. N. Y., vol. 10, p. 104, 1871; A. Milne Edwards, Crust. Rêg. Mex., p. 244, pl. 44, fig. 1, 1880; Faxon, Mem. Mus. Comp. Zool., vol. 18, p. 16, 1895; Rathbun, Proc. Washington Acad. Sci., vol. 5, p. 281, 1902; Proc. U. S. Nat. Mus., vol. 38, p. 583, 1910.

Name: Professor Stimpson named this species in honour of Captain J. M. Dow who collected many new and unusual crustaceans on the west coast of America, about 1855 to 1870 .

Diagnostic characters.-Anterolateral margins evenly rounded, quadrilobate. Carapace, chelae and ambulatories finely granulose and coarsely setiferous.

Type.-Professor Stimpson's type material was collected in San Salvador by Captain Dow and in Panama by Alexander Agassiz and was deposited in the "museum of the Smithsonian Institution." I understand that the type is no longer extant.

Galapagos distribution.-Off Hood Island, Arcturus station 54, specimens secured by William Beebe, while diving in 15 feet of water. Tagus Cove, Albemarle Island, on reef north of Tagus Hill (Hopkins-Stanford Expedition).

General distribution.-Panama; San Salvador; Galapagos archipelago and Ecuador.

Material examined.-Eighteen males, four females and six megalops from station 54, off Hood Island, Galapagos, taken by William Beebe, while diving in 15 feet of water. This extensive series does not show the males to be "considerably narrower than the female" as did the material obtained by the Hopkins-Stanford Expedition and examined by Miss Rathbun.

Color.-The very young specimens of this species, about 3 to $5 \mathrm{~mm}$. wide, have alternate red and cream white stripes radiating from the central part of the posterior region outward to the frontal and lateral margin. In older specimens, $10 \mathrm{~mm}$. or more wide, the stripes are replaced by solid orange-red coloration.

Habits.-This interesting Actaea dwells in the crevices of the coral rocks. It feeds on worms, small amphipoda and larval crustaceans. 
Technical description.-Carapace very convex anteriorly, oval; $9 \mathrm{~mm}$. long, $13 \mathrm{~mm}$. wide; covered with fine close-set granules which are more prominent anteriorly; also set with coarse, stiff, up-standing yellow-brown setae. Interorbital space $5 \mathrm{~mm}$. wide; median notch large, V-shaped; frontal edge recurvate, granulate; the superior and inferior orbital margins are granular and unbroken except for the internal orbital hiatus. The frontal region is divided by a median sulcus into two lobes and two more sulci run backward from just inside the preorbital angle defining the outer pair of the four frontal lobes. The anterolateral border is divided into four lobes which do not project beyond the rounded lateral border; the sulci defining them are distinct but not especially deep. The pterygostomian regions and under sides of the carapace are also finely granulate.

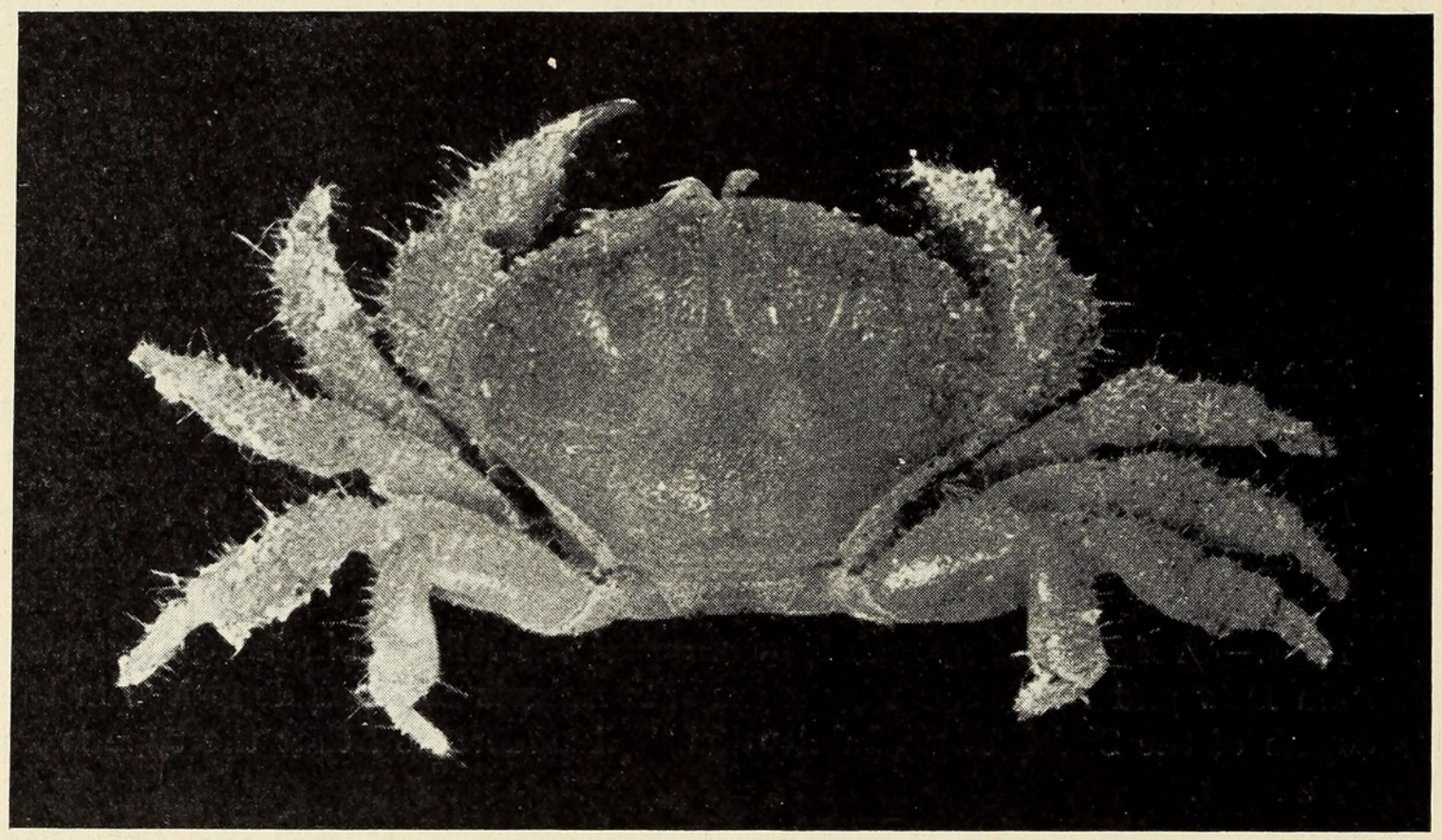

Fig. 71. Actæa dovii, $\times 3$.

The female abdomen is very narrow, with the distal end tapering and rounded and the entire margin heavily fringed with setae. It is seven-segmented, the sixth and seventh segments each being nearly twice as long as the fifth segment.

The male abdominal belt is five-segmented, segments three, four and five being anchylosed. The first pair of male appendages are well developed rods with the distal end flattened and spinose.

The chelipeds are equal in both sexes. They are covered with coarse granules on the upper and outer surface of the merus, carpus and propodus, with occasionally a few tubercles on the proximal part of the fingers. They have the coxal and basis joints small; the ischium fused distally with the merus; the merus is very stout and produced on its inferior distal margin into a rounded knob; the carpus is moderately rounded on its outer surface and is a trifle longer than the palm of the propodus; the propodus has the hand convex and almost as wide and high as it is long; the fingers are a trifle more than half as long as 
the palm and are very strong. The propodal finger is deeply grooved on its outer and under surfaces and bears a strong basal tooth, followed by two more well developed teeth and the acuminate tip; the hinged finger is as large as the propodal but is more curved and bears five teeth on the cutting edge besides the tip; it is also deeply fluted. The fingers fit closely upon each other.

The first three pairs of ambulatory legs are subequal, the fourth pair is similar in structure but much smaller, reaching scarcely to half way the length of the propodus of the third leg. Each leg has the meral, carpal and propodal joints stout, the meral joints being half as wide as long and granulous along the upper edge and the exposed parts of the dorsal surface; the carpus and propodus are each about three-fourths as wide as long and granulose and setigerous; the dactyl is a trifle longer than the propodus and less than half as wide; compressed cylindrical, curved and tapering distally to a sharp, horny point. The dactyli are also granulose and setigerous.

The antennulae are well developed and fold transversely within the fossett.

The external antennae are very small; the basal joint is anchylosed and is produced at the inner distal angle into a sharp point; the next two joints are free, very small and lie within the orbital hiatus; the flagellum is composed of about ten tapering articles and reaches to the cornea.

The external maxillipeds are close-fitting, rectangular. The exognath has a small basal joint and a long, slender second joint which is produced into a tooth-like process on its distal inner angle; the ischium is subrectangular, almost two-thirds as wide as long, with the inner margin fringed with setae; the merus is about half as long as the ischium and has the anterior border oblique; the palp has the basal joint stout, the second and third joints tapering, the latter being heavily fringed with setae.

\section{Actaea angusta Rathbun.}

Actaea angusta Rathbun, Proc. U. S. Nat. Mus., vol. 21, p. 582, pl. 42, fig. 2, 1898.

Diagnostic characters. - "Carapace narrow, posteriorly lobulated; lateral lobes dentiform; fingers rough." (Rathbun.)

Type.-The type of this species, an immature female, was taken by the steamer Albatross, at Station 2812, off Hood Island, Galapagos, in 20 fathoms, and is deposited in the United States National Museum (Cat. No. 21578).

Galapagos distribution.-Off Hood Island, Albatross station 2812, in 20 fathoms.

General distribution.-Known only from the type-locality.

Material examined.-Being unable to secure material of this species, I quote Dr. Rathbun's diagnosis of the type.

Technical description.- "Carapace narrow, slightly convex, lobulate on the posterior as well as the anterior half; lobules granulous. The posterior half of the mesogastric region is long, and its sides are distinctly convergent backward; the depressions which form its lateral borders are continued posteriorly in divergent lines, thus forming a figure the shape of an hour-glass. On either side of this there is a large branchial lobule, not distinctly limited posteriorly. Front slightly deflexed, its margin visible in a dorsal view; lobes oblique, nearly 
straight, separated by a broad V-shaped notch. Lateral lobes four, besides the orbital, dentiform, the first very short, the second twice as long, the third much the longest. Inner suborbital lobe rounded, prominent."

"Chelipeds covered with spiniform tubercles, the carpus deeply grooved, the tubercles on the hands arranged in longitudinal rows. Fingers deeply

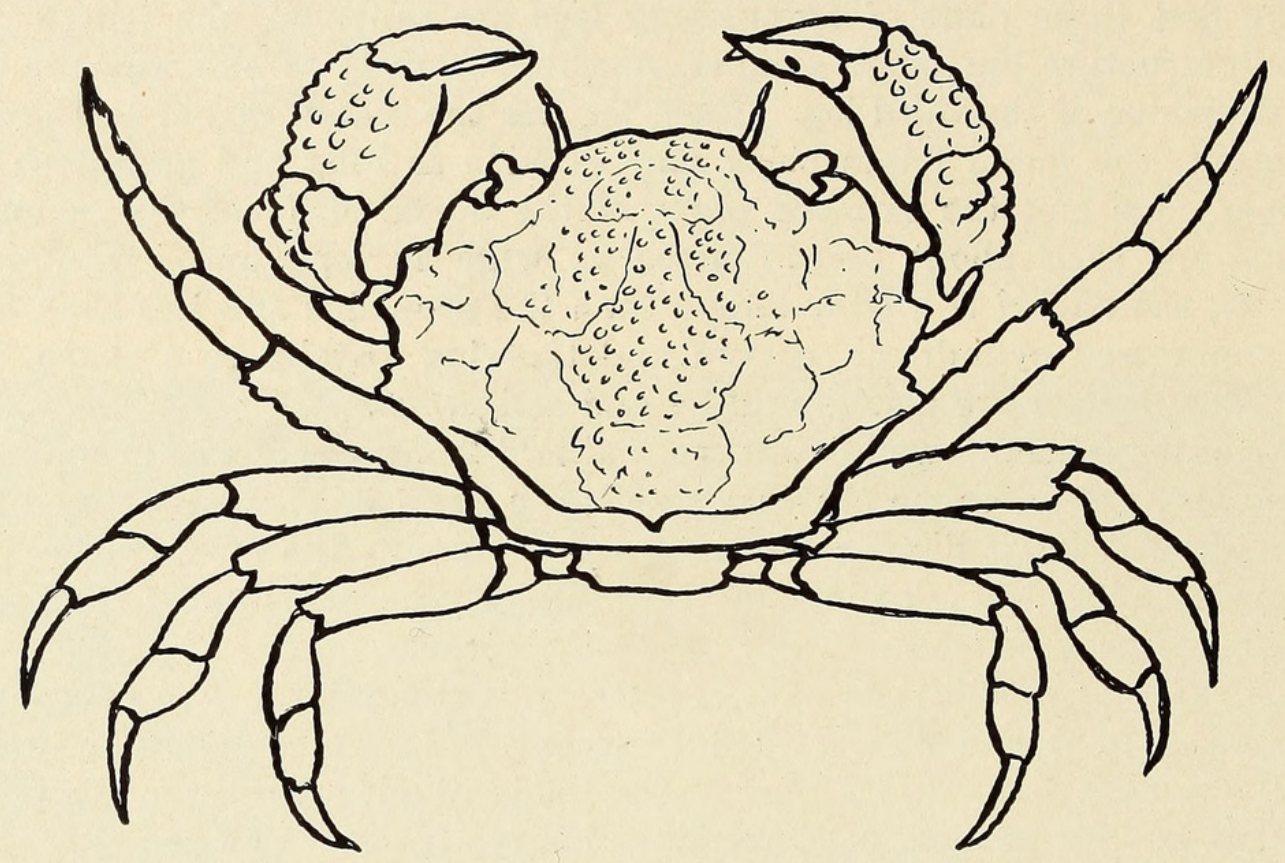

Fig. 72. Actæa angusta, $\times$ about 4 (After Rathbun).

grooved, the intervening ridges rough with spiniform tubercles. Ambulatory legs granulate."

This species resembles Actaea setigera (Milne Edwards) and Actaea dovii Stimpson in the ornamentation of the carapace and in the chelipeds; it differs from them in being narrower and posteriorly areolated, and having dentiform lateral lobes. It resembles Actaea bifrons Rathbun in its proportions and lateral lobes, and differs in its front, posterior areolations and roughened and grooved fingers."

\section{Genus Platypodia Bell}

Platypodia gemmata Rathbun (Galapagos Jewelled Crab).

Platypodia gemmata Rathbun, Proc. Wash. Acad. Sci., vol. 4, no. 8, p. 279 pl. 12 , figs. 5 and 6, 1902 ; Proc. U. S. Nat. Mus., vol. 38, p. 584, 1910.

Diagnostic characters.-Frontal edge thin, slightly bilobed; anterolateral margins quadrilobate. Anterior two-thirds of carapace divided into about twenty lobules.

Type.-The type, an ovigerous female, and three additional specimens were taken on a reef north of Tagus Cove, Albemarle Island, by the Hopkins-Stanford Galapagos Expedition and are deposited in the United States National Museum (Cat. No. 24850).

Galapagos distribution.-Known only from the type-locality.

Material examined.-None. I have not been able to secure this species for examination. 
Technical description.-The following is the original description of the type: "Anterior two-thirds of the carapace divided into about twenty lobules, for the most part circular, except the mesogastric lobule; covered with crowded depressed granules and separated from each other by depressions, filled with a dense furry coating. The front has a thin bilobed edge, the lobes slightly sinuous. The antero-lateral margin is thin and covered above by a short fringe

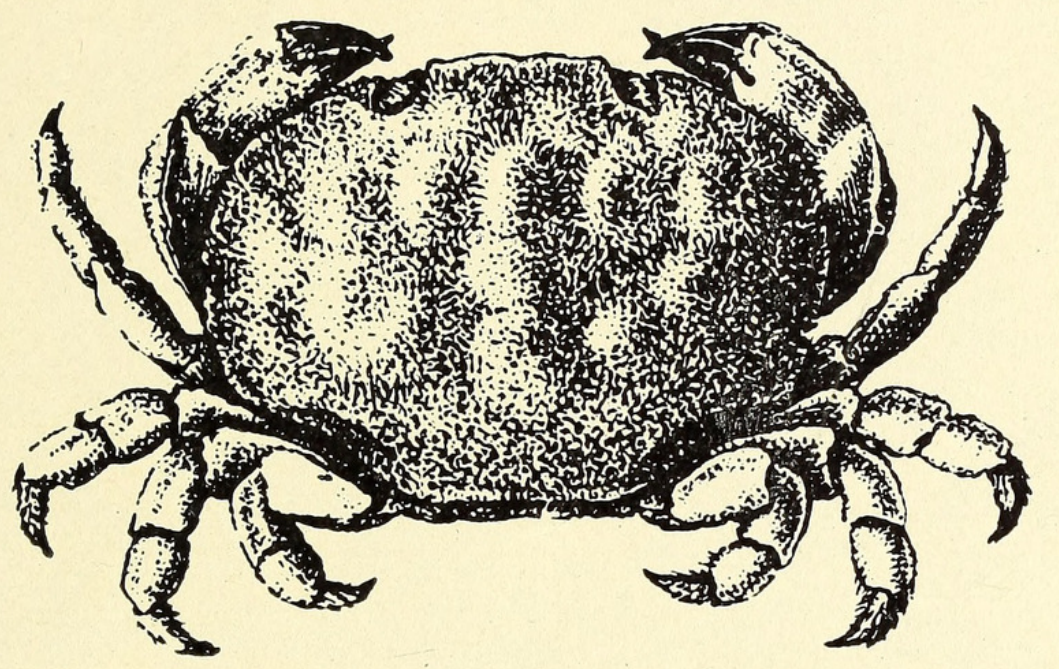

Fig. 73. Platypodia gemmata, $\times$ about 6 (After Rathbun).

of fur; below, there are three fissures visible, dividing the margin obscurely into four lobes. The posterolateral borders are short and deeply cut.

The upper border of the merus, carpus and propodus of the chelipeds and ambulatory legs is sharply cristate. The chelipeds are granulated on the outer surface, the granules larger than on the carapace and arranged on the lower half of the hand in four longitudinal rows. The ambulatory legs are partially granulate. Dimensions: Ovigerous female, length $6.8 \mathrm{~mm}$., width 9.6 , frontoorbital width 4.9 , width of front $2.8 . "$

\section{Subfamily: CHLORODIELLINAE}

\section{Genus Xanthias Rathbun, 1852}

Key to the Galapagos species of the genus Xanthias.

Black tip of fixed finger of chelae produced backward on propodus almost to basal joint; carpus and propodus and anterior region of carapace uniquely nodulose.

Brown tip of fingers not produced backward on propodus; carpus, propodus and anterior region of carapace roughly granular.

insculpta

politus

Xanthias insculpta (Stimpson), 1871. (Sculptured Crab; Volcanic Pebble.)

Xanthodes insculpta (Stimpson), Ann. Lyc. Nat. Hist. N. Y., vol. 10, p. 105, 1871.

Xanthias insculptus Rathbun, Bull. Lab. Nat. Hist. State Univ. Iowa, vol. 4, $p .271,1898$

Xanthias insculpta Rathbun, Zoologica, N. Y. Zool. Soc., vol. 5, p. 157, fig. $38,1924$. 


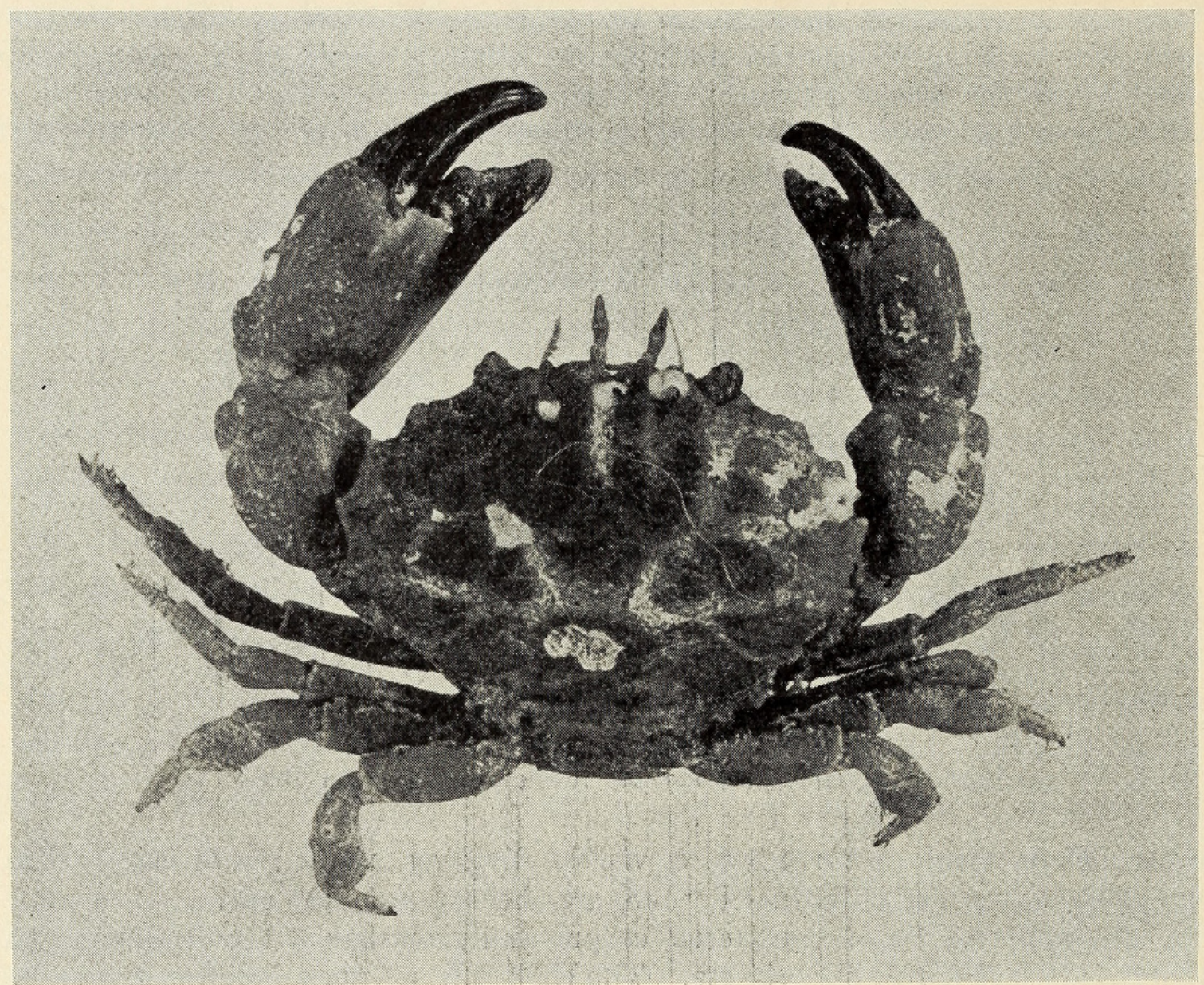

Fig. 74A. Xanthias insculpta, $\times 3.2$.

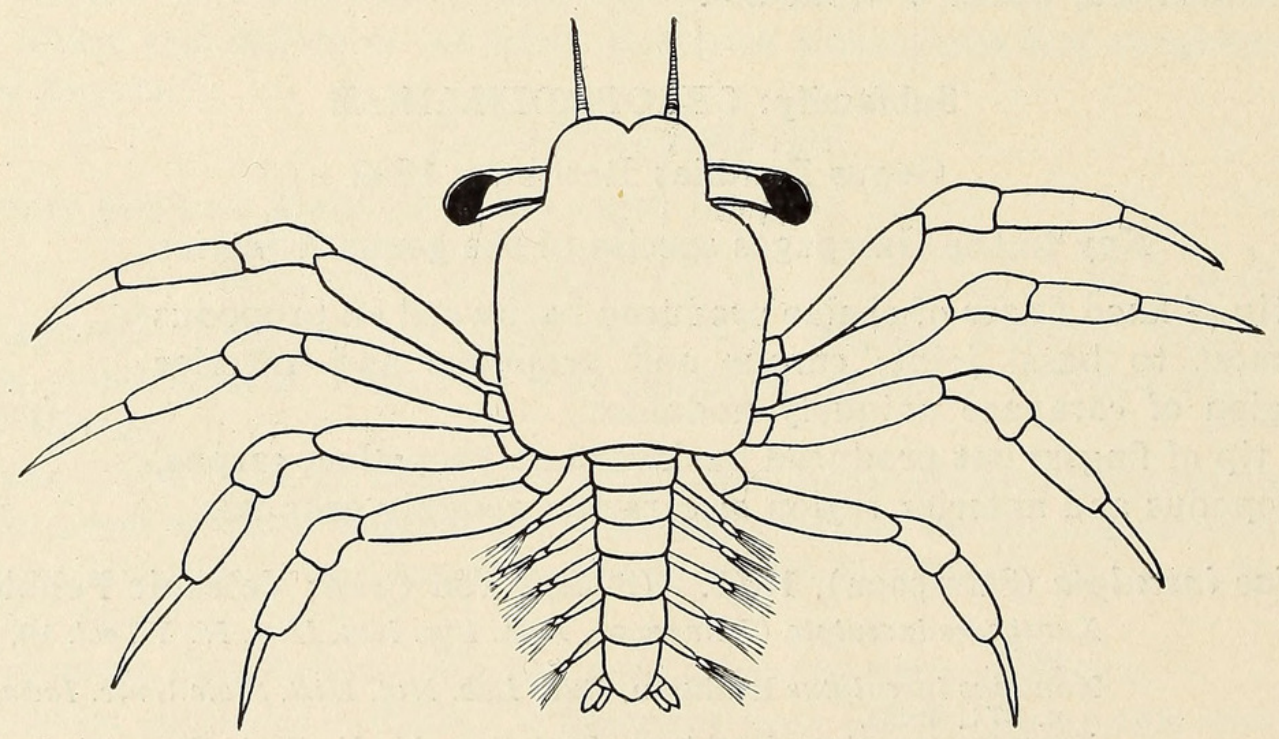

Fig. 74B. Xanthias insculpta, megalops, $\times 20$. 
Diagnostic characters.-Black tip of fixed finger of chelae produced backward on propodus almost to basal joint; carpus and propodus uniquely nodulose; anterior region of carapace similarly rugose and nodulose.

Type.-The specimen on which Stimpson founded this species was taken at Cape St. Lucas, Lower California and is unfortunately no longer extant.

Galapagos distribution.-Eden Island, five fathoms, (Harrison Williams Expedition); Arcturus station 54, off Hood Island, 15 feet.

General distribution.- This species was known only from the type-locality, Cape St. Lucas, Lower California, where it was taken in 1871, until the Harrison Williams Galapagos Expedition, 1923, when an immature male and one other young specimen were secured off Eden Island, in five fathoms of water, by William Beebe.

Material examined.- No better illustration of the marvelous advantages a collector may secure by the use of a diving helmet could be desired than the splendid series of elf-like crabs and megalops representing this species obtained by William Beebe, diving in fifteen feet of water at Station 54, off Hood Island. One megalops, 42 males, 30 ovigerous females, 24 females not ovigerous mostly young specimens, were secured, ranging in size from the miniature megalops figured $(74 \mathrm{~B})$ through a series of minute ovigerous females and males to the seeming great-great-grandfather of the species, (Fig. 74A).

Technical description.-Carapace $12 \mathrm{~mm}$. greatest length; $14 \mathrm{~mm}$. greatest width; interorbital margin broad, produced into two lobed teeth separated by a $\mathrm{V}$-shaped sinus, which is produced posteriorly on the gastric region in the form of a median sulcus; a lesser notch at the outer margin of the median tooth is similarly produced separating the inner orbital lobe from the median; the anterolateral margin is broken by four subequal and subequally spaced teeth; the most anteriorly placed tooth is the largest and while pointed is less incurved on its anterior margin, the second and third teeth are equal and are decidedly forward-directed, the fourth tooth is situated at the terminatoin of the carination with traverses the carapace and is outward-directed. The frontal and gastric regions are deeply nodulose; the upper outer half of the carpus and wrist are similarly nodulose. There is a less distinct transverse row of nodules ruoghly paralleling the posterior sulcus and a less distinct sulcus brokenly traversing the carapace and terminating in the third lateral tooth. The postlateral margins are sharply convergent; the posterior margin is produced into a ridge-like thickening. The male abdomen is five-jointed. The female abdomen is ovate, seven-jointed and fringed marginally with long golden hairs. In ovigerous females the abdomen is expanded behind the carapace and the pleopoda of the third, fourth and fifth segments are long, slender, biramose; the outer rami are projected like rays of a fan from the side of the abdomen; the inner rami are projected ventrally at an oblique angle; both rami are rod-like and heavily fringed with long setae; the inner rami and hairs form the central stem for the grape-like clusters of eggs. A single female $7 \mathrm{~mm}$. wide, $5.5 \mathrm{~mm}$. long carried 742 eggs.

Mr. Beebe, when diving, collected lumps of coral rock in a bucket and later these little crabs were picked out of the small crevices into which they fitted snugly, facing the entrance which was well guarded by their huge-Lilliputian 
chelae. It is understandable that thus guarded the unusually exposed eggclusters escape their myriad enemies. The eggs are encased in a transparent membrane through which the minute old ivory tinted embryos with blackish grey eyes may be seen. The eggs taken average a diameter equal to one-fourth of that of the cornea of the adult.

The basal antennal joint is very short and broad, the flagellum, situated in the orbital hiatus, is somewhat longer than the orbit.

The eyes are well-developed, translucent, golden-brown in color.

The chelipeds are massive, the left is slightly larger than the right; when closed, only the distal part of the merus is seen in a dorsal view, the proximal part of the leg being hidden under the body. The carpus is very convex dorsally, much dilated distally; the left hand continues the characters of the carpus but is even more dilated; it is laterally compressed, outwardly convex; the lower half smooth; the approximate center traversed by a longitudinal carination which terminates at the inner angle of the fixed finger; the upper half of the carpus is nodulose. The fixed finger is very broad basally, triangulate, and bears a strong molar tooth near the base of the inner margin and two lesser teeth near the apex. The movable finger is slender, strongly curved, the fingers meet apically, but there is a wide gape even when closed. The ambulatory legs are short, subequal; have the meral, carpal and propodal joints flattened, lamellar, and the dactyl slender, lance-like.

Xanthias politus (Rathbun).

Micropanope polita Rathbun, Proc. U. S. Nat. Mus., vol. 16, p. 238, 1893. Panopeus tanneri Faxon, Bull. Mus. Comp. Zool., vol. 24, p. 154, 1893; Mem. Mus. Comp. Zool., vol. 18, p. 19, pl. 3, fig. 4, 4a, 1895.

Xanthias politus Rathbun, Bull. Labr. Nat. Hist. State Univ. Iowa, vol. 4 , p. 271, 1898; Proc. U. S. Nat. Mus., vol. 21, p. 587, 1898; Proc. Washington Acad. Sci., vol. 4, p. 281, 1902.

Diagnostic characters.-Front broad, median notch narrow, lobes nearly straight. Five anterolateral teeth. Anterior margin of merus of external maxillipeds sinuous.

Type.-The type of this species was taken off Magdalena Bay, Lower California, lat. $24^{\circ}, 58^{\prime}, 15^{\prime \prime}$ N., long. $115^{\circ}, 53^{\prime}$ W., 36 fathoms, station 2889 , U. S. Fish Commission Steamer Albatross, and is deposited in the United States National Museum.

Galapagos distribution.-Hood Island, 20 fathoms; Tagus Cove, Albemarle Island, 12 fathoms; off Galapagos Islands, 53 fathoms.

General distribution.-Lower California, 31 to 36 fathoms; near Cocos Island, 66 fathoms, Galapagos Islands, 12 to 53 fathoms.

Material examined.-None.

Technical description.-The following is Miss Rathbun's description of the type: "Carapace transverse, convex longitudinally, smooth and punctate posteriorly, rough-granulate anteriorly, the granules most prominent on the hepatic regions. Front broad, median notch narrow, lobes nearly straight, thin, denticulate. Areolations distinct. Antero-lateral teeth five (with the orbital angle); a concave sinus between the first and second; last tooth similar in character to the others, but smaller. Inferior regions of the carapace and surface of maxillipeds granulate. Sternum and abdomen smooth and punctate. Ab- 
domen of male with five segments, the first and second broad, the second narrowest at its distal end. Basal antennal joint reaching the front. Anterior margin of merus of outer maxillipeds sinuous. Large cheliped, with merus

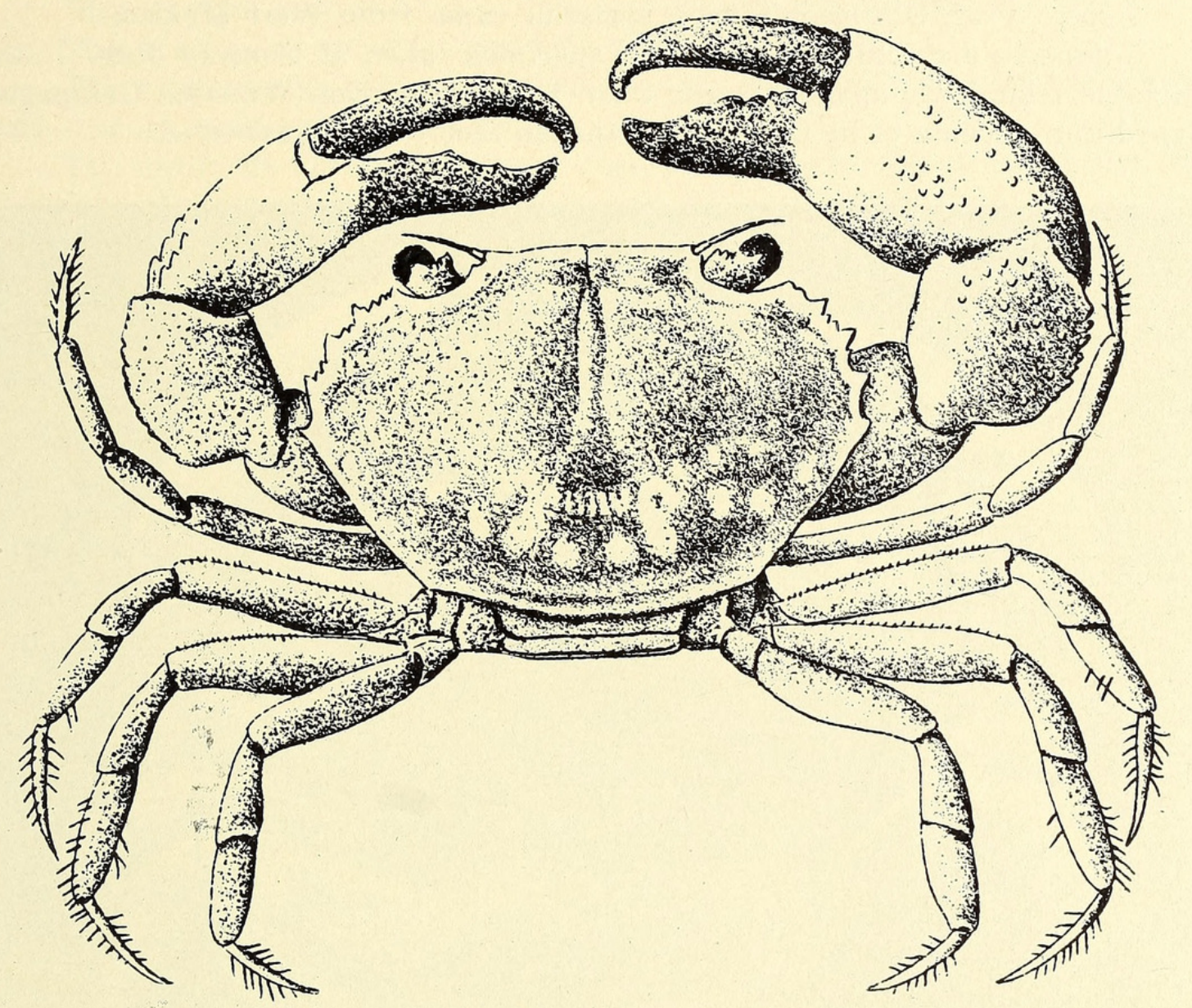

Fig. 75. Xanthias politus, $\times$ about 4 (After Faxon).

finely granulate, dentate on the upper margin; carpus with spiny granules arranged in indistinct transverse ridges, an acute spine inside; hand granulate above and near the carpus, smooth and punctate elsewhere; palm broad, convex on lower margin; fingers brown, with lighter tips. The small cheliped differs in its much narrower, more granulate hand, with almost straight lower margin. Ambulatory legs slender, punctate, spinulous above, last three joints hairy.

Length of carapace 6.2 , width 9.8 millimeters."

\section{Subfamily: PANOPEINAE}

\section{Genus Eurypanopeus A. Milne-Edwards}

\section{Eurypanopeus transversus (Stimpson).}

Panopeus transversus Stimpson, Ann. Lyc. Nat. Hist. N. Y. vol. 7, p. 210, 1860. - Benedict and Rathbun, Proc. U. S. Nat. Mus. vol. 14, p. 367, pl. 22, fig. 2, pl. 24, fig. 9, 1891.

Eurypanapeus transversus Rathbun, Proc. U. S. Nat. Mus. vol. 38, p. 543, fig. 2, 1910.

Diagnostic characters.-A small Panopeus with the anterior half of the cara- 
pace decidedly convex, the posterior half rather flattish; anterolateral margin cut into five lobate teeth. The coxal joint of the fifth legs are in contact with the third abdominal segment.

Type.-Prof. Stimpson's type material came from West Mexico.

Galapagos distribution.-One male specimen taken at Conway Bay, Indefatigable Island, Galapagos, April, 1923, by the Harrison Williams Galapagos Expedition appears to be the first Galapagan record for this species.

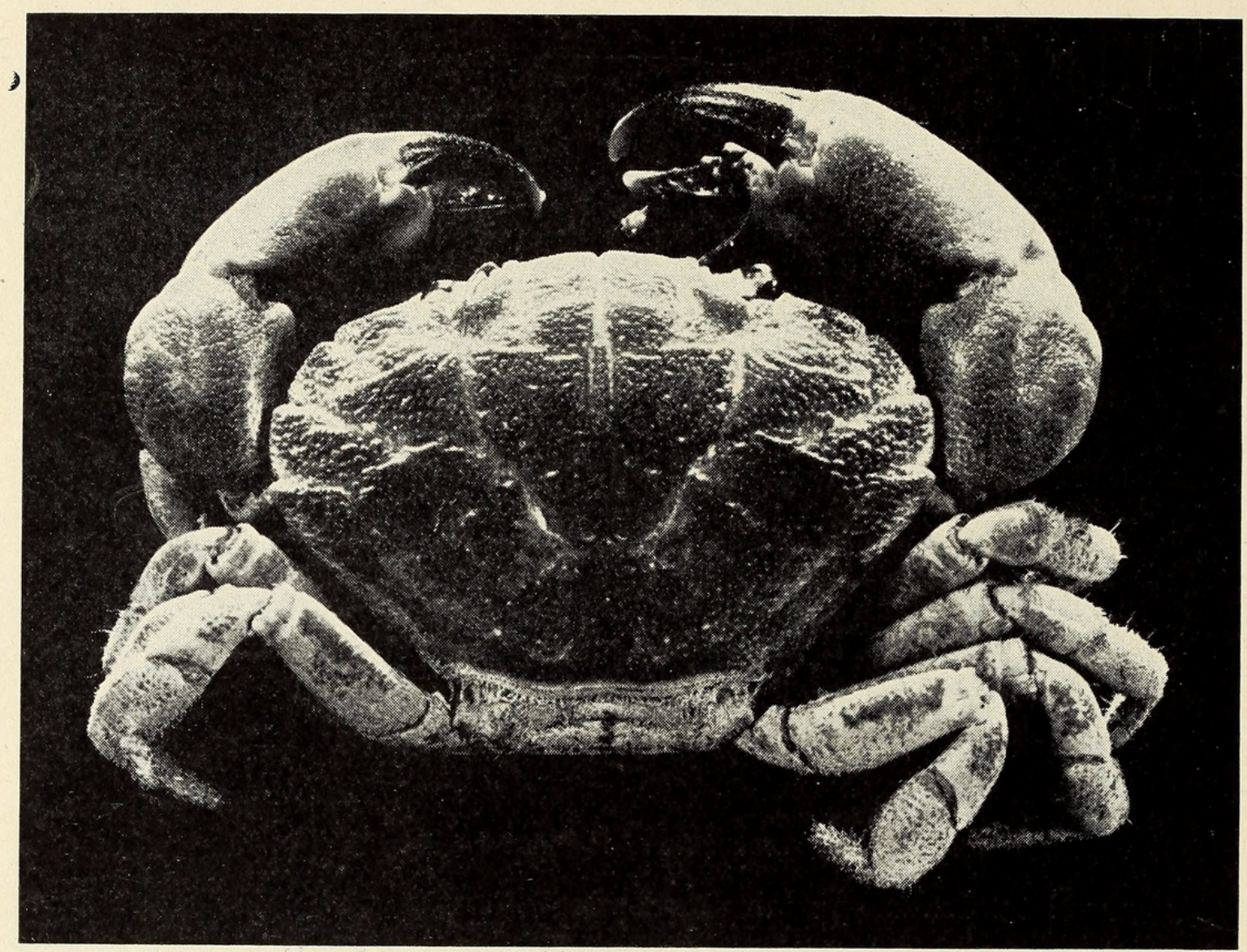

Fig. 76. Eurypanopeus transversus, $\times 3$.

General distribution.-Acajutla, San Salvador (Yale Museum); Las Vacas, near Capon, Peru (U. S. National Museum); Galapagos Islands (Noma Expedition).

Technical description.-Carapace $20 \mathrm{~mm}$. wide, $12.7 \mathrm{~mm}$. long, broadly oval, with the anterior half decidedly convex, curving downward to the frontal margin; the posterior half flattish; areolations clearly defined but not especially raised. The interorbital region equals about one-third of the width of the carapace and is divided by a small median notch, and a pair, one each near the outer angle. The anterolateral margin is broadly rounded with the first and second teeth completely fused, forming a blunt lobe; the third and fourth are subequal, truncated, separated by a slight V-shaped incision from the apex of which a brief groove runs inward; the fifth tooth is dentiform and con- 
tinuous posteriorly with the converging postlateral margins. The abdomen is seven segmented; the third abdominal segment is in contact with the coxal joint of the fifth pair of legs.

The eyestalk is short; the cornea is large but not dilated.

The antennulae are stout and fold within the septum.

The antennae have the peduncular joints situated in the orbital hiatus, and a short multiarticulate flagellum.

The chelipeds are distinctly unequal; the proximal joints are strong, the merus is rather massive; the carpus is long, with the upper and outer surfaces rounded, a blunt tooth at the inner angle; the propodus is evenly rounded, well developed the dactyli are slender, subequal; the lower finger has a large basal tooth in the male.

The ambulatories are rather narrower for a Eurypanopeus.

\section{Genus Eurytium Stimpson, 1859}

Eurytium affine (Streets and Kingsley) 1877.

Panopeus affinis Streets and Kingsley, Bull. Essex. Inst., vol. 9, p. 106, 1877. Eurytium affine A. Milne Edwards, Crust. Rég. Mexic $\phi, p$. 334, pl. 60 , fig. 1, 1880; Rathbun, Proc. U. S. Nat. Mus., vol. 38, p. 585, 1910.

Diagnostic characters. - Carapace but little convex; four anterolateral teeth besides the postorbital tooth; these are distinctly separated - the first and second being broad and blunt, the third and fourth raised and angled.

Type.-The type specimen came from Lower California and is probably deposited in California Academy of Science collections.

Galapagos distribution.-One male specimen of this species, taken at Conway Bay, Indefatigable Island, by the Harrison Williams Galapagos Expedition, established the first Galapagan record for this rare species, hitherto known only from Lower California.

General distribution.-Lower California (type-locality) and Galapagos Islands. Dr. Rathbun cites Ecuador as a doubtful record of this species, without explanation of the source of her information.

Material examined.-One male specimen from Conway Bay, Indefatigable Island, secured by the Harrison Williams Galapagos Expedition.

Technical description. - Carapace $15 \mathrm{~mm}$. long, $20 \mathrm{~mm}$. maximum width; interorbital space $7 \mathrm{~mm}$. wide. The carapace is only a little convex from the front to back and has the regions clearly delineated; these defining grooves being heavier on the posterior regions. The frontal border is a little more than onethird the maximum width of the carapace and has the frontal margin straight, granulose, divided into two lobes by a slight median fissure from which a median groove runs backward on the carapace and bifurcates, defining the cardiac region. The outer angles of the frontal lobes are right-angled. The superior orbital margin is slightly raised and granular, and defined by an obtuse postorbital tooth which is separated from the first marginal tooth by a shallow curve. The anterolateral margins are cut into four teeth, in addition to the postorbital tooth. The first tooth is obtuse and but little more than half as wide as the second tooth; the second tooth is broad and blunt with a slight point near its anterior angle; the third tooth is about as wide as the second but 
is more raised, and has a median rib of granules on its inner surface, giving it a triangular aspect; the fourth is the smallest of the series and is also raised and has a median rib of granules running inward from its apex. Behind this fourth tooth the posterior margins converge abruptly. The branchial regions are slightly tumid. In addition to grooves delineating the regions of the carapace, there are many fine low granules especially on the anterior region of the carapace. Some of these form irregular, broken, transverse lines on the gastric and branchial regions. The undersides of the carapace are slightly pubescent and granular.

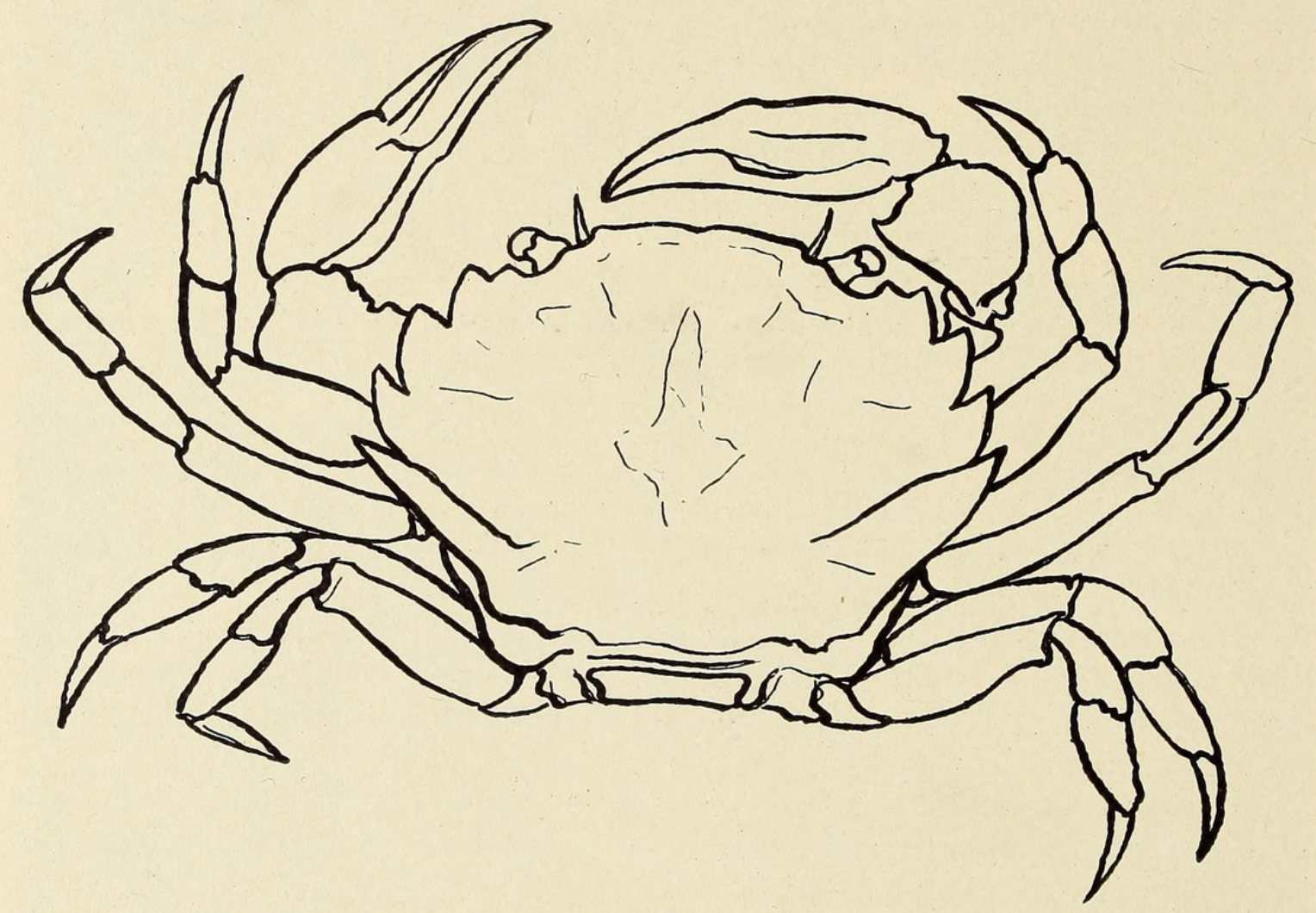

Fig. 77. Eurytium affine, $\times 2.5$.

The eyestalk is short, decidedly constricted below the cornea and produced on the upper surface into a small, rounded process that projects upon the cornea; the cornea is spherical and is composed of many very minute hexagonal facets.

The antennulae are well developed and fold transversely within the septum.

The external antennae have the basal article lodged at the outer end of the antennulae, in the oribtal hiatus; the second joint is small, compressed, subcylindrical, the third joint is only about half as long as the second; the flagellum consists of about 25 annulations and extends to the anterior margin of the first lateral tooth.

The external maxillipeds have the second joint of the exognath long, rectangular; the ischium is subrectangular with the inner margins rounded basally, the outer face is channelled longitudinally and has this line set with coarse setae; the merus is about three-fifths as long as the ischium and has its outer distal 
border produced and rounded, its inner distal border notched and its outer surface irregularly channelled, granulated and covered with bristly setae; the three-jointed palp is stout, tapering, subcylindrical.

The chelipeds are unequal in the male; they have the meral joint stocky, trigonal, with the inner surface flattened and closely appressed to the sides of the carapace; the carpus is rounded on the upper and outer surfaces and finely granular; there is a triangulate tooth on the inner subdistal margin; the propodus is one-half as long as the maximum width of the carapace, the fingers comprising about two-fifths of this length; the propodus is three-fourths as high as it is long, with the outer and upper surfaces convex and the inner surface concave on its proximal part; all three surfaces are finely granular; the fingers are short, stout, weakly channelled by shallow, longitudinal grooves, and with a gap between them. The hinged finger bears a large, blunt, basal tooth. The fingers of the small chela lack this large basal tooth and they do not gape.

The four pairs of ambulatories are similar and slightly decrease in length from the first to fourth pairs, in the order named. All are long and slender and have the meral joint very long and compressed laterally, the carpus and propodus are approximately subequal and taken together are as long as the merus. The dactyl is almost straight, very slender, tapering and acuminate; the sides of the dactyl and the distal under part of the propodus are covered with stiff, bristly setae.

\section{Subfamily: MENIPPINAE}

\section{Genus Pilumnoides Milne Edwards and Lucas}

Pilumnoides pusillus Rathbun.

Pilumnoides pusillus Rathbun, Proc. Washington Acad. Sci., vol. 4, p. 281, pl. 12, figs. 9, and 10, 1902; Proc. U. S. Nat. Mus., vol. 38, p. 585, 1910.

Diagnostic characters. - Anterolateral margin four-toothed; anterior region of carapace lobulated; upper surface of carpus and propodus of chelipeds lobulated. Chelae unequal.

Type.-This species was founded on two male specimens taken at Tagus Cove, Albemarle Island, on reef north of Tagus Hill, March 16, 1899, by the Hopkins-Stanford Galapagos Expedition and which are deposited in the United States National Museum.

Galapagos distribution.-Tagus Cove, Albemarle Island (type-locality) and Arcturus station 54, off Hood Island, in 15 feet of water.

General distribution.-Known only from the Galapagos Archipelago.

Material examined.-Five male specimens and one female taken at Arcturus station 54, off Hood Island, Galapagos Island by William Beebe, while diving in 15 feet of water.

Technical description.-Carapace $4 \mathrm{~mm}$. long, $6 \mathrm{~mm}$. wide, moderately convex anteriorly and distinctly lobulate; the frontal region is divided by a median longitudinal sulcus into two prominent lobules and there are four prominent and one feeble lobules on the anterior region adjacent to the anterolateral margin, one lobule being postorbital in position and each of the other four being inside of the respective anterolateral teeth; occasionally the feeble lobe, which is adjacent to the last tooth, is obsolete. The entire surface of the 
carapace and the outer and upper surfaces of the chelipeds and ambulatories are finely granulate. The interorbital border is $1.7 \mathrm{~mm}$. wide, slightly sinuate, with the outer angles forming an obtuse tooth. The superior orbital border is sinuate and is marked by two lines indicating closed fissures. The postorbital tooth is small. The anterolateral border is broken into four distinct, triangular tuberculiform teeth; the first, second and third teeth are subequal, the fourth tooth is smaller but very acuminate; a transverse beading runs inward from

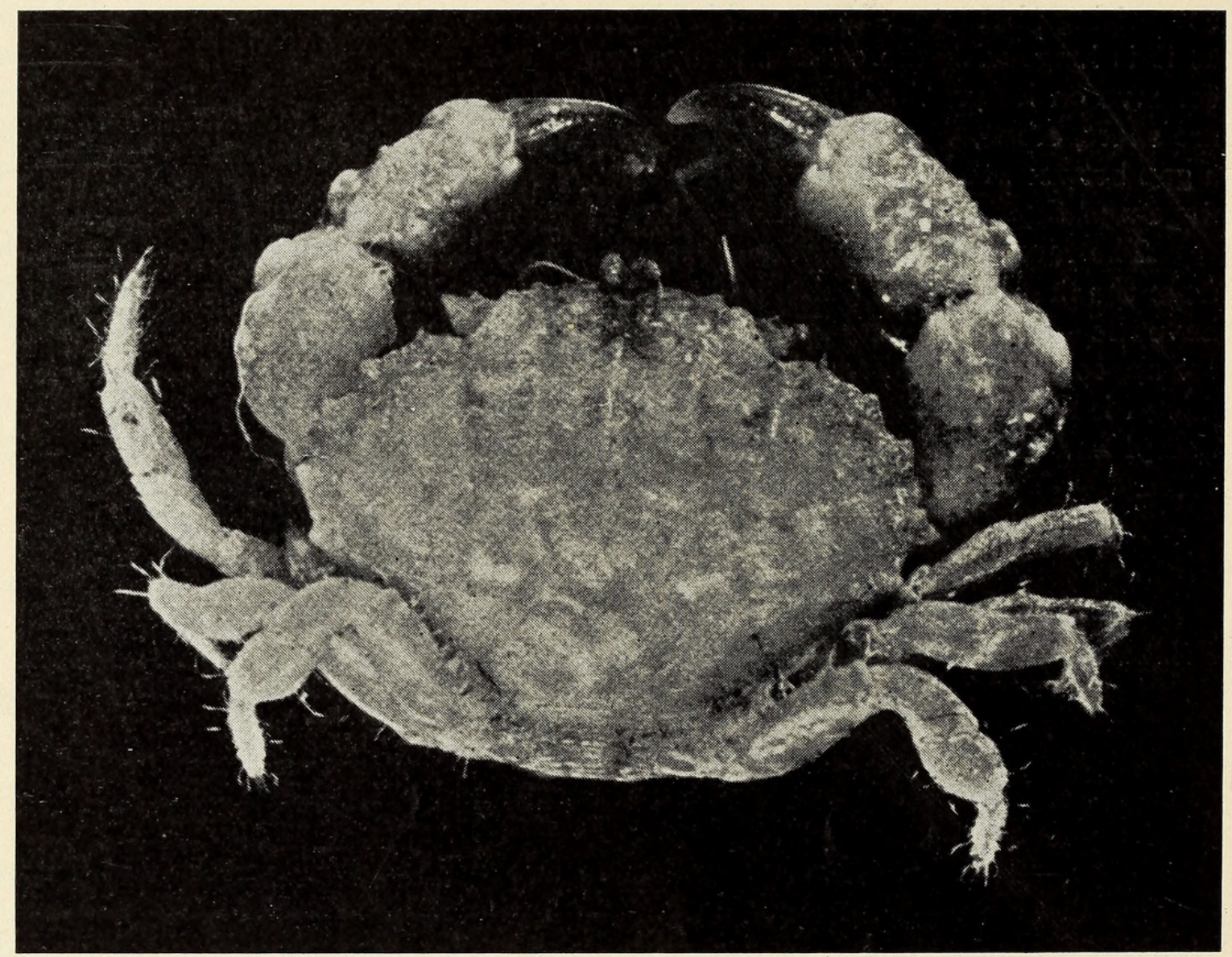

Fig. 78. Pilumnoides pusillus, $\times 9.5$.

the fourth tooth upon the carapace. The postlateral margins are convergent. The pterygostomian region and under sides of the carapace are finely granular.

The antennulae are well developed, and fold almost transversely within the fossette beneath the frontal lobes.

The external antennae have the basal segment almost reaching the inferior orbital margin; the first free segment small, rectangular, situated in the orbital hiatus, the flagellum long, composed of eight, long, slender articles.

The external maxillipeds have the second joint of the exognath a long, narrow rectangle, reaching to the distal border of the merus; the ischium is rectangular, about two-thirds as wide as long; the merus is a little more than half as long as the ischium and has the inner margin somewhat rounded; the palp consists of three stout, tapering articles. 
The chelipeds are moderately unequal in both sexes. The merus is welldeveloped yet is scarcely visible in a dorsal view. The carpus and propodus are greatly developed and project beyond the carapace conspicuously. Both are lobulated on the upper and outer surfaces; the propodal finger is stout, strongly toothed on the cutting edge and marked by two carinae, the lower one of which runs backward on the palm. The hinged finger has a deep groove on the upper surface and is decidedly curved and distinctly toothed. When closed, the fingers of the large chela have a small basal gap; those of the small chela vary, being sometimes close-fitting and occasionally with a hiatus.

The four pairs of ambulatory legs are small, similar; the first three pairs are subequal; the fourth pair is much shorter. Each has the meral, carpal and propodal joints broad, the dactylus long, slender and but little curved, except at the horny tip. All the legs are sparsely set with long hairs.

\section{Subfamily: PILUMNINAE}

\section{Genus Pilumnus Leach, 1815}

Key to the Galapagos species of the genus Pilumnus.

Anterolateral margin four-toothed including the postorbital, each of which is serrated by fine spinules.

Anterolateral margin five-toothed, including the postorbital; spinulifer carapace distinctly areolated, anterior region rough with broken transverse rugae of beadlike tubercles.

beebei

Anterolateral margin obtuse and rounded, broken into four coalesced teeth. Anterior region of carapace and chelipeds covered with rounded tubercles and densely hirsute.

pygmaeus

Pilumnus spinulifer Rathbun.

Pilumnus spinulifer Rathbun, Proc. U. S. Nat. Mus., vol. 21, p. 585, pl. 42, figs. 6-8, 1898; Proc. Washington Acad. Sci., vol. 4, p. 281, 1902 ; Proc. U. S. Nat. Mus., vol. 38, p. 585, 1910.

Diagnostic characters. - Chelae unequal, large one with palm diagonally half smooth, small chela with entire surface rough. Carapace distinctly areolated, anterior region quite rough. Anterolateral margin four-toothed.

Type.-This species was founded on two male specimens taken by the Albatross off Cape St. Lucas, Lower California, at station 2829, in 31 fathoms. They are deposited in the United States National Museum.

Galapagos distribution.-Off Hood Island, at Arcturus station 54, depth fifteen feet, four specimens taken by William Beebe; also taken at Tagus Cove, and on a reef north of Tagus Hill, Albemarle Island, by the HopkinsStanford Galapagos Expedition.

General distribution.-Off Cape St. Lucas, Lower California and Galapagos; in depths ranging from on reef to fifteen feet, also at twelve and thirty-one fathoms.

Material examined.-Two females and two male specimens, taken at Arcturus station 54, off Hood Island, by Dr. Beebe, while diving in 15 feet of water. 
Technical description.-Carapace $4 \mathrm{~mm}$. long, $5 \mathrm{~mm}$. wide; interorbital region $2 \mathrm{~mm}$. wide, convex; regions deeply delineated, surface covered thinly with fine setae and short spinular granules which are more abundant on the anterior region, and which are larger and developed into spinules along the anterolateral margin. The frontal border is two-fifths of the maximum width of the carapace and is divided in the middle by a prominent wide V-shaped sinus; the margin is thin and granular, the outer angles of the frontal lobes are rectangular. The superior orbital margin is coarsely granulous or spinulous;

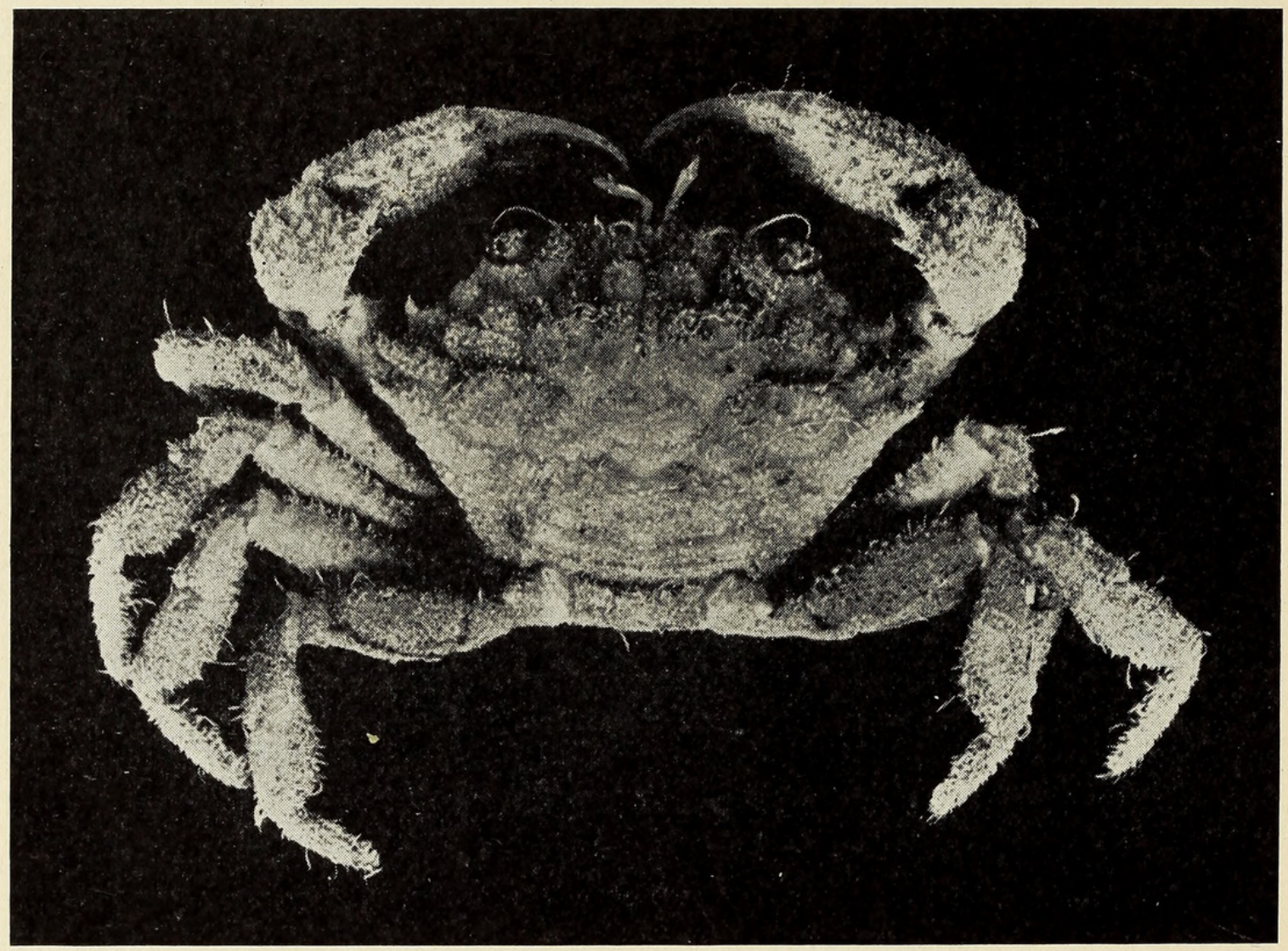

Fig. 79. Pilumnus spinulifer, $\times \mathbf{9 . 5}$.

the inferior orbital margin is set with slender spines; the inner suborbital tooth is very prominent, spinulous and acute. The anterolateral margin is armed with four spines including the postorbital, each of which is serrated by fine spinules; the first and second teeth are separated from each other by a wider curve than exists between any of the remaining teeth. Below and between the first and second teeth there is a subhepatic tooth which is smaller than the marginal teeth. The under sides of the carapace are covered with tough spiny granules similar to the upper surface.

The inner antennae are very large and fold transversely with in the septum.

The external antennae rather small but support a slender flagellum which is about three-fourths as long as the interorbital border.

The eyestalk is stout, cylindrical, a little swollen and produced on the 
upper surface into a short rounded tongue-like process which projects on the cornea.

The external maxillipeds have the exognath well-developed; the ischium is rectangular with the lower part of the inner margin a little rounded; the merus has the distal margin oblique and the inner distal angle notched; the threejointed palp is well-developed.

The chelipeds are conspicuously unequal in both sexes; the proximal three joints are small, the merus is trigonal, granular on the outer surface, these granules developing into spinules along the margins, those of the upper surface increase in size distally; the carpus is large, convex and very spinous; the propodus of the large chela is large, high and swollen, being three-fourths as long as the maximum width of the carapace; the fingers comprise four-fifths of this length; a little of the upper inner surface, the dorsal surface and the upper basal half of the outer surface of the palm are covered with spinose granules which in most, but not all, specimens become more regularly placed and more granular on the lower and distal regions. The palm of the small cheliped is entirely covered on the outer surface by spinules arranged in longitudinal rows; there are two such rows on the upper surface and the inner surface is very granulose except near the fingers. The basal finger of the large cheliped is stout, marked by two longitudinal grooves on the outer surface and furnished with a large sub-basal and four smaller teeth; the hinged finger is slenderer, more curved and has one very large basal tooth and several small teeth; it is rough with spinules on the upper basal part. The fingers of the small chela are more heavily fluted and frequently more roughened with spinules.

The ambulatories are similar, subequal in length and sparsely setigerous. The meral joints are furnished on the anterior margin with a row of slender spines; their posterior margins are set with spinulose granules; the carpal and propodal joints are armed on the upper, lower and distal margins with spines, the dactyli are slender, acuminate, and spinous on the upper distal margin.

\section{Pilumnus beebei, sp. nov.}

Name: I take pleasure in naming this species in honour of William Beebe, Director of the Arcturus Oceanographic Expedition, whose indefatigable industry in collecting material secured at station 54 within a radius of a few square yards forty-six of the sixty-nine known species of Brachyurans of the littoral crustacean fauna of the Galapagos and further increased this fauna by the addition of nine species, hitherto known only from the West American coast and by five new species of crabs.

Diagnostic characters. - Carapace distinctly areolated; anterior region rough with broken transverse rugae of bead-like tubercles. Anterolateral margins five-toothed counting the postorbital as the first of the series. Chelipeds unequal, large one with palm diagonally half smooth; small chela with the entire surface rough with granules.

Type.-Seven specimens, three females and four males were taken at Station 54, off Hood Island, Galapagos, by William Beebe while diving in 15 feet of water. 
Galapagos distribution.-Off Hood Island, in 15 feet of water, Arcturus station 54, type-locality.

General distribution.-Known only from the Galapagan type-locality.

Material examined.-Three females and four males from off Hood Island, Galapagos, station 54.

Technical description.-Carapace $5 \mathrm{~mm}$. long, $7 \mathrm{~mm}$. maximum width, deeply areolated, moderately convex, dorsal surface covered with irregular, acuminate granules and fine sparse pubescence. The granules are coarser and

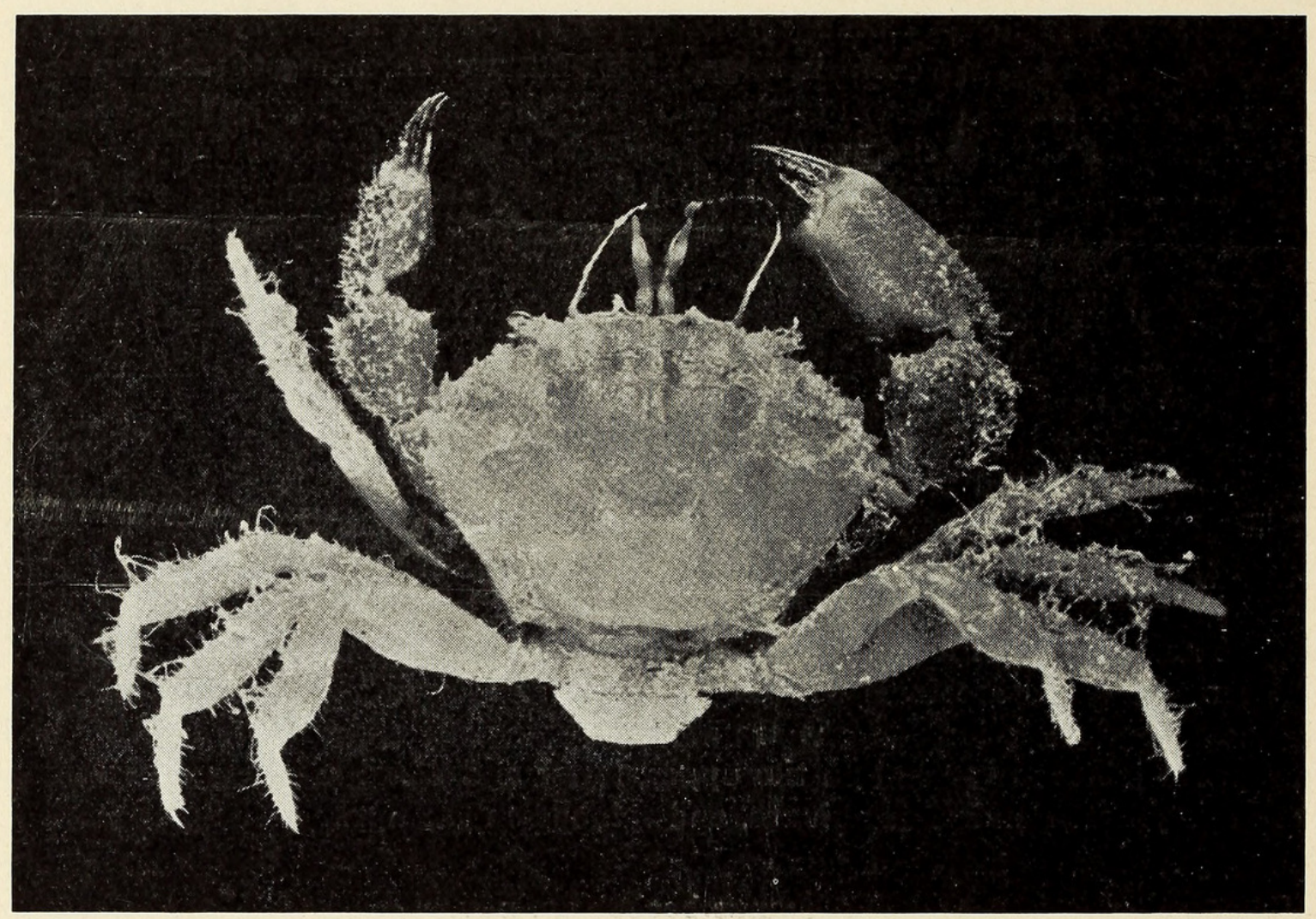

Fig. 80. Pilumnus beebei, $\times 6$.

more acuminate on the anterior part of the carapace, tending to a bead-like serrate formation along the anterolateral margins; on the posterior region they are finer but very abundant. The interorbital space is $2 \mathrm{~mm}$. wide, with the margin straight, thin and granulate with the outer angles rectangular; the median notch is conspicuous, V-shaped; a shallow sulcus runs inward from it onto the gastric region, defining the two large frontal lobes. The superior and inferior orbital margins are coarsely granulous. The inner, inferior orbital tooth is sharp. The pterygostomian regions and under sides of the carapace are granulous, similar to the dorsal surface of the carapace. The anterolateral margin is quinquedentate, counting the small postorbital tooth as the first tooth. The space between the first and second teeth is greater than that between any of the succeeding teeth; a small, acuminate subhepatic spinule from below the margin is visible dorsally, situated about midway between the first and second 
spines. The second spine is usually triangulate, obtuse and subequal to the third spine from which it is separated by a short V-shaped sinus; the fourth tooth is more acuminate than the third and is separated from it by a deeper serration than that between the second and third teeth; the fifth tooth is also acuminate, but is smaller than any of the preceding teeth. The posterolateral margins are convergent.

The male abdomen is triangulate, narrow, five-segmented, the third segment being composed of three coalesced segments. The female abdomen is sevensegmented and narrowly oval.

The chelipeds are conspicuously unequal in both sexes. But little of the meral joint is visible dorsally; this, the distal end, is covered with granules; the carpus is about three-fourths as long as the palm of the propodus and has its upper distal border triangular and finely serrate by coarse granules; the upper and outer surface is also rough with granules; the propodus is four-fifths as long as the carapace is wide, the palm being three-fifths of this length and the fingers comprising the remaining two-fifths. The propodus is thick and is approximately half as high as long with the outer surface convex; the upper surface and the upper half of the outer side are covered with large granules which decrease in size as they approach the lower margin, the lower half or occasionally lower third to fourth being smooth; the fingers are well-developed, brown, the lower one being the thicker and armed with three teeth; the upper finger is more curved and devoid of teeth. Both fingers are fluted by a series of longitudinal carinae and each has a few sharp tubercles usually forming a longitudina] row on the proximal portion. There is a groove-like depression on the upper surface of the propodus which is accentuated by the line-like arrangement of the tubercles. The propodus of the small cheliped is like the large one except that it is more coarsely granulose, the grooves are deeper, and the entire outer surface is covered with acuminate granules.

The first three pairs of ambulatory legs are approximately subequal, the fourth pair is similar but noticeably shorter. All are covered with long setae and have a very few granules on the upper marginal surfaces of the meral, carpal and propodal joints, the dactyli are approximately as long as the propodi and are but little curved except at the horny tip.

The antennulae are quite robust and fold transversely in the fossette, under the frontal margin.

The external antennae are quite small and have the basal joint short, not quite touching the front, the second and third joints slender and situated in the orbital hiatus, the flagellum is composed of about twenty tapering joints and is quite long.

The external maxilliped is rectangular and the ischium has its distal margin a little oblique; the merus is a little more than half as long as the ischium and has its distal border almost transverse; the palp is three-jointed, the basal joint being very well-developed.

Pilumnus pygmaeus sp. nov. (Pygmy Crab).

Diagnostic characters.-Anterolateral margin arcuate with four obtuse teeth faintly delineated. Anterior two-thirds of carapace and chelipeds covered 
with rounded granules and dense pubescence. Palms of both chelipeds with entire outer surface granulose.

Type.-The type, an adult female, three ovigerous females, six females, one megalops, and four males were taken at Arcturus station 54, off Hood Island, 15 feet, and are deposited in the New.York Zoological Society collections.

Galapagos distribution.-Arcturus station 54, off Hood Island, 15 feet, and Tower Island, shore zone, station 37.

General distribution.-Galapagos Islands.

Material examined.-Ten females, three of which are ovigerous, one megalops and four males, taken at station 54, by Dr. Beebe while diving in 15 feet of water; also three males and six females from station 37 , shore zone, Tower Island.

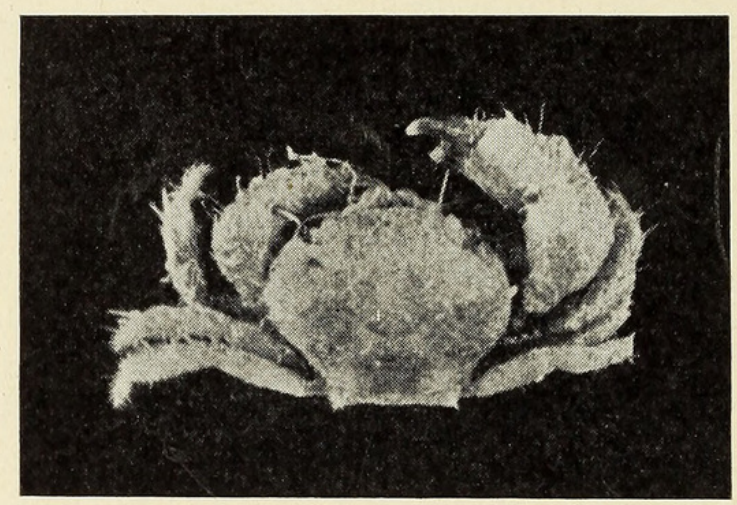

Fig. 81. Pilumnus pygmæus, $\times 6$.

Technical description.-Carapace $2.8 \mathrm{~mm}$. long, $3 \mathrm{~mm}$, wide; interorbital space $1.5 \mathrm{~mm}$. wide; moderately convex in both directions; interorbital space one-half of the maximum width of carapace; frontal border straight, granulose, with a distinct median notch; superior orbital border semi-elliptical, finely granulose, as is also the inferior orbital margin; anterolateral margin arcuate, broken into four broad, obtuse teeth, which do not, or scarcely, extend beyond the marginal line; anterior two-thirds of carapace covered with prominent rounded tubercles, which are more abundant near the margins; also with a thick pubescence. The undersides of the carapace are also granulose; hirsute. The female abdomen is oval, seven-segmented, fringed with setae; the outer rami of the appendages are extended spoke-like beyond the belt to help support the egg-mass which is attached to the long setae of the inner rami. The male abdomen is five-segmented, triangular; the first pair of male appendages are substantial rods, tapering to an acuminate point.

The chelipeds are conspicuously unequal in both sexes; the merus is trigonal and closely appressed to the carapace, only the upper distal surface showing dorsally; the carpus is very large, convex, approximately three-fourths as long as the palm; the palm is high, very convex on the outer surface; the distal end of the merus, the carpus and the propodus are densely covered with rounded granules and with a thick, long, furry, curved spinose setae. These granules cover the entire upper and outer surface of both palms and are frequently visible 
on the proximal parts of the fingers. The fingers are stout, fluted externally, cutting edges dentate and close-fitting.

The four pairs of ambulatories are similar, densely hirsute, the meral, carpal and propodal joints are flattened and the dactyl long, slender and acuminate.

\section{Subfamily: OZIINAE}

Genus Ozius H. Milne Edwards, 1834.

Key to the Galapagos species of the genus Ozius.

Anterolateral angles decidedly produced and broken into three distinct teeth.

verreauxii

Anterolateral angles produced, margin vaguely tridentate. A transverse line from the lateral angle back onto the gastric region. Chelipeds extremely unequal, granulose.

Frontal margin rather broadly rounded. Anterior portion of carapace and upper and outer surfaces of chelae and legs corrugated. Chelipeds moderately unequal.

agassizii

perlatus

Ozius verreauxii (de Saussure), (Velvet-fingered Crab.)

Ozius verreauxii $\mathrm{H}$. de Saussure. Rev. et Mag. de Zool. 2nd série, t. V. p. 358, pl. XII, fig. 1, 1853 . Ann. Lyc. Nat. Hist. N. Y. No. 2, p. 83, 1860 Ozius verreauxii A. Milne Edwards, Crust. Rég. Mex., p. 277, pl. 55, fig. 4, 1880; Faxon, Mem. Mus. Comp. Zool., vol. 18, p. 21, 1895; Rathbun Proc. U. S. Nat. Mus., vol. 21, p. 583, 1899; Proc. U. S. Nat. Mus., vol.

38, p. 587, 1910; Zoologica N. Y. Zool. Soc., vol. V, no. 14, p. 158, 1924.
Xantho grandimanus Lockington, Proc. Calif. Acad. Sci., Sept. 1876.

Name: This species was named in honour of M. Verreaux.

Diagnostic characters.-Anterolateral angles decidedly produced, and broken into three distinct teeth.

Type.-H. de Saussure's type material on which this species was founded was secured at Mazatlan, Mexico, as long ago as 1853.

Galapagos distribution.-The earliest Galapagan record for this species appears to be that of Dr. Habel, in 1869 who simply records "Galapagos Islands." The Hassler voyage took it at James Island in 1872. The Albatross secured it at Charles, James, Chatham and Indefatigable Islands, 1887-88 and 1891. It was taken by the Harrison Williams Galapagos Expedition at Indefatigable Island in 1923.

General distribution.-Cape St. Lucas, and La Paz, Lower California; Mazatlan, Mexico; Cocos Island; Galapagos Islands and southward to the coasts of Ecuador.

Material examined.-One very large female and a smaller male specimen were taken by the Arcturus Expedition at Cocos Island, May 13, 1925.

Technical description.-Carapace moderately convex, finely granulose and eroded on the anterior region; posterior region smooth. Interorbital margin quadridentate, the submedian pair of teeth being broadly rounded, the outer pair similar but slightly smaller. Anterolateral margin rounded, anterolateral angles decidedly produced, broken into three distinct teeth, of which the most anterior is broad and blunt, the median, acute and separated from the preceding by a transverse line which is continued on the branchial region, the third tooth is 
similar to, but only about half as large as, the second. The postlateral margins are convergent, delineated by a fine line, below which the side walls of the carapace are dorsally visible. The regions of the carapace are clearly delineated, except the mesogastric, which is vaguely outlined. There is a deep sulcus running backward from the median frontal notch and bifurcating on the gastric region. In addition to this, there is a deep transverse sulcus behind the frontal margin which bends abruptly behind the outer orbital margin and vanishes near the anterior of the mesogastric region. The orbit is subcircular with the margin raised and the lower inner angle prominent.

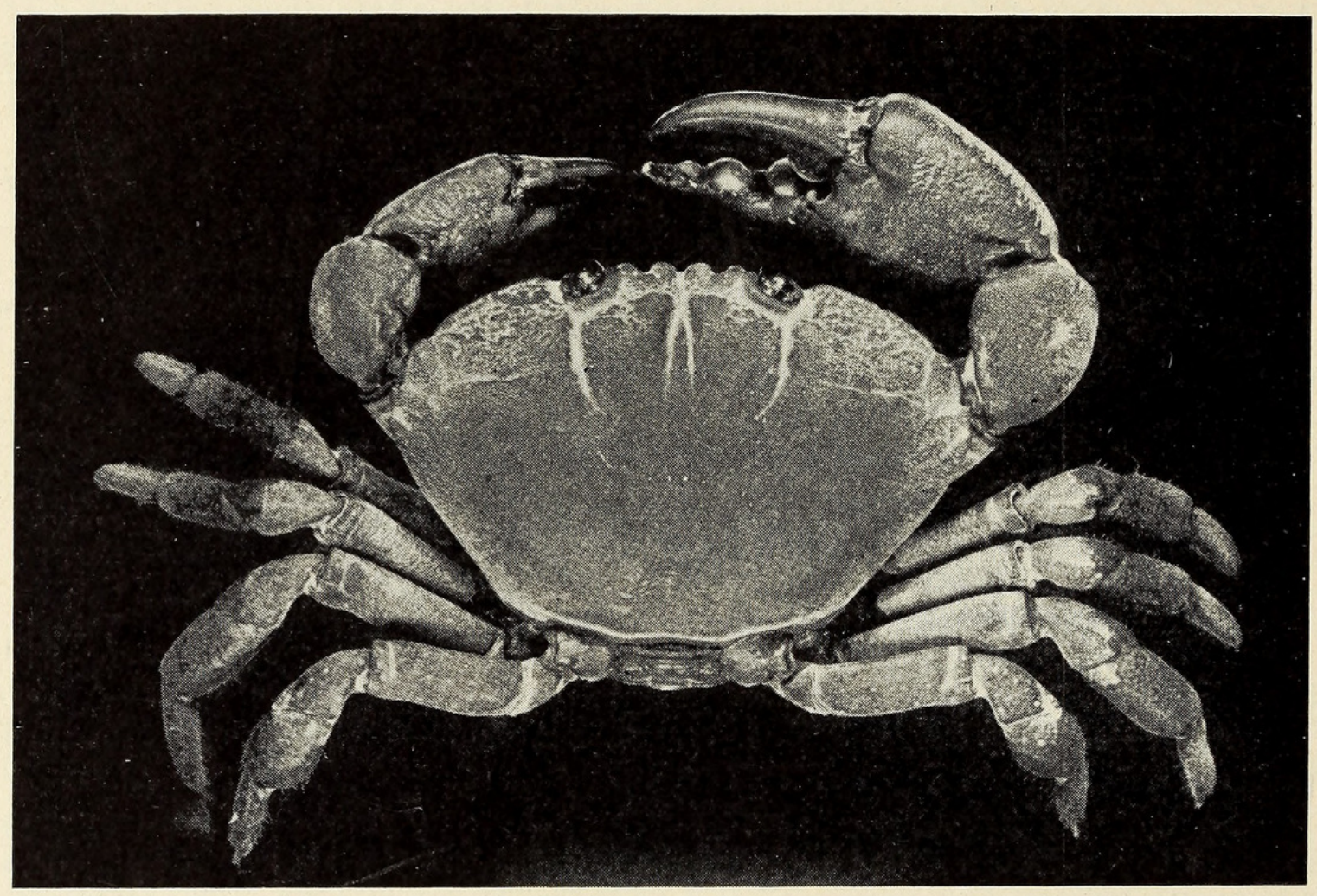

Fig. 82. Ozius verreauxii. Reduced to $1 / 2$ of natural size.

The eyestalk is dilated basally, constricted on the outer surface below the cornea; the latter is terminal, subelliptical, shiny black.

The outer antennae have the basal joint enlarged, the distal joint stout, small, and the flagellum minute.

The inner antennae are fleshy and fold transversely within the septum.

The external maxillipeds are squarish, devoid of setae except along the inner surfaces of the ischium. The exognath is very slender, slightly curved, and bears a long internal lash. The ischium is elongate, subrectangular; the merus about as long as wide, traversed by two longitudinal sulci, and with the upper margin truncated at both corners and deeply incised between these sulci at the efferent aperture. There is a compressed three-jointed palp which arises near the inner distal margin of the merus and bends down adjacent to the inner margin. The pterygostomian regions are finely granulose but devoid of setae. 
The female abdomen is broadly ovate, covering practically all of the sternal region, except that between the chelipeds, which is densely furred with setae; the abdomen consists of seven segments and is fringed marginally with fine setae. Segments two, three and four and five bear biramose pleopoda similar in shape to those of Ozius agassizii. The male abdomen is narrow, seven-segmented, the third segment being conspicuously the widest, the sixth the longest, the seventh triangulate. The male appendages are similar to those of Ozius perlata.

The chelipeds are unequal; the large one is very massive, has the merus three-sided, compressed, not projecting beyond the carapace; the carpus is convex, dilated distally; the propodus very convex on the outer surface, considerably higher than the carapace, twice as long, including the finger, as high; the propodal finger is heavy, triangulate, armed with a low basal molar, a high, median and small distal molar and bluntly pointed distally. The hinged finger is slenderer, curved, armed with a gigantic basal molar and five small rudimentary teeth, the tip is blunt; the fingers gape. Both fingers are blackish brown. This coloring extends backward on the propodus. The small cheliped is similar to the larger one except that it has longer slenderer fingers which are not gaping.

The ambulatory legs are similar; the first three pairs are subequal, the last pair being only two-thirds as long as the preceding. The joints are stout, moderately compressed laterally. The merus is decidedly the longest joint and is transversed distally by a constriction on the upper surface just below the distal margin; the carpus is dilated distally and produced diagonally to a point on the upper surface; the propodus is stout, compressed, the dactyl is slightly longer than the propodus and slenderer and is tipped with a stout horny nail. The dactyl, propodus and distal part of the carpus are covered with fine, silky brown setae, forming a velvety surface.

Color.-The color plate of this species made by Isabel Cooper shows it to be slate gray with bandings of coral at the meral and carpal joints of the ambulatory legs.

Ozius agassizii A. Milne Edwards, (Long-clawed Pebble Crab.)

Ozius agassizii A. Milne Edwards, Crust. Rég. Mexico, p. 279, pl. 55, fig. 1, 1880; Rathbun, Proc. U. S. Nat. Mus., vol. 38, p. 586, 1910.

Diagnostic characters.-Chelipeds extremely unequal, granular. Anterolateral angles produced, margin finely tridentate. A transverse line from the anterolateral angle in to the gastric region.

Type.-This is one of the many species that owes its discovery to Alexander Agassiz, who secured the type at Panama. It is deposited in the Museum of Comparative Zoology at Cambridge, Mass.

Galapagos distribution.-Duncan Island; Arcturus station 54, off Hood Island, 15 feet.

General distribution.-Ozius agassizii is found from the Gulf of Panama (type-locality) to Ecuador and also in the Galapagos Islands and Cocos Island.

Material examined.-As unusually fine representative series of young and a few older specimens, including two egg-laden females, of this species were secured by William Beebe while diving in fifteen feet of water at Station 54, off Hood Island. (Fifteen females, and one male, including four soft-shell speci- 
mens). Eleven males, seven females and one very young specimen from Tower Island, station 37, shore zone D to E, April 10, 1925. Three females were taken at Cocos Island, May 19, 1925.

Color, habits. - This species was found in association with the closely allied Ozius perlatus Stimpson, which it resembles in coloration, being a rich red-brown.

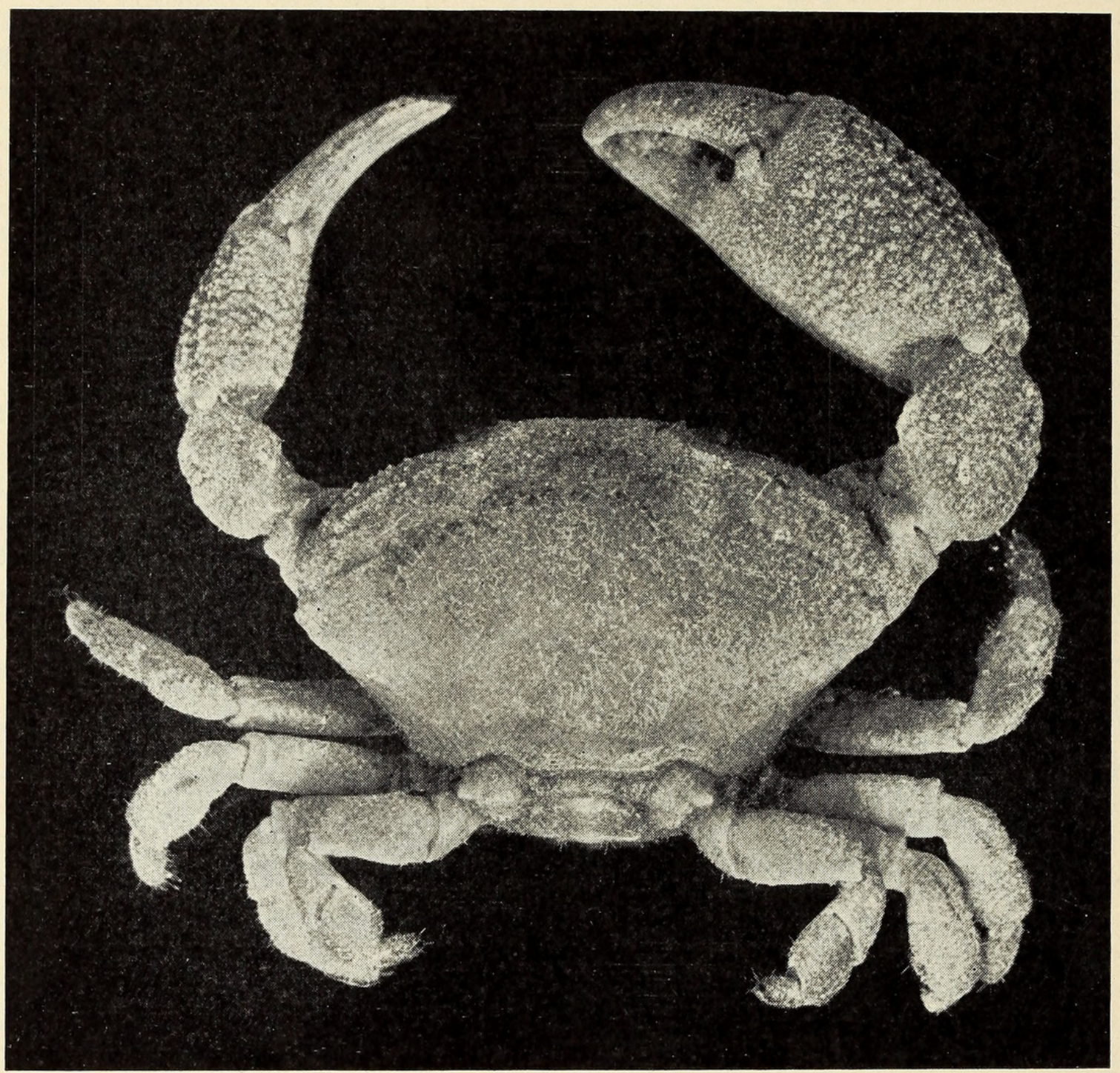

Fig. 83. Ozius agassizii, $\times 1.5$.

The present species also dwells in the crevices of coral rocks. It is enabled to entrench itself firmly therein by means of its stout sharp-pointed dactyli. Four specimens in the collection are soft-shelled. The integument is of a tough, fleshy texture, and presents all the characters of the hard shell, except inflexibility.

Technical description.-Carapace flat with the anterolateral margin ovate; anterolateral branchial region much produced and with three small dental prominences; the posterolateral margins decidedly converging; the branchial, 
gastric and cardiac regions are delicately delineated. A distinct transverse line extends from the anterolateral angle onto the gastric region. The anterior region of the carapace is rugose, being covered with rounded granulations between which occur small pits. This rugose granulation also occurs on the lower sides of the carapace, the upper, outer surfaces of the ambulatory legs and covers the chelipeds. It differs from the rugose surface of Ozius perlatus which has an eroded appearance while that of agassizii is roundly granular. The interorbital margin is depressed, rather than straight in a dorsal view, but is deeply incised in the median line and produced into a pair of obtuse submedian teeth beyond, the ridged margin is recurved terminating in a pair of obtuse teeth near the superior inner orbital angle. The orbit is subcircular with the margin a granulose ridge, the inner superior angle being obtuse and slightly greater than the inner inferior angle.

The eyestalk is short, constricted below the cornea and finely granulate, the distal margin around the cornea being fringed with fine silky setae. The cornea is terminal, ovate, convex, shining black. It is much larger than that of $A$. perlatus.

The outer antennae have the elongated basal article lodged in the orbital sinus; the distal article is stout; the flagellum consists of about twelve articles and is almost as long as the orbital cavity is wide.

The inner antennae are very stout and fold transversely within the septum.

The external maxillipeds are densely setigerous, rectangular and very closefitting. The exognath is an elongate rectangle and bears a long lash which is internal in position. The ischium of the engonath is a much wider rectangle, the inner edge being thickly fringed with short setae; the merus is not quite as long as wide, has the outer distal margin flaring, rounded, the upper distal margin is deeply incised at the efferent aperture; there is a stout threejointed palp which arises near the inner distal angle of the merus and curves downward beside its inner margin.

The abdomen (female) is widely ovate, seven-segmented, fringed with long setae which also clothe the anterior sternal region. The second to fifth segments inclusive each bear a pair of subequally biramose appendages, the outer branch of which is longer, scythe-shaped and densely fringed with long hairs; the inner branch is bent inward toward the median line for the first third of its length and then slightly bowed and lying near the median line. When the crab is egg-laden, the four outer branches are spread like the spokes of a fan outside the belt around which they curve like the walls of a basket, encupping the eggs or larvae which are attached to the thread-like hairs of both appendages. The male abdomen is narrow, seven-segmented, the sixth and seventh segments being decidedly longer than the preceding ones. The male appendages are similar to those of Ozius perlatus.

The chelipeds are even more conspicuously unequal than are those of Ozius perlatus. The large one is very massive, has the merus projecting beyond the carapace and transversely grooved on the surface near the distal end and a short longitudinal groove; the propodus is expanded, about half as high as long, and is much higher than the carapace; the finger comprises about one-third of the length of the propodus and is conical and armed with five molars; the 
upper finger is similar to the lower but more curved; it also has five small molars. Both fingers are slaty black with white molars and maroon tips. The small cheliped is approximately as long as the large one but it is exceedingly slender; the finger is three-fifths of the length of the propodus and is very slender, tapering and pointed. The hinged finger is similar to the lower, both are finely dentate along the inner margin and each has five larger triangulate teeth regularly interspaced among the smaller teeth. The female chelipeds are approximately as large and as unequal as those of the male. The ambulatory legs are similar, the first pair being scarcely three-fifths as long as the chelae, the remaining pairs successively decreasing in length posteriorly. All are stout, decidedly compressed laterally and have strong dactyli, tipped with a horny nail. The dactyli are densely covered with a thick felt, the propodus and. distal part of the carpus are sparsely covered with the same texture.

As previously stated, the surfaces of the chelipeds and, in a less degree, the upper surfaces of the ambulatories are covered with rounded granules interspaced by pits, giving the surface a rugose appearance.

Young.-A young female speciman $3.5 \mathrm{~mm}$. wide and $3 \mathrm{~mm}$. long has all the major specific characters of the species, including the rugose granular surface on the anterior region of the carapace and legs. As is usual in very young crabs of this genus, the interorbital space appears very wide and the eyes proportionately much larger than those of older specimens. The legs are setigerous and a downy fuzziness clothes the carapace.

Eggs, Larvae.-The eggs are very numerous, a crab of $12 \mathrm{~mm}$. greatest width carrying over 1000 eggs. They are minute, less than $0.5 \mathrm{~mm}$. in diameter, golden spheres individually attached to the long plumose setae of the pleopoda.

One one of the ovigerous females the eggs, scarcely half a millimeter in diameter, show the well developed opaque embryos with tiny black eye-spots.

Another specimen shows the embryos in a much more advanced stage. These are about $0.7 \mathrm{~mm}$. in diameter, chocolate brown, with huge, black, elliptical eye-spots.

\section{Ozius perlatus Stimpson. (Eroded Pebble Crab.)}

Ozius perlatus Stimpson, Ann. Lyc. Nat. Hist. N. Y., vol. VII, p. 83, 1860 A. Milne Edwards, Crust. Rég. Mexico, p. 278, pl. 55, figs. 2a-c, 1880.

Diagnostic characters.-Chelae moderately unequal. Anterior portion of carapace and upper and outer surfaces of chelae and legs corrugated. Distinguished from the analogous West Indian species, Ozius reticulatus Desbonne and Schamm, by the more broadly rounded frontal margin of the present species.

Type.-The type material "was found in considerable numbers at Cape St. Lucas, by Mr. Xantus and was deposited in the United States National Museum."

Galapagos distribution.-Arcturus station 37, shore zone D to E, Tower Island, and station 54, off Hood Island where this species was taken in great abundance, establish the first Galapagan records for this species.

General distribution.-Ozius perlatus Stimpson has been taken from Cape St. Lucas, Lower California, and at Panama along the tide-line and in shallow water; also at the Galapagos Islands. 
Material examined.-The material secured by the Arcturus Expedition extends the range of this species to the Galapagos archipelago. Twenty-two specimens, ranging in size from minute organisms to very large forms, some of which are egg-laden, were secured at Station 37, shore zone D to E, Tower Island, April 16, 1925, and a representative series of thirty specimens was

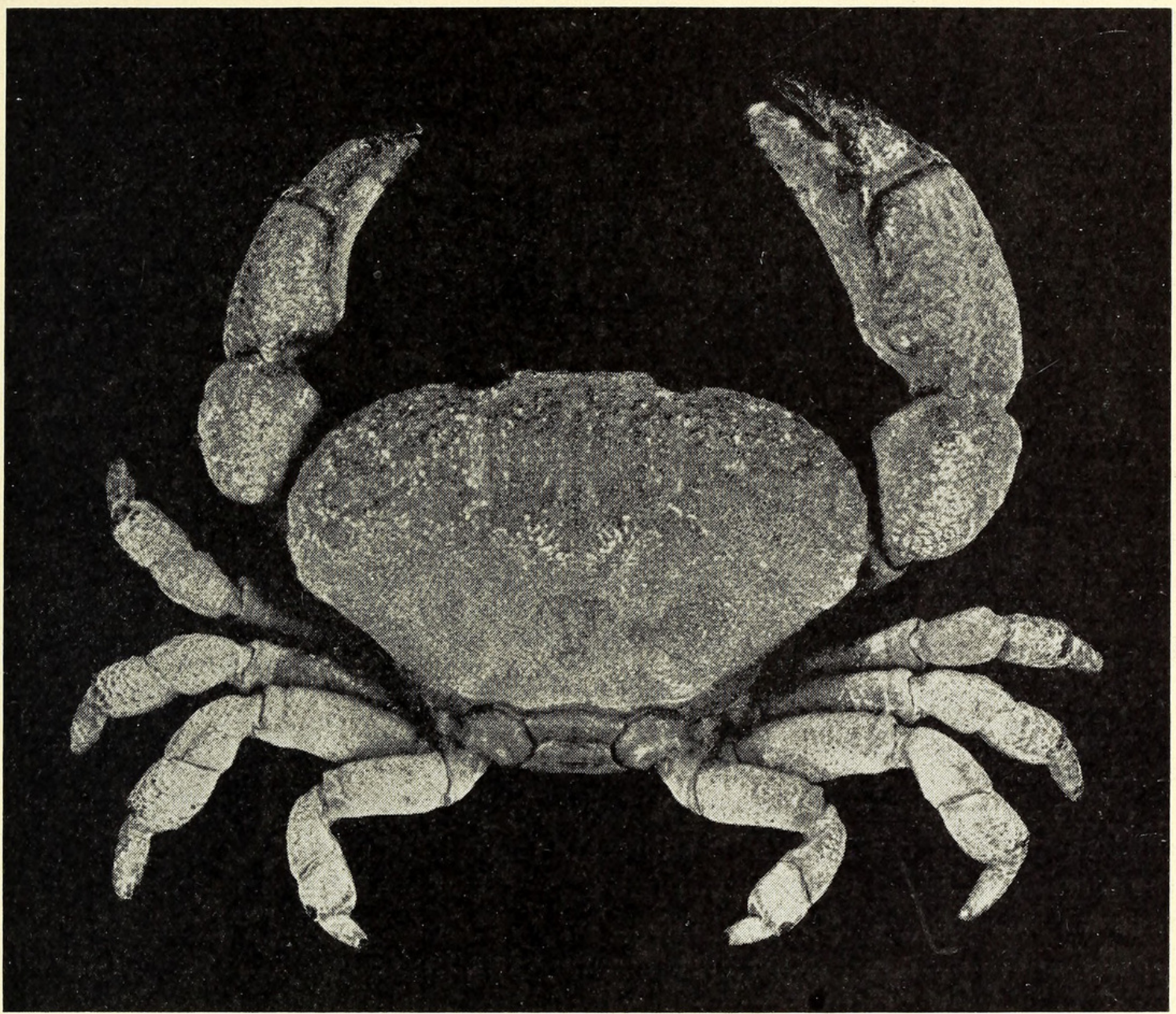

Fig. 84. Ozius perlatus, $\times 1.9$.

secured at station 54, off Hood Island, by William Beebe, while diving in 15 feet of water.

Color and habits.-These curious little red-brown organisms were difficult to distinguish from the coral rocks in the crevices of which they were fitted like bits of living mosaic, the rugose surface of their bodies further accentuating the similarity.

Technical description. - Carapace quite broad (28 mm. wide, $17 \mathrm{~mm}$. long), depressed, anterolateral margins broadly rounded, posterolateral margins decidedly converging. Interorbital margin relatively straight in a dorsal view, depressed, and transversely channelled, but actually decidedly broadly obtusely bidentate on the frontal margin. The female abdomen is seven-segmented, 
broadly rounded distally, and fringed with setae, as is the anterior sternal region; the second to fifth segments bear biramose pleopoda, the outer branch being curved, scythe-like and the inner one bent inward toward the median line for the first third of its length, and with the distal two-thirds slightly arcuate and lying near the median line. The male abdomen is also sevensegmented, the first and second segments are dorsal, the third segment is conspicuously the widest; the fourth, fifth and sixth segments being successively longer; the terminal segment is triangular. The first pair of male appendages are stout basally, taper distally and are slightly tortuous and three-sided, the margins of this distal region are finely spinous, the apex is a spoon-shaped concavity which is continued as a groove on the inner of the three sides. The second pair of appendages are exceedingly slender, rodlike processes which are finely attenuated distally and curved inward in a deep semicircle, then curved downward in another semicircle which approximately parallels the first curve. The anterior region of the carapace, upper and outer surface of the chelipeds and of all the ambulatory legs are corrugated, the raised areas being irregularly shaped and reticulating, the channels deep, eroded; the posterior region is flat and smooth except for a few fine granulations. The branchial regions are distinctly delineated; the pterygostomian regions are coarsely granulated.

The orbit is small, circular, with the margin slightly ridged. The eyestalk is very short, bulbous, filling the ocular cavity; the cornea is terminal, obliquely set, exceedingly small and slightly convex, shining black.

The outer antennae are situated at the inner lower orbital angle and have the basal article narrow and slightly projecting, the distal article minute and the flagellum quite small.

The inner antennae are well-developed and fold transversely in the antennal septum.

The external maxillipeds fit closely in the aperture and are beset with clusters of setae; the ischium is subrectangular, longitudinally channelled near the median area and fringed with fine setae along the inner margin; the merus is as wide and approximately half as long as the ischium and traversed by two longitudinal sulci, the inner of which is a continuation of the sulcus on the ischium, and the outer one, in line with the depression between the exognath and endognath; the distal margin is deeply incised at the efferent aperture, and a tapering, three-jointed palp arises from near the inner distal angle; the exognath consists of a short, broad, bent base, an elongate rectangular second joint, which extends almost to the distal angle of the merus, and is slightly depressed distally and bears a long, flexible cylindrical whip which is flagellum-like and fringed with plumose setae.

'The male chelipeds are massive and conspicuously subequal, having the basis and ischium short and stout, the merus swollen, three-sided, with the lower distal angle acutely produced; the carpus is broadly rounded outwardly and produced knob-like on the upper inner side; the propodus is broad and high and dilated distally; the fixed finger is massive, gaping and bears three distinct molars; the hinged finger swings obtusely and is a trifle slenderer than the basal. It also bears three small molars. Both fingers are slaty black tipped with maroon. The small cheliped differs from the large only in size and in having 
the fingers meet along the cutting edge. As previously noted, both the chelipeds and ambulatories are rugose on the upper and outer surfaces. The first and second pair of ambulatory legs are subequal, the third pair, decidedly the longest, while the fourth pair are conspicuously the shortest. They are all similar in structure being stout and somewhat compressed laterally, except the dactyli which are cylindrical, short, tapering to a strong horn-like point; the sides of the dactyli are covered with felt-like setae and this extends in clusters upon the propodus.

Young.-A very young male crab,-4 $\mathrm{mm}$. wide and $3 \mathrm{~mm}$. long,-bears all the specific characters of the species but differs from the above described older specimens in being finely, conspicuously setigerous all over; in the absence of the eroded surface of the carapace and chelae, which is finely granulate on the young specimen, in having the fingers meeting, not gaping, and the molars more conspicuous than in the older worn specimen. In the little crab the interorbital space is proportionately much wider than in the older crabs, giving the little creature a quaint, big-eyed, flat-faced expression.

Eggs. - The eggs are minute, spherical, golden and very numerous. A crab about one inch wide carried approximately 1500 eggs.

\section{Subfamily: ERIPHIINAE}

Genus Eriphia Latreille, 1817

Key to the Galapagos species of the genus Eriphia.

Carapace with granulations covering the entire gastric and hepatic regions and the anterior portions of the branchial regions and present also in a reduced form on the back.

granulosa

Carapace with scale-like tubercles, each of which is ringed with setae, on the anterior borders of the carapace. Chelipeds similarly ornamented.

squamata

Eriphia squamata Stimpson, 1859. (Beaded Crab.)

Eriphia squamata Stimpson, Ann. Lyc. Nat. Hist. N. Y., vol. 7, p. 56, 1859; Sydney I. Smith, Rept. Peabody Acad. Sci., p. 90, 1869; A. Milne Edwards, Crust. Rég. Mexico, p. 339, pl. 56, fig. 3, 1880; Rathbun, Proc. U. S. Nat. Mus., vol. 38, p. 544, pl. 41, fig. 1, 1910.

Diagnostic characters. - Chelipeds conspicuously unequal with the scale-like tubercles of wrist and hand squamous and each tubercle ringed anteriorly with fine setae.

Type.-Professor Stimpson's type came from Cape St. Lucas, Lower California and was deposited in the "Museum of the Smithsonian Institution."

Galapagos distribution.-Three large females, two of which were ovigerous, were taken at Eden Island, Galapagos, by the Harrison Williams Expedition and three small females, one of which is ovigerous, and two small males taken at Station 54, Hood Island, by the Arcturus Oceanographic Expedition comprise the Galapagos records for this species.

General distribution.-This species has been recorded from Cape St. Lucas, Lower California; the west coast of Mexico; Panama; Nicaragua; Peru and Chile. 


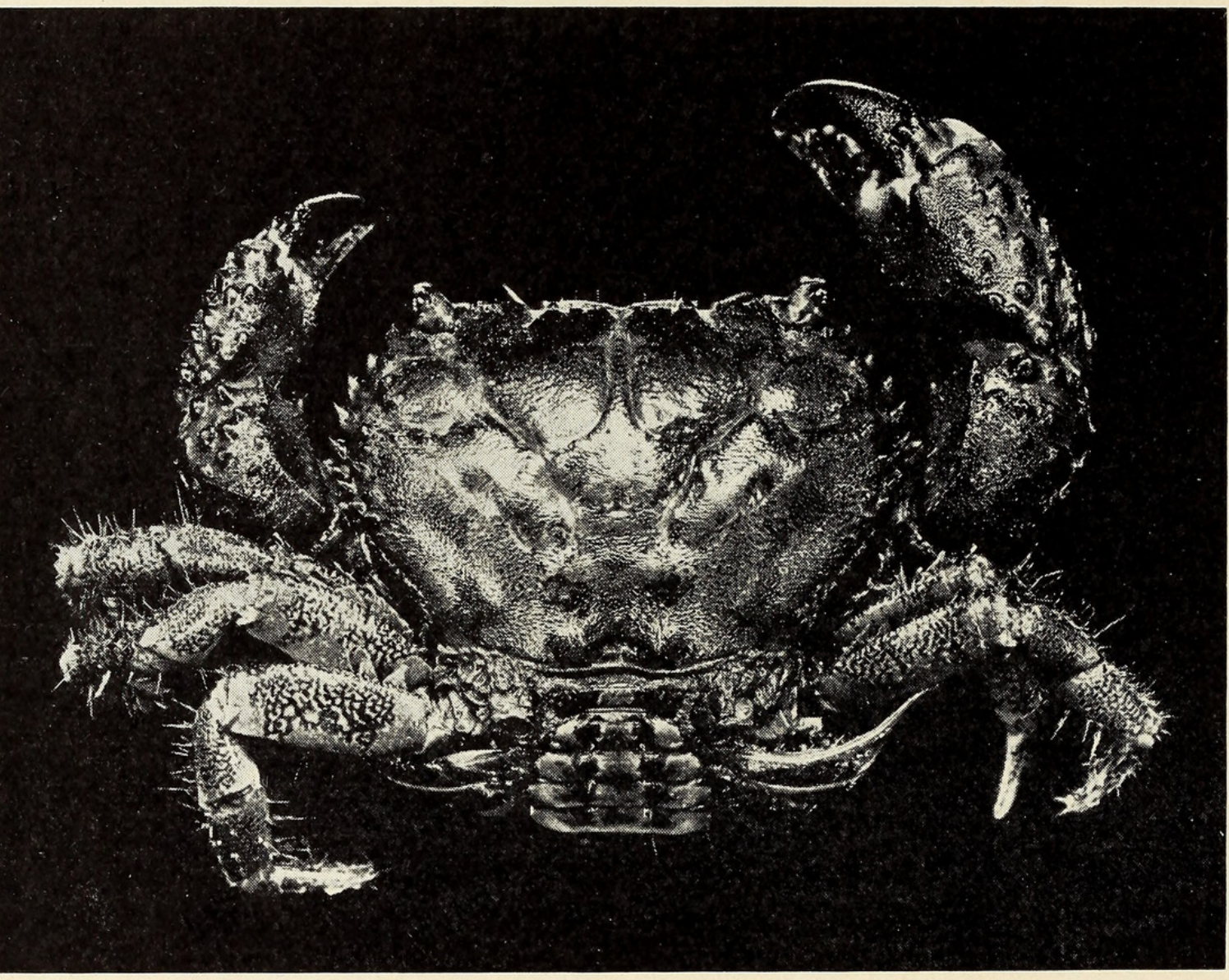

Fig. 85A. Eriphia squamata, $\times 1.7$.

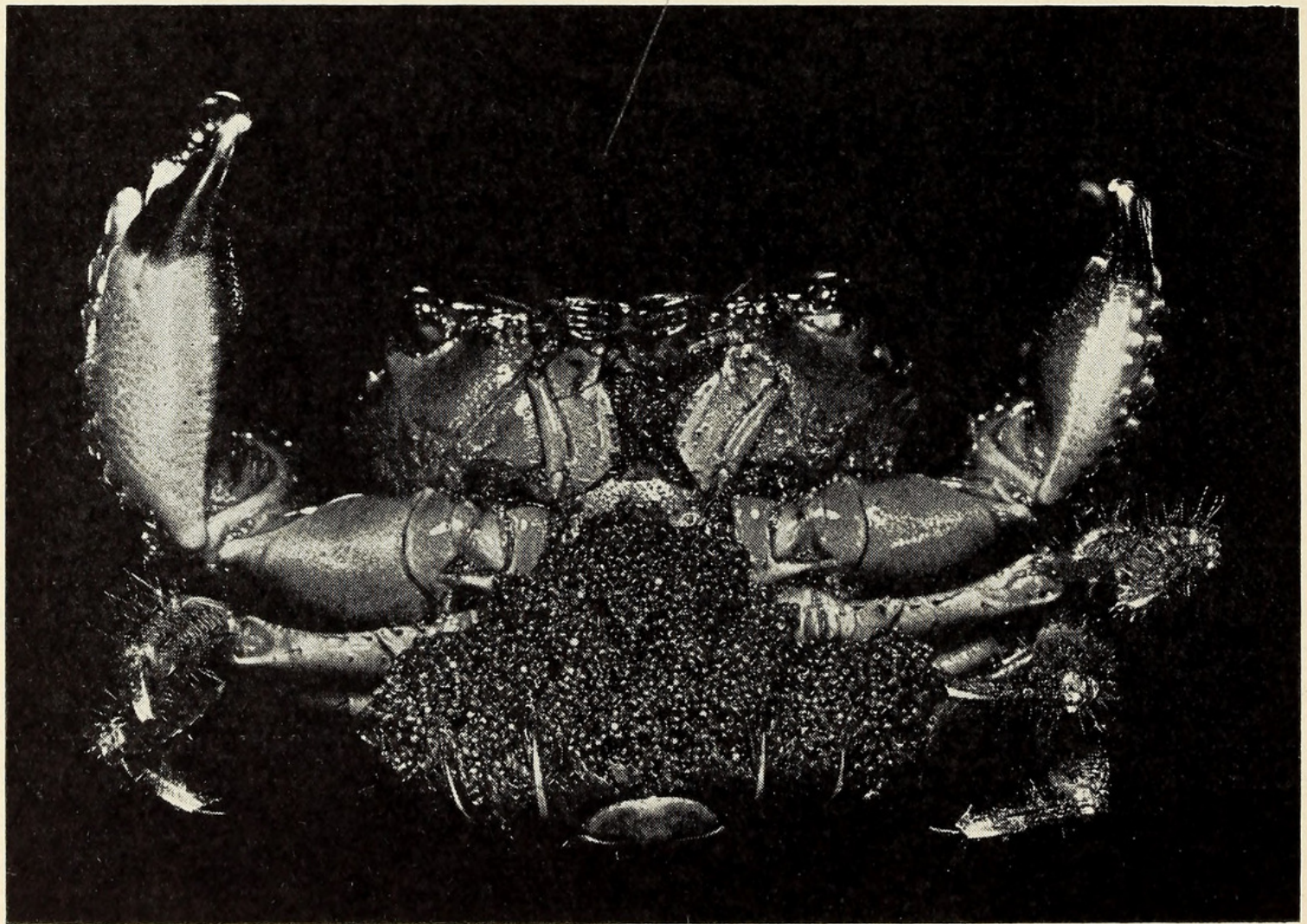

Fig. 85B. Ventral view of same specimen shown in Fig. 85A. 
Material examined.-Three small females, one of which is ovigerous, and two small males were taken at Station 54, off Hood Island by William Beebe, while diving in fifteen feet of water. Dr. Beebe states that these crabs were found in crevices of the coral rock which they so much resemble. One large female was taken at Cocos Island, May 13, 1925, by the Arcturus. Three large females, two of which are ovigerous, were taken at Eden Island, Galapagos, by the Harrison Williams Galapagos Expedition.

Color.-Purplish red shading into magenta.

Technical description.-The anterior three-fifths of the carapace is very wide as contrasted with the posterior two-fifths, whose sides converge abruptly. The greatest width of the carapace is $30 \mathrm{~mm}$; the interorbital space is $18 \mathrm{~mm}$.; the length of the carapace is $23 \mathrm{~mm}$. The carapace is ornamented anteriorly with squamous granules and tubercles which in some places simulate rugae. The regions of the carapace are distinctly indicated by sulci. The interorbital space is truncate; the margin is channeled and is divided into two major lobes, a deep longitudinal median sulcus extending back on the gastric region. The anterolateral margin is convex and is armed with six (including the postorbital), acute, forward-curved teeth, of which the anterior three are subequal and larger. the last three gradually decrease in size posteriorly. Although six is the usual number of spines on the lateral border, occasional large specimens have seven, or, more rarely, eight teeth. Some specimens I have examined have six teeth on one side, and eight on the other, the two extra teeth apparently being irregular development of squama of the carapace pushed out to the margins. The pterygostomian region is sparsely setiferous.

The female abdomen is oval, seven-segmented, with the entire margin densely fringed with hairs, as is the sternal area opposite the distal abdominal segment. The second to fifth segments inclusive bear paired biramose appendages. The outer branch of each appendage is long and curved; the inner branch consists of a short, proximal segment and a long distal segment. Both branches are heavily fringed with long, plumose setae. The radial basketforming position assumed by these branches in supporting the eggs is wellillustrated in figure 85B. The paired female genital apertures, situated in the sternal plate which is opposite to the second ambulatory legs, are near the median line of the cavity and are curiously overarched by a tongue-like calcareous process which is derived from the sternal plate; the under margin of the aperture is heavily fringed with coarse black setae.

The male abdomen is narrow, seven-segmented with the apex triangulate. The first pair of male appendages are well developed rods; the second pair are nearly as long as the first and are very slender with distal end forming one and one-half or two coils of a spiral.

The inner antennae are typical and fold transversely with the fossett.

The external antennae are small; the basal segment is firmly anchylosed and situated at the outer end of the antennular fossett; there is one large squama on it; the second and third articles are compressed; the flagellum consists of about twenty-six articles and reaches to the base of the eyestalk.

The external maxillipedis fit closely into the buccal cavity except for a notch at the efferent aperture. The ischium is rectangular with a deep longi- 
tudinal groove on its outer surface; the merus is about half as long as the ischium and has the distal margin angulated; the three-jointed palp arises from the inner distal margin of the merus.

The chelipeds are conspicuously unequal in both sexes; robust; the merus is smooth except for a single sharp tooth at the upper distal angle and a similar obtuse tooth at the lower distal angle; the carpus and propodus are smooth on the inner and lower sides but the outer and upper sides are covered with large squamose tubercles forming a close-set, scale-like pattern. Each squama is fringed anteriorly with fine dense hairs. The fingers are well developed; the movable finger of the large cheliped has a stout tooth basally, and is strongly curved apically; the fixed finger bears a trilobed molar basally; the fingers of the smaller cheliped are slenderer, uniformly dentate, not gaping.

The ambulatory legs are compressed, subequal, set with clusters of hairs, especially on the distal three joints.

Young.-One of the young female specimens secured at Station 54, measures $4 \mathrm{~mm}$. long; $6 \mathrm{~mm}$. anterior diameter. It conforms in all details to the description of the adult, but the young specimen is covered with sparsely set long hairs, especially on the ambulatory legs and dorsal surface of the carapace and to these is fastened a protective coating of algae, bryozoa, bits of shell and sand.

Eggs.-One female only $7 \mathrm{~mm}$. wide, $5 \mathrm{~mm}$. long was carrying about 100 embryos. These were spherical with slit-like black eyespots.

The large female photographed (Fig. $85 \mathrm{~A}$ and B) carried several thousand small chocolate-colored spherical eggs.

Eriphia granulosa A. Milne Edwards. (Also known as “Beaded Crab.”)

Eriphia granulosa A. Milne Edwards, Crust. Rég. Mex. p. 339. pl. 56, fig. 2 , 1880; Rathbun, Proc. Wash. Acad. Sci. vol. 4, p. 282, 1902; Zoologica, N. Y. Zool. Soc. vol. 5, no. 14, p. 158, 1924.

Diagnostic characters.-As stated by Prof. Milne Edwards, this species is readily distinguished from all other members of the genus by the presence of granulations which cover all the gastric region, the hepatic regions, the anterior portions of the branchial regions, and are also evident in a reduced form on the back.

This species may prove to be only a subspecies of Eriphia squamata Stimpson.

Type.-The type, a unique specimen, is in the Paris Museum and is labelled "Chile."

Galapagos distribution.-One young specimen, collected in rock pools, Eden Island, April 26, 1923, by the Harrison Williams Galapagos Expedition, was identified by Miss Rathbun as Eriphia granulosa. The same writer reports six specimens from Tagus Cove, Albemarle Island, secured by the Hopkins-Stanford Expedition and cites Chatham Island, from material collected by Dr. W. H. Jones, U. S. N.

General distribution.-Chile (type-locality); Galapagos Islands; and Cocos Island (Arcturus Expedition).

Material examined.-One female, taken at Cocos Island, by the Arcturus, May 3, 1925. 


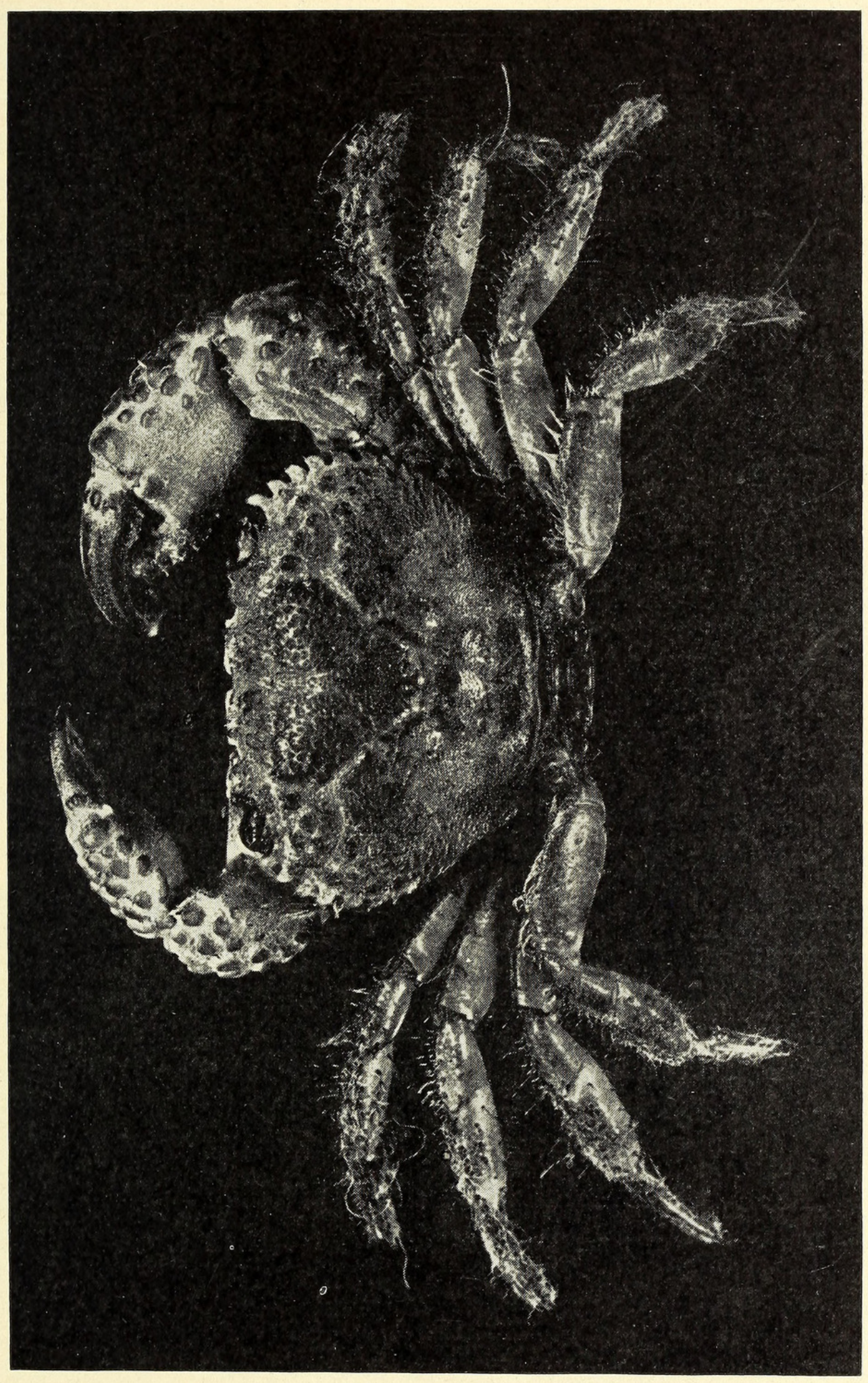

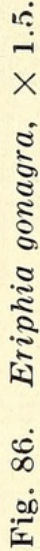


Color.-Carapace raisin purple; setae brownish.

Technical description.-This species is very closely related to Eriphia squamata of the West Coast, and also to E. gonagra of the East Coast. It is frequently found in association with squamata, both species inhabiting the crevices of the coral rock bottoms.

Eriphia granulosa has the carapace much flatter and the frontal region less deflexed than that of squamata. It is as long and only about five per cent narrower than that of squamata, but the convexity of squamata, when contrasted with the flattish carapace of granulosa, causes the latter to appear much narrower. The frontal border is divided into four lobes; the larger, inner pair being the wider and separated from each other by a deep median groove which terminates in a notch anteriorly. The regions of the carapace are clearly delineated; the hepatic region being deeply circumscribed. The superior orbital border is microscopically granulated and bears two coalesced lines indicating closed sinuses; the external angle is a sharp tooth, similar to and slightly larger than those of the anterolateral border. The inferior orbital border is smooth and terminates at its inner end in a blunt tubercle. The anterolateral border is cut into five, sharp, forward-curved teeth (in additional to the postorbital tooth) which successively decrease in size posteriorly. The gastric, hepatic and anterior portions of the branchial regions are covered with tubercles and rough granulations.

The chelipeds are quite similar to those of squamata, being unequal, and having the upper and outer faces of the carpus and propodus covered with large, close-set, rounded tubercles, each of which is fringed around the anterior half of its base with short, brown setae. The fingers are strong, deep purplish red; the curved, hinged finger of the larger cheliped bears a huge, subbasal molar tooth.

The ambulatories are similar to those of squamata.

\section{Genus Eriphides Rathbun}

\section{Eriphides hispida (Stimpson). (Purple Bristle Crab.)}

Eriphia hispida Stimpson, Ann. Lyc. Nat. Hist. New York, vol. 7, p. 218, 1860.

Pseuderiphia hispida A. Milne Edwards, Crust. Rég. Mex., p. 340, pl. 56, fig. 1, 1880.

Eriphides hispida Rathbun, Proc. U. S. Nat. Mus., vol. 38, p. 586, 1910 ; Proc. Washington Acad. Sci., vol. 4, no. 8, p. 282, 1902; Zoologica, $N$. Y. Zool. Soc., vol. 5, no. 14, p. 158, 1924.

Diagnostic characters.-Carapace and legs purplish, covered everywhere with coarse, short, stiff, black setae, which usually arise from tubercles.

Type.-Professor Stimpson's type, which he states was deposited in the "Museum of the Smithsonian Institution," was found on the west coast of Central America, by Captain J. M. Dow.

Galapagos distribution.-Tagus Cove, Albemarle Island, (Hopkins-Stanford Expedition; also Albatross); Eden Island, (Harrison Williams Expedition); Tower Island, Shore zone, Station 37, (Arcturus Expedition).

General distribution.-Central America, Panama and the Galapagos Islands.

Material examined.-Five males, two being very small, and two females from Station 37, shore zone, Tower Island, Galapagos, taken by the Arcturus; 


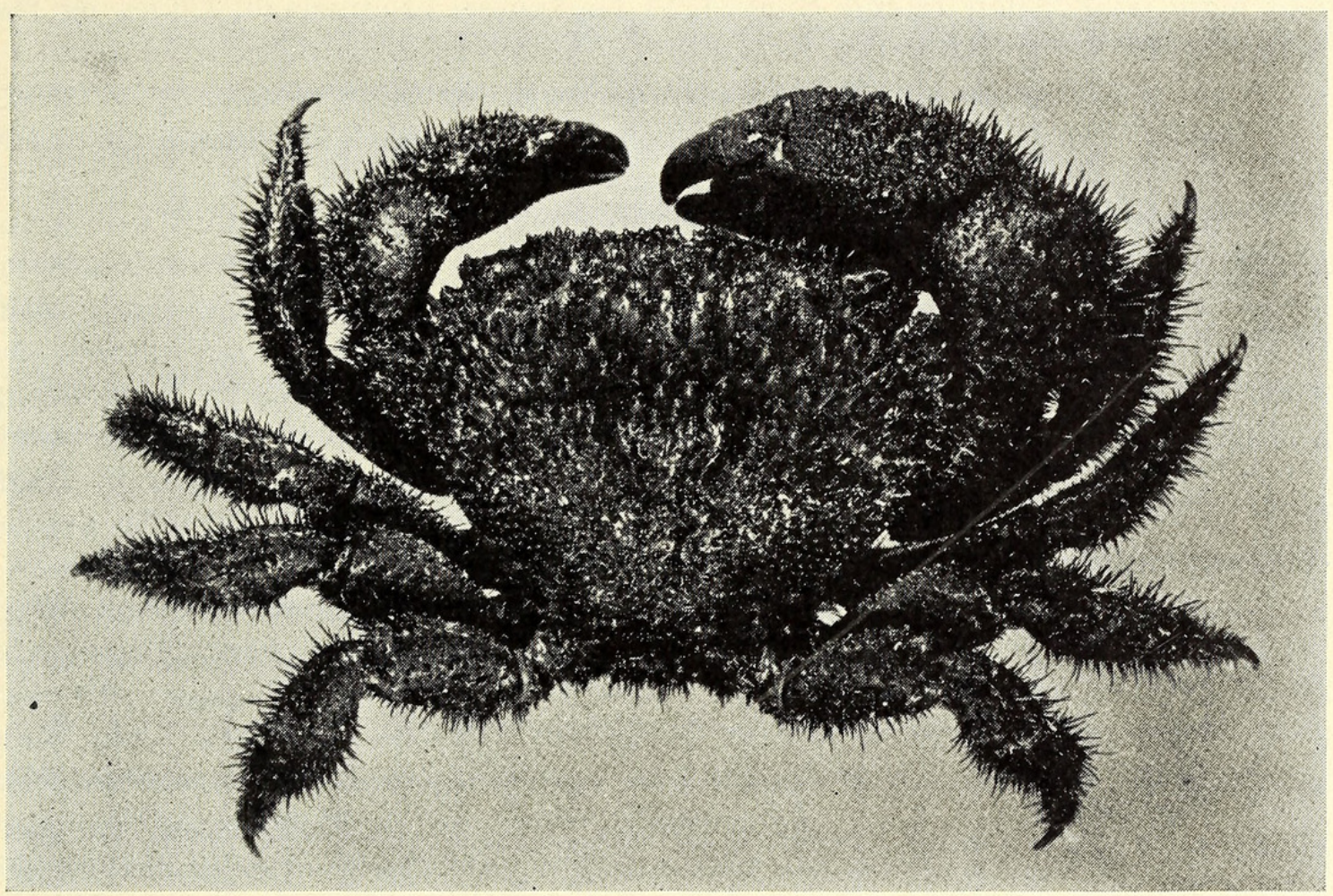

Fig. 87A. Eriphides hispida, adult. Reduced to $3 / 4$ of natural size.

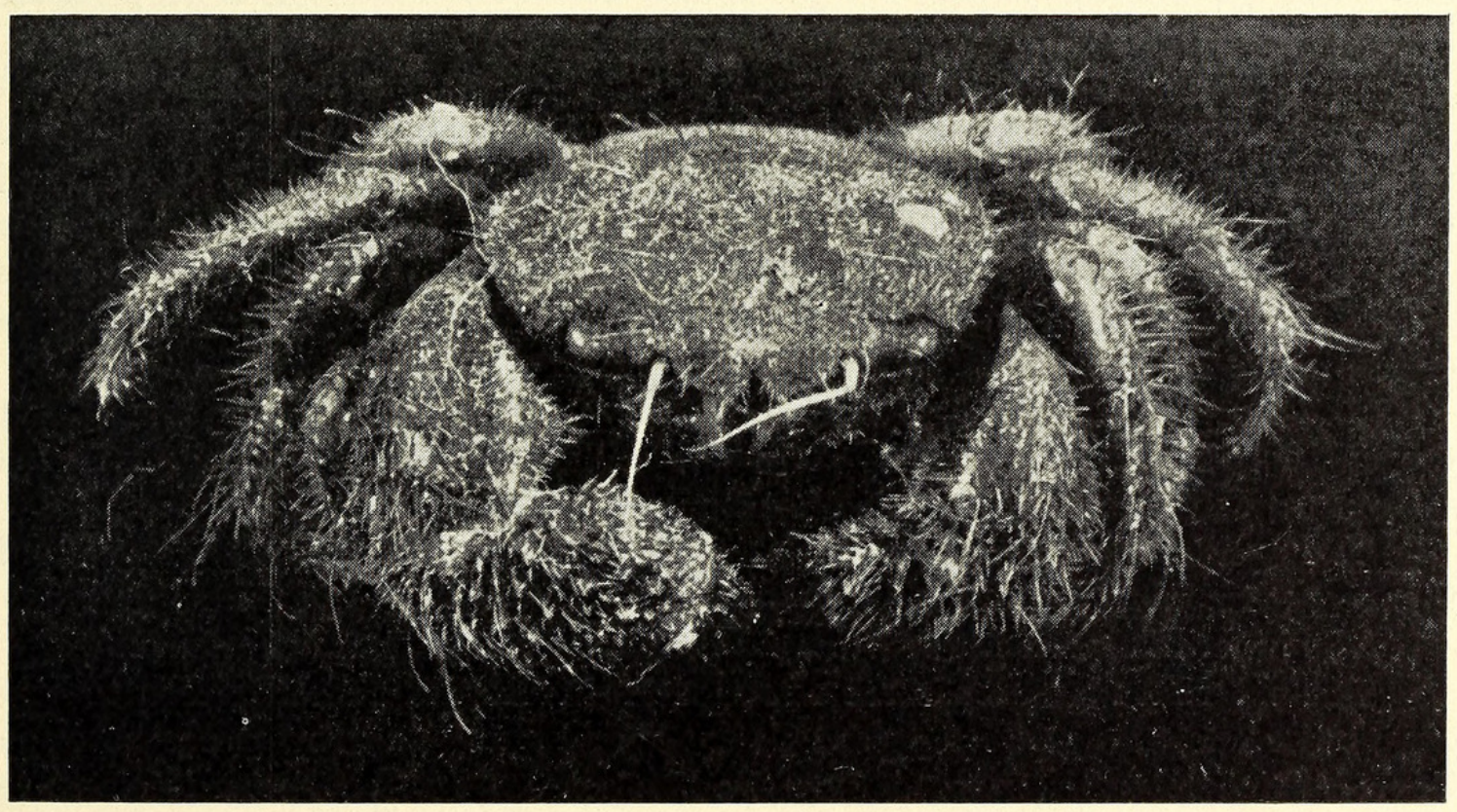

Fig. 87B. Eriphides hispida, young, enlarged $71 / 2$. 
one male from Eden Island (tag 2111) Galapagos archipelago, taken by the Harrison Williams Galapagos Expedition (photographed specimen, fig. 87A).

Color.-Carapace and feet purplish beneath the black setae. (Stimpson.)

Habits.-In his "Galapagos-World's End" (p. 131) Dr. Beebe gives the following vignette of Eriphides hispida and its neighbors:

"The crabs should have a whole chapter to themselves, ever more wonderful scarlet chaps who came down from the upper caves to see what we were doing, appearing and disappearing like flickering flames among the smoky sea-weed. Bristly crabs inhabited small individual lava cells which were so like the hollows worn by sea-urchins that it was certain that they were worn only by the drawing and quartering of the rightful architects. Yet they seemed to fit strangely well into their niches, and could not be pried out. They were ever ready to pinch with their claws, or to draw blood by shutting down on a finger with any of their walking legs."

Technical description.-Carapace; maximum width $51 \mathrm{~mm}$.; $38.5 \mathrm{~mm}$. long; interorbital border $28 \mathrm{~mm}$. Carapace broader through the anterior two-thirds, decidedly narrower posteriorly; rather flattish with the frontal border somewhat deflexed; areolations only faintly indicated. Carapace covered with low squamose tubercles which are larger and more abundant toward the anterior region. Each tubercle is fringed anteriorly with sort stiff setae and the posterior part of the carapace also has bristly setae between the tubercles; the frontal border is bilobed in the median region, a deep sulcus running back from this median sinus onto the gastric region; the frontal margin is irregularly set with uneven denticle-like tubercles. Just below these the pterygostomian region is also tuberculate. There are six teeth (including the postorbital tooth) on the anterolateral margin, the first four are large and bi- or tri-dentate, the posterior two are smaller and acute. The superior orbital margin is set with denticles; the inferior orbital margin is also denticulate and has a deep hiatus near the external angle.

The male abdominal belt is narrow, seven-segmented, with the distal segment triangulate. The first pair of male appendages are slender, curved rods with a deep channel on their inner side; the distal end is small, pointed and channelled by this groove. The second pair of male appendages consist of a stout, short basal joint and an exceedingly slender attenuated process which extends almost as far forward as the first pair and then curls forming two loops of a spiral.

The female abdomen is oval, narrow, seven-segmented, wider throughout the distal half. The four pairs of female appendages are biramose and very setigerous, the outer being curved, the inner biarticulate.

The eyestalk is bulbous basally, constricted abruptly below the cornea and thence tapering. The cornea is small and set obliquely at the end.

The inner antennae are small and fold transversely within the septum.

The external maxillipeds are squarish and close the buccal cavern tightly except the aperture of the efferent channel, and a very narrow space between ischia, which latter is covered by sieve-like setae. The exognath is elongate and bears a toothlike projection on its inner distal margin and a slender palp which arises from its distal end; the ischium is subrectangular and is traversed 
on its outer surface by a longitudinal depression and is denticulate on its inner margin; the merus is about one-half as long as the ischium, is trapezoidal, with a slight emargination below the efferent aperture; the palp arises just inside this emargination and the inner distal angle of the merus is angulated beneath the palp; the palp is rather fleshy and consists of three joints.

The chelipeds are conspicuously unequal in both sexes, but this inequality is more pronounced in the male. The three basal joints are small but strong; the merus is compressed and appears to be smaller than the carpus; there is a decided transverse subdistal constriction on the upper, outer and inner faces of the merus; the carpus is convex on its outer surface, dilated distally, and in the small cheliped is about as large and more swollen than the palm of the propodus, while the carpus of the large cheliped is almost as large as that propodus. The upper surface of the merus is finely tuberculate and covered with short, stiff bristles; that of the carpus is coarsely tuberculate and rugose and also is covered with bristles. The propodus of the great chela is about twice as long as the carpus, the fingers comprising approximately one-half of this length; the palm is quite as high as the carapace and convex; the upper surface is coarsely and rather thickly tuberculate as is also the upper half of the outer surface, the tubercles vanishing along a diagonal line extending from the base of the hinged finger to the lower basal margin; the remaining lower outer surface of the palm is devoid of bristles and is covered with low, flat scale-like tubercles. On the small chela, the entire outer surface of the propodus is covered with bristles and tubercles. The fingers are purplish black, those of the large chela are widely gaping except at the tip; the propodal finger is stout and bears one large median tooth; the hinged finger is longer and curved and bears a small, sub-basal tooth; the fingers of the small cheliped are spoon-shaped at the tip and meet for the greater part of their inner faces, there being only a small gape basally and no teeth. The female chelipeds are ornamented similar to those of the males.

The great chela of the male projects conspicuously beyond the carapace, its width at the wrist being almost equal to one-half of the width of the carapace.

The four pairs of ambulatory legs are similar in structure, stout, strong, with the upper, outer, and in a less degree, the lower surfaces densely covered with short, stiff bristles. The first and second pairs are subequal in length, the third pair is a little shorter, reaching to not quite to midway the dactyl of the second leg; the fourth pair of legs are conspicuously shorter reaching only midway the propodus of the third pair. All four pairs of legs have the meral joint long, wide and flattened with a transverse subdistal constriction and the upper margin finely denticulate; the carpal joint is narrow proximally, wider distally and about as long and thick as the propodal joint; the latter narrows slightly distally and is stout and convex outwardly; the dactyli are about threefourths as long as the propodi and are very strong, cylindrical, curved, terminating in a strong, horny spine. 


\section{Subfamily: TRAPEZINAE}

Genus Trapezia Latreille, 1825

Trapezia cymodoce ferruginea Latreille. (Enamelled Crab.)

Trapezia ferruginea Latreille, Encyc. Meth. Ent., vol. 1, p. 695, 1825.

Trapezia cymodoce Dana, Crust. U. S. Explor. Exped., pt. 1, p. 257, 1852, atlas pl. 15, fig. 5, 1855; A. Milne Edwards, Crust. Rég. Mexico, p. 342, $1880 ;$ S. I. Smith, Boston Soc. Nat. Hist., vol. 12, p. 287, 1869; Lockington, Proc. Calif. Acad. Sci., for Sept., 1876; Faxon. Mem. Mus., vol. 18, p. 22, 1895.

Trapezia cymodoce ferruginea Rathbun, Proc. U. S. Nat. Mus., vol. 38, p. $586,1910$.

Diagnostic characters. - This is a rather large species compared with its American congeners. Frontal margin six-lobed without a submarginal groove. Breadth and width almost equal. One vague median lateral tooth.

Type.-I have not been able to ascertain where Latreille's type material is deposited. It came from the Indo-Pacific region.

Galapagos distribution.-One ovigerous female from Station 37, zone F, Darwin Bay, taken by the Arcturus appears to be the only Galapagos record for this widely distributed species.

General distribution.-This species, so often confused with its congeners, has been definitely recorded from Acapulco, Mexico, by Dr. Faxon, and from the Pearl Islands, Bay of Panama, by Milne Edwards, S. I. Smith and Faxon. It has also been recorded from the Indo-Pacific region by Latreille, Dana, Faxon and Rathbun. The Arcturus material extends the range of this species to include Cocos Island and the Galapagos.

Material examined.-One ovigerous female from Station 37, zone F, Darwin Bay, Galapagos Islands; three males and one female from Cocos Island, May 19, 1925, secured by the Arcturus Oceanographic Expedition.

Color.-In life this little crab is a bright orange red with brownish black eyes and wood-brown fingers. Preserved specimens are usually faded to a vivid orange. It has a highly polished shining surface.

Technical description.-Carapace $11 \mathrm{~mm}$. long, $13.5 \mathrm{~mm}$. maximum width, moderately convex in both directions, narrower in the postorbital regions than in the median diameter. Interorbital space $7 \mathrm{~mm}$. wide, with the margin thin and grooved above, six-lobed, the median pair being smallest, most acute, the intermediate pair being the widest and rather rounded; the external pair are rounded, and slightly deflexed, intermedial in size between the first and second pairs, and with the outer distal side a trifle bent downward. The superior orbital margin is unbroken; the postorbital angle is acute; the lateral margins are strongly curved, the carapace being widest in the middle, the margins converging anteriorly where the width between the postorbital angles $12.5 \mathrm{~mm}$. the maximum median width being $13.5 \mathrm{~mm}$. and the posterior margin width being $5.5 \mathrm{~mm}$. There is a shallow vague tooth midway, which the lateral margins converge decidedly behind this tooth, being only $5.5 \mathrm{~mm}$. apart at the posterior margin. There is an irregular row of punctae behind the frontal and orbital margins. Scattered punctae are also present on the dorsal surface of the carapace and legs.

The female abdomen is very broad, subcircular distally, the first and second segments are short and narrow and are visible dorsally; the third, fourth, 
fifth, sixth and seventh segments successively increase in length, the last one being the widest of the series and having its margin semicircular. The margins of all the segments are fringed with short, thick setae. The second to fifth segments inclusive bear the paired biramose appendages to which the eggs are attached. Each appendage consists of a short base supporting a long curved,

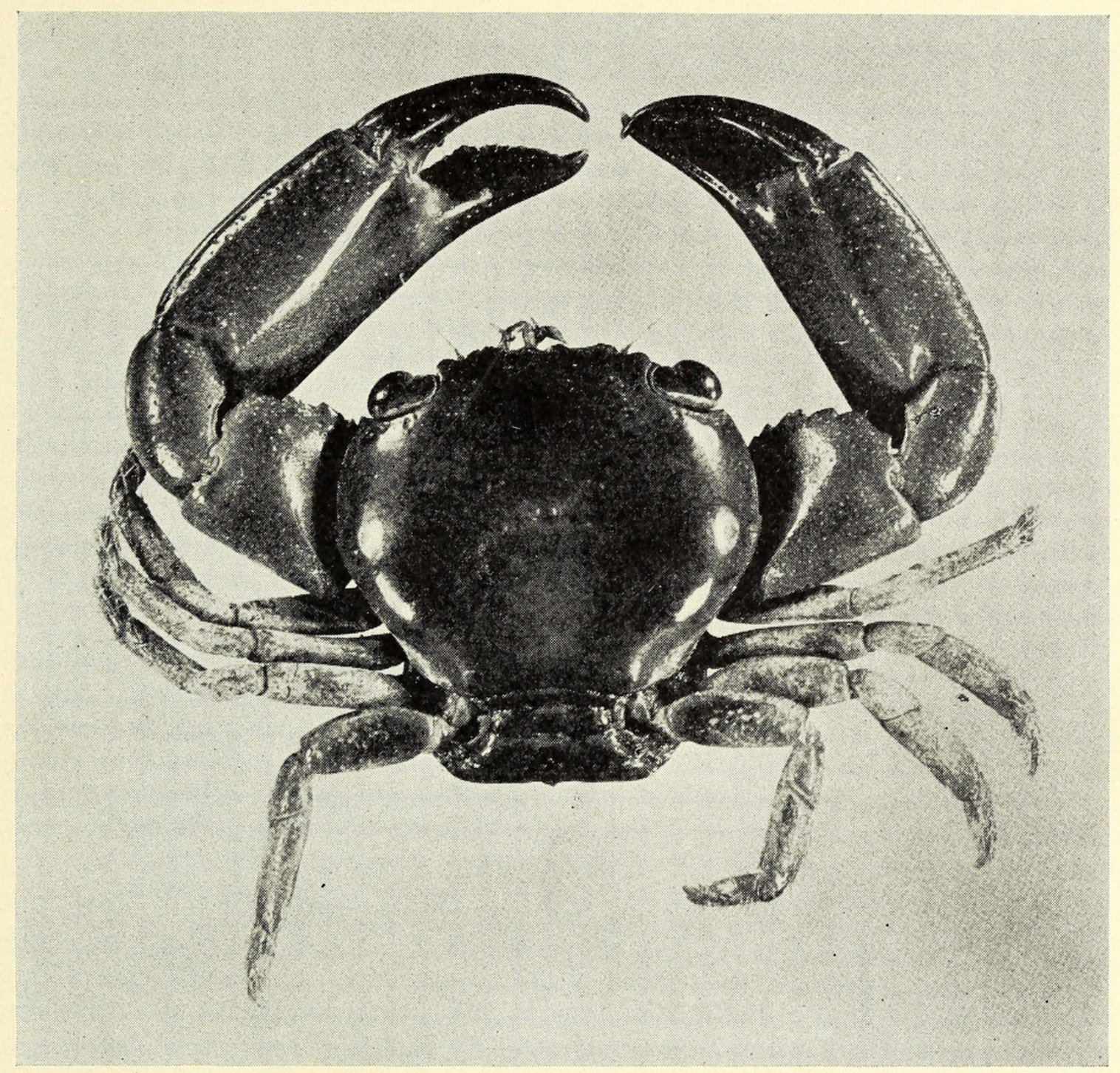

Fig. 88. Trapezia cymodoce ferruginea, $\times 3$.

heavily fringed outer branch which lays parallel to the outer margin of the abdomen, and a slender inner branch, consisting of an inbent proximal joint and a distal portion consisting of ten subequal articles, which are heavily fringed with long setae, to which the eggs are attached.

The male abdomen is narrow, triangulate, five-segmented, the first and second segments are extremely short; the third segment is composed of the third, fourth and fifth segments anchylosed, but with segment lines visible near the outer margin; the fourth segment is not half as long as the preceding and 
is rhomboidal; the fifth segment is very short with its free margin rounded. The first pair of male appendages are slender curved rods, with an acute distal process which is set with short, rough setae on the inner surface.

The eyestalk is short, regularly cylindrical and produced on its upper and under surfaces into uneven, rounded processes that project upon the cornea. The cornea is oval, and very convex, set obliquely at the terminal; the facets are very minute.

The antennulae are moderately large and fold transversely within the fossett.

The external antennae are small; the three basal joints are placed diagonally at the outer side of the basal joint of the antennulae, reaching to the sinus between the preorbital and second frontal lobes, beyond which the slender, 24jointed flagellum extends almost to the distal margin of the cornea.

The external maxillipeds are large, squarish, close-fitting, with a very large palp. The basal joint of the exognath is wide; the second joint is dilated on its inner margin and extends almost to the distal edge of the merus; the palp is very long, slender, curved and setigerous; the ischium is as broad basally as it is long and has the inner margin broadly rounded, narrowing distally; there is a deep sulcus subparallel to the inner margin; the merus is about three-fourths as long as the ischium and has its three margins rounded; the large palp arises from the inner distal border of the merus and curves downward around the merus, the tip of the distal joint reaching slightly more than half way the length of the ischium and the tuft of hairs on the tip of the palp reaching to the base of the ischium.

The chelipeds are moderately unequal in both sexes, smooth and shining, with a few punctae irregularly scattered on the surface. The merus joint is short and wide, being produced on its anterior surface into a wing-like process which is sharply serrated into four or five (rarely six) teeth; the anterior distal margin is also serrated; the posterior outer proximal margin is sharply angulated; the carpus is about two-thirds as long as the merus and is produced to a blunt tooth on its inner margin and is convex on its upper and outer surfaces; the propodus is a little longer than the width of the carapace and it is stout and folds obliquely under the front of the carapace, the tips of the fingers reaching to the base of the merus of the other chela; the propodal finger comprises about one-third of the length of the propodus and is rather stout with the tip acute and upcurved; the cutting edge is serrated by thirteen weak teeth, one large tooth is fourth in position from the base; the hinged finger is thinner and more sharply curved distally; it has one strong basal tooth and two or three weak ones on the cutting edge; the fingers fit closely upon each other with the curved tips crossing.

The four pairs of ambulatory legs are practically subequal, the more dorsal point of attachment making the fourth pair appear shorter, though in reality they are as long as the others. Each has the meral joint broad, half as wide as long; the carpus is narrow basally; produced on its anterior distal margin, and is about half as long as the merus; the propodus is almost as long as the merus but is narrower and is produced at its distal end into a lateral rounded process on each side between which the propodus articulates; there is a smaller, roundish 
process on the posterior side of the dactyl which coördinates with the propodal process; the dactyl is stout, compressed, curved at the tip and almost as long as the propodus. The distal half of the carpus and entire propodus are moderately set with long stiff setae and the dactyl is thickly set with similar setae.

Eggs and zoea.-The above described female is carrying about fifteen hundred small yellow oval eggs in which the developing embryos are visible. They are about $0.25 \mathrm{~mm}$. diameter and show the eyes as small black circles; the uncurled embryos show a smooth globular carapace and narrow segmented abdomen with slender rhipidura. The feet are very frail.

\section{Genus Ectaesthesius Rathbun, 1899}

Ectaesthesius bifrons Rathbun.

Ectaesthesius bifrons Rathbun, Proc. U. S. Nat. Mus., vol. 21, p. 591, pl. 42, figs. 12-14, 1899.

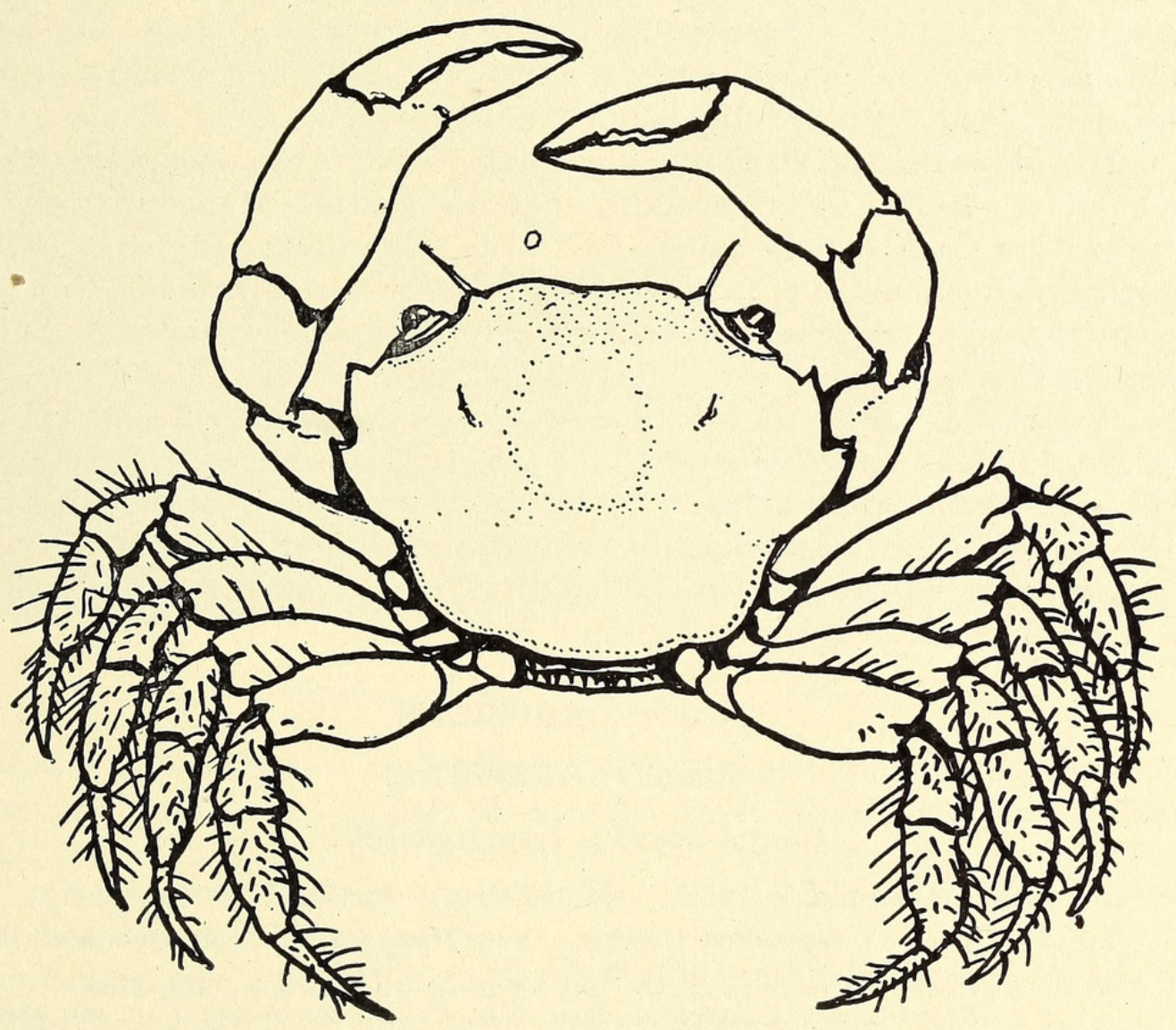

Fig. 89. Ectæthesius bifrons, $\times$ about 4 (After Rathbun).

Diagnostic characters.-Orbital fissure closed; sides two-toothed.

Type.-One ovigerous female from off Chatham Island, Galapagos Islands (Albatross station 2809), 45 fathoms; deposited in the United States National Museum.

Galapagos distribution.-Off Chatham Island, 45 fathoms.

General distribution.-Known only from the type-locality.

Material examined.-None. 
Technical description.-(As given by Rathbun): “Carapace slightly convex in both directions, about three-fourths as long as wide, antero-lateral margin arcuate, postero-lateral margins sinuous and rapidly converging. Surface smooth, except near the front and lateral teeth, where fine granulation may be detected with the lens. Front nearly half the width of the carapace, slightly arcuate, almost imperceptibly bilobed, edge thin, retreating at the outer angles. Just above, behind, and parallel to the margin, at a distance of about 0.2 , of a millimeter, is a sharp ridge which is slightly interrupted at the median line. Orbit less than half the width of the front; outer angle inconspicuous, not advanced beyond the general outline of the orbital margin. The tooth at the lateral angle of the carapace is situated a little in front of the middle of the length of the carapace and is subacute. The first tooth of the antero-lateral margin is about one-third the distance between the orbital angle and the lateral tooth and is obtuse. The abdomen of the mature female is narrow; third, fourth, and fifth segments subequal in length as well as in width; sixth of the same width, but longer; seventh narrower, length and breadth subequal, extremity rounded. Peduncular joints of antennae short.

Merus of chelipeds extending but little outside the carapace, trigonal, widest near the middle. Carpal tooth large and sharp. Manus with the inner surface swollen toward the proximal end, as in Grapsillus; margins smooth and rounded; superior margin slightly convex, inferior margin sinuous, that of the pollex being concave. Dactylus longer than the superior margin of the palm. Fingers not gaping, marked with a few lines of punctae; dactylus without teeth; pollex of the larger cheliped with one low tooth on basal half and two teeth and a few denticles on terminal half; in the smaller cheliped the teeth of the pollex are all on the terminal half. The ambulatory legs are of the same nature as those of Grapsillus; dactyli nearly as long as the propodi.

Dimensions.-Ovigerous female: length, $7 \mathrm{~mm}$.; width, $9.7 \mathrm{~mm}$.; width of front, $4.4 \mathrm{~mm}$.; exorbital width $7.2 \mathrm{~mm}$."

\section{Family: GRAPSIDAE}

\section{Subfamily: GRAPSINAE}

\section{Genus Grapsus Lamarck 1801}

Grapsus grapsus (Linnaeus), 1758. (Rock Crab; "Sally Lightfoot.”)

Paqurus maculatus Catesby, Nat. Hist. Carolina, Florida and Bahama Islands, vol. 2, p. 36, pl. 36, fig. 1, 1743.

Cancer grapsus Linnaeus, Sys. Nat. ed. 10, vol. 1, p. 630, 1758.

Grapsus pictus Latreille, Hist. Nat. Crust., vol. 6 and 7, p. 69, 1802, and 1803.

Grapsus webbi Milne Edwards, Ann. Sci. Nat. Ser. 3, Zool., vol. 20, p. 16, and p. 167 (133), 1853.

Grapsus goniopsis pictus de Haan, Fauna Japon, Crust., p. 33, 1835.

Grapsus maculatus Milne Edwards, Ann. Sci. Nat. ser. 3, Zool., vol. 20 p. 167 (133), pl. 6, figs. 1-1n, 1853 .

Grapsus ornatus Milne Edwards, ibid., vol. 20, p. 168, (134) 1853.

Grapsus altifrons Stimpson, Ann. Lyc. Nat. Hist. New York, vol. 7, p. 230, 1860.

Grapsus grapsus Ives, Proc. Acad. Nat. Sci. Phila., for 1891, p. 90; Faxon, Mem. Mus. Comp. Zool., vol. 18, p. 30, 1895, Rathbun, Bull. 97 U. S. Nat. Mus., p. 227, pls. 53-54, 1917; Bull. Am. Mus. Nat. Hist., vol. 48, p. $629,1923$.

Diagnostic characters.-Carapace vivid scarlet, discoidal; carpal spine 
ovate-acuminate; fingers spoon-shaped. Front vertical, depth in median line slightly greater than half its length.

Type.-America and Ascension Island. The type material is no longer extant.

Galapagos distribution.-Eden, Tower, Chatham, Hood, Albemarle, Indefatigable, James and Duncan Islands.

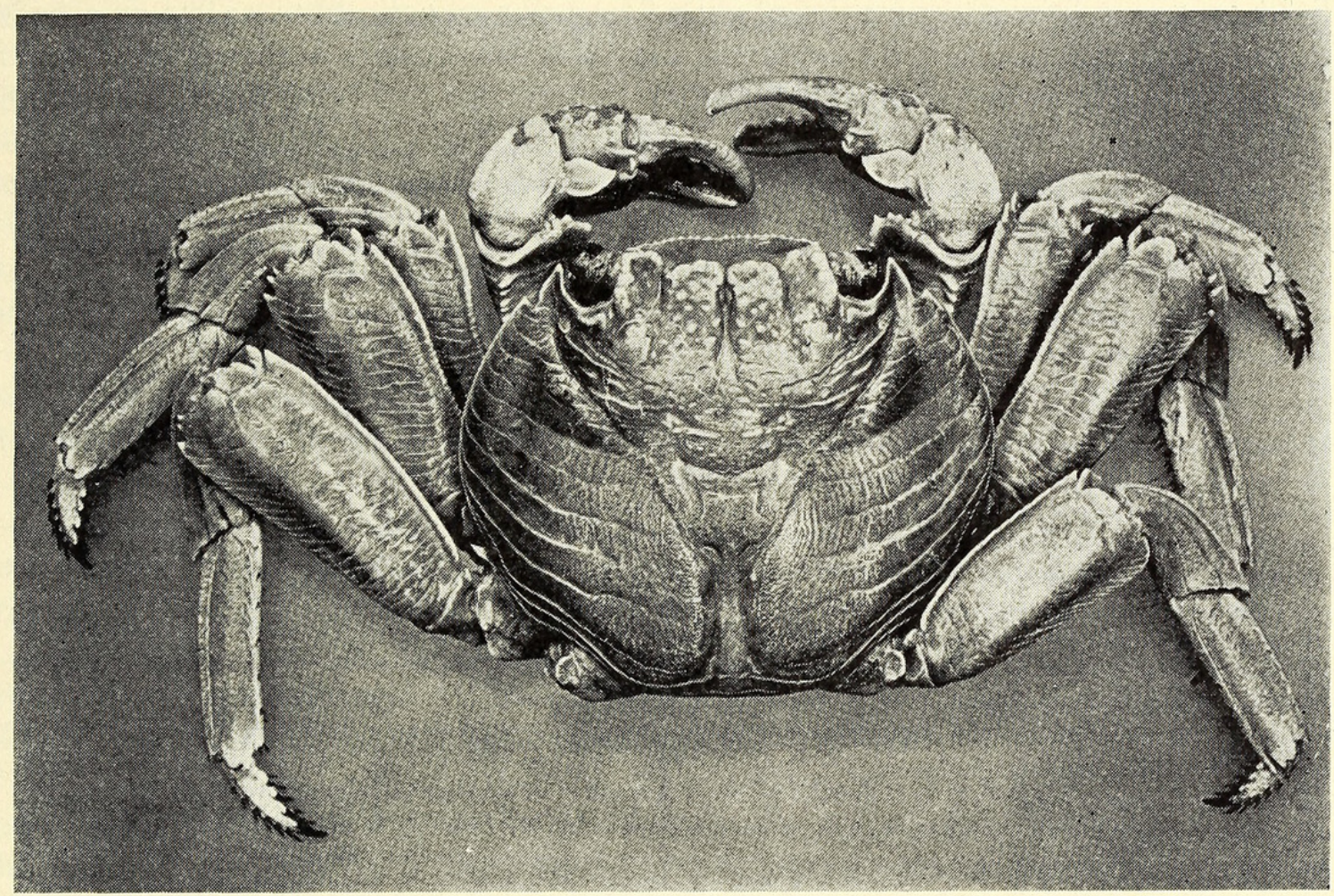

Fig. 90. Grapsus grapsus. Reduced to $1 / 2$ of natural size.

General distribution.- "Sally Lightfoot" is a well-known inhabitant of the tropical and subtropical shores of America from Miami, Florida, southward through the West Indies and Bermudas to Pernambuco, Brazil, on the East Coast, and on the West Coast from San Benito Island, Lower California, southward, including the Galapagos Islands, down to Chile; it is also known from the tropical eastern Atlantic including the Azores and the west coast of Africa.

Material examined.-One large male specimen from Hood Island (tag W. B. 817); two large males from South Seymour Island; one adult male and four small young specimens from Station 37, Tower Island, shore zone D to E, April 10, 1923; two young specimens from Station 54, off Hood Island, 15 fathoms, and five young specimens from Cocos Island, were secured by the Arcturus Oceanographic Expedition. Four males from Eden Island, Galapagos, taken by the Harrison Williams Expedition.

Color.-Color plates were made by the staff artist, Isabel Cooper, of both the adult and young of Grapsus grapsus. Adult male: on the dorsal surface of the carapace, chelipeds and legs, bright scarlet is dominant; the epistome is 
light orange yellow touched with scarlet; the pterygostomian region and underside of carapace are neropalin blue streaked with light orange yellow; parts of the inner and under sides of the basal joints of the legs are neropalin blue; the merus, carpus and part of the propodus are bright scarlet; the distal part of the propodus and dactyl are light orange yellow; the chelipeds have these latter joints vivid scarlet. The eyestalks are yellow; the cornea is violaceous.

Young-male and female.-The carapace is chocolate brown striated with light orange yellow and maculated with flecks of neropalin blue. The chelipeds are predominantly neropalin blue basally with the carpus and propodus vivid scarlet, the finger-tips orange. The ambulatory legs have the basal, meral and carpal joints light scarlet maculated with light orange yellow; the propodus reddish-brown; the dactyl, brownish-yellow with black spines. The eyestalks are yellow, the cornea violaceous.

Habits.-As long ago as 1725, Hans Sloane observed these Mardi Gras dwellers of the rocky shores of Jamaica and noted their abundance, in his "Natural History of Jamaica."

William Beebe, Director of the Arcturus Oceanographic Expedition, who secured the specimens of the present report, has given the following account of Grapsus grapsus in his "Galapagos-World's End:"

"As we walked along, hosts of scarlet crabs scuttled away from our pathcrabs which we were to know as the most conspicuous and ever-present feature of Galapagos shores. They were old friends and I had seen them years ago in Cuba and Mexico, and scampering over the rocks in St. Thomas and Jamaica. In the latter island they call them Sally Lightfoot, a name much more apt than that by which the carcinologist knows them-Grapsus grapsus grapsus, - the old Greek word for crab thrice repeated.

"Catesby writing of the natural history of Florida and the Bahamas one hundred and eighty years ago, gives a vivid paragraph of them in smooth and sonorous English. 'These crabs inhabit the rocks overhanging the sea; they are the nimblest of all other crabs; they run with surprising agility along the upright side of a rock and even under rocks that hang horizontally over the sea; this they are often necessitated to do for escaping the assaults of rapacious birds which pursue them. These crabs, so far as I could observe, never go to land, but frequent mostly those parts of the promontories and islands of rocks in and near the sea, where by the continual and violent agitation of the waves against the rocks they are always wet, continually receiving the spray of the sea, which often washes them into it, but they instantly return to the rock again, not being able to live under water and yet requiring more of that element than any of the crustaceous kinds that are not fish.'

"Nowhere had I ever seen them of so vivid a scarlet as against these sombre lava rocks, and nowhere as abundant. Lying flat on the gentle slope of a huge cube, twenty feet each way, I watched the waving tentacles of anemones far below me. Suddenly a scarlet curtain swept across the whole face of the rock, as an army of crabs skittered into view. Their armour clattered as they ran against or over one another, in their fright they blew strings of little bubbles out of their comic faces and in their haste a number scurried over me. Then came the cause of their fright, - a little bob-tailed, slaty-blue heron, a copy of 
our own northern green heron except for the dull, lava-like hues and stouter build, Butorides sundevalli. Whether the easy life led by these small herons on the islands has induced corpulency I do not know, but it is a fact that they weight more than two-thirds as much again as their continental relatives.

"My cancrivorous heron watched me suspiciously for a moment, flicking his tail up and down, then dashed at the crabs and seized a leg which its owner promptly discarded. Flying to the top of a neighboring rock, the heron hammered off the terminal joints, crushed the largest and swallowed them. After a short rest the bird made another foray, again secured a stray leg and feasted upon part of it. During coming days I observed this performance on the part of at least four individuals on two islands, - a source of food as certain as it was remarkable, for the discarded limbs are almost always renewed, the crabs being little the worse for the loss of one of their eight feet.

"As Catesby truly says, these crabs never go inland, but are always found within reach of the water, and yet they are indifferent swimmers. This was the first of the many confusing facts with which the Galapagos teemed, - that this species could occur on the Pacific coast with fifty good miles of dry land or equally inimical fresh water between them and their Atlantic fellows, and here seven hundred miles or more away, were thousands forever hurrying about the cooled lava. No change had taken place in their anatomy, although thirtyfive millions of years may have elapsed since the Oligocene period when the waters of the Atlantic and Pacific were mingled.

"These hosts of Sally Lightfoots were the most brilliant spots of colour above water in these islands, putting to shame the dull drab hues of the terrestrial organisms and hinting of the glories of colourful animal life beneath the surface of the sea. When such an outburst of crabs occurred as I have described, darting out of all possible and impossible cracks and crevices of the lava, they appeared to the imagination as organic reminders of the sparks and flames which once reddened these great beaches, and these plains and mountains of lava.

"Flying about, close to the precipitous cliffs, just this side of a cave which marked the end of the beach, was a flock of Galapagos purple martins, Progus modesta. They are smaller than the martins of the mainland and have less white upon their plumage, and have established themselves in small colonies on many of the islands. Darwin observed them on James island, and long before his visit, old buccaneers wrote in their journals of the "swallows" of these islands, birds which took their minds back for a moment to English downs or the eaves of France.

"There were seven birds in sight, one of which was immature, all swooping about and twittering in the usual martin way, and by their fluttering visits to the side of the cliff I located six nests. These were in deep sheltered ledges or in angular tunnels made by the splitting off of the rocks along the weak lines of crystalline deposit. One nest was not more than twenty feet up and by the aid of acrobatic efforts on a long improvised ladder I managed to reach the old bird on her nest, and saw a full-fledged youngster scuttle up a narrow chute out of sight. On my next ascent I was able to dislodge a mass of the cliff which almost buried me as it fell. I just managed to leap out of the way of the hurtling rocks and looking up saw the young fledgling flutter out. It dropped nearly into 
my hand, recovered itself and flew with remarkably steady flight out over the jagged summit. I was in time to see the little bird drop exhausted into the water and flap itself ashore, only to be promptly seized by a huge scarlet crab. Holding its prey aloft in the great pincers, the crab climbed the lava slope with others of its bright-hued envious fellows following at a respectful distance. I thought the little swallow had had about enough for one day and I relentlessly pursued the crab and rescued the bird quite unhurt."

"Our boat grounded gently and we walked up through the colony, the iguanas hardly moving out of our way. For a long time we watched these strange beings, we saw them challenge one another, and pay court to indescribably ugly black lady lizards. And then I saw something which I shall probably mention in another chapter, but it will bear repetition. An iguana about three feet long was resting partly on the sand and partly on a water-smoothed stone, when a large scarlet crab approached slowly, crawled over the whole length of the reptile, and picked off two ticks as it went. If my companions had not been watching at the same time I should hesitate to record such a remarkable occurrence.

"Minute by minute we were ever more impressed by the tame life of the Galapagos, but the crabs were an exception. I could creep close to them but their eyes would watch me closely and they would always slide out of reach, slowly if I approached gently, or like a scarlet flash if I grabbed quickly. Here, however, in this magic cave of Eden there were three crabs which in point of fearlessness might have been the Three Musketeers. When I walked up from the boat one came slowly to meet me, one of the biggest, his carapace fairly aflame in the sunlight. On and on he came, his eyes twiddling comically on their stalks, his thick spoon-shaped claws making queer calabastic signs, intelligible only to the race of Cancer. After waving them about regardlessly for a time, he would go through a series of about a dozen motions, absurdly like an American private saluting with both hands at once, the claws being raised to the stalked eyes and brought down simultaneously with a quick jerk. Then followed more irregular signs, and later a quivering as of a drummer's hands beating a tattoo.

"I stood quietly until he came within a foot, then I leaned down, slowly reached out and rubbed his shell. He sank down upon the sand, lowered his eyes into their sockets and wiggled his maxillipeds estatically. I took all manner of liberties, lifting one leg after another, raising him from the ground and replacing him, standing him upon his head, and tapping gently upon his hard back. Surely this must be a very ill crab, or an idiot crustacean, or somehow abnormal. I walked slowly away and to my amazement he turned and followed me. Another crab jointed the first and I felt like a walrus or a carpenter. I took a few steps inland, rounded up a half-dozen ordinarily wary crabs and rushed them in the direction of the tame pair. The stampede was infectious and as I splashed along the water's edge, all fled at full speed. My tame crabs were inextricably mingled with the crowd, and although I tried to stalk them again, they had lost their fearlessness and psychically as well as physically had merged into the mean of the race." 
"I killed a red crab and threw it to my particular quartet (young seals). They dived after it and nosed it but apparently were not yet weaned to such food. In fact I believe that crabs seldom if ever enter into their diet, for these crustaceans show absolutely no fear of the sea-lions, sometimes actually scampering over their sleeping bodies. In the stomach of these we secured I found only remains of fish. The sleek brown animals and the black rocks, the scarlet crabs, the pure emerald of the shallows and the dashing white foam and spray taxed the extreme gamut of colors of our marine artist."

"Everywhere were the crabs - the same great scarlet fellows, scurrying out of the way of the playful pups, (seals) then following them up without fear. One climbed over the rim of my desk, as the one on Eden had done, and twiddled his stalked eyes at me in a most disconcerting way. These eyes were a rich lavender and his shoulders a deep violet blue, while here and there the scarlet of his back reappeared in small monograms and hieroglyphics - a palimpsest telling more of the past history of Grapsus than I shall ever decipher. There must have been five hundred of these craibs in sight, spotting the black lava and pink strata with violent splashes of color.

"At Amblyrhynchus Cove on Eden Island I walked to within four feet of a lizard with my graflex camera. It was half on sand and half on lava and I wished a photograph in just that position as showing the two general types of habitat. As I took the first picture I saw a large red crab approaching on the lava. When I had changed plates, the crab had reached the head of the iguana, and instead of turning aside, crawled straight ahead, the lizard closing its eyes to avoid the sharp legs of the crustacean. On and on the crab went, slowly descending the whole length of the lizard. Three times it stopped and picked a tick from the skin beneath it, the black tissue being tugged high as the crab tugged away. I took another picture as the crab reached the forelegs. I could not see whether the crab even attempted to eat the ticks, but when it had gone on its way over the sand, I put down my camera, crawled forward, caught the lizard, and with my lens found two places where ticks had been. There was no sign of a third having been pulled off, but there were sixteen ticks still remaining on the skin. The whole thing had come as an absolute surprise for while I had several times seen crabs walking on the iguanas, I had not noticed any deliberate attempt to tick catching. These ticks are Amblyomma darwini and are closely related to a new species which I discovered on the land lizards."

"I never saw the iguanas dive for food, and indeed there would seem to be no need for it, for at ordinary times an abundance of the weed was always exposed. As this growth thrived only where there was active surface, so the feeding reptiles were often completely covered, three or four feet deep, by an incoming wave. At such times they and the big scarlet crabs all about gripped tight with their claws and, limpet-like, were immovable. Never did I see one dislodged, and from my experience of trying to drag them out of crevices, I count any such danger as negligible." 
Technical description.-Carapace discoidal; frontal border vertical, its depth slightly more than half its length; anterior dorsal interorbital surface with a median longitudinal groove which is posteriorly confluent with the mesogastric lines; a submedian notch and its slight posterior sulcus bisect each half of the frontal region. The postorbital tooth is acute; slightly behind it is a second sharp tooth, just anterior to the base of the latter the unusually deep cervical groove arises, proceeds diagonally to the urogastric region and thence runs posteriorly close together outside the cardio-intestinal region. The anterior frontal interorbital region is marked by irregular, transverse rows of low tubercles. There are twelve prominent transverse slightly arcuate ridges, the anterior of which begins at the inner basal angle of the anterolateral tooth and curves across the carapace to near the median dorsal area. All the transverse grooves become vague in the median dorsal region, where the oblique grooves defining the regions of the carapace predominate. The surface of the carapace between the grooves is decidedly reticulated; the subcentral region of the carapace being marked with heavier longitudinal reticulations. There are a pair of depressions at the outer margin of the urogastric region.

The orbits are not quite half as long as the interorbital border, with a distinct notch near the inferior outer angle and a wide inner hiatus which is partly filled by the antennal peduncle, and partly by an isolated tooth. The eyestalks are cylindrical with a distinct median constriction on the outer upper side and a rounded process projecting on the cornea, which is very convex, elliptical, set obliquely terminal.

The antennulae are set nearly transverse in narrow fossae and are partly concealed by the frontal border.

The antennal peduncle partly fills the orbital hiatus and has a conspicuous excretory tubercle on its basal joint; the flagellum is quite small and lies within the orbital hiatus.

The external maxilliped has a tapering rod-like exognath which is twothirds as long as the endognath and bears an inner, thread-like flagellum about half as long as the basal rod; the ischium of the endognath is subrectangular with its inner margin fringed with setae as long as the merus, the latter being a trifle wider distally than the ischium, and having its inner distal margin depressed; the palp arises from the antero-external angle, and is an unusually large sublobate first joint which fits upon the distal border of the merus, and has its inferior distal margin produced; the second joint is much smaller but distinctly three-sided; the third joint is quite small but thick and armed on its inner surface with a brush of setae. The maxillipeds are set wide apart from each other, showing the mandibles. This space between the maxillipeds at its widest point is one and one-half times as wide as the width of the maxilliped at the distal end of the ischium. The pterygostomian region is finely tomentose.

The abdominal belt consists of seven segments in both sexes; in the male the basal segments are as wide as the sternal plate between the fifth pair of legs. The first pair of male appendages are very stout, extend to midway the sixth segment and have the distal fourth somewhat dilated and are produced at the middle of the distal end into a strong horny tooth, which is dentate at its outer distal angle and rounded distally; the inner distal lateral angle is produced into a 
blunt white tooth and armed on its inner and distal surfaces with coarse spiny setae; the outer distal angle is bluntly rounded and armed with similar setae.

The chelipeds (male) have the coxa produced to a tooth-like process at its outer distal angle; the basis is small and fused with the ischium; the latter is produced to a tooth-like process on its distal ventral margin and bears four or more sharp little teeth on its inner ventral margin; the merus is slightly longer than its distal width; three-sided with all three margins denticulate, the inner ventral one most pronouncedly so; the carpus is short, convex and denticulate on its outer margin, with a large lanceolate-acuminate tooth on its inner marginal angle; the propodus is high, subovate, convex on its outer surface, with a sharp flat tooth at the upper distal margin near the propodal finger, with the upper edge of the propodus and half the finger denticulate; below this are several irregular flat tubercles, a longitudinal carina composed of bead-like tubercles runs from the base of the propodus to the inner angle of the propodal finger; a second, similar carina runs almost to the tip of the propodal finger; below this carina a series of ten oblique ridges, the distal of which are bead-like, ornament the lower outer surface of the propodus and lower finger; the fingers are subequal, spoon-shaped at the tip, the lower finger is armed with five teeth along the cutting edge, inside of which are a series of tufts of coarse setae; the upper finger is similarly toothed and tufted. The fingers meet only at the tips.

The ambulatory legs are similar, successively increasing in length posteriorly, the first pair being shorter than the second by the length of almost half the propodus and the dactyl of the latter; the third, fourth and fifth pairs increase in length by less than half the length of the dactyl. All except the first pair have the basal joint produced into a tooth-like process at both its inner and outer distal angles; the basis fused with the ischium, the latter produced to a tooth-like process on the dorsal anterior distal angle, only on the fourth and fifth pairs of legs; all four pairs of legs have the merus conspicuously dorsoventrally compressed, slightly more than twice as long as wide with the frontal margin ridge-like; the distal margin multidentate; the upper surface reticulated by many oblique striae; the carpus is half as long as the merus, very narrow basally and dilated distally, produced to an acuminate point on the anterior distal angle, and longitudinally traversed by a wide groove-like depression and two carinae. The propodus is about as wide but somewhat longer than the carpus, has a distinct longitudinal groove near its anterior margin and a series of spines and bristles on its postlateral margin; the dactyl is very powerful terminating in a strong, claw-like tooth, and armed with four longitudinal rows of strong, tooth-like horny spines, the series successively increasing in size distally.

Young.-Specimens $15 \mathrm{~mm}$. in diameter show all the characters of the above described adult which is $90 \mathrm{~mm}$. diameter. They, of course, appear more fragile, and have the different coloration described above.

\section{Genus Geograpsus Stimpson, 1858}

\section{Geograpsus lividus (H. Milne Edwards). (Little Rock Crab.)}

Grapsus lividus Milne Edwards, Hist. Nat. Crust., vol. 2, p. 85, 1837; Dana, U. S. Expl. Exped., vol. 13, Crust. pt. 1, p. 340, 1852; atlas, pl. 21 , 
figs. 5 a-c, 1855, Stimpson, Ann. Lyc. Nat. Hist. New York, vol. 7, p. 230. 1860 .

Grapsus brevipes Milne Edwards, Ann. Sci. Nat., ser. 3, Zool., vol. 20, p. 170 (136), 1853.

Geograpsus occidentalis Stimpson, Ann. Lyc. Nat. Hist. New York, vol. 7, p. 230, 1860.

Orthograpsus hillii Kingsley, Proc. Acad. Nat. Sci. Philadelphia, p. 194, 1880.

Geograpsus lividus Rathbun, Bull. 97, U. S. Nat. Mus., p. 232, pl. 55, 1917.

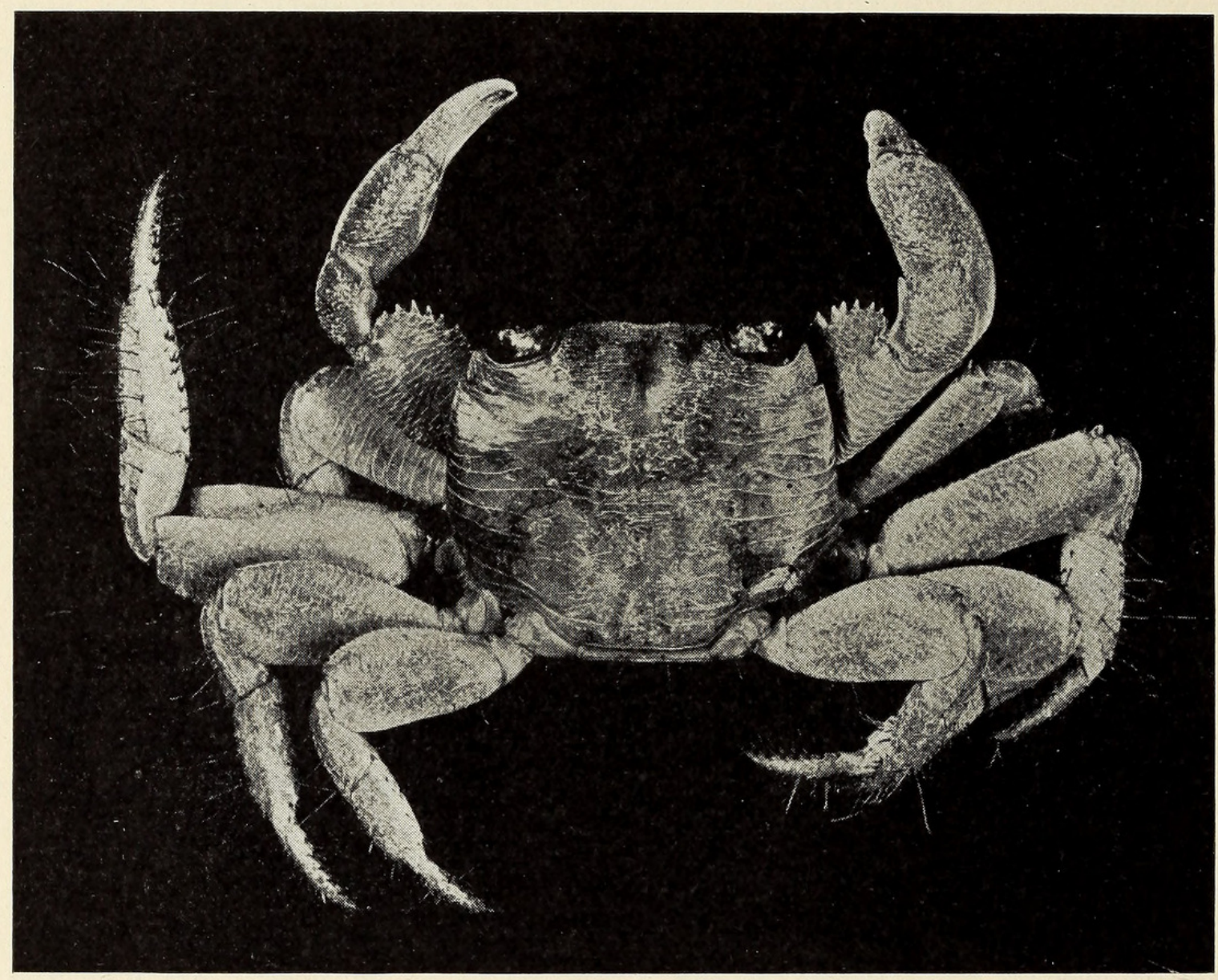

Fig. 91. Geograpsus lividus, $\times 1.2$.

Diagnostic characters.-Fingers pointed. Frontal border slightly deflexed; lateral margins clearly delineated.

Type.-Prof. Milne Edwards type material came from the Antilles, and is deposited in the Paris Museum.

Galapagos distribution.--James, Eden and Hood Islands.

General distribution.-On the east American coast this species occurs from the Florida Keys, southward through the West Indies and Bermudas to Sao Paulo, Brazil; it is also known from the Cape Verde Islands. On the West Coast it ranges from La Paz, Lower California to the Galapagos Islands, Peru and Chile. It has also been taken in the Hawaiian Islands.

Color.-The color plate made by Isabel Cooper shows the carapace dragon's blood red shading into apricot orange with the margins and striae yellow ochre; maculations of neropalin blue and yellow ochre ornament the carapace and 
meral joints of the ambulatories with an occasional few on the carpal joints; the propodal joints are dragon's blood red; the dactyli trend from this color basally toward apricot orange distally. The carpal and propodal joints of the chelipeds are dragon's blood red; the tips of the fingers are vivid yellow ochre. The eyes are fluorite violet.

Habits. - This species frequents the same haunts as Grapsus grapsus with which it is so frequently confounded in the field, but from which it is at once distinguished by the pointed fingers of the present species as contrasted with spoon-shaped fingers of Grapsus grapsus.

In his "Galapagos-World's End" Dr. Beebe gives the following sketch of Geograpsus lividus:

My favorite crabs were rich crimson little fellows, the largest not of a penny's diameter, who had no height, only length and breadth. Everything about them was broad and flat and thin as tissue, and it needed all one's attention to catch one, for they could slip between closed fingers and into the merest crack of a crevice, like magic. When cornered, they gave up all attempt at escape and waved their claws valiantly and even rushed forward to attack a finger."

Technical description.-Carapace $20.5 \mathrm{~mm}$. long; 24.6 maximum width; moderately convex, subquadrate; frontal border almost straight or a little concave in a dorsal view; four prominent tubercles along the upper part; lateral margins sharply defined throughout its entire length, a little sinuous posteriorly. Dorsal surface covered with fine transverse, granulate striae which are exceedingly faint on the gastric region and absent on the cardiac region.

The chelipeds are moderately subequal in both sexes; the merus has the inner margin expanded, serrated proximally with small teeth, distally with larger ones; the carpus is convex outwardly and has an acute spine at the inner angle; the propodus is moderately developed, convex outwardly; the fingers are subequal, slightly gaping dentate and pointed at the tips. The outer surfaces of the chelipeds is covered with squamiform striae and the upper border of the merus, carpus and propodus are tuberculate.

The ambulatories decrease in length in the following order: second, third, fourth, first. All four pairs have the meral joints quite broad, the maximum breadth being slightly more than half the length of the respective joints; the carpus, propodus and dactylus of each leg is covered with conspicuous, long, slender bristles.

Genus Pachygrapsus Randall, 1840

Key to the Galapagos species of the genus Pachygrapsus

A small species. Merus of last ambulatory legs dentate on posterior distal margin.

transversus

A large species. Merus of last ambulatory legs smooth on posterior distal margin.

crassipes

Pachygrassus transversus (Gibbes). (The Striated Pachygrapsus.)

Grapsus maurus Lucas, Explor. Sci. Algerie, Zool. Insectes, vol. 1, p. 20 and vol. 4 (atlas), pl. 2, fig. 5, 1846.

Goniograpsus simplex Dana, Proc. Acad. Nat. Sci. Phila., vol. 5, p. 249, 
1851; U. S. Expl. Exped., vol. 13, Crust., pt. 1, p. 344, 1852; atlas, pl. 21, fig. 8, 1855.

Leptograpsus maurus Milne Edwards, Ann. Sci. Nat., ser. 3, Zool., vol. 20. p. 173 (139) 1853.

Pachygrapsus simplex Stimpson, Proc. Acad. Nat. Sci. Phila., vol. 10, p. $102(48), 1858$.

Pachygrapsus maurus Kingsley, Proc. Acad. Nat. Sci. Phila., p. 199, 1880.

Pachygrapsus maurus Rathbun, Bull. 97, U. S. Nat. Mus., p. 244, pl. 60, figs. 1 and 2, 1917.

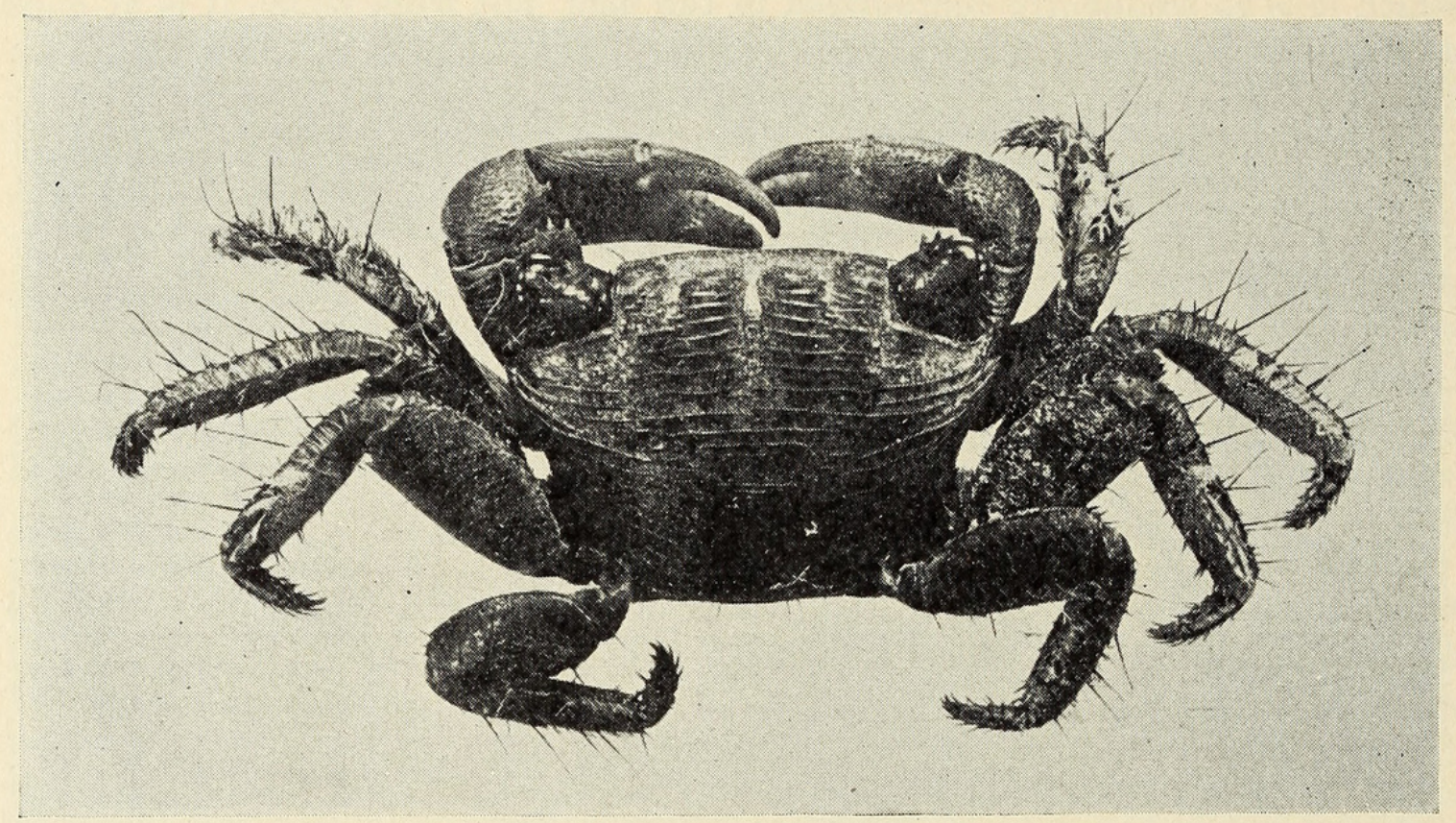

Fig. 92. Pachygrapsus transversus, $\times 3.7$.

Diagnostic characters. - Small species. Interorbital border more than half as wide as carapace, sinuous; lateral margins decidedly convergent; one acute lateral tooth behind the postorbital tooth. Merus of last ambulatory leg dentate on posterior distal margin.

Type.-Gibbes' type, which is no longer extant, came from Key West, Florida, However, the types of many of the synonyms of this species are preserved, that of Dana's Gonigrapsus innonatus being deposited in the United States National Museum; of Milne Edwards' Leptograpsus rugulosus, in the Paris Museum; Saussure's Metapograpsus dubius and Metapograpsus miniatus are in the Geneva Museum; Heller's Grapsus declivifrons and Pachygrapsus intermedius are deposited in the Vienna Museum; and cotypes of Stimpson's Pachygrapsus socius are in the Museum of Comparative Zoology, Cambridge, Mass.

Galapagos distribution.-Chatham and Albemarle, Tower, (Arcturus station 37) and Hood (Arcturus station 54) Islands.

General distribution. - This little species has a rather cosmopolitan distribution in the warm seas, having been recorded from Charlestown, South Carolina, southward along the Florida coasts, the Gulf of Mexico, the Bahamas, Cuba, Jamaica, Porto Rico, St. Thomas, Bermuda, Trinidad, Curacao, Brazil and down as far as Uruguay on the east American coasts. On the Pacific 
American coasts it is known from the Gulf of Lower California, Mexico, Costa Rica, Panama, the Galapagos Islands, Cocos Island; and down to Metapalo, Peru.

It is also recorded from the West African coasts. Likewise it is rather abundant in the Oriental region.

Material examined.-Three males, two females from Cocos Island; two males and seven females, one of which is ovigerous, from Tower Island; five males and three females from Station 37, shore zone D to E, Tower Island, April 10, 1925. Two males and one female from Station 54, off Hood Island, taken by William Beebe, while diving in 15 feet of water; three males and nine females, one of which is carrying eggs and two more are carrying embryos, from Sargassum, taken at Station 3, in the Atlantic Ocean; one female from Atlantic Sargassum.

Habits.-Although Pachygrapsus transversus is most frequently found among the stones, coral rock bottom and sandy shores of the littoral region, it is sometimes taken far out at sea as a dweller in the floating jetsam, Sargassum, etc. It was taken along with Planes minutus (L.) by the Arcturus in the Sargasso Sea, clinging to Sargassum. The females of this series were all carrying either eggs or young embryos. One male captured at Tower Island, Galapagos, was eating a cluster of crab eggs which appear to be those of this same species. Miss Rathbun records specimens taken from the bottom of a whaler at Provincetown, Mass. The multispinose setae of the dactyli indicate that such pelagic journeys are normal for the species.

Eggs.-A female $9 \mathrm{~mm}$. wide carried 1754 eggs. These were minute creamy white spheres (preserved specimen) being of slightly smaller diameter than the distal width of the outer branch of the egg-supporting appendage.

Embryos and zoea.-Another female from the same station showed the developed embryos in which the eyes were tiny dots and segmentation indistinguishable. A second female from this station carried well-developed embryos which were spherical, quite two and a half times as large as the undeveloped egg and which showed clearly the large subspherical black-eyes and the lines of segmentation on the distinctly delineated but folded abdomen. A third female carried zoea breaking through the encasement. It is of interest to note that in all cases the eggs of a female were in a practically identical state of development.

Technical description.-Carapace $10 \mathrm{~mm}$. greatest width; $8 \mathrm{~mm}$. long; front deflexed, interorbital space $6 \mathrm{~mm}$. long, margin slightly sinuous and granular; the sides are moderately vaulted and decidedly convergent posteriorly; there is one acute lateral tooth, smaller than and situated just behind the acute postorbital tooth; the posterior margin is subparallel to and about as wide as the interorbital border. The inferior orbital border is sharply denticulated. The dorsal surface of the carapace is covered with oblique and transverse striae which are granulated and more prominent on the anterior half of the carapace, but are less distinct on the cardiac and intestinal regions; the interspaces between the striae are granulose. The female abdomen is seven-segmented, broadly oval, fringed with setae; the second to fourth segments respectively bear paired biramose appendages to which the eggs are attached. The outer 
branch is lamellar, scythe-shaped, tapering distally and fringed with setae; the inner branch consists of a basal article which comprises about two-fifths of its length and is directed inward toward the center, and a distal portion which is composed of seven subequal articles and is directed outward and fringed with very long silky setae. The male abdomen is seven-segmented, narrow, triangulate with the sides of the segments converging anteriorly, the seventh segment being almost an equilateral triangle. The first pair of male appendages are rather stout, decidedly vaulted basally, and moderately spatulate in the distal part of the calcareous rod beyond which there is a thin, flattened, curved, hook-like process of a horny, translucent substance which tapers distally to an outward pointing apex.

The eyestalk is cylindrical, granulose and with a few oblique rugae; it is produced to a small rounded process which projects on the upper surface of the cornea. The cornea is convex and composed of many minute hexagonal facets. It is of about the same diameter as the stalk and extends outward about to the apex of the postorbital spine.

The internal antennae have a large basal article which is fitted into the antennal septum transversely and a slender, elongated, compressed second article; a somewhat shorter and stouter third article which is dilated distally and bears a small four-jointed flagellum and a stouter one consisting of ten tapering articles, which bear a brush of thick setae on the lateral surface.

The external antennae are quite small and are placed in the inner orbital hiatus; the basal article is very short, about four times as wide as long and with the outer side roundly flared; the second article is a trifle longer than the first and is quite bulbous being produced to a convex node on the external side; the third article is less than half the size of the second, being only a trifle longer than the basal flagellum article; the flagellum is of six small articles and reaches to the base of the cornea.

The external maxillipeds are separated from each other by a space almost equal to the width of one maxilliped. The exognath is quite slender, tapers distally on the inner side and bears a palp composed of one long slender basal article and eleven short annulations, the last of which is tipped with a tuft of long setae. The ischium is set obliquely and is wider basally than distally, the inner margin is fringed with setae; the merus is almost three-fifths as long as the ischium and has its outer and distal margins rounded, its inner margin diagonal and carinated with its distal angle produced; the palp has the basal angle flattened, its outer margin convex, its inner recurvate, its distal truncated and supporting the much smaller second joint which in turn bears the little tapering conical distal joint; all three joints are finely setigerous, the distal one being especially so.

The chelipeds are about equally massive in the male and female. The first and second joints are small; the latter is fused with the ischium; the ischium is produced to a point on its anterior distal margin and has its anterior lateral margin tridentate; the merus is three-sided and is produced to a wing-like expansion on its anterior distal part, the anterolateral margin being dentate and the distal margin being cut in three acute teeth on the inner dorsal surface, and produced to one on its posterior ventral distal angle. The carpus is short, 
convex dorsally and made rugose by numerous striae and produced to an acute tooth on its inner margin; the propodus is massive being about as long as all the preceding joints taken together and its height is equal to half or slightly more than half is own length; the palm is convex on its outer surface and rather thin on the basal part of its upper margin; the propodal finger is about one-third of the length of the entire propodus and is rather stout, with its distal end narrowly spoon-shaped and tipped with a horn-like substance; the cutting edge is furnished basally with two small and one large tooth followed by five small well developed, triangulate teeth; the lower part of the propodus is longitudinally traversed by a diagonal carina which extends to the tip of the finger; below this carina there are several transverse striae. The hinged finger is slenderer and more curved than the propodal, upon which its horn-tipped apex fits; the cutting edge of the hinged finger is furnished with ten moderate, unequal triangulate teeth which touch, but scarcely interlock with those of the opposing finger. The upper surface of the meral and carpal joints is rugose with transverse and oblique striae.

The first three pairs of ambulatory legs successively increase in length posteriorly, the third pair being the longest; the fourth pair is almost equal in length to the second pair. All have the basal three joints short; the meral joint is broad being about half as wide as it is long, with the dorsal surface transversely striated and the anterior lateral surface set with small spines, one being at the distal angle, the posterior distal margin is cut into three teeth (occasionally only two teeth); the carpus is narrower than the merus and only about half as long, wider distally and with both distal angles acute; the propodus is as wide as the distal part of the carpus and about twice as long; both the carpus and propodus are traversed by two longitudinal striae, the anterior one of which on the first, second and third pair of legs, and the posterior one on the fourth pair of legs, are furnished with fringes of close-set plumose setae; the margins of both these joints are also set with very long spinose setae; the dactyli are about threefourths as long as the propodi and are quite stout and tipped with a very acute spine and also armed with two dorsal and two ventral marginal rows of stout, sharp spines.

\section{Pachygrapsus crassipes Randall. (The large Pachygrapsus.)}

Pachygrapsus crassipes Randall, Journ. Acad. Sci. Philadelphia, vol. 8, $p$. 127, 1839: De Man, Notes Leyden Mus., vol. 12, p. 86, pl. 6, fig. 11, 1890. Grapsus eydouxi Milne Edwards, Ann. Sci. Nat. ser. 3, Zool., vol. 20, p. 170 (136) 1853.

Leptograpsus gonagrus Milne Edwards, Ann. Sci. Nat., ser. 3, Zool., vol. $20, p .173$ (139), 1853.

Pachygrapsus crassipes Rathbun, Bull. 97, U. S. Nat. Mus., p. 241, pl. 59, 1917.

Diagnostic characters.-Carapace with the side very convex anteriorly; one lateral tooth present; striae of dorsal surface quite long. Merus of fifth ambulatory entire of posterior border.

Type.-Randall's type-locality is given as Sandwich Islands; the specimen is deposited in the Museum of the Philadelphia Academy of Natural Sciences. (Dr. Rathbun states without explanation that "Sandwich Islands" is probably an error for "California coast.")

Galapagos distribution.-Albemarle, Chatham and James Islands. 
General distribution.-From Oregon to the Gulf of California; also Galapagos Islands, and Cocos Island; Chile; Japan and Korea; Sandwich Islands (type-locality).

Material examined.-One female from Cocos Island, May, 1923, taken by the Arcturus.

Color.-Mottled red-brown with ochreous maculations.

Technical description.-Carapace $44 \mathrm{~mm}$. long, $52 \mathrm{~mm}$. wide; interorbital border $24 \mathrm{~mm}$. wide; quadrate, only a little wider than long with lateral regions arched anteriorly, decidedly convergent posteriorly. The postorbital tooth is

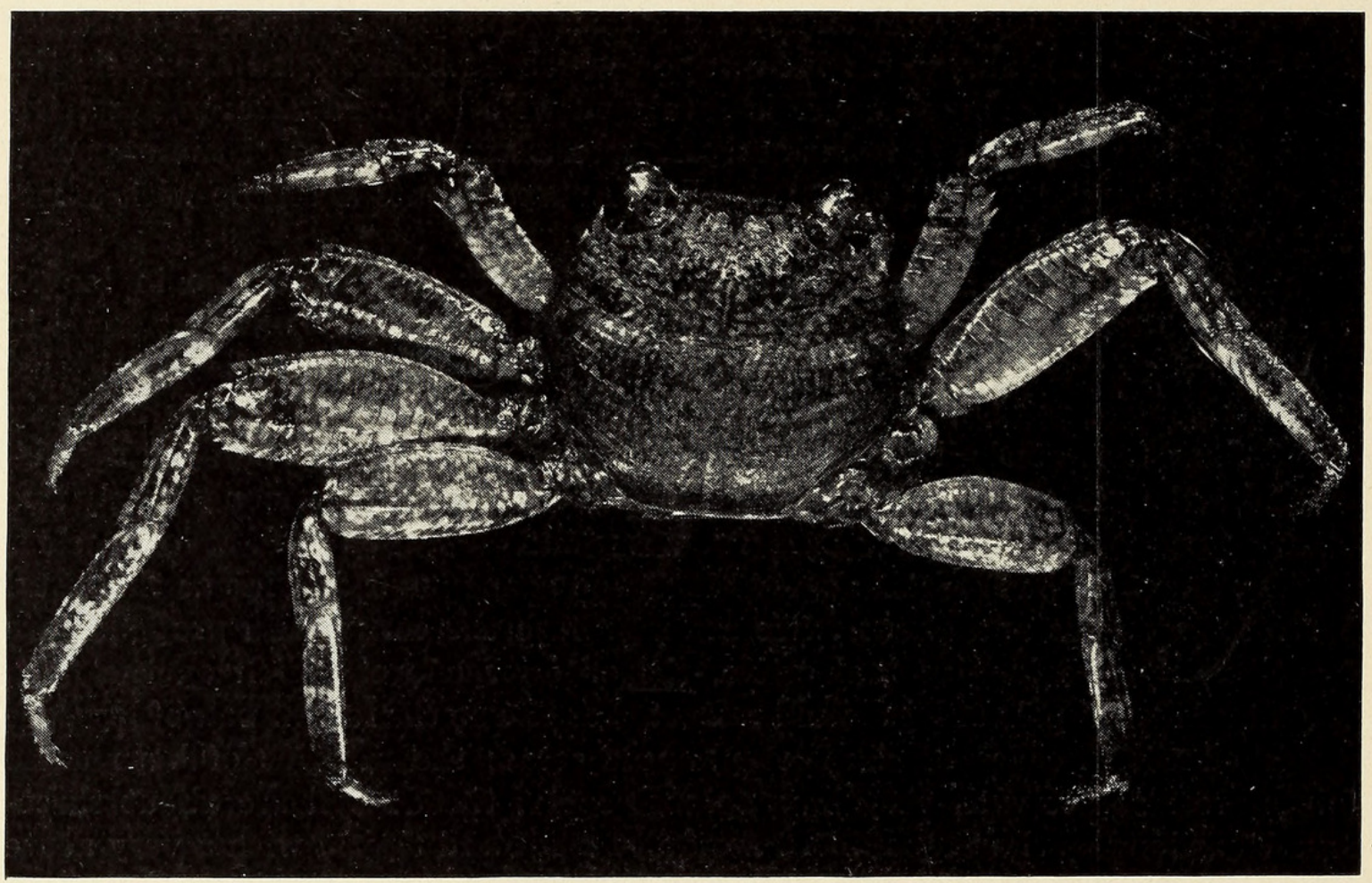

Fig. 93. Pachygrapsus crassipes. Reduced to 0.6 of natural size.

followed by a smaller tooth. The frontal border is almost half as wide as the carapace with the margin sinuous and the outer angles forming a decided lobe. The orbits are oblique with the upper margins finely granulose, the lower margin denticulate. The buccal cavity is squarish with the anterior angles rounded; there is a rhomboidal space separating the halves of the external maxillipeds. The ischium is longer than the merus; the latter bears the coarse three-jointed palp on its outer anterior border.

The chelipeds are subequal, rather massive, approximately one and threefourths times as long as the carapace; the merus is finely striated on its upper surface, smooth; its inner margin is produced, the distal margin is dentate; the carpus is also striated and bears a subacute tooth at its inner angle; the propodus is nearly smooth, except for an obliquely longitudinal carina which runs from the proximal end of the propodus to the base of the finger. The fingers are long and gaping. 
The ambulatories decrease in length in the following order: second, third, first and fourth pairs; the meral joints of each has a subdistal spine near the anterior border and the three anterior pairs each have several teeth near the distal end on the posterior meral border; this area being devoid of teeth in the fourth pair of legs.

\section{Genus Planes Leach, 1825}

Planes minutus (Linnaeus), 1758. (Columbus' Crab; Sargassum Crab; Gulfweed Crab.)

Cancellus marinus minimus quadratus Sloane, Nat. Hist. Jamaica, vol. 2, p. 270, pl. 245, fig. 1, 1725.

“'Turtle Crab," Browne, Hist. Jamaica, p. 421, pl. 42, fig. 1, 1756

Cancer minutus Linnaeus, Syst. Nat. ed. 10, vol. 1, p. 625, 1758.

Cancer pusillus Fabricius, Syst. Entom., p. 402, 1775.

Cancer glaberrimus Herbst, Naturg. Krabben $u$. Krebse, vol. 1, p. 262, pl. 20, fig. 115, 1790.

Pinnotheres minutus Bosc, Hist. Nat. Crust., vol. 1, p. 244, and X (18011802).

Pinnotheres pusillus Bosc, Hist. Nat. Crust, vol. 1, p. 244, and X (18011802).

Pinnotheres glaberimus Bosc, Hist. Nat. Crust., vol. 1, p. 244, and X (18011802).

Grapsus minutus Latreille, Hist. Nat. Crust., vol. 6, pl. 68, and XI (18021803).

Grapsus cinereus Say, Journ. Acad. Nat. Sci. Phila., vol. 1, p. 99, 1817

Grapsus pelagicus Say, Journ. Acad. Nat. Sci. Phila., vol. 1, p. 41, 1818.

Planes clypeatus Bowdich, Excursions in Madeira and Porto Santo, p. 15, pl. 12 , figs. $2 s$ and $2 b, 1825$.

Grapsus testudinum Roux, Crust. Medit., p. (52), pl. 6, figs. 1-6, 1828

Grapsus pelagicus Roux, Crust. Medit., p. (55), pl. 6, figs. 7-9, 1828.

Grapsus (Grapsus) pusillus de Haan, Fauna Japon, Crust., p. 59, pl. 16, fig. 2, 1835.

Nautilograpsus minutus Milne Edwards, Hist. Nat. Crust., vol. 2, p.90, 1837.

Grapsus diris Costa, Fauna Napoli, Crust., pl. 4, fig. 1, 1838.

Nautilograpsus major McLeay, in Andrew Smith's Zool. South Africa, Annul., p. 66, 1838 .

Planes minutus White, List. Crust. Brit. Mus., p. 42, 1847.

Planes linnaeana Bell, Brit. Stalk-eyed Crust., p. 135, 1851.

Planes cyaneus Dana, Proc. Acad. Nat. Sci. Phila., vol. 5, p. 250, 1851, (issued 1852).

Nautilograpsus angustatus Stimpson, Proc. Acad. Nat. Sci. Phila., vol. 10, p. 103, (49), 1858.

Planes minutus Verrill, Trans. Connecticut Acad. Arts and Sci., vol. 13, p. 325, text-fig. 7, pl. 13, figs. $a-j ; p l .27$, fig. 6, 1908.

Planes minutus Rathbun, Bull. 97, 'U. S. Nat. Mus., p. 253, pl. 63, 1917.

Planes marinus Rathbun, Bull. 97, U. S. Nat. Mus., p. 258, pl. 64, 1917.

Diagnostic characters.-Carapace squarish, uniformly convex, button-like. Color pattern a mimicry of seaweed. The power of changing its coloration in imitation of that of its surroundings is the outstanding field-character of this species.

Type.-Linnaeus' type-locality is given; "In Palagi Fuco natante." His type specimen is, unfortunately, no longer extant.

Galapagos distribution.-On green turtle, off Galapagos (Rathbun); Arcturus station 54, off Hood Island (Beebe).

General distribution.-This quaint "little wanderer" of the tropical and subtropical areas of both the Atlantic and Pacific Oceans is perhaps the oldest recorded crab of the new world, for, as stated by Hans Sloane (1705): "Columbus on finding this alive on Sargaffo floating in the Sea, concluded himfelf not far from fome land in the firft voyage he made on the difcovery of the Weft Indies." It occurs most abundantly in gulfweed, especially in the Sargasso Sea and is 
occasionally found on turtles, floating logs and debris and large jellyfishes. It is sometimes found along the shore lines after severe storms.

Material examined.-An extensive series of specimens of this species representing practically all stages of development from egg to adult were secured by the Arcturus Oceanographic Expedition:

Two hundred small adults, about 50 per cent. of the females carrying eggs; females $5 \mathrm{~mm}$. wide, were heavily laden with eggs; from Gulfweed, Atlantic Ocean, March 4, 1925.

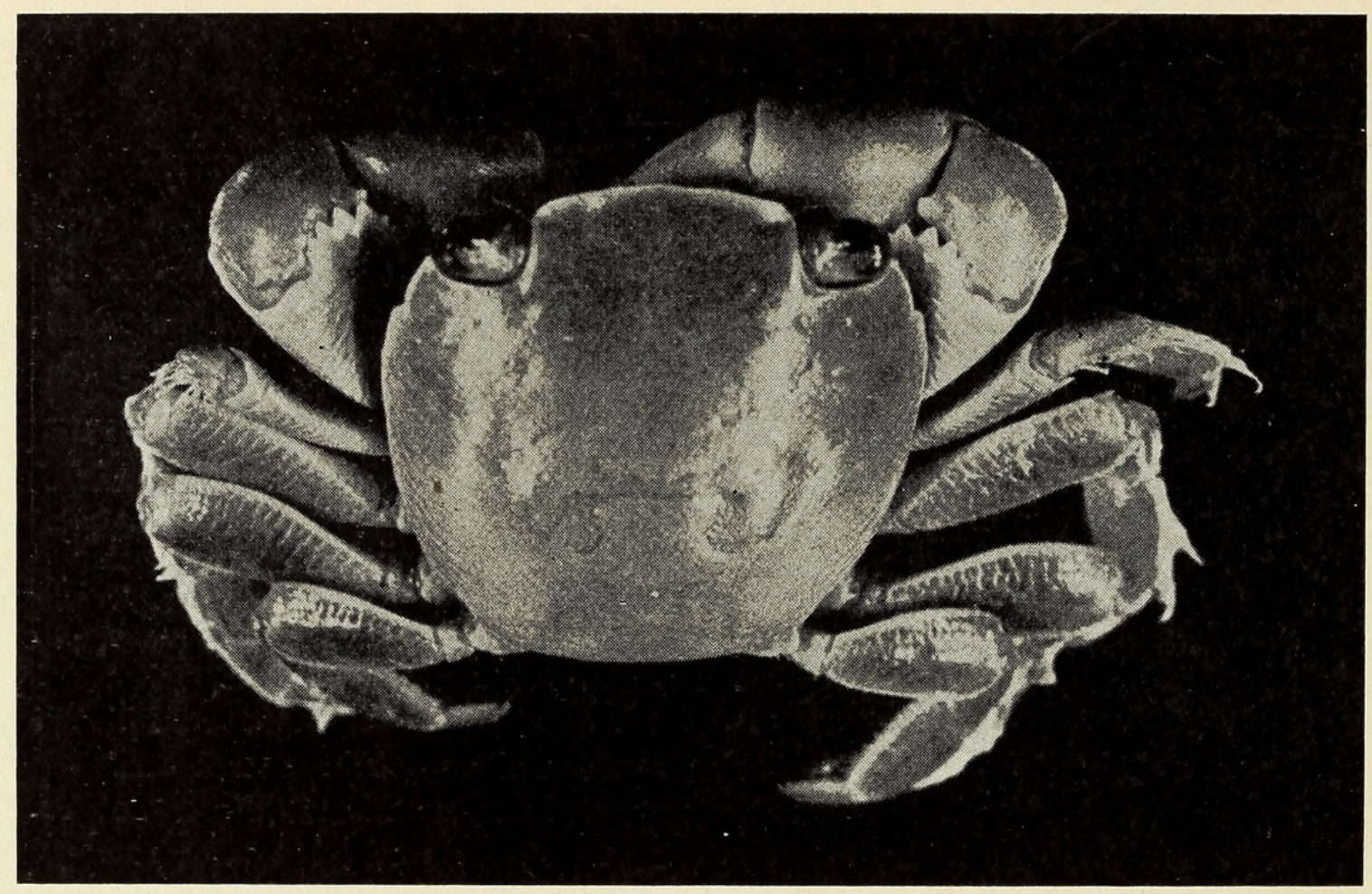

Fig. 94. Planes minutus, $\times 3$.

Thirty-seven specimens somewhat larger than the above series, many of the females with eggs, from Sargassum weed, Atlantic Ocean, March 7, 1925.

Thirty-six specimens from Sargassum, Atlantic Ocean.

About seventy-five specimens, some with eggs from Sargassum, Sargasso Sea, Lat. 25 degrees 56 minutes N., Long. 55 degrees 42 minutes W.

Thirty-six specimens from Sargassum, Sargasso Sea, February, 1925.

Fifty-six adults from Sargassum near the Sargasso Sea, February 20, 1925; most of this series were very small adults, some with eggs.

Twelve small adults from Sargassum, Atlantic Ocean, February 21, 1925.

Six young adults, from Station 5 Sargasso Sea, Lat. 26 degrees 42 minutes N., Longitude 52 degrees 59 minutes W., on Sargassum February 11, 1925. (Color plate of these specimens was made by Isabel Cooper.)

Seventeen specimens, including two very large males, from floating log, Station 74, sixty miles south of Cocos Island, Pacific Ocean.

Four males, including one very large specimen from the tide rip, Station 31 , 
Pacific Ocean (tag W.B. 802). Color plate of these specimens was made by Isabel Cooper.

Four very large specimens, three males and one ovigerous female, were obtained from the surface at Station 31 ; one male and one female specimen bear young goose barnacles attached to their carapaces. The ovigerous female is carrying zoea about ready to escape from the test. These zoea measure 0.6 $\mathrm{mm}$. diameter.

One male and two females from station 54, off Hood Island.

Color.-A series of five sketches was made by the staff artist, Isabel Cooper, showing the range of color variation of which this unusual little crab is capable. In sketch No. 1 the ground color of the carapace and appendages is pale light salmon mottled with light pinkish cinnamon, the legs being banded with this color; a large subovate whitish area occupies the anterior half of the carapace. In sketch No. 2, the design is the same as in No. 1 , but instead of salmon the ground-color is tawny-olive and the mottlings a light vinaceous brown. In No. 3 the design is the same as in Nos. 1 and 2 but the ground color is light yellowish olive mottled with brownish olive. In No. 4 there is no large white area on the carapace, the ground color is very pale salmon mottled and banded with gull grey; the carapace is flecked with minute vinaceous brown spots, and the chelipeds and distal half of the ambulatory legs is light ochraceous salmon. In No. 5 the design is similar to that of No. 4 but the ground color is tawny olive and the mottlings are vinaceous brown and the chelae are light ochraceous salmon.

Technical description.-Carapace ovate-quadrate usually about as wide as long, decidedly convex, surface usually smooth, with the regions scarcely indicated in small to medium-sized specimens but in several specimens of $20 \mathrm{~mm}$. or more in diameter, the branchial, mesogastric, urogastric, cardiac and intestinal regions are distinctly delineated, the anterior gastric region is deeply bilobed and the lateral tooth is emphasized, while the transverse lines on the branchial region are unusually prominent. The inteorbital space is half or more than half the width of the carapace; the frontal border is relatively straight, the orbit is oval, a little oblique with the postlateral angle sharp, the inferior border straight, with a deep inner hiatus which is partially filled by an isolated tooth and the basal antennal article. The eyestalk is cylindrical, slightly swollen basally, and with a shallow constriction on its outer upper median surface, and with a small rounded process on the upper surface of the cornea; the cornea is placed obliquely on the outer distal end of the stalk and is a deep dark brown color.

The antennulae are nearly transverse, and have the basal article long, cylindrical, the second article slightly shorter and dilated distally, the stouter branch of the flagellum composed of twelve conically tapering articles that bear a brush of setae on the outer margin; the slenderer branch composed of eight articles each of which bears two short setae on its distal margin.

The antennae have the basal article outwardly convex and wider than long, the second article with both lateral margins produced, rounded and fringed with setae; the third article narrow, cylindrical supporting a small flagellum base which bears six subequal, tapering articles. 
The epistome is well-developed.

The external maxillipeds are set wide apart, the gap being nearly as wide as the ischium of the endognath. The exognath has a distally tapering rod that reaches to about midway the merus and bears a long, slender palp consisting of a slender basal article and about twelve annulations. The ischium of the endognath is elongate, cleaver-shaped, with the inner margin slightly rounded and finely setigerous; the merus is two-thirds as long as the ischium and much wider with its lateral borders roundly produced and its distal border excavate in the median area for the reception of the palp; the latter has the basal joint quite dilated distally; the second and third joints subequal in length, quite fleshy, the latter tapering distally with its margins heavily setigerous as on the margins of the merus.

The male abdominal belt consists of seven segments which taper to a triangulate apex distally; the basal segments are as wide between the fifth pairs of legs as the sternal plate. The first to seventh segments successively increase in length distally, the sixth and seventh segments being conspicuously wider than the preceding series. The first pair of male abdominal appendages arise from a strong, vaulted, archlike base and consist of a pair of very strong, stout, club-like processes that reach forward to the fourth from front sternal plate, whose sidewalls have a concave depression fringed with setae, into which the tip of the process fits; there is a prominent rounded tubercle on the outer posterior margin of the cavity of the third sternal plate, just in front of the tip of the genital appendage. The appendage is bluntly rounded at the distal end but bears on the outer distal margin a spoon-like corneous process which has its concavity on the outer posterior side and its convex surface covered with brushlike setae.

The female abdomen is seven-segmented, broadly rounded, covering the entire sternal plate between all the respective pairs of legs, and anteriorly reaching forward to the base of the maxillipeds. This abdomen is strongly convex, and has its entire margin heavily fringed with setae. The second to fifth segments inclusive bear the four pairs of female abdominal appendages. These are similar and subequal, consisting of a very brief basal article, a long curved outer branch, fringed with rather short plumose setae, and a two-jointed inner branch whose proximal article is directed diagonally toward the center and whose distal part consists of the subequal articulations each of which bears at its distal margin a cluster of exceedingly long nonplumose setae, which form a limb that lies along the median line of the cavity. The round genital apertures of the female are in the fourth from front sternal plate which lies between the second pair of ambulatory legs. A female measuring $5.2 \mathrm{~mm}$. diameter carried 2268 eggs in her pouch. (I am indebted to Mr. Serge Chetyrkin for painstakingly counting these eggs.)

The chelipeds are equal, those of the female are well-developed but those of a male of equal diameter are distinctly more massive than those of the female. The coxal, basal and ischial joints are short, the merus is three-sided, dilated distally, with its anterior ventral margin finely serrate and this distal angle strongly quadridentate; the carpus is convex on the upper surface, with a pronounced acuminate tooth on the inner lateral margin. The propodus is longer 
than the combined length of the merus and carpus, has the palm high, depressed cylindrical, with the outer surface convex and finely punctate; the propodal finger is short, obtuse, with the tip narrowly spoon-like, the inner margin with two very large teeth midway its length, flanked by two small teeth basally and four distally; inside these teeth there is a row of sensory setae. The upper finger is set semi-obliquely and is more curved and tapering than the lower, and has a similar rounded tip; the cutting edge is set with a very large basal tooth, followed by four fairly large and eight small teeth.

The ambulatories are similar; the first pair is slightly shorter than the second and third pairs which are about equal, while the fourth pair only reaches midway the propodus of the third. All have the basal joints short, the merus, carpus and propodus approximately half, or in places more than half, as wide as long; there is a subdistal tooth on the anterior margin of the merus and the dorsal surface of the latter is striated with transverse ridges, and has its posterior distal margin and armed with several (usually three or four) sharp teeth, those on the second and third legs usually but not invariably stronger than those of the fourth and fifth legs. The anterior margin of the carpus and propodus is fringed with close-set plumose setae and the posterior margin of the propodus is armed with two rows of alternately set spines; the dactyl is quite stout with its anterior margin rounded distally and the apex tipped with strong spines; there are two rows of spines on the anterior lateral margin and two similar rows on the posterior lateral margin of each dactyl; there are setae interspersed with these spines.

The extensive series of Planes minutus (Linnaeus) obtained by the Arcturus Oceanographic Expedition show in varying degree some or, occasionally, all of the distinguishing specific characters of Planes marinus Rathbun. A critical comparison of the type of this species, with the Arcturus material from both the Atlantic (Sargasso Sea) and the Pacific Ocean show conclusively that Planes marinus is merely an unfixed variation within the species Planes minutus.

The "broader carapace" ascribed to Planus marinus is not borne out by measurement of the type which is quite within Miss Rathbun's own diagnosis of Planes minutes, "the carapace varies from a little longer than broad to a little broader than long," a point repeatedly illustrated by the Arcturus collection. The "carapace depressed about the middle" is scarcely to be accepted as a specific character, since in the three specimens of Planus marinus it may be due to some shrinkage in the preserved specimens, or to the age of the specimens, for in Planes minutes, as in Grapsus grapsus, there is a marked increase of sculpturing in the older specimens. Also the factor of ecdysis must be considered. Hun dreds of Planes minutus which I have had moult in my laboratory aquaria at Miami, Florida, have cast shells deeply grooved for the species, and emerged with an ungrooved soft shell. The physical condition of the crab and its consequent capacity to produce a rapid increase in size and a heavily calcareous shell were evidently factors affecting the appearance of the carapace.

The "nearly straight" posteriolateral margins ascribed to Planes marinus are, unfortunately, not apparent in Miss Rathbun's illustration of this species, nor discernible in the type itself when the latter is compared with a large series of Planus minutes for the latter show considerable variation in this respect. 
Several specimens, with the carapace narrower than long, and devoid of median depressions have a posterolateral margin which is more nearly straight than that of the type of marinus.

The "broader basal joint of the antennae and broader merus joint of the outer maxilliped, both its inner and outer lobes being more strongly developed" cited by Miss Rathbun, are usual but not invariable characters of all the large old Planes minutus in the present collection; they are as frequent in specimens longer than wide as in those wider than long. Some have these characters combined with an extremely arcuate postlateral margin.

The "feebler dentition of the distal end of the inner expansion of the arm" is too variable to merit serious discussion. It is not infrequently found on one arm, while the opposite arm will present a decided dentition. Sometimes in old specimens of both sexes this dentition is much worn down. Often in regenerated limbs it is decidedly feebler.

\section{Subfamily: PLAGUSIINAE}

\section{Genus Plagusia Latreille}

Plagusia immaculata Lamarck. (Pacific Log-rider.)

Plagusia immaculata Lamarck, Hist. Anim. Sans Vert., vol. 5, p. 247, 1818; Miers, Ann. Mag. Nat. Hist., ser. 5, vol. 7, p. 150, 1878; Challenger Rept. Zool., vol. 17, p. 273, pl.22, fig. 1, 1886; Rathbun Bull.97, U. S. Nat. Mus., p. 335, pl. 103, 1917.

Plagusia tuberculata Rathbun (not Lamarck) Proc. U. S. Nat. Mus., vol. 21, p. $605,1898$.

Diagnostic characters. - Tubercles of carapace depressed, subsquamose.

Type.-Lamarck's type-locality is given as: "la Mediterranae Je la crois de l'Ocean Indien." The type is deposited in the Paris Museum.

Galapagos distribution.-Arcturus station 54, off Hood Island, appears to be the first Galapagan record of this pelagic species.

General distribution.-As long ago as 1818, this species was recorded from the Indian Ocean. Its range was greatly extended in the Indo-Pacific region by the explorations of the Challenger Expedition. More recent findings of the United States government agents and private collectors have established the distribution of Plagusia immaculata along the west American coast from Costa Rica to Panama.

Material examined.- One ovigerous female, one male from Station 74, from floating log. Four large ovigerous females, four small females, one large male and six small males from the tide-rip, Station 31. Two ovigerous females from driftwood, Cocos Island; one of these is a very large specimen. The smaller of these Cocos specimens carried 17,300 eggs. (Counted by Mr. Serge Chetyrkin). Two young specimens from Station 54, off Hood Island.

Habits, color.-This fearless little mariner of the tropical Pacific spends much of its life on the floating jetsam of the ocean although it has also been recorded occasionally from specimens captured along the rocks at high tide where they probably were beached. Although Plagusia immaculata is an excellent swimmer it is better known as "log-rider." Its color pattern of dark vinaceous brown mottled with deep sea-foam green, a pattern so designed that it simulates the color scheme of the dull decaying log splashed by spray, renders 
the little crab relatively indistinguishable from its environment. This illusion is further enhanced by the posterior margin of the legs being heavily fringed with sea-green hairs which resemble the tufts of algae and bryozoa found on floating

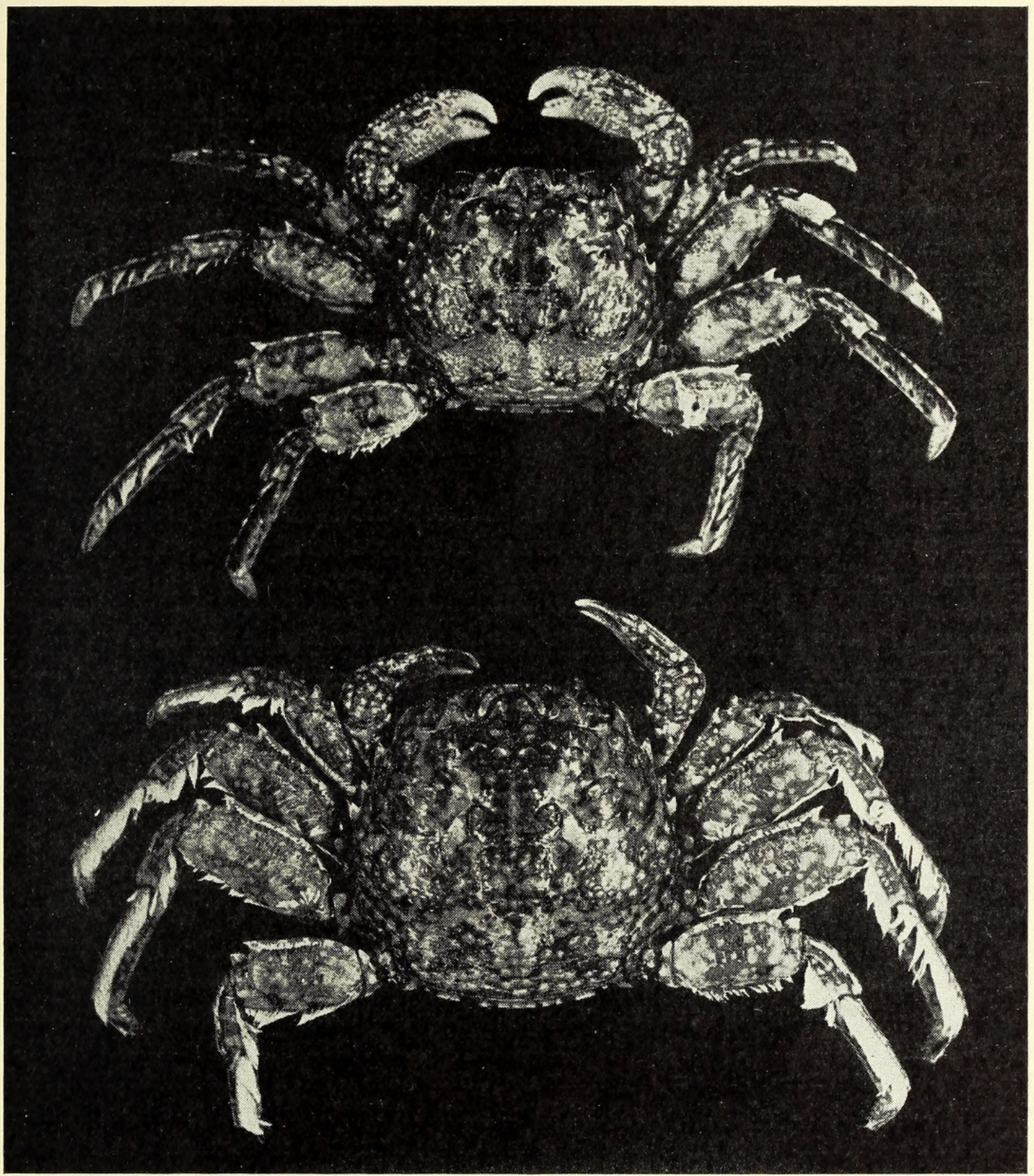

Fig. 95. Plagusia immaculata, upper figure female; lower figure male, natural size.

logs. The merus of the legs is flattened dorso-ventrally and armed with teeth distally, while the slender carpus, propodus and spinose dactylus are deflected, forming an effective device for holding on to the pelagic homes.

Although this species was discovered as long ago as 1818, the interesting 
habits of this little crab were ignored or entombed in misleading language until the present year when William Beebe published the following notes in his "Arcturus Adventure," p. 49, 1926 (Putnam, New York City): "I was afraid that all the small folk in the wooden sanctuary must have fallen out from the shaking and the banging to which the log had been subjected; but little did I know the clinging powers of these small beings. In the case of this particular log they might have all come of the race of Jumblies. . . Crabs in multitudes crept about or were picked out of crevices and waterworn cracks. Some were pale olive gray, irregularly mottled with maroon, looking like bright-colored conglomerate rocks. On the legs were sea-green swimming fringes. The ivory white underparts never showed, as the crabs always scurried about with bodies held close to their pelagic island. Some of the forward-bent abdomens were cupped about a large mass of chocolate spawn."

Technical description.-Carapace subcircular, very convex, feebly tuberculate; tubercles not fringed with setae; all the regions of the carapace are distinct. There is a pair of small, submedian rostral teeth and four sharply defined subequal teeth on each anterolateral margin (including the orbital tooth). Eight low squamose tubercles are in a subcresentic formation on the anterior part of the gastric region. In small specimens, (about $20 \mathrm{~mm}$. long), these tubercles are relatively invisible, but in older specimens, (about $36 \mathrm{~mm}$. long), they are very evident. The epistome is prominent, extending ridge-like beyond the anterior border of the carapace, divided into five lobes, the submedian pair being finely crenulate.

The abdominal belt of the male is triangular with rounded apex; it consists of seven segments; segments one and two articulate as a unit, as also do segments three, four, five and six; the last segment swings on a very flexible hinge. The female abdominal belt covers the entire sternum except a slight margin of the plate between the chelipeds, and is very convex externally, and concave internally, forming a pouch in which the eggs are carried. The first and second segments articulate as a unit, as do the third, fourth, fifth, sixth and seventh; the entire free margin of the belt is fringed with setae; the margin of the ventral surface of the crab in the semicircle extending from the base of the second ambulatory legs forward, is also fringed with close-set fine hairs, their density increasing in the median area. The abdominal appendages are setose.

The male chelipeds are massive, the hand and finger together being almost as long as the carapace; very convex on the outer surface; three-fifths as broad as long, covered except near the apex of the fingers by rounded tubercles which near the upper margin are stronger, and are arranged in distinct longitudinal rows. The distal margins of the carpus and merus are multispinose. The inner margin of the meral, carpal and propodal joints of the male cheliped have tufts of strong, irregularly spaced brush-like setae which face the finely and sparsely setigerous under parts of the carapace. The chelipeds of a female of about the same size as the above-described male are small, weak; the hand and fingers together being equal to only half the length of the carapace, scarcely one-third as wide as long, practically devoid of tubercles and finely reticulate. The ambulatory legs are very powerful, about the same size in both sexes, the merus is well-developed, approximately half as broad as long, dorsally flattened 
and keeled, has a large spine near the distal margin and the distal margin itself is broken into several short spines; the carpus and propodus are slender, the carpus being two-thirds as long as the propodus which is about as long as the merus; the dactyl is stout, terminates in a very stout spine and has a longitudinal row of five spines on the inner margin. There is a long fringe of sea-green setae on the posterior margin of the legs, thin on the merus but long and heavy on the carpus, propodus and dactyl, resembling algae on driftwood. Occasionally on large, (36 mm. wide), specimens of both sexes there is a weak thin fringe of much shorter hairs on the anterior margin along the groove of the same segments.

\section{Family: OCYPODIDAE \\ Subfamily: OCYPODINAE}

Genus Ocypode Fabricius, 1798

Ocypode gaudichaudii Milne Edwards and Lucas, 1843.

Ocypode gaudichaudii Milne Edwards and Lucas, d'Orbigny's Voy.dans l'Amer. Merid., vol. 6, 1843, Crust., p. 26, vol. 9, atlas, pl. 17, figs. 4-4b, 1847; Rathbun, Bull. 97, U. S. Nat. Mus., p. 373, pl. 129, fig. 1, pl. 130,

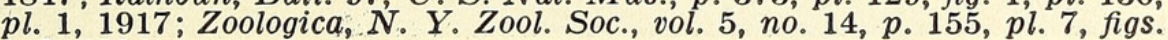
$1-3,1924$.

Name: Dr. Robert E. Coker states that this crab is known in Peru as the "carreto" or cart-driver. It is also known as the west coast "beach crab" and "ghost crab."

Diagnostic characters.-Fingers truncated. Eyestalks produced to a point beyond the eyes.

Type.-The type material of this species came from Chile and is deposited in the Paris Museum.

Galapagos distribution.-Chatham Island (Albatross); South Seymour Island (Arcturus) Eden Island (megalops; Harrison Williams Expedition); Black Bight, Albemarle Island (Hopkins-Stanford Expedition).

General distribution.-This species is known from San Pablo, California, southward including the Galapagos Islands, to Valparaiso, Chile. Cano has recorded it from Honolulu.

Material examined.-Three females were obtained at South Seymour Island, Galapagos, by the Arcturus Oceanographic Expedition; one megalops from puffer, Eden Island (Harrison Williams Expedition).

Habits. - The species follows practically the same mode of life as its close relative, Ocypode albicans.

Technical description.-Carapace rectangular, moderately convex, frontal border sinuous, with anterolateral angles prominent, almost right-angled; lateral margins a trifle arcuate anteriorly, convergent posteriorly. Width at anterolateral angles $35 \mathrm{~mm}$., length at median dorsal line $30 \mathrm{~mm}$., interorbital space $4 \mathrm{~mm}$. wide. The sidewalls of the carapace are high and prominent, being tumid anteriorly, slightly concave above the base of the second leg and with the posterolateral region outlined by a bifurcation of the lateral margin which forms a triangulate area. The posterior margin is decidedly arcuate. The superior orbital border is excavate at the inner angle for the reception of the eyestalk then produced into a rounded lobe fitting the constriction of the stalk, then 


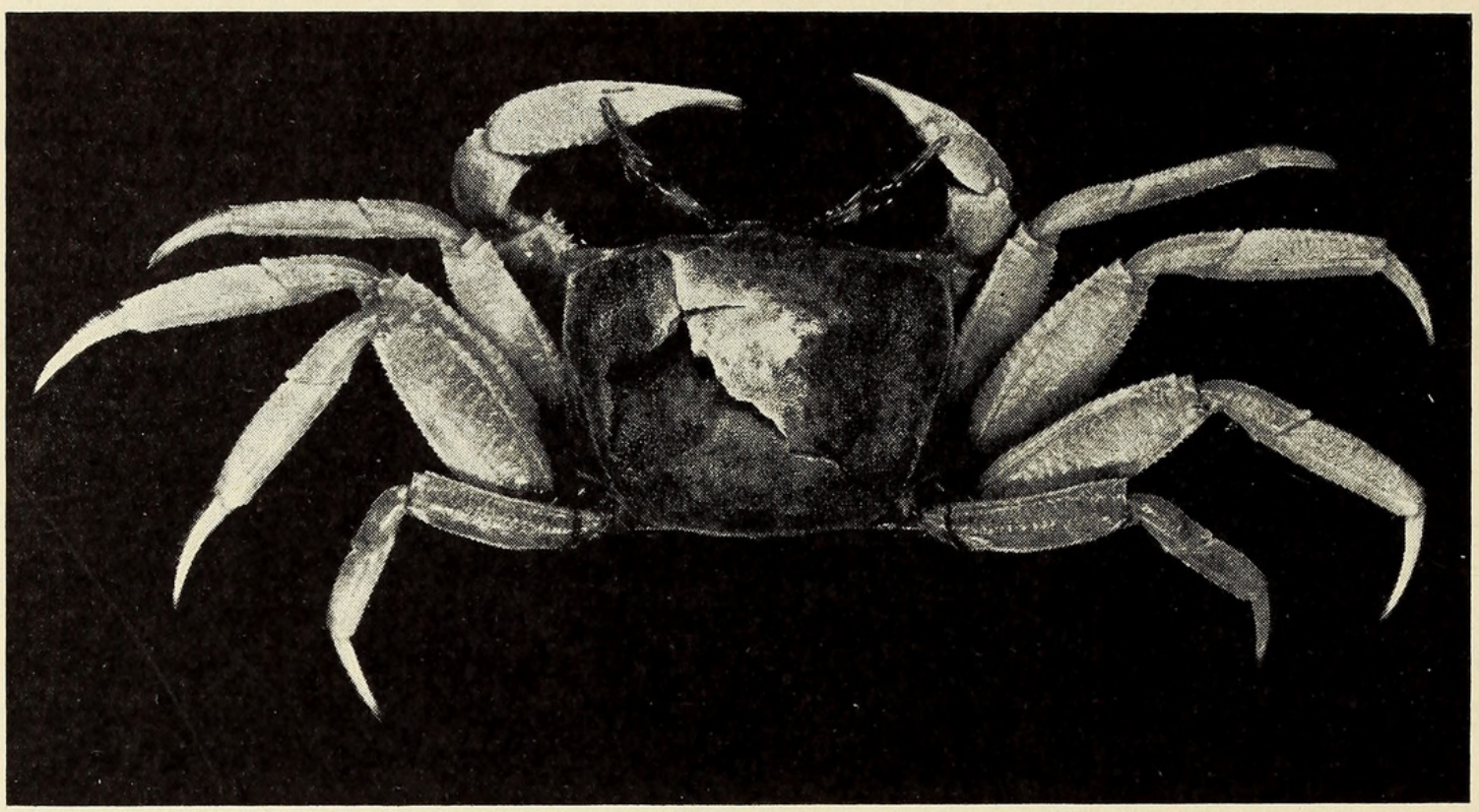

Fig. 96A. Ocypode gaudichaudii, adult. Reduced to $6 / 7$ of natural size.

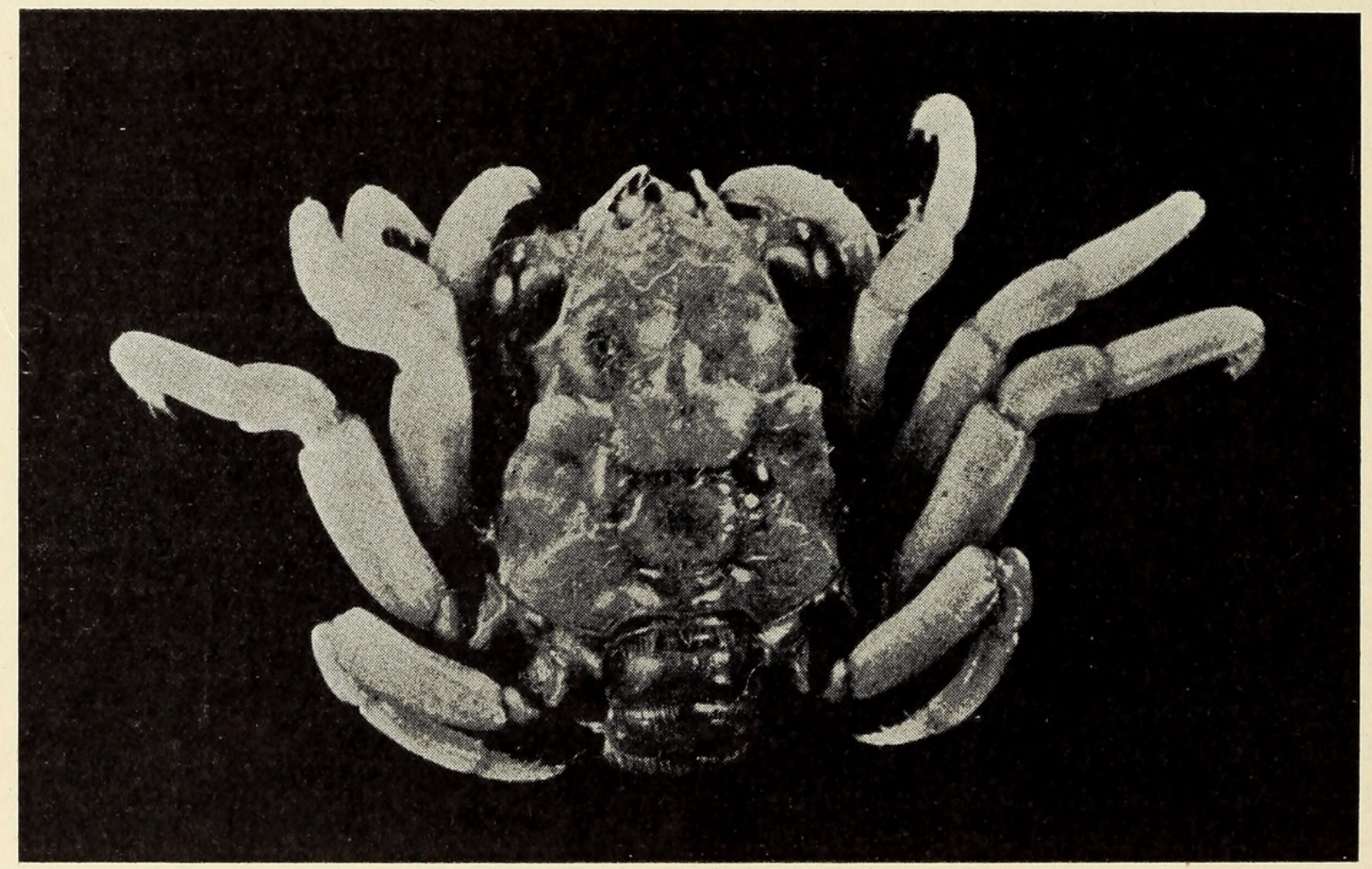

Fig. 96B. Ocypode gaudichaudii, megalops, enlarged $\times 7$. 
sloping backward, the outer angle being almost right-angled. The outer inferior margin of the orbit is excavated to accommodate the style of the eyestalk; there is a deep notch approximately midway the lower margin and there is a short sharp tooth inset near the base of the eyestalk. The upper and lower margins of the orbit are finely serrate. The ventral region is strongly convex. The abdominal belt of the female is broadly oval. The first segment is very short and extremely narrow, the second and third segments are subequal in length each being about one-third longer than the first segment; the fourth segment is about a third longer than the third; the fifth is about a third longer than the fourth; the sixth, which is the longest of the series, is about one-third longer than the fifth and has its anterolateral angles roundly produced; the seventh segment is very small, set in the middle of the anterior border of the sixth, and has its anterolateral borders rounded. The apex reaches the anterior border of the first sternal plate. There are four pairs of biramose abdominal appendages, similar in structure to those of Ocypode albicans, borne by the second to fourth segments respectively.

The eyestalk is cylindrical, constricted near the base of the cornea but produced along the dorsal surface separating the edges of the cornea, and beyond the distal end of the cornea forming a slender cylindrical, slightly up-and-outward ovoid; the cornea is elongate-ovoid, the corneal area on the dorsal surface being scarcely half as long as that on the outer and ventral surfaces; the dorsal edges of the cornea being separated by the produced stalk.

The antennulae have the basal article which contains the auditory organ, very tumid, closely fitted into the cavity on each side of the median frontal "tongue" which partly conceals the basal and entirely conceals the remaining joints of the antennulae, which are rudimentary and consist of two short subequal articles of about the diameter of an ordinary sewing-needle, and a stubby, round knob representing the stouter branch of the flagellum and two minute slender articles representing the slender branch of the flagellum.

The antennae have the basal article decidedly bent upon its proximal portion and lodged with the minimum of flexibility in the space between the antennulae and the orbital sinus; the second joint, which is almost squarish with its outer surface convex, and is a little bent inward distally, differs in shape and proportion from that of Ocypode albicans; the third joint is small, cylindrical and directed outward and supports the tapering eleven-jointed flagellum which scarcely reaches the apex of the isolated tooth near the inner lower orbital angle.

The external maxillipeds are slightly larger in proportion to the rest of the animal, than are those of Ocypode albicans and they are also more strongly vaulted and protruding than those of Ocypode albicans. The exognath is a simple rod without palp which reaches only to the base of the merus; the ischium of the endognath is broad, rectangular, with its inner margin decidedly setigerous and almost touching; the merus is only half as long as the ischium and is only about two-thirds as wide distally as it is proximally with its distal margin truncated and its inner margin raised in a conspicuous ridge; the palp arises from the outer distal angle of the merus and fits across the distal border of the merus, having its distal portion dilated; the second article is only half the length of the merus but is swollen club-like, the third joint is cylindrical, quite slender, 
fringed with setae, tapering to a blunt point which reaches almost to the middle of the ischium.

The chelipeds are unequal in both sexes, but are similar in structure. The three basal joints are small. The merus is three-sided, one margin being posterior and two anterior; both of the latter are denticulate, the upper one being especially so and produced to a dentate point distally; the carpus is short, convex on its outer surface with both the upper and lower distal marginal angles produced to a tooth; the palm is high and flattened, its outer surface a little convex and covered with coarse squamosities; the width of the propodus is equal to its length from base to beginning of the finger, which is approximately as long as the palm. The stridulating ridge which runs across the distal inner surface of the palm is composed of about seventeen tubercles on the upper half and fortyfive striae on the lower half; it plays across a smooth complementary ridge which longitudinally traverses the distal half of the anterior surface of the ischium. The upper and lower margins of the propodus including that of the propodal finger, and the proximal half of the hinged finger, are quite serrate. The fingers are high and flat and decidedly truncated at the tip with the inner angle forming a little tooth; the propodal finger is somewhat broader than the hinged; and is longitudinally traversed by two carinae composed of slightly larger squamosities than those on the remaining surface; a similar, single carina traverses the upper finger; both fingers are continuously denticulate along the cutting edges which meet throughout their entire length.

The ambulatory legs are long, slender and similar in structure. The second pair is the longest of the series, exceeding the length of the first pair by about two-fifths of the length of its dactyl, and likewise exceeding the third pair by one-fifth the length of its dactyl; the fourth pair of legs is conspicuously shorter and only reaches halfway the length of the propodus of the third pair. All have the basal three joints small; the meral joint the longest of the series, being approximately as long as the carapace is wide or high, and in the second, third and fourth meral joints, especially the third, their greatest width is approximately one-half their length; the carpus is about one-half as long as the merus, quite narrow basally, moderately dilated distally; the propodus is threefourths as long as the merus, is quite narrow, depressed cylindrical, traversed on its upper side by a longitudinal carina, slightly posterior to the median line; the dactyl is about as long as the propodus and is very slender, slightly curved, tapering to an acuminate point. The merus, carpus and propodus are laterally compressed but the dactyl is dorsoventrally flattened, more conspicuously so distally. The merus has the anterior edge carinate and finely serrate and the posterior margin finely serrate also; there is a transverse constriction on the upper side just behind the distal border of the merus; the upper meral surface is distinctly reticulated and sparsely ornamented with squamose tubercles; the carpus is subquadrate in cross-section, the paired dorsal edges are coarsely serrate or denticulate and the surfaces of the carpus are covered with rough squamosities; the upper distal angle of the carpus is produced into a tooth-like process which bears two rows of about four denticles each; the propodus also is covered with rough squamosities which are more prominent along the dorsal border; there is a line of fine setae along the longitudinal groove of this segment 
on the upper dorsal surface of the distal end there is a patch consisting of fine spinose setae; the dactyl has the dorsal surface between the two carinated dorsal margins filled with similar spinose setae, below the dorsal carinae; the ventral surface is fluted with three or four carinae which extend nearly to the tip and which have short setae in the depressions between them; the tips are flattened dorsoventrally and very acuminate.

The following is Miss Rathbun's description of the megalops:

"A small crab was taken from the surface of a puffer, Spheroides annulatus, in a pool at Eden Island. It proved to be a megalops, or one of the later developmental stages of a crab; it is similar to a known megalops of Ocypode albicans, and for that reason I have ventured to give it the name of the only sand crab occurring at the Galapagos, viz.: O. gaudichaudii. In the adult of this species the eyes are remarkable in having a slender style projecting from them; this style may be as long as the eye and its stalk.

The carapace of the megalops is $4.6 \mathrm{~mm}$. long, $4 \mathrm{~mm}$. wide. Its sides are high and are crossed obliquely by three furrows into which as many ambulatories may fit; between the first (or anterior) and the second groove, there is a prominent, rectangular, hepatic tubercle; on the branchial region on the posterior margin of the second groove there is a sharp oblique ridge. The mesogastric and cardiac regions are each set off by deep grooves; the mesogastric is partially divided into three parts. The front is deeply cut into three narrow, deflexed lobes, of which the lateral are only half as long as the median lobe. A deep median groove extends forward from the gastric region. The body is covered with pigment spots which are larger anteriorly and diminish in size and number posteriorly, being very few on the sixth abdominal somite and absent from the telson. The raised portions of the carapace are covered with a short pubescence, while a transverse line of hairs crosses the branchial and anterior cardiac regions. The posterior border of the first six abdominal somites is fringed with short hair, and of the pleopods with long hair.

The ambulatories are sparingly dotted with fine pigment spots which thin out distally, being absent from the dactyl and upper half of the propodites. Five spines below each dactyl, the second spine from the tip being the longest. No hairs between bases of second and third ambulatories."

\section{Genus Uca Leach, 1814.}

Key to the Galapagos species of the genus Uca.

Anterolateral angles of carapace almost right angles, but with the corner produced slightly forward. Orbital margin moderately oblique.

Anterolateral angles of carapace retreating. Orbital margin pronouncedly oblique.

galapagensis helleri

Uca galapagensis Rathbun.

Uca galapagensis Rathbun, Proc. Washington Acad. Sci., vol. 4, p. 275, pl. 12, figs. 1 and 2, 1902; Bull. 97, U. S. Nat. Mus., p. 403, pl. 142, and text fig. 167, 1917: Zoologica, N. Y. Zool. Soc., vol. 5, no. 14, p. 155, 1924.

The odd aspect of this group of crabs, resulting from the strikingly dis- 


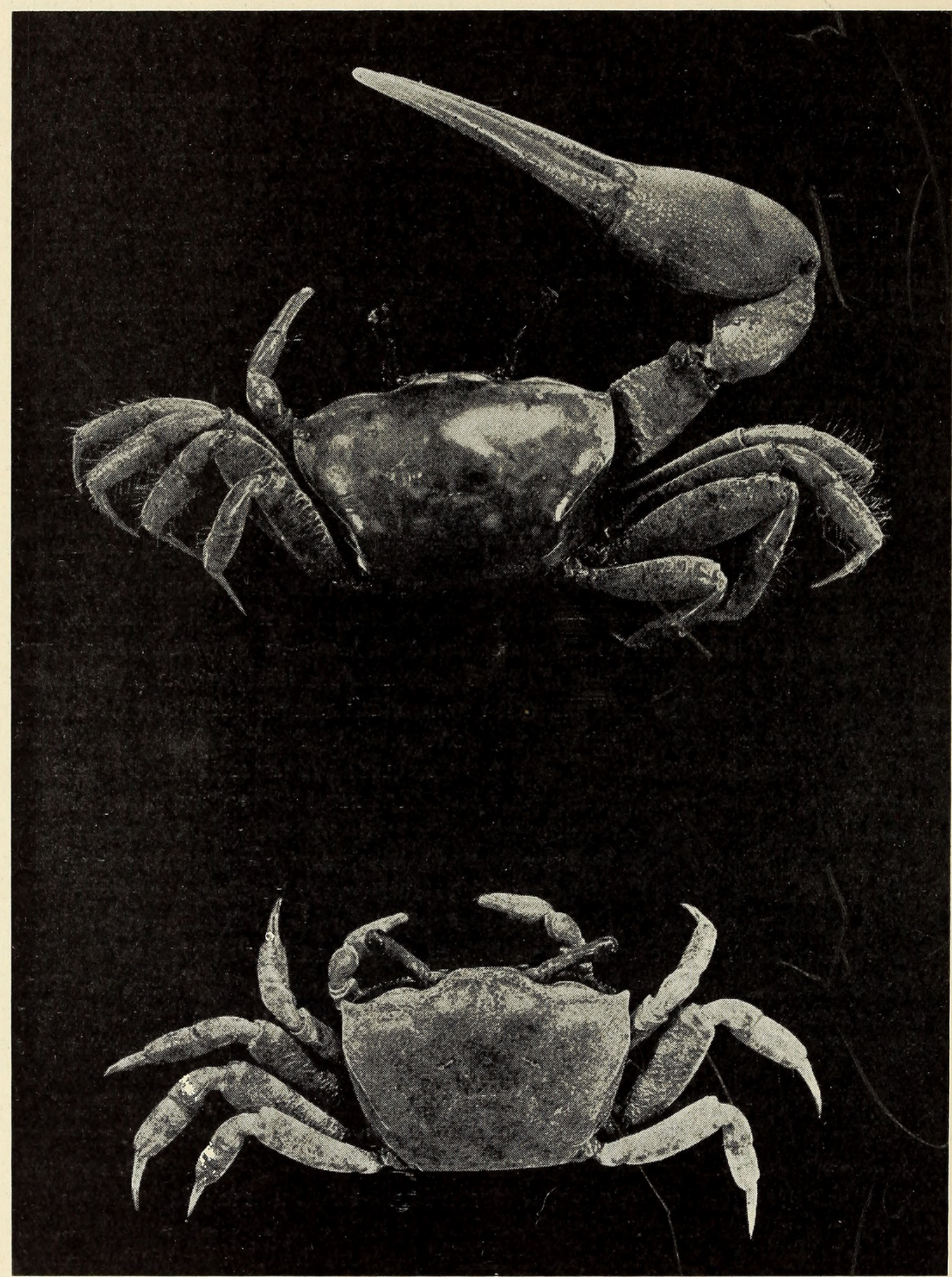

Fig. 97. Uca galapagensis, upper figure male; lower figure female, $\times 1.8$. 
proportionate size attained by one of the claws in the male and the curious manner in which the little creatures handle this claw, has been a source of comment among the peoples of many lands, which has found expression in a series of quaint common names. Among English-speaking folk, it is known as the "calling crab" because it seems to be forever beckoning with its huge claws. Another name, and the one by the way, most widely used along the coasts of the southern United States is "fiddler" crab, from the fancied resemblance of this great claw to this musical instrument.

The Japanese have woven a legend around the species of $U c a$ common in Japan, and give it the name Siho maneki, which means "beckoning for the return of the tide." Linnaeus and Latreille have both indirectly referred to this habit of the little crab, in giving it scientific names. To the Peruvians these crabs are known as "maestro-sastre," (master-tailor). Long before the coming of Columbus to the New World, these little crabs were woven in the folk-lore of the Indians who dwelt along the coast. Since the present species falls within that group of the genus characterized by a broad front, Miss Rathbun has designated galapagensis as "broad fronted fiddler" crab, a name which seems not especially fortunate in view of the fact that it is equally applicable to several species, one of which is the other Galapagan fiddler, Uca helleri.

Diagnostic characters.-Distinguished from the other Galapagan fiddler by having its anterolateral angles almost right-angled, but with the corner produced slightly forward, whereas in Uca helleri this angle is slightly retreating. The orbital margin is oblique but less so than in helleri. The oblique ridge inside the palm is continued to the upper margin, in both galapagensis and helleri, but this item serves to distinguish them from several other species; as does the fact that both species have the merus of the ambulatory legs enlarged.

Type.-The type-material (six male specimens) was taken by the United States Bureau of Fisheries Steamer Albatross, at Indefatigable Island, Galapagos Islands, April 12, 1888, which fact was seemingly overlooked fourteen years until the Hopkins-Stanford Galapagos Expedition secured nine specimens at South Seymour Island and submitted these to the United States National Museum for classification.

Galapagos distribution.-This species was taken by the above mentioned expedition at Indefatigable, James and South Seymour Islands, Galapagos. The Harrison Williams Galapagos Expedition secured it at James, South Seymour, Indefatigable and Eden Islands, Galapagos, where Dr. Beebe records it as "common about salt ponds."

General distribution.-In addition to the above records this species was taken on the salt flats of Puerto Grande, Rio Zarumilla, Peru, by Dr. Robert E. Coker of the U. S. Bureau of Fisheries.

Material examined.-One female secured by the Arcturus Oceanographic Expedition at Cocos Island. The following specimen secured by the Harrison Williams Galapagos Expedition were also examined: two males from Eden Island (2042); two males (2624) from James Island; and two males (2139) from South Seymour Island, Galapagos.

Color.-A color plate of this species was made by Isabel Cooper. The carapace is light buff around the edges of the dorsal surface; the central portion 
of the carapace is dark dull gray. The eye-stalks are light buff, the cornea deep gray, the chelipeds are orange cinnamon; the ambulatory legs are light buff.

Habits.-Uca galapagensis was found by William Beebe to be abundant on the salt marshes and tide flats of Galapagos. He also notes a less known haunt of these little crabs, in his "Galapagos-World's End" (p. 154):

"There were woods here, (James Island) real trees of moderate height, and we revelled in the luxury of shade and of walking almost free from broken lava. Mocking birds, fly-catchers and finches were numerous and even tamer than those we encountered elsewhere. They were curious too and followed us at arm's length, cocking their heads and inspecting us carefully. Now and then a scuttling sound as of some large animal in the carpet of dead leaves drew attention to a giant hermit crab hurrying away through the forest in the house that was his only by right of seizure. Fiddler crabs skittered about more quietly."

Uca galapagensis usually makes its home in burrows which it digs along the shore near the high water mark. It is gregarious, for although never more than a pair of crabs have been found occupying one hole, whole communities are found with the holes in close proximity to one another. These holes average three-quarters of an inch in diameter and extend downward for about eight to twelve inches, the upper corridor being nearly perpendicular, or a little oblique, and the lower chamber usually nearly horizontal. The work of digging these burrows is largely performed at night, or in the cool of early dawn when the tide is out. The huge chela of the male, and in the case of the females, either chela, form the shovel with which the sand is broken away. By cleverly coördinated manipulation the loosened sand is rolled into a pellet which is clasped by the three hinder anterior ambulatory legs, while the crab climbs out of its burrow by using its front anterior ambulatory leg and chela and its four posterior ambulatories. Upon attaining the entrance to the burrow the crab ludicrously scans the horizon with its long stalked eyes, and if satisfied that no enemy menaces, scuttles forward with its burden for at least a foot from the entrance, drops its burden, scurries back to the entrance, pauses, tip-toe, scans the horizon with its periscope eyes, and if all is well, loafs a bit at the doorway before returning to its den. The dexterity and rapidity with which these small crabs manipulate their huge claws in digging, and the engineering skill displayed in tunneling their "homes upon sand" is truly marvelous. One of the uses of their "voice," that is, the noise caused by the stridulating ridge of the giant chela, is to warn other members of the species that their particular burrow is inhabited, a warning that is usually respected.

The life cycle of this species has not yet been successfully worked out. No females carrying either eggs or young have been reported so far. However, the structure of the female abdominal appendages indicates that these crabs probably do carry the eggs at least during the pre-zoea stage.

Technical description.-Carapace $20 \mathrm{~mm}$. wide at anterior margin, interorbital margin rounded, $4.5 \mathrm{~mm}$. wide between eyestalks, $10 \mathrm{~mm}$. wide at posterior margin; $13 \mathrm{~mm}$. long in median dorsal line; strongly convex in all directions; surface finely punctate and sparsely setigerous; regions faintly indicated, except the H-depression of the urogastric region which is more definitely defined. The interorbital border at its widest point between the eyestalks is less than one- 
fourth of the width of the anterior border of the carapace, and is clearly visible as a carinated edge in a normal dorsal view of the crab; the upper orbital border is sinuous and shows this carination continued, widening in the median area and vanishing near the anterolateral angle. The anterolateral angles are almost right-angled, but with the corner produced slightly forward; the anterior half of the lateral margins are out-curved, the posterior parts are moderately convergent, the posterior margin is relatively straight and is emphasized by a wide flat carina along its border. The inferior orbital margin is but little sinuous and forms a pronounced hiatus at the outer angle to accommodate the cornea; the entire margin is beaded, and setigerous both above and below this crenulation. The eyestalk consists of a short basal joint and a well-hinged, exceedingly flexible, long, cylindrical distal joint which reaches to the lateral margin; it is produced into narrow tongue-like projection on the dorsal surface which separates the margins of the cornea and terminates in a rounded process on the outer convex distal end; the cornea is elongate, cylindrical, decidedly more dilated than the stalk, very convex, situated obliquely-terminal, extending about two-fifths of the length of the distal joint of the eyestalk; the latter bears a dorsal longitudinal row of setae that function as "lashes."

The frontal and lateral walls of the carapace are high, strongly vaulted, the frontal region being tumid and coarsely tomentose; the upper margin of this tomentose area is distinctly channeled by a sulcus which extends from near the outer orbital angle inward to the efferent aperture near the outer distal angle of the external maxilliped.

The male abdominal belt is composed of seven segments, of which the first, second, third and fourth are of about equal width, while the fifth and sixth are microscopically narrower, and the seventh, which has its anterior margin broadly rounded, is slightly narrower than the sixth. The first and second segments are exceedingly short, their combined length being less than that of the third segment; the fourth segment is a trifle longer than the third segment; the fifth segment is a little longer than the fourth; the sixth segment is as long as the fifth; the seventh segment is only two-thirds as long as the sixth segment and is heavily fringed with setae around its anterior margin; it also bears a median transverse row of setae. The first pair of male appendages have an arched united base which arises from the first segment, and a pair of long slender curved processes that reach forward as far as midway the base of the chelipeds; these rods are three-sided, the wider side being that one appressed to the sternal plates, the angle formed by the union of the two narrower sides being the inner margin of the outer side of the appendage; the distal end of the appendage is rounded and curved, spoon-like, concave on its outer surface which is surrounded with close-set spinose setae, the inner surface is convex and bears a dense tuft of setae.

The female abdomen is also seven-segmented, but is very broadly oval, being nearly as wide as the sternal plates between the legs and reaching forward to the anterior margin of the first sternal plate. Its segments have the same length relationship as in the male; but the seventh segment in the female is only about half as wide as the sixth segment, whose antero-lateral angles are roundly produced. The lateral margins of all the segments are densely fringed 
with long plumose setae. The second to third abdominal segments each bear paired appendages. Each appendage consists of a short peduncular joint, a long curved outer blade, whose proximal portion is directed diagonally inward toward the median line, the distal portion lying subparallel to this line. The appendages of the second segment have the outer blade only about half as long as the inner blade; the remaining appendages have the blades subequal. All the blades are heavily fringed with long silky setae.

The inner antennae are situated in a septum beneath the frontal margin; the basal angle is flat externally, dilated basally, narrowed distally, and bears two free, club-shaped articles which fold obliquely and fit into the septum; the proximal of these articles is slightly smaller than the distal and is dilated distally, filling the entire cavity when folded; the second article is also dilated distally and bears a rudimentary flagellum which consists of a short knob-like joint that is setigerous on its outer distal margin.

The external antennae have the basal joint much wider than long, bent transversely upon itself, set in the hiatus between the inner orbital angle and the inner antennal septum; the second joint, which is free, is much longer than wide, convex outwardly and closely appressed to the proximal end of the basal joint of the inner antennae and to the basal joint of the eyestalk; this second joint of the outer antennae bears a brush of fine long sensory setae on its anterior distal margin, and a palp arises from the posterior distal margin; this palp is composed of rather long cylindrical basal articles and about thirteen short, tapering rings and reaches about one-fifth of the length of the orbit.

The external maxillipeds are very large, being approximately one-third of the width of the carapace and nearly two-thirds as high as they are wide. The maxillipeds are separated from each other by a space equivalent to about twothirds of the width of one maxilliped. They have the external surface setigerous and channeled, a longitudinal groove parallels the inner margin of the ischium and unites with one which curves around subparallel to the meral margins; all the margins of maxilliped are heavily fringed with long setae; the exognath is a slender, tapering rod which reaches half way the length of the merus and supports an inner whip-like palp that is about two-thirds as long as the rod, and is tipped with setae; the ischium of the endognath is rectangular and is about three-fifths as wide as long; the merus is about one-half as long as the ischium and has its outer lateral margin slightly produced near the base; the palp arises from the outer distal margin; the inner distal margin is rounded; the palp is three-jointed; the basal joint is about as long as the second and third, which are subequal, taken together, and is produced on its inferior lateral margin into a laminar projection which fits under the upper margin of the merus; the second and third joints, which are cylindrical, lie along the inner margin of the merus with their own margins adjacent but not touching; the palp is remarkably setigerous.

The chelipeds are strikingly unequal in the male, the propodus of the great chela in the specimen under discussion, being $28 \mathrm{~mm}$. long and $10 \mathrm{~mm}$. high while that of the small chela is $7 \mathrm{~mm}$. long and $2.5 \mathrm{~mm}$. high. The chelipeds of the female are approximately equal but are extremely small, those of a specimen $18 \mathrm{~mm}$. anterior width, and $12 \mathrm{~mm}$. long having a propodus scarcely $4 \mathrm{~mm}$. 
long and $2 \mathrm{~mm}$. high. The great cheliped of the male has an unusually strong coxa, a small basis fused with the ischium which in turn is fused with the merus; the merus is three-sided, produced to a point on its distal surface and enlarged distally and is exactly one-half as long as the anterior width of the carapace; the joint between the merus and carpus is well-developed; the carpus is about three-fourths as long as the merus and slenderer, with its upper outer surface convex; the propodus when folded at rest, projects beyond the carapace for a distance equal to the entire length of the palm and the fingers extend across the front to the anterolateral angle of the opposite side. The palm is high, convex, outwardly carinated along its upper margin; the entire outer surface is granulate, that of the upper half, and especially of the carina, being more coarsely granular; a longitudinal row of setae parallel the upper marginal carina, running from the base of the propodus to near the base of the hinged finger; the propodal finger is less curved and somewhat shorter than the hinged finger, and tapers a little to a blunt apex; two rows of blunt crenulations form low tooth-like processes along the cutting edge of this finger. The hinged finger resembles the fixed finger in its general proportions and dentitions, but differs in having the distal end more tapering and decidedly curved. The fingers are widely gaping, meeting only at the tips. The small chela (male) resembles the large chela in the structure of its three basal segments but differs in having its merus very slender, elongate, not projecting outward beyond the carapace but directed upward, reaching as high as the anterolateral angle of the carapace, the carpus is convex outwardly and is about half as long as the merus; the propodus is rather flat with the palm as high as long and but little convex; the fingers are about three-fifths of the entire length of the propodus and are but little tapering, devoid of teeth on the cutting margins, but rounded spoon-shape distally, margined with a horny brown substance and fringed with tufts of setae. The female chelipeds resemble the small male cheliped in general structure but differ in having the palm thicker, more swollen, the fingers only about one-half of the entire propodal length; the propodal finger is carinated throughout the entire length of its outer surface by a line of denticles; the hinged finger is similarly carinated along the proximal two-thirds of its upper margin. The upper and outer surfaces of the propodus are also granular.

The male crab has the ambulatory legs distinctly longer than those of a female of equal size. In the male, the first ambulatory on the side with small chela and, a trifle less conspicuously, the first ambulatory behind the large chela, are distinctly directed obliquely forward from the meral joint instead of outwards, as are the three posterior pairs of legs. In the female this is even more conspicuous, as if the first ambulatories functioned in coöperation with, or as accessories to, the chelipeds. In the male the second pair of ambulatories are the longest, exceeding the first pair by the length of the dactyl and half the propodus; but being almost subequal in length to the third pair of legs; the fourth pair are the shortest reaching only one-third of the length of the propodus of the third pair. All of the ambulatories are similar in general structure, having the proximal three joints short, the merus the longest joint of the limb and also conspicuously widened and reticulated with transverse striations which are made up of minute granulations; the carpus and propodus taken together are 
about as long as the merus, the carpus being only two-fifths of this; both joints are much narrower than the merus; the distal half of the carpus and the entire propodus is set with long spine-like hairs; the dactyl is very strong, slender, fluted, nearly as long as the propodus and set with several rows of short spinelike hairs.

There are accessory respiratory orifices between the basal joints of the chelipeds and first ambulatory legs; a second larger orifice between the bases of the second and third ambulatories.

Uca helleri Rathbun.

Uca helleri Rathbun, Proc. Washington Acad. Sci., vol. 4, p. 277, pl. 12, figs. 3 and 4, 1902; Bull. 97, p. 415, pl. 151, 1917.

This species was apparently named for Edmund Heller, one of the naturalists of the Hopkins-Stanford Galapagos Expedition.

Diagnostic characters. - Carapace widest at anterolateral angles; orbits very oblique. Upper margin of propodus of male without a carina; oblique ridge continued to the upper margin.

Type.-The type, a male specimen; two additional males and a female were taken at Mangrove Point, Narborough Island, Galapagos Islands, March 1899, by the Hopkins-Stanford Galapagos Expedition and are deposited in the United States National Museum.

Galapagos distribution.-Mangrove Point, Narborough Island; Black Bight, Albemarle Island; Tower Island, Arcturus station 37.

General distribution.-Known only from the Galapagos Islands.

Material examined.-Three males and two females were taken at station 37, Tower Island, by the Arcturus Oceanographic Expedition.

Technical description.-Carapace $9 \mathrm{~mm}$. long, $.12 \mathrm{~mm}$. greatest width between anterolateral angles; interorbital width (between the eyestalks) 1.6 $\mathrm{mm}$. Carapace moderately convex in both directions minutely granulose and with scattered punctae; areolations very faint; frontal border narrow and obtusely rounded between the eyes, anterior margins sloping abruptly to the anterlateral angles; but little sinuous; the lower orbital margin is also visible in a dorsal view, being projected beyond the upper margin, and convex and finely denticulate. The anterolateral angles are prominent and practically right angled; the sides decidedly slope toward each other posteriorly. The male abdominal belt is seven-segmented, rather broad, with the distal segment rounded. The first pair of male appendages are long substantial rods, grooved on the outer side and bent inward just before the tips, which are tapering and channelled.

The female abdomen is seven-segmented, broadly oval and fringed with setae. The four pairs of biramose appendages are also fringed.

The inner antennae are situated in a septum beneath the frontal margin; the basal article is enlarged and flattened externally; it bears two club-shaped articles which fold obliquely and fit into the septum; the distal article supports the rudimentary flagellum.

The external antennae have the basal article much wider than long, bent slightly upon itself, set in the hiatus at the inner orbital angle; the next joint, 
which is free, is about a third longer than wide, flattened slightly bent and fringed on its inner distal-lateral margin with three or four long, spinose setae; the third joint is slender, elongate, cylindrical and supports a tapering, sixjointed flagellum.

The external maxillipeds are rectangular and very close-fitting; their width is approximately equal to one-third of that of the carapace and their outer surfaces are setigerous and channelled; all the margins of the maxilliped are

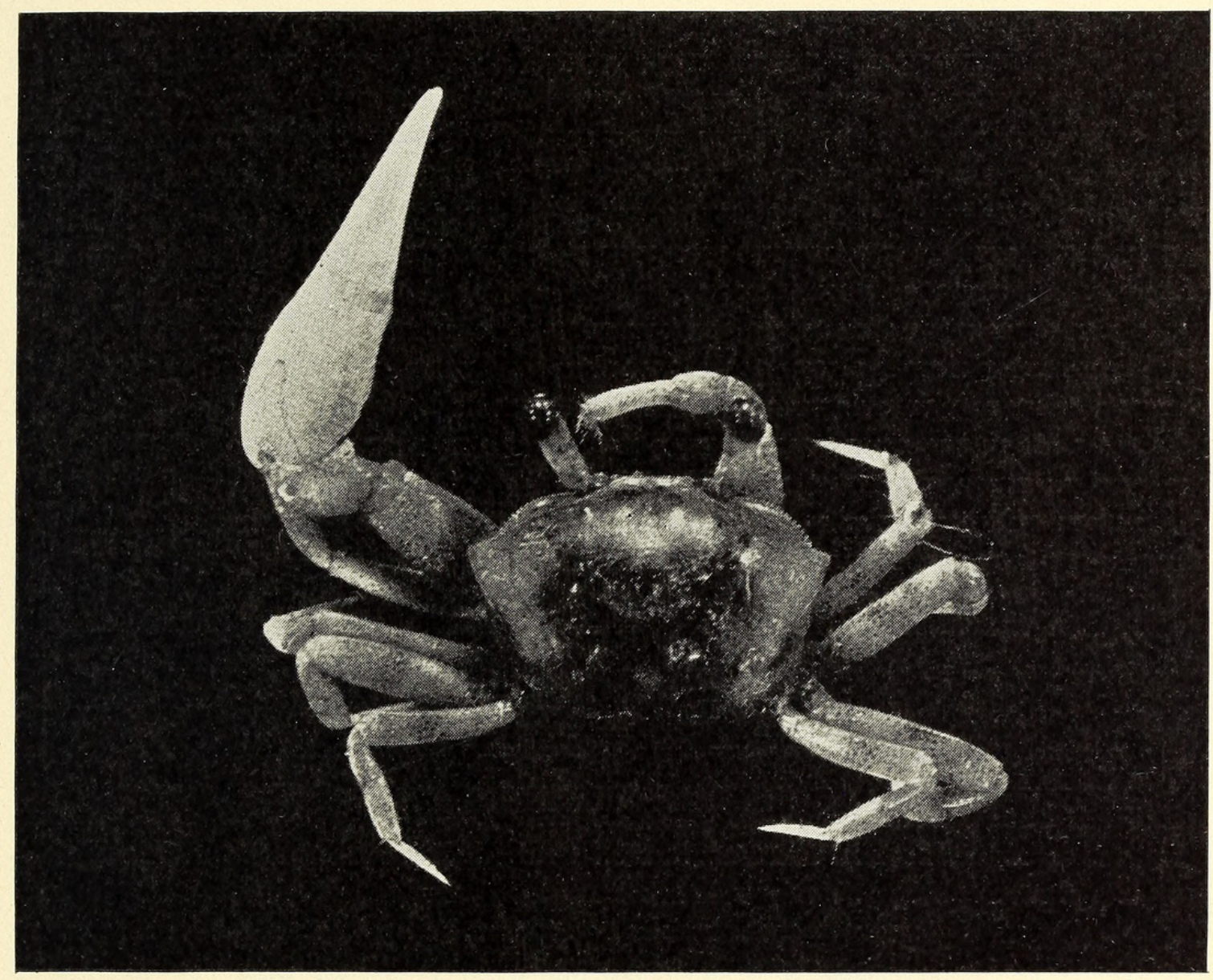

Fig. 98. Uca helleri, male, $\times 2.9$.

fringed with setae - those of the inner edges being especially heavy. The exognath is very narrow and long; the ischium is rectangular, about three-fourths as wide as long; the merus is about half as long as the ischium and has its outer borders raised, convex, the palp is three-jointed, well-developed, setigerous.

The chelipeds are very strikingly unequal in the male, the propodus of the great chela of the specimen under discussion being $9 \mathrm{~mm}$. long and $3 \mathrm{~mm}$. high, while that of the small chela is only $3.5 \mathrm{~mm}$. long and $1.1 \mathrm{~mm}$. high. The chelipeds of the female are approximately equal but are exceedingly small and weak, those of a specimen $10 \mathrm{~mm}$. wide having the propodus $3.7 \mathrm{~mm}$. long; the fingers are spoon-shaped. The great chela of the male projects grotesquely beyond the body. The proximal three joints are small but very strong; the 
merus is elongated, trigonal, with a transverse curved subdistal ridge on the inner face, and a corresponding ridge on the inner half of the upper surface; the carpus is small and is produced on distal point of the upper lateral margin into a rounded laminar process; the propodus is high and rather compressed with the outer side moderately convex, covered with granules which are larger on the upper surface and finer on the outer and lower parts, having a somewhat reticulated appearance. The oblique ridge of the inner surface is at an angle of approximately 45 degrees to the lower margin, turning at the middle of the palm at an obtuse angle and continuing in an irregular line to the upper margin. The surface between the ridges is nearly smooth. The fingers, which comprise slightly more than one-half of the propodal length, are subequal, long, slender and widely gaping. The cutting edges are finely denticulate and there is a larger tooth near the middle of the basal finger; also one at the basal third and occasionally another at the distal third of the hinged finger. In very young specimens these larger teeth are frequently absent. The fingers of the propodus of the small chela comprise about three-fifths of the propodal length and are gaping, meeting only at the broad corneous, spoon-shaped tips.

The four pairs of ambulatories are similar, all have the meral joint much elongated, in the anterior three pairs this joint is also dilated; the carpus and propodus taken together are about as long as the merus, but are much slenderer; the dactyli are approximately as long as the propodi and are very acuminate. All five pairs of legs are sparsely set with long, spinose hairs, which are more abundant on the distal joints.

Tribe: OXYSTOMATA

Family: CALAPPIDAE

Subfamily: CALAPPINAE

Genus Calappa Fabricius, 1798

Calappa convexa Saussure. (Purple Box Crab; Round Box Crab; West American Box Crab).

Calappa convexa Saussure, Rev. et Mag. de Zool., ser. 2, vol. 4, p. 362, pl. 13, fig. 3, 1853; Rathbun, Proc. U. S. Nat. Mus., vol. 38, p. 593, 1910; Zoologica, N. Y. Zool. Soc., vol. 5, no. 14, p. 158, 1924.

Diagnostic characters.-Carapace subcircular, very convex, with many rugosities on anterior region; chelipeds crested, hand with eight teeth on the upper margin. Color: lilac-lavender.

Type.-The type material came from Mazatlan, Mexico (Geneva Museum.)

Galapagos distribution.-Eden Island (Harrison Williams Galapagos Expedition), appears to be the first Galapagos record for this exquisite species.

General distribution.-Cape St. Lucas, Lower California, to Ecuador; Cocos Island; Galapagos Islands.

Material examined.-One large male specimen taken at Eden Island, Galapagos, by the Harrison Williams Galapagos Expedition; one small male from the stomach of a fish, Cocos Island, taken by the Arcturus Oceanographic Expedition.

Color.-A color plate of the large specimen secured at Eden Island was 
made by the staff artist, Isabel Cooper. It shows the entire exposed dorsal surface of the crab to be an exquisite shade of lilac-lavender. The ambulatory legs are banded alternately with light rose and lavender on the three distal joints. This plate has been reproduced in Dr. Beebe's: "Galapagos-World's End," published by Putnam's, New York City.

Technical description..-The carapace is very convex, $64 \mathrm{~mm}$. long, $87 \mathrm{~mm}$. greatest width. The interorbital area is $8 \mathrm{~mm}$. medium width, narrowing toward the frontal margin where two rounded horns are separated by a shallow u-shaped sulcus. Two lines indicate two closed sinuses on the superior orbital margin.

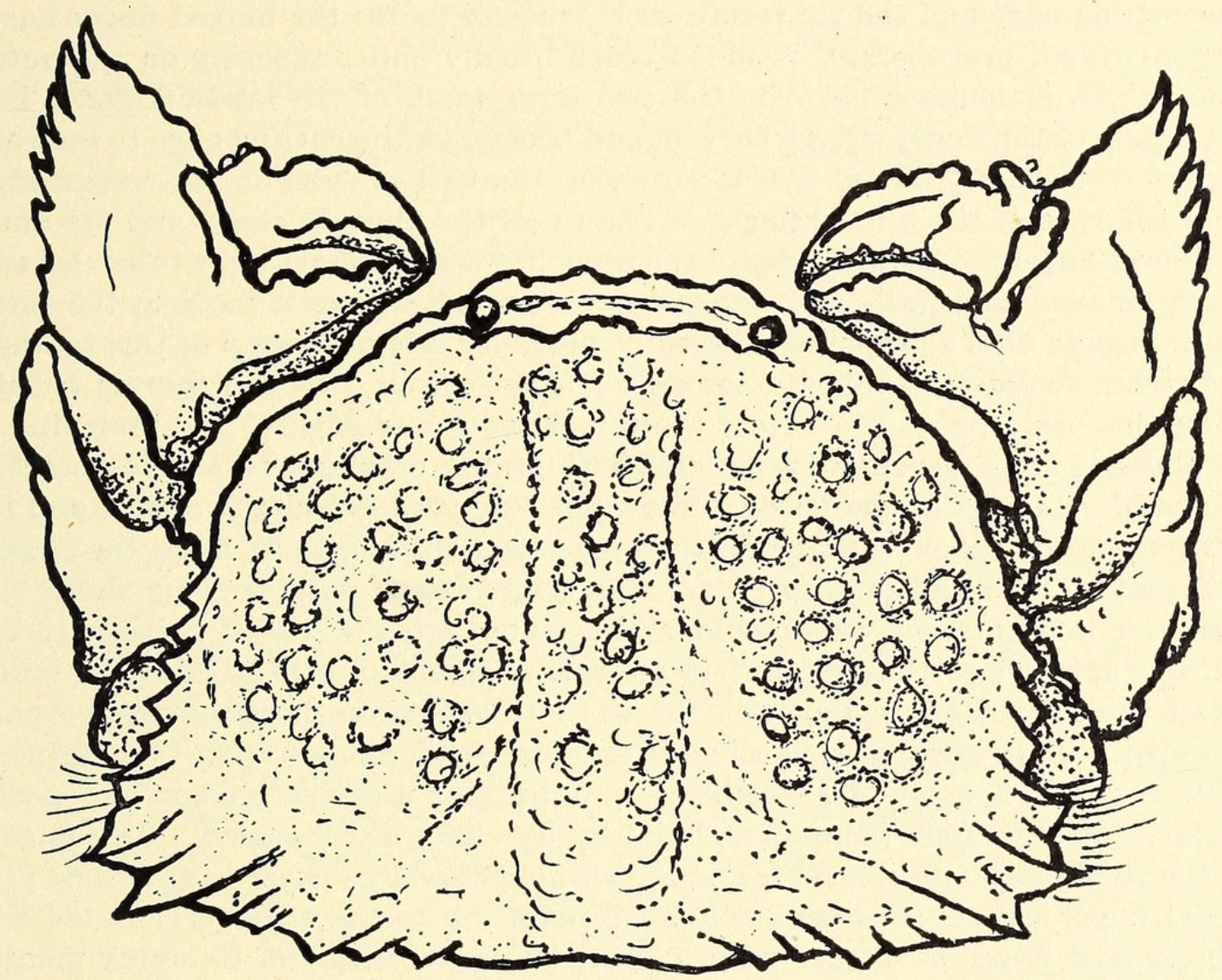

Fig. 99. Calappa convexa, natural size.

The anterolateral margins are rounded toward the front, from about midway to the posterior margin they are broken into 8 lateral teeth which increase in size posteriorly; the four most anterior teeth being small, obtuse; the first three are subequal, the fourth is a trifle wider; the fifth, sixth and seventh teeth are much larger and are produced to a triangulate point, each tooth successively increases in width and length posteriorly; the seventh being the greatest; the eighth is smaller than the seventh and has a prominent apex-its posterior margin is confluent with the posterior margin of the carapace which bears two small acute teeth. The carapace is covered with low rugose tubercles - those on the anterior two-thirds being much larger; those on the lateral area, smaller; on the posterior region the tubercles are replaced with linear rugosities. Beadlike carina midrib the seventh and eighth teeth and also the two pair of small 
postlateral teeth. The regions of the carapace are definitely delineated. Two deep longitudinal channels groove the carapace, one on either side of the cardiointestinal area.

The chelipeds are close-fitting, crested, the upper margin of the propodus being produced into a high crest serrated by eight triangular teeth.

The chelae are unequal, the larger claw is not any higher but the fingers are more strongly developed, the propodal finger is thick basally and has a large blunt tooth on its outer side - and another large high blunt tooth inner and sub-basal-this latter is followed by three successively smaller teeth along the cutting edge and the tip forms another acute tooth; the hinged finger has a large, curved, protuberant, rounded tooth basally and projecting on the outer side, which articulates between the two large teeth of the lower finger. The main part of the finger is very curved, and broken on the cutting edge to indicate three low molars. There is a large obtuse flattish process on the upper edge near the base of the hinged finger. The tip of the finger is sharp and fits upon the lower finger. The front face of the propodus bears several large tubercles and many small squamosities. There is a single prominent, acute tooth at the outer basal margin of the propodus; the outer posterior lateral margin of this tooth is somewhat rounded and finely crenulate and setigerous, its inner margin is only about half as long as the outer; the remaining lower edge of the propodus is emphasized by a beadlike carina which along the proximal two-thirds bears a fringe of setae. The merus surrounds and extends beyond the carpus and its outer margin is produced into four teeth, the most anterior tooth being the largest and pointed near the anterior part, its anterior lateral margins being short, the posterior margin about twice as long and truncated; the second tooth is threefourths as wide as the first but is more triangulate, the third tooth is much smaller but is also triangulate; the fourth tooth has its postlateral margin evenly rounded. This winglike expansion of the merus coördinates with the produced wing of the carapace under which it fits, in forming a protective box-like cavity under which the four pairs of ambulatory legs may be concealed. The fingers of the small chela are slenderer and are without the large basal teeth. The propodal finger has seven subequal teeth in addition to the stronger pointed tip. The hinged finger is slender with a heavy fringe of setae on its upper margin and eight very small teeth along its cutting edge.

The four pairs of ambulatory legs are similar and successively decrease in size posteriorly. The dactyli are longer than the propodi and are fluted and pointed. The three distal joints are ringed alternately with light and dark color bands.

The male abdominal belt is five-segmented, the first segment being very short; the second segment longer and tuberculated; the third segment is three and one third times as long as the second and is composed of the third, fourth and fifth segments which are anchylosed; the fourth segment is not quite half as long as the preceding; the fifth segment is triangulate and is one and one-half times as long as the fourth. The external antennae are minute and are situated in the inferior orbital hiatus.

The external maxillipeds are very high reaching almost to the anterior margin of the carapace. They are set wide apart, being separated from each 
other by a space equal to the width of the ischium. The exognath is very long and narrow and fringed on both edges with setae; the ischium is rectangular and finely denticulate and setigerous along the inner margin; the merus is about half as long as the ischium and is notched on the inner distal angle for the reception of the three jointed palp. The merus is covered with furry setae both on the edge and outer surface.

\section{Family: LEUCOSIIDAE}

\section{Subfamily: LEUCOSIINAE}

Genus Leucosilia Bell, 1855

Leucosilia jurinei Saussure.

Leucosilia jurinei Saussure, Rev. et Mag. de Zool., no. 8, p. 12, pl. 1 b fig. 4, 1853; Bell, Trans. Linn. Soc. London, vol. 21, p. 294, pl. 32, fig. 1 1855; Rathbun, Proc. U. S. Nat. Mus., vol. 38, p. 594, 1910.

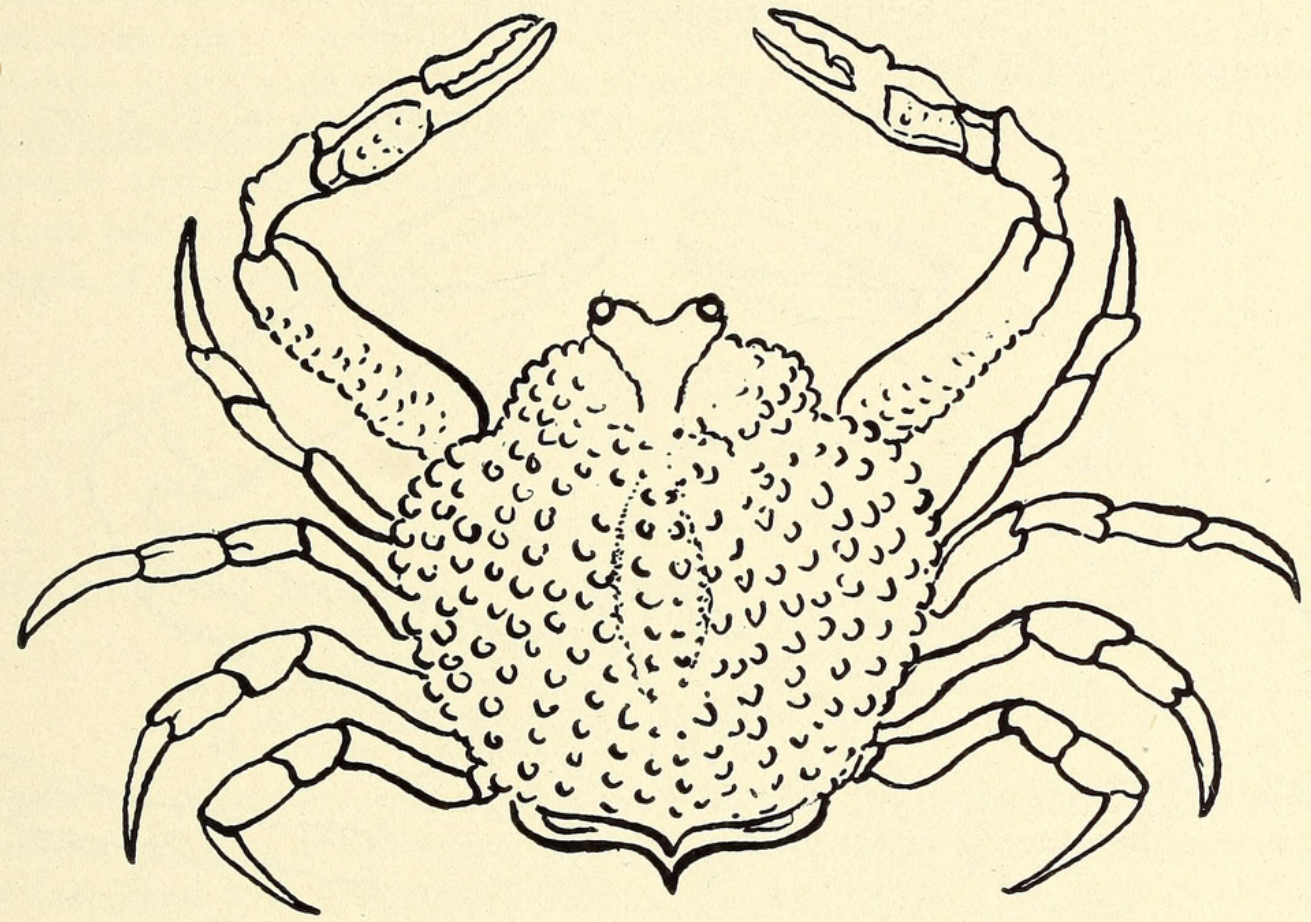

Fig. 100. Leucosilia jurinei, $\times$ about 2 (After Bell).

Name: This beautiful species was named for M. Jurine.

Diagnostic characters.-Body globular in both sexes; a single small tubercle present on the posterior part of the carapace.

Type.-Saussure's type material came from Mazatlan, Mexico, and is believed to be deposited in the Geneva Museum.

Galapagos distribution.-Galapagos Islands.

General distribution.-Mazatlan, Mexico, to Peru and Galapagos Islands.

Material examined.-None.

Technical description.-The following is Mr. Bell's description of the type:

"Carapace orbicular, very convex, the sides rounded, the surface covered with large contiguous granulations, excepting on the frontal and part of the hepatic regions, which are smooth, there is a small elevation on each hepatic 
region. The front with two small, triangular, divergent teeth, forming the hood-shaped roof of the antennary fossae, which are oblique and open. Orbit with three small fissures. There is a single obtuse tooth or tubercle on the intestinal region. External pedipalps with the outer branch very slightly curved, not dilated as in Myra, nor narrowed forwards as in Persephona, but with nearly parallel margins. Abdomen in the male very long, triangular, the penultimate segment with a strong, sharp tooth directed backwards; in the female broad, oval, very convex, with a broad central carina. The whole body above and below, with the exception before stated, covered with large granulations. Anterior legs much resembling those in Persephona, half as long again as the carapace, the arm granulated, the hand short and thick, the fingers slightly curved, armed with very small distinct tubercles, the points crossing a little when closed.

\section{Genus Persephona Leach, 1817}

Persephona edwardsii Bell.

Persephona edwardsii Bell; Horae Carcinologicae, vol. 21, p. 294, pl. 31, fig. 8, 1855; Rathbun, Proc. U. S. Nat. Mus., vol. 38, p. 595, 1910.

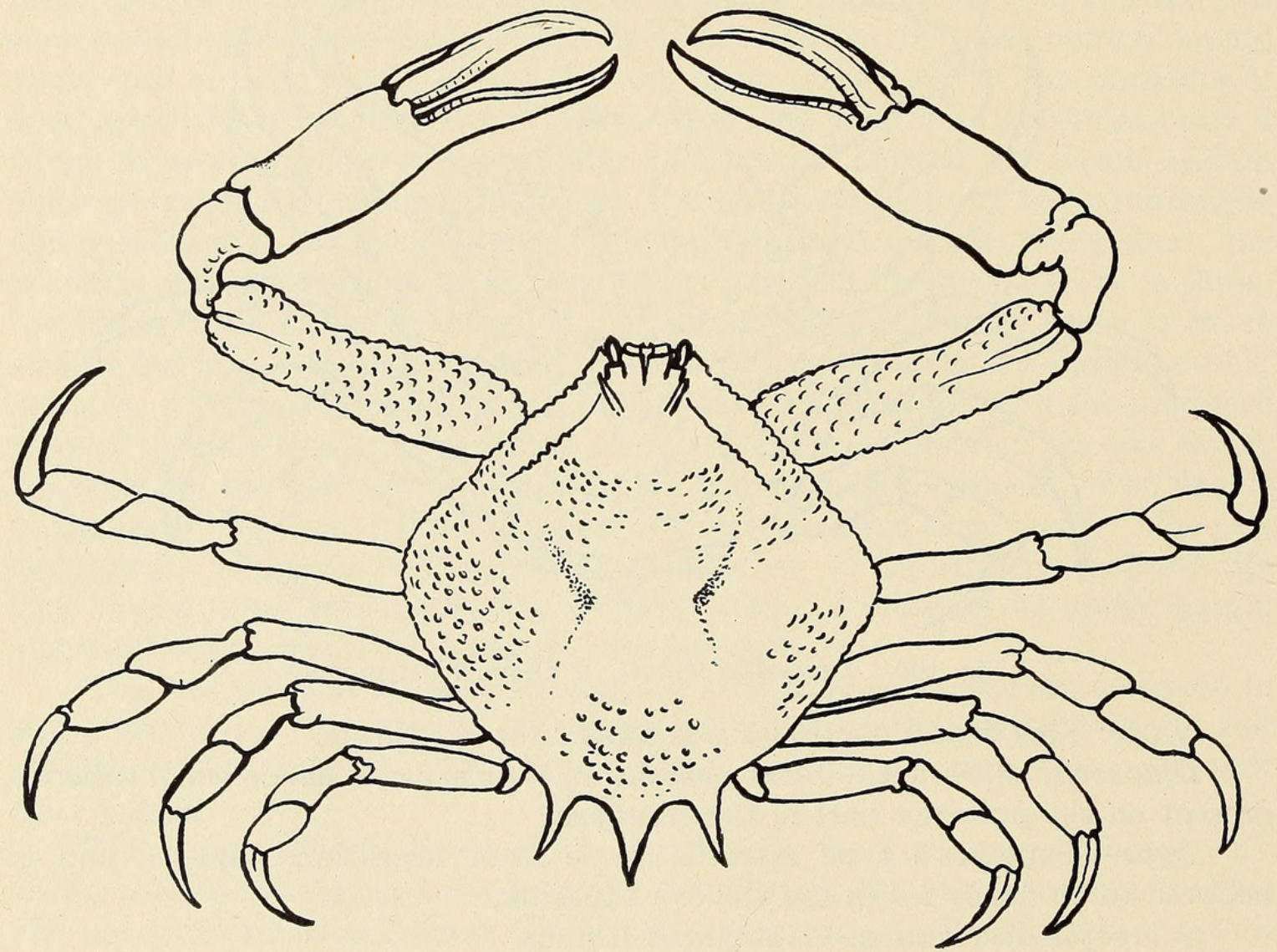

Fig. 101. Persephona edwardsii, about natural size (After Bell).

Name: This species was dedicated to Professor Milne Edwards.

Diagnostic characters.-Carapace suborbicular, somewhat produced and narrowed anteriorly, pterygostomian angle obsolete; marked by only a slight elevation. 
Type.-This species was founded on two specimens collected in the Galapagos Islands, depth 6 fathoms, by D. Cuming. I have not been able to ascertain the present repository of these specimens. fathoms.

Galapagos distribution.-Galapagos Islands, dredged in coral sand at six

General distribution.-Panama and Galapagos Islands.

Material examined.-None..

Technical description.-The following is Mr. Bell's description of the type:

"Carapace nearly orbicular, somewhat produced and narrowed anteriorly, minutely punctate, covered, excepting at the anterior portion, with very small distinct granules, of which a distinct line borders the latero-anterior portion; the anterior margin waved, the pterygostomian angle obsolete, marked only by a slight elevation Front broad, slightly emarginate; lateral and posterior margin much rounded, the spines placed in nearly a right-angled triangle, nearly equal, recurved at the apex. Anterior legs with the arm everywhere tuberculated, the wrist slightly granulated on the inner side, the hand minutely punctate. External pedipalps as in $P$. orbicularis. Abdomen (female) slightly granulated at the posterior and lateral portions.

Colour pale buff.

Length of carapace 1.3 in."

\section{Subtribe: DROMIACEA}

Family: DROMIIDAE

\section{Genus Dromidia Stimpson}

Dromidia larraburei Rathbun.

Dromidia sarraburei Rathbun, Proc. U. S. Nat. Mus, vol. 38, p. 553, vol. 48, fig. 4, 1910 (error for larraburei, Rathbun).

Dromidia larraburei Schmitt, Univ. of California, Pub. Zool. vol. 23, p. 183, pl. 33, fig. 1, 1921.-Rathbun, Bull., Amer. Mus. Nat. Hist., vol. 48 , p. 619 , pl. 33 , figs. $1-4,1923$.

Diagnostic characters.-A Dromidia with the carapace high, subglobular; anterolateral margins are directed obliquely inward toward the buccal cavity and are furnished with four small teeth.

Type.-The type was taken in the Bay of Sechura, west of Matacaballa, Peru, in about $5 \mathrm{fms}$., by Señor Don Carlos Larrabure y Correa, and is deposited in the collections of the United States National Museum.

Galapagos distribution.-A broken female, also a last-stage megalops were taken at station 54, off Hood Island, in 15 feet of water, by William Beebe. This appears to be the first authentic record of this species from the Galapagos Archipelago, although Schmitt lists Galapagos in his discussion of the species he fails to state where his Galapagos specimens are deposited or by what expedition they were secured.

General distribution.-Sechura Bay, Peru, 5 fms.; Monterey Bay and Long Beach, California; Magdalena Bay, Lower California; Galapagos Islands. Material examined.-One adult and one megalops from station 54, off Hood Island, Galapagos, secured by William Beebe, while diving in 15 feet of water. 


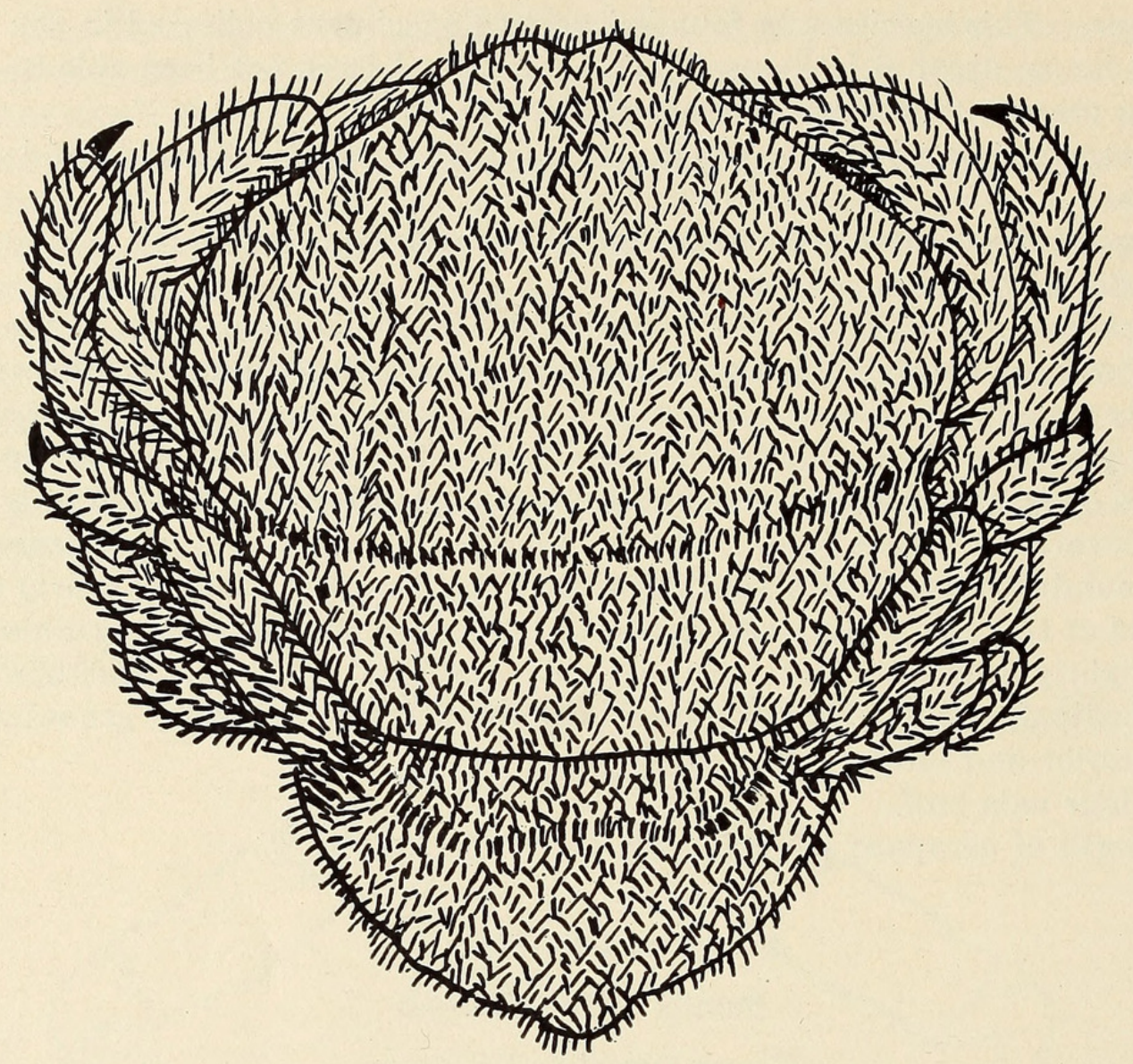

$102 \mathrm{~A}$
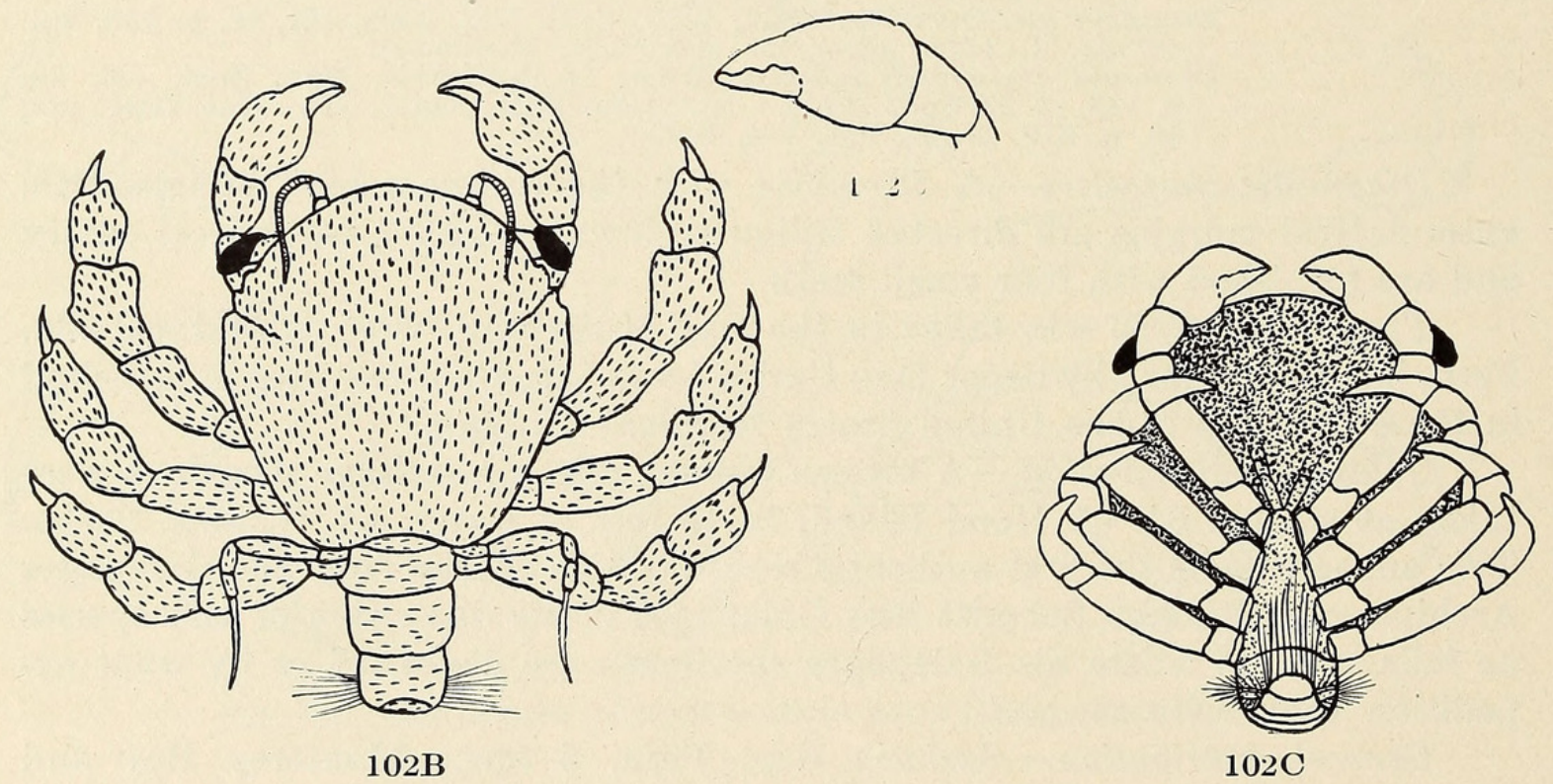

Fig. 102A. Dromidia larraburei Rathbun, adult $\times 2$; B. megalops, dorsal view $\times 4$; cheliped; C. ventral view of same megalops; D. cheliped of megalops. 
Technical description.-Carapace with the dorsal surface convex, approximately as long as the maximum width which is across the mesogastric region, while posterior border which is three-fourths as wide as the mesogastric region represents the minimum width. The interorbital region is very narrow depressed, concave, produced to a short, conical, median rostral tooth, which is in line with the antennary peduncles; just behind the median tooth the frontal border is produced into a pair of prominent submedian teeth which are situated one at each inner superior orbital angle. The superior orbital margin is sinuate, being produced to a small denticle approximately midway its length; the inferior orbital margin is much shorter than the superior border, and terminates inwardly in a prominent denticle. The anterolateral margins are directed obliquely inward toward the buccal cavity and are furnished with four small teeth which are nearly concealed under the dense fur-like pilosity which covers the entire carapace and legs except the tips of the fingers of the chelipeds and dactyli. The hepatic region is slightly concave. There is a decided oblique furrow extending inward from the base of the most posterior lateral tooth across to the branchial region vanishing in confluence with the grooves which define the cardiac region. The urogastric line is the most prominent, terminating in a pit at each end, from which another groove curves forward on the mesogastric region bifurcating, one branch running forward toward the orbital border, while the other, more definite branch runs outward to the base of the third anterolateral tooth. The sidewalls of the carapace are high, vaulted, flattened, fitting closely against the merus of the chelipeds. The male abdominal belt is triangulate, composed of seven segments.

The chelipeds are subequal, large, stout, with the meral joint trigonal, fitted closely against the carapace, armed with a row of five (or six), subequally spaced, low-rounded tubercles forming a longitudinal line along the anterior lateral margin of the merus; there is a transverse, subdistal constriction on the outer face of the merus; the carpus is quite as long as the hand of the cheliped and is rounded on the outer surface; there is a decided tooth on the outer lateral margin of the carpus; another median carpal tooth at the distal margin and a third slightly smaller subdistal tooth at the termination of the inner lateral margin; the hand is stout, convex on its upper and outer surfaces, three-fourths as high as long and armed with a longitudinal series of three low, rounded, subequally spaced tubercles along the upper margin of the inner face; the propodal finger is short, stout, triangular, armed with four subequal triangulate teeth along the margin and with the tip broad, rounded, and channelled; the hinged finger fits closely upon the propodal, but has its upper surface curved; it is armed with three teeth along the cutting edge, in addition to the apical tooth.

The first and second pairs of ambulatory legs are similar, having the merus, carpus and propodus stout, the dactyli less so with a curvate horny tip, also a row of horny spines on the inferior lateral margin. The third and fourth pairs of ambulatory legs are subdorsal, smaller, prehensile, bent sharply at the meral-carpal joint and terminating in strong hook-like dactyli. There is a short sharp spine on the distal end of the propodus with which the tip of the dactyl interfits. The fourth pair of legs is much longer than the third 
pair, and are closely appressed to the carapace, recurved, the bent meral carpal joint reaching half way the length of the carapace.

Megalops.-The single megalops taken (figs. 102B and C), shows the characters of the species in the shape and ornamentation of its carapace and chelipeds. 


\section{$2 \mathrm{BHL}$ Biodiversity Heritage Library}

Boone, Lee. 1927. "The littoral Crustacean fauna of the Galapagos Islands. Part I Brachyura." Zoologica : scientific contributions of the New York Zoological Society 8(4), 127-288. https://doi.org/10.5962/p.184693.

View This Item Online: https://www.biodiversitylibrary.org/item/207688

DOI: https://doi.org/10.5962/p.184693

Permalink: https://www.biodiversitylibrary.org/partpdf/184693

\section{Holding Institution}

Smithsonian Libraries

\section{Sponsored by}

Biodiversity Heritage Library

\section{Copyright \& Reuse}

Copyright Status: In Copyright. Digitized with the permission of the rights holder

Rights Holder: Wildlife Conservation Society

License: http://creativecommons.org/licenses/by-nc/3.0/

Rights: https://www.biodiversitylibrary.org/permissions/

This document was created from content at the Biodiversity Heritage Library, the world's largest open access digital library for biodiversity literature and archives. Visit BHL at https://www.biodiversitylibrary.org. 